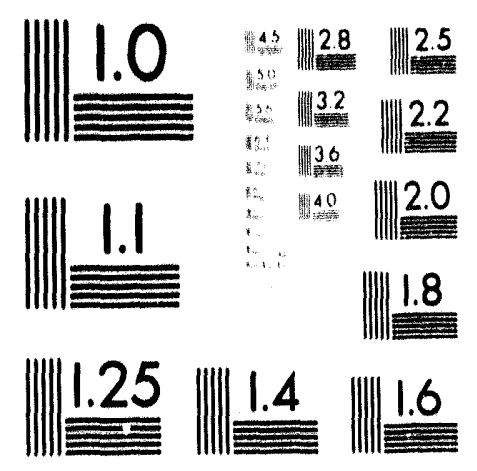



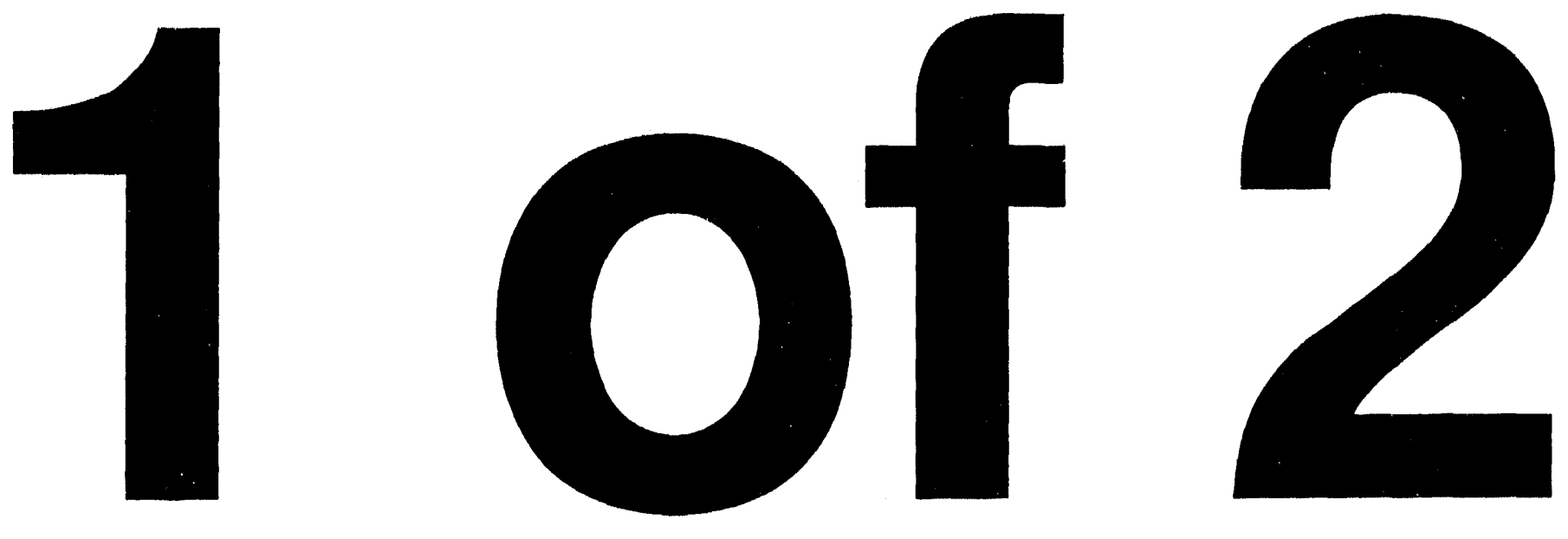
SAND92-2165

Distribution

Unllmited Distribution

Category UC.610

Published June 1993

\title{
MELCOR 1.8.1 Assessment: PNL Ice Condenser Aerosol Experiments
}

\author{
Robert J. Gross \\ Thermal/Hydraulic Analysis Division \\ Sandia National Laboratories \\ Albuquerque, New Mexico 87185
}

\begin{abstract}
The MELCOR code was used to simulate PNL's Ice Condenser Experiments 11-6 and 16-11. In these experiments, $\mathrm{ZnS}$ was injected into a mixing chamber, and the combined steam/air/aerosol mixture flowed into an ice condenser which was $14.7 \mathrm{~m}$ tall. Experiment 11-6 was a low flow test; Experiment 16-11 was a high flow test. Temperatures in the ice condenser region and particle retention were measured in these tests. MELCOR predictions compared very well to the experimental data. The MELCOR calculations were also compared to CONTAIN code calculations for the same tests. A number of sensitivity studies were performed. It was found that simulation timestep, aerosol parameters such as the number of MAEROS components and sections used and the particle density, and ice condenser parameters such as the energy capacity of the ice, ce heat transfer coefficient multiplier, and ice heat structure characteristic length all could affect the results. Thermal/hydraulic parameters such as control volume equilibrium assumptions, flow loss coefficients, and the bubble rise model were found to affect the results less significantly. MELCOR results were not machine dependent for this problem.
\end{abstract}




\section{Table of Contents}

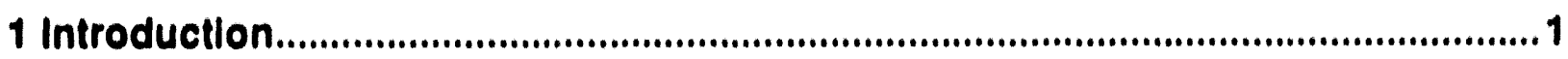

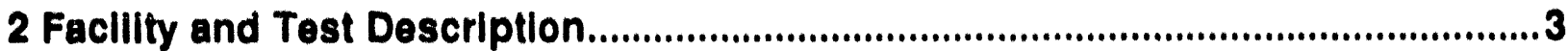

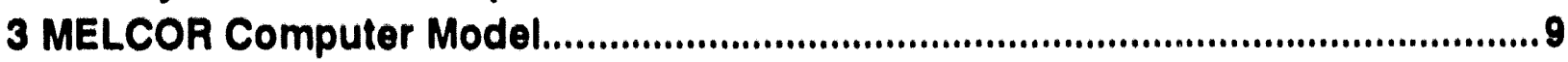

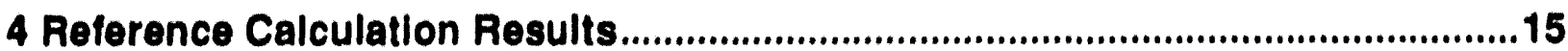

4.1 Experiment 11-6 Reference Calculation Results ....................................15

4.2 Experiment 16-11 Reference Calculation Results ..................................21

5 Machine Dependency and TImestep Effects.......................................................22

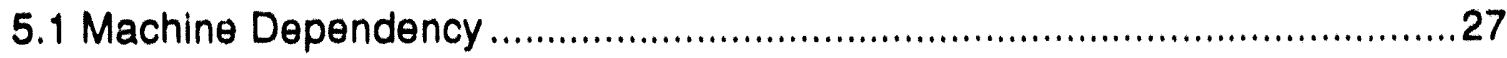

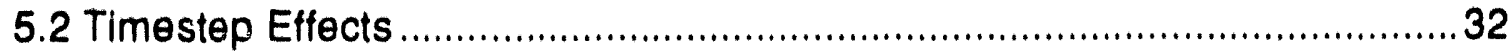

5.3 Heat Structure Numerical Damping Coefficient ................................................38

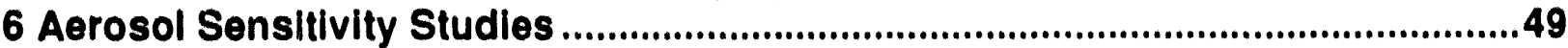

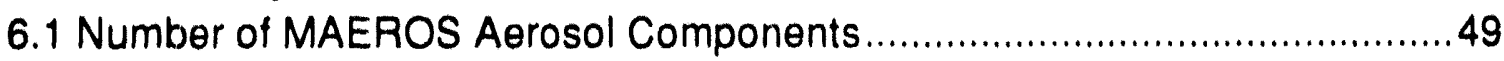

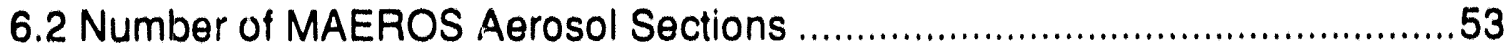

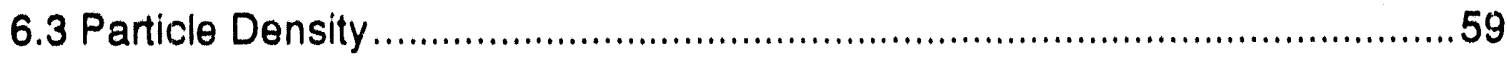

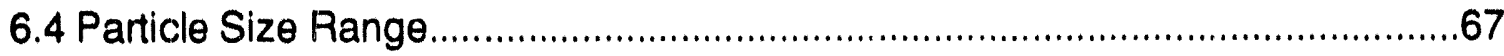

7 Thermal/Hydraulic \& Flow Sensitivity Studies ................................................................73

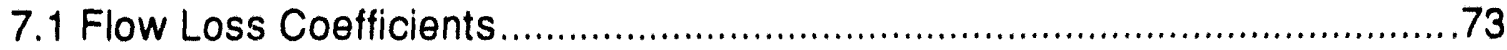

7.2 Equilibrium / Nonequilibrium Thermodynamics...............................................

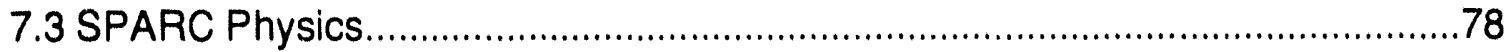

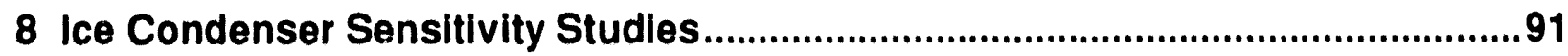

8.1 Energy Capacity and Temperature Range of the Ice ...............................91

8.2 Ice Heat Transfer Coefficient Multiplier..........................................................98

8.3 Ice Heat Structure Characteristic Length ............................................... 104

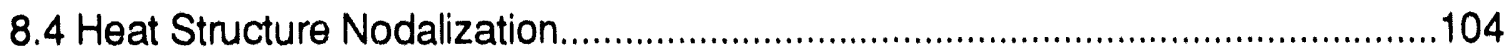

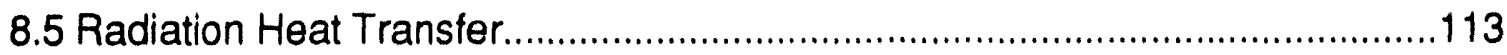

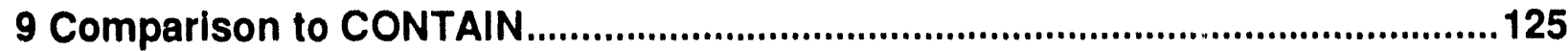

10 User Guidelines for Ice Condenser Calculations .............................................129

11 Code Limitations Identified................................................................................131

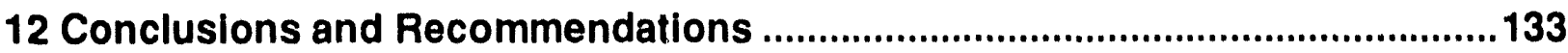

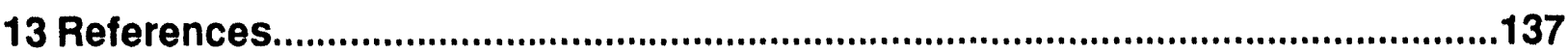

Appendix A Experiment 16-11 Reference Calculation MELCOR Input Deck...........139 


\section{List of Figures}

Elaure

Pege

2.1 Schematic of the Ice Condenser Test Faciity at PL.......................................4

2.2 Elevation View of the West Face of the lce Condenser Test Section.....................5

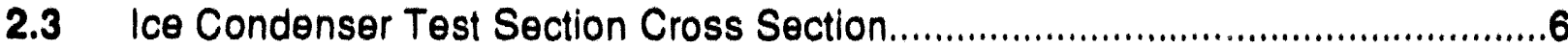

3.1 MELCOR Nodalization Diagram for the lce Condenser Test Facility, showing Control Volumes and Flow Paths (not to scale)

3.2 MELCOR Nodalization Diagram for the Ice Condenser Test Facility, showing Heat Structures (not to scale)

4.1.1 Experimental and MELCOR temperatures in the lower ice condenser for Experiment 11-6 - Final Reference Results.

4.1.2 Experimental and MELCOR temperatures in the middle ice condenser for Experiment 11-6 - Final Reference Results.

4.1.3 Experimental and MELCOR temperatures in the upper ice condenser for Experiment 11-6 - Final Reference Results.

4.1.4 Experimental and MELCOR particle retention for Experiment 11-6 - Final Reference Results.

4.2.1 Experimental and MELCOR temperatures in the lower ice condenser for Experiment 16-11 - Final Reference Results

4.2.2 Experimental and MELCOR temperatures in the middle ice condenser for Experiment 16-11 - Final Reference Results.

4.2.3 Experimental and MELCOR temperatures in the upper ice condenser for Experiment 16-11 - Final Reference Results.

4.2.4 Experimental and MELCOR particle retention for Experiment 16-11 - Final Reference Results.

5.1.1 Particle Retention for Experiment 11-6 (top) and Experiment 16-11 (bottom). Machine Dependency Sensitivity Study.... 


\section{List of Figures (continued)}

Elaure

Page

5.1.2 Vapor Temperature in CV 300 for Experiment 11-6 (top) and Experiment 16-11 (bottom). Machine Dependency Sensitivity Study

5.1.3 Vapor Temperature in CV320 for Experiment 11-6 (top) and Experiment 16-11 (bottom). Machine Dependency Sensitivity Study 30

5.1.4 Computer Processor Unit time for Experiment 11-6 (top) and Experiment 16-11 (bottoln). Machine Dependency Sensitivity Study.

5.2.1 Particle Retention for Experiment 11-6. Timestep Sensitivity Study..... 33

5.2.2 Vapor Temperature in CV300 for Experiment 11-6. Timestep Sensitivity Study. .34

5.2.3 Vapor Temperature in CV310 for Experiment 11-6. Timestep Sensitivity Study. .35

5.2.4 Vapor Temperature in CV320 for Experiment 11-6. Timestep Sensitivity Study......

5.2.5 Computer Process Unit time for Experiment 11-6. Timestep Sensitivity Study.

5.2.6 Particle Retention for Experiment 16-11. Timestep Sensitivity Study.

5.2.7 Vapor Temperature in CV300 for Experiment 16-11. Timestep Sensitivity Study. 40

5.2.8 Vapor Temperature in CV310 for Experiment 16-11. Timestep Sensitivity Study.....

5.2.9 Vapor Temperature in CV320 for Experiment 16-11. Timestep Sensitivity Study.

5.2.10 Computer Process Unit time for Experiment 16-11. Timestep Sensitivity Study. .43 


\section{List of Figures (continued)}

Elqure

Paqe

5.3.1 Particle Reterition for Experiment 11-6 (top) and Experiment 16-11 (bottom). Heat Structure Damping Coefficient Sensitivity Study..... .44

5.3.2 Vapor Temperature in CV300 for Experimient 11-6 (top) and Experiment 16-11 (bottom). Heat Structure Damping Coefficient Sensitivity Study. 45

5.3.3 Heat Transfer Coefficient in CV300 for Experiment 11-6 (top) and Experiment 16-11 (bottom). Heat Structure Damping Coefficient Sensitivity Study.

6.1.1 Particle Retention for Experiment 11-6 (top) and Experiment 16-11 (bottom). Aerosol Component Sensitivity Study .50

6.1.2 Suspended Aerosol Masses for Experiment 11-6 (top) and Experiment 16-11 (bottom). Aerosol Component Sensitivity Study.

6.1.3 Aerodynamic Mass Median Diameter for Experiment 11-6 (top) and Experiment 16-11 (bottom). Aerosol Component Sensitivity Study..... 52

6.1.4 Ice Mass Melted in CV300 for Experiment 11-6 (top) and Experiment 16-11 (Bottom). Aerosol Component Sensitivity Study.

6.1.5 Vapor Temperature for CV300 for Experiment 11-6 (top) and Experiment 16-11 (bottom). Aerosol Component Sensitivity Study. .55

6.1.6 Computer Processor Time for Experiment 11-6 (top) and Experiment 16-11 (bottom). Aerosol Componerit Sensitivity Study. .56

6.2.1 Particle Retention for Experiment 11-6 (top) and Experiment 16-11 (bottom). Aerosol Section Sensitivity Study.

6.2.2 Vapor Temperature for CV300 for Experiment 11-6 (top) and Experiment 16-11 (bottom). Aerosol Section Sensitivity Study. .58

6.2.3 Computer Processor Time for Experiment 11-6 (top) and Experiment 16-11 (bottom). Aerosol Section Sensitivity Study...... 


\section{List of Figures (continued)}

Eloure

Page

6.3.1 Particle Retention for Experiment 11-6 (top) and Experiment 16-11

(bottom). Aerosol Density Sensitivity Study....

6.3.2 Suspended Aerosol Masses for Experiment 11-6 (top) and

Experiment 16-11(bottom). Aerosol Density Sensitivity Study.

6.3.3 Aerodynamic Mass Median Diameter for Experiment 11-6 (top) and Experiment 16-11 (bottom). Aerosol Density Sensitivity Study.

6.3.4 Vapor Temperature for CV300 for Experiment 11-6 (top) and Experiment 16-11 (bottom). Aerosol Density Sensitivity Study.

6.3.5 Vapor Temperature for CV320 for Experiment 11-6 (top) and

Experiment 16-11 (bottom). Aerosol Density Sensitivity Study

6.3.6 Computer Processor Time for Experiment 11-6 (top) and Experiment 16-11 (bottom). Aerosol Density Sensitivity Study.

6.4.1 Particle Retention for Experiment 11-6 (top) and Experiment 16-11 (bottom). Minimum Aerosol Particle Diameter Sensitivity Study.

6.4.2 Vapor Temperature for CV300 for Experiment 11-6 (top) and Experiment 16-11 (bottom). Minimum Aerosol Particle Diameter Sensitivity Study.

6.4.3 Ice Mass Melted in CV300 for Experiment 11-6 (top) and Experiment 16-11 (Bottom). Minimum Aerosol Particle Diameter Sensitivity Study .70

6.4.4 Distribution of ZnS Particles in the Five Sections for Experiment 11-6. Minimum Aerosol Particle Diameter Sensitivity Study.

6.4.5 Computer Processor Time for Experiment 11-6 (top) and Experiment 16-11 (bottom). Minimum Aerosol Particle Diameter Sensitivity Study.

7.1.1 Particle Retention for Experiment 11-6 (top) and Experiment 16-11 (bottom). Flow Loss Coefficient Sensitivity Study....

7.1.2 Vapor Temperature for CV300 or Experiment 11-6 (top) and Experiment 16-11 (bottom). Flow Loss Coefficient Sensitivity Study.... .75 


\section{List of Figures (continued)}

Elqure Page

7.1.3 Vapor Temperature for CV310 for Experiment 11-6 (top) and Experiment 16-11 (bottom). Flow Loss Coefficient Sensitivity Study

7.1.4 Vapor Temperature for CV320 for Experiment 11-6 (top) and Experiment 16-11 (bottom). Flow Loss Coefficient Sensitivity Study.

7.2.1 Vapor Temperature for CV300 or Experiment 11-6 (top) and Experiment 16-11 (bottom). Equilibrium/Nonequilibrium Sensitivity Study.

7.2.2 Vapor Temperature for CV310 for Experiment 11-6 (top) and Experiment 16-11 (bottom). Equilibrium/Nonequilibrium Sensitivity Study

7.2.3 Vapor Temperature for CV320 for Experiment 11-6 (top) and Experiment 16-11 (bottom). Equilibrium/Nonequilibrium Sensitivity Study.

7.2.4 Ice Mass Melted in CV300 for Experiment 11-6 (top) and Experiment 16-11 (Bottom). Equilibrium/Nonequilibrium Sensitivity Study.

7.2.5 Particle Retention for Experiment 11-6 (top) and Experiment 16-11 (bottom). Equilibrium/Nonequilibrium Sensitivity Study.

7.2.6 Computer Processor Time for Experiment 11-6 (top) and Experiment 16-11 (bottom). Equilibrium/Nonequilibrium Sensitivity Study

7.3.1 Vapor Temperature for CV300 or Experiment 11-6 (top) and Experiment 16-11 (bottom). SPARC Physics Sensitivity Study .85

7.3.2 Vapor Temperature for CV310 for Experiment 11-6 (top) and Experiment 16-11 (bottom). SPARC Physics Sensitivity Study

7.3.3 Vapor Temperature for CV320 for Experiment 11-6 (top) and Experiment 16-11 (bottom). SPARC Physics Sensitivity Study

7.3.4 Particle Retention for Experiment 11-6 (top) and Experiment 16-11 (bottom). SPARC Physics Sensitivity Study

7.3.5 Computer Process : Time for Experiment 11-6 (top) and Experiment 16-11 (bottom). SPARC Physics Sensitivity Study 


\section{List of Figures (continued)}

Elqure

Page

8.1.1 Vapor Temperature for CV 300 for Experiment 11-6 (top) and Experiment 16-11 (bottom). Energy Capacity of Ice Sensitivity Study.

8.1.2 Vapor Temperature for CV310 for Experiment 11-6 (top) and Experiment 16-11 (bottom). Energy Capacity of Ice Sensitivity Study

8.1.3 Vapor Temperature for CV320 Experiment 11-6 (top) and Experiment 16-11 (bottom). Energy Capacity of Ice Sensitivity Study.

8.1.4 Temperature of HS300 for Experiment 11-6 (top) and Experiment 16-11 (bottom). Energy Capacity of Ice Sensitivity Study.

8.1.5 Particle Retention for Experiment 11-6 (top) and Experiment 16-11 (bottom). Energy Capacity of Ice Sensitivity Study. 96

8.1.6 Computer Processor Time for Experiment 11-6 (top) and Experiment 16.11 (bottom). Energy Capacity of Ice Sensitivity Study.

8.2.1 Vapor Temperature in CV 300 for Experiment 11-6 (top) and Experiment 16-11 (bottom). Ice Heat Transfer Coefficient Multiplier Sensitiviity Study. 99

8.2.2 Vapor Temperature in CV310 for Experiment 11-6 (top) and Experiment 16-11 (bottom). Ice Heat Transfor Coefficient Multiplier Sensitivity Study 100

8.2.3 Vapor Temperature in CV320 for Experiment 11-6 (top) and Experiment 16-11(bottom). Ice Heat Transfer Coefficient Multiplier Sensitivity Study

8.2.4 Mass of lce Melted in CV300 for Experiment 11-6 (top) and Experiment 16-11 (bottom). Ice Heat Transfer Coefficient Multiplier Sensitivity Study........102

8.2.5 Particle Retention for Experiment 11-6 (top) and Experiment 16-11 (bottom). Ice Heat Transfer Coefficient Multiplier Sensitivity Study. 103

8.2.6 Computer Processor Time for Experiment 11-6 (top) and Experiment 16-11 (bottom). Ice Heat Transfer Coefficient Multiplier Sensitivity Study. 105

8.3.1 Vapor Temperature for CV300 or Experiment 11-6 (top) and Experiment 16-11 (bottom). Ice Heat Structure Characteristic Length Sensitivity Study....106 


\section{List of Figures (continued)}

Elqure

Page

8.3.2 Vapor Temperature for CV310 for Experiment 11-6 (top) and Experiment 16-11 (bottom). Ice Heat Structure Characteristic Length Sensitivity Study

8.3.3 Vapor Temperature for CV320 for Experiment 11-6 (top) and Experiment 16-11 (bottom). Ice Heat Structure Characteristic Length Sensitivity Study......108

8.3.4 Heat Structure Temperatures of HS 300 for Experiment 11-6 (top) and Experiment 16-11 (bottom). Ice Heat Structure Characteristic Length Sensitivity Study. 109

8.3.5 Particle Retention for Experiment 11-6 (top) and Experiment 16-11 (bottom). Ice Heat Structure Characteristic Length Sensitivity Study 110

8.4.1 Particle Retention for Experiment 11-6 (top) and Experiment 16-11 (bottom). Heat Structure Nodalization Sensitivity Study.

8.4.2 Mass of lce Melted in CV300 for Experiment 11-6 (top) and Experiment 16-11 (bottom). Heat Structure Nodalization Sensitivity Study 112

8.4.3 Vapor Temperature in CV300 for Experiment 11-6 (top) and Experiment 16-11 (bottom). Heat Structure Nodalization Sensitivity Study....

8.4.4 Vapor Temperature in CV310 for Experiment 11-6 (top) and Experiment 16-11 (bottom). Heat Structure Nodalization Sensitivity Study.

8.4.5 Vapor Temperature in CV320 for Experiment 11-6 (top) and Experiment 16-11 (bottom). Heat Structure Nodalization Sensitivity Study. 116

8.4.6 Heat Structure Temperatures of HS 300 for Experiment 11-6 (top) and Experiment 16-11 (bottom). Heat Structure Nodalization Sensitivity Study

8.4.7 Computer Processor Time for Experiment 11-6 (top) and Experiment 16-11 (bottom). Heat Structure Nodalization Sensitivity Study.

8.5.1 Particle Retention for Experiment 11-6 (top) and Experiment 16-11 (bottom). Radiation Heat Transfer Sensitivity Study....

8.5.2 Vapor Temperature in CV 300 for Experiment 11-6 (top) and Experiment 16-11 (bottom). Radiation Heat Transfer Sensitivity Study... 


\section{List of Figures (continued)}

Eloure

8.5.3 Vapor Temperature in CV310 for Experiment 11-6 (top) and Experiment 16-11 (bottom). Radiation Heat Transfer Sensitivity Study.

8.5.4 Vapor Temperature in CV320 for Experiment $11-6$ (top) and Experiment 16-11 (bottom). Radiation Heat Transfer Sensitivity Study.

8.5.5 Suspended Aerosol Masses for Experiment 11.6 (top) and Experiment 16-11 (bottom). Radiation Heat Transfer Sensitivity Study

9.1 Comparison of Experiment 11.6 Particle Retention Data to MELCOR and CONTAIN predictions.

9.2 Comparison of Experiment 16-11 Particle Retention Data to MELCOR and CONTAIN predictions. 


\section{List of Tables}

Inble

Page

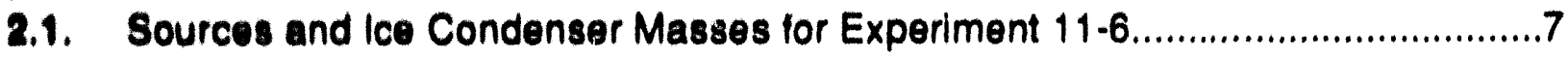

2.2 Sources and lce Condenser Massesfor Experiment 16-11 .............................. 


\section{Acknowledgments}

First, I would like to thank the NRC/RES/Accident Evaluation Branch for funding this effort. A number of individuals contributed to this work. Luba Kmetyk performed much of the initial literature search and also contributed her extensive expertise from several previous MELCOR assessments. Russ Smith diagnosed and readily made changes to the ice condenser model whenever a problem occurred. Arnold Elsbernd ran the ice condenser problems on the 486 PC and the CRAY, also helped in some problem troubleshooting, and created improved official versions of MELCOR in a timely fashion. Randy Cole also participated in many troubleshooting sessions and diagnosed the last bug that occurred in the Radionuclide Package. Nancy Russell provided the CONTAIN information and was helpful in discussions concerning the nodalization of the problem. Sam Thompson contributed the HISPLT plotting software that produced the majority of plots for this report. Finally, I would like to thank Richard Gido, Luba Kmetyk, and Ken Washington for their efforts in reviewing and substantially improving this document. 


\section{Introduction}

MELCOR [1] is a fully integrated, engineering-level computer code being developed at Sandia National Laboratories for the U.S. Nuclear Regulatory Commission (USNRC). The term "fully integrated" refers to the high level of uniformity and integration of the database that ties the various packages together, as well as the input and output structure. The term "engineering level" means that MELCOR was designed to model the progression of severe accidents in light water reactor nuclear power plants, but its flexibility allows it to be used in a wide range of physical problems. The entire spectrum of severe accident phenomena -- reactor coolant systems; containment thermal and hydraulic response; core heatup, degradation and relocation; and fission product release and transport -- is treated in MELCOR for several types of nuclear reactors. MELCOR has been successfully applied in severe accident analyses ([2] and [3]). As part of an ongoing quality and technical assessment program, a number of assessment calculations have been performed, including calculations of the FLECHT SEASET natural circulations experiments [4], the ACRR source term experiments [5], and the LACE aerosol experiments [6]. This document addresses an assessment of MELCOR relating to the ice condenser experiments performed by Pacific Northwest Laboratory (PNL) [7] in recent years.

The pressurized water reactor (PWR) ice-condenser contairıment system is designed to suppress the rise in pressure within the reactor containment that would result from a rupture in the reactor coolant system. In addition, the ice-condenser may also serve to capture radioactive aerosols as gases pass through the condenser. A series of largescale experiments were conducted at the High Bay Test Facility (HBTF) at PNL to investigate the extent to which an ice condenser may capture and retain air-borne particles.

Recently, a new model was added to MELCOR to model ice condensers [8]. The model physics was, in part, based on the ice condenser model in CONTAIN. However, the heat structure outgassing model in MELCOR was extensively used because the physics is similar and use of proven code already in place saved development time. The MELCOR code with the ice condenser model, then, was used to simulate two HBTF experiments, Experiment 11-6 (also referenced as Experiment 6) and Experiment 16-11 (also referenced as Experiment 11). Experiment 11-6 was a low-flow test, while Experiment 16-11 was a relatively high-flow test. In both cases, $\mathrm{ZnS}$ was used as the aerosol. In both tests, temperatures and particle retention were monitored.

Reported are the comparison of MELCOR results to the experimental data, and also to CONTAIN calculations ([9] and [10]) for both Experiments 11-6 and 16-11. Both the experimental data and the CONTAIN results were available to provide guidance to the MELCOR calculations. In addition, sensitivity studies were performed relating to machine dependence, time step size, flow resistances, number of aerosol components and sections, effective ice condenser heat of reaction, ice condenser heat structure characteristic lengths, allowable size range of aerosol particles, heat structure heat transfer coefficient multiplier, equilibrium versus nonequilibrium thermodynamics, and inclusion of a bubble 
rise model. MELCOR version 1.8LF was used for all the calculations whose results are shown in this report. This version should be considered the earliest version with which to perform ice condenser calculations. 


\section{Facility and Test Description}

The experimental geometry of the HBTF aerosol tests, excerpted with permission from [7], is shown in Figures 2.1 and 2.2. The entire test section was 17.1 meters high. The 14.6 meter ice column was centered between two turning vane assemblies located at the inlet and outlet of the ice-basket region. The initial downcomer section contained provision for the hot air and steam injection, as well as injection of the aerosol. After the injection assemblies, mixing chambers were positioned to allow the gas to become homogenous. The piping then changed from a cylindrical to a square cross-section, and went through a 90-degree turn, changing the flow from downward vertical to horizontal. In the horizontal section, a diffuser section enlarged the flow area. From the diffuser outlet, another 90-degree section with turning vanes changed the flow from horizontal to upward vertical. Then, the flow went through the 14.6 meter ice condenser. Another 90-degree section changed the flow back again to horizontal, again with turning vanes. After an area decrease, the flow was directed to a scrubber.

For an experiment, the ice-condenser was loaded with ice after the test section had been pre-chilled. For Experiment 11-6, steam and hot air were actually injected for about 30 minutes prior to the introduction of aerosol particles. This pretreatment attempted to better represent the ice inventory after the blowdown phase of a postulated severe reactor accident. Because of this pretreatment, almost half the ice initially loaded into the ice condenser in Experiment 11-6 was melted at time "zero" for the test, the pretreatment phase not being counted as part of the actual experiment. Further, from the description of the procedure for loading the ice, it is assumed that each 14.6 meter ice column did not have any vertical impediments preventing the ice pieces from moving downward to replace ice melted at the bottom of the column. This latter assumption is important because, at present, MELCOR does not make any provision for the solid ice to move from one region to another.

Another unique feature of Experiment 11-6 was that the flow rate was so low as to allow recirculation to occur within the ice condenser. The cross-section of baskets for the ice, shown in Figure 2.3, was such that there were four main irregularly shaped, and connected, flow channels. In Experiment 11-6, the data clearly indicated that flow in one of the channels was in the downward direction. Any model of this experiment had to account for this significant event.

In both tests, the aerosol introduced was $\mathrm{ZnS}$. The steam, hot air, and aerosol were injected into the test apparatus for a specified time. Experiment 11-6 was considered to be a low flow test that lasted over 120 minutes, while Experiment 16-11 was a high flow test lasting approximately 70 minutes.

The pertinent hydrodynamic and aerosol sources and ice condenser masses for both experiments are shown in Tables 2.1 and 2.2. 


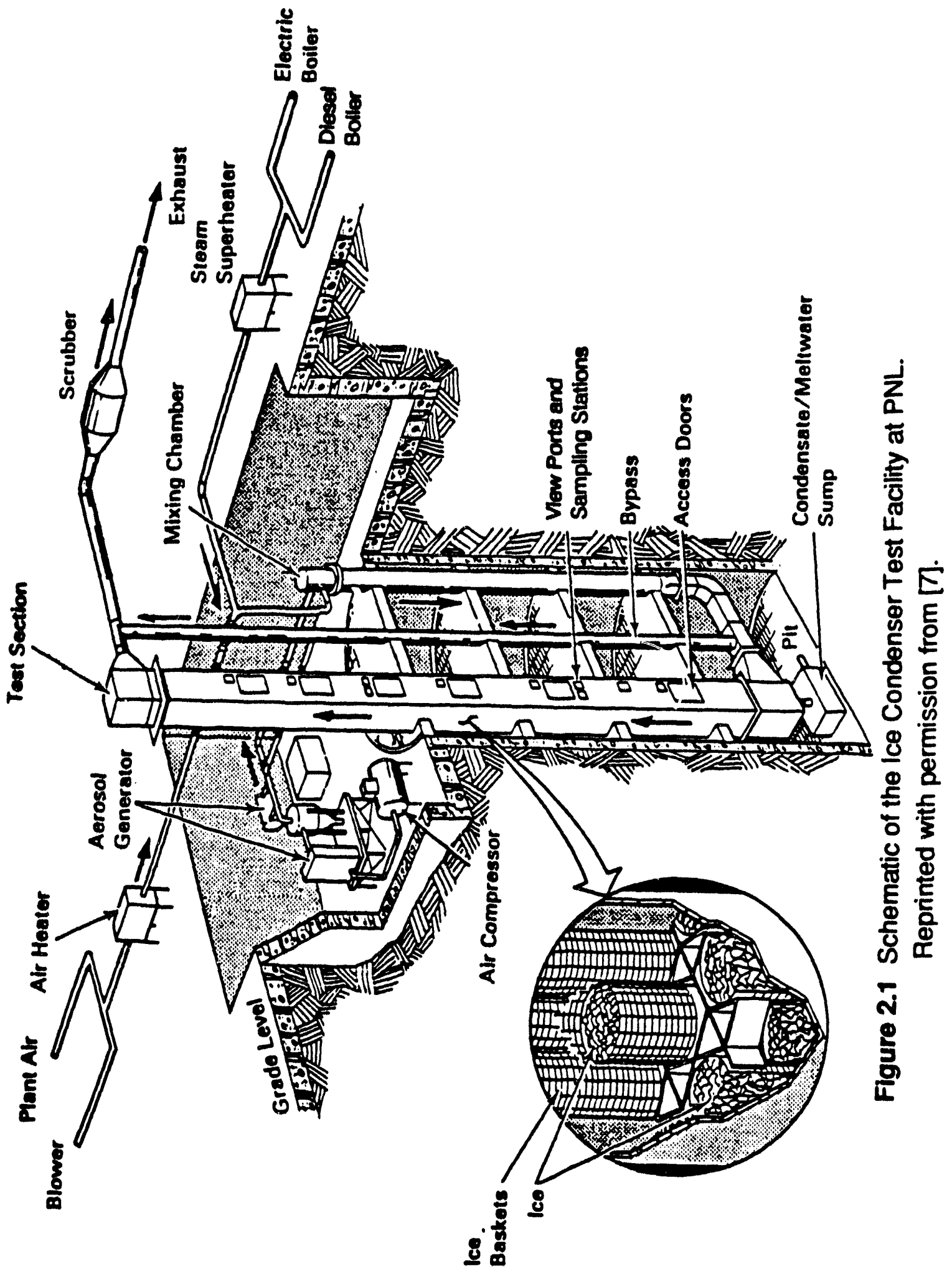




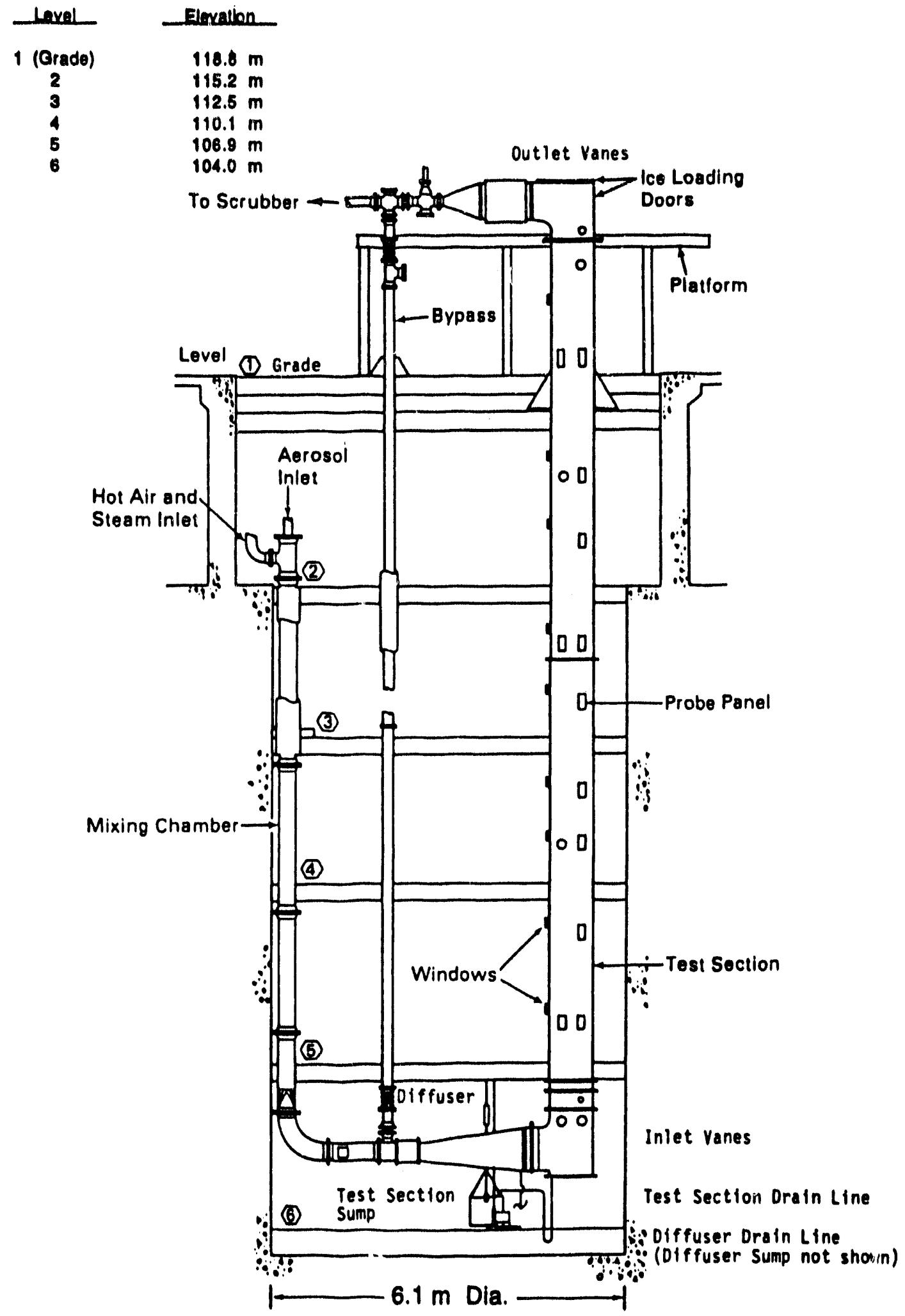

Figure 2.2 Elevation View of the West Face of the Ice Condenser Test Section Reprinted with permission from [7]. 

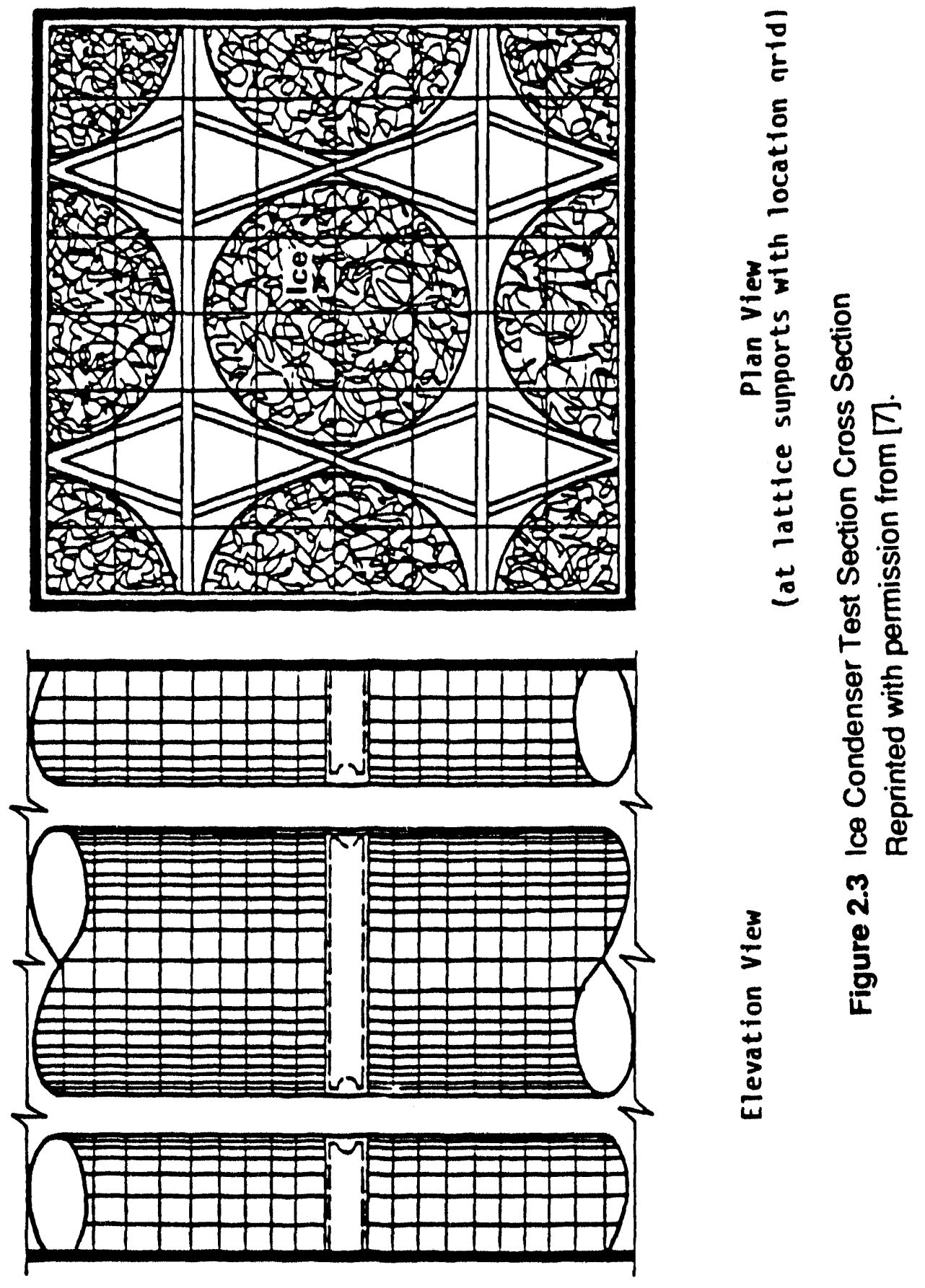
Table 2.1. Sources and Ice Condenser Masses for Experiment 11-6

Hydrodynamic Sources:

\begin{tabular}{|c|c|c|c|}
\hline Material & $\operatorname{Tim} \theta(\mathbf{s})$ & Rate $(\mathrm{kg} / \mathrm{s})$ & Temperature (K) \\
\hline \multirow{5}{*}{$\mathrm{N}_{2}$} & 0 & 0.03576 & 400. \\
\hline & 3300 . & 0.03576 & 393. \\
\hline & 4380. & 0.03576 & 400. \\
\hline & 7200. & 0.03576 & 393. \\
\hline & 7500. & 0.03576 & 400. \\
\hline \multirow[t]{5}{*}{$\mathrm{O}_{2}$} & 0. & 0.00894 & 400. \\
\hline & 3300. & 0.00894 & 393. \\
\hline & 4380. & 0.00894 & 400. \\
\hline & 7200. & 0.00894 & 393. \\
\hline & 7500. & 0.00894 & 400. \\
\hline \multirow[t]{5}{*}{ Steam } & 0. & 0.06184 & 400. \\
\hline & 3300. & 0.06184 & 393. \\
\hline & 4380. & 0.06184 & 400. \\
\hline & 7200. & 0.06184 & 393. \\
\hline & 7500. & 0.06184 & 400. \\
\hline
\end{tabular}

Aerosol Sources (Time Independent):

Aerosol (ZnS) Flowrate

Aerosol Mass Median Diameter (AMMD)

Geometric Standard Deviation (GSD)
$0.011 \mathrm{~kg} / \mathrm{s}$

$3.5 \times 10^{-6} \mathrm{~m}$

2.0

Ice Condenser (Heat Structure) Massess:

Ice Condenser Location (Heat Structure\#)

$$
\begin{aligned}
& \text { Lower (HS300) } \\
& \text { Middle (HS310) } \\
& \text { Upper (HS320) }
\end{aligned}
$$

Initial Ice Mass (kg)

675.65

675.65

0.0 
Table 2.2. Sources and Ice Condenser Masses for Experiment 16-11

Hydrodynamic Sources:

\begin{tabular}{|c|c|c|c|}
\hline Material & $\operatorname{Tim} \theta(\mathrm{s})$ & Rate $(\mathrm{kg} / \mathrm{s})$ & Temperature (K) \\
\hline \multirow[t]{5}{*}{$\mathrm{N}_{2}$} & 0. & 0.03172 & 363. \\
\hline & 360. & 0.03172 & 363. \\
\hline & 362. & 0.03045 & 370. \\
\hline & 2100. & 0.03000 & 378. \\
\hline & 4200. & 0.02950 & 383. \\
\hline \multirow[t]{5}{*}{$\mathrm{O}_{2}$} & 0. & 0.00793 & 363. \\
\hline & 360. & 0.00793 & 363. \\
\hline & 362. & 0.00761 & 370. \\
\hline & 2100. & 0.00750 & 378. \\
\hline & 4200. & 0.00737 & 383. \\
\hline \multirow[t]{4}{*}{ Steam } & 0. & 0.20000 & 363. \\
\hline & 360. & 0.20000 & 363. \\
\hline & 2100. & 0.19750 & 370. \\
\hline & 4200. & 0.19500 & 383. \\
\hline
\end{tabular}

Aerosol Sources (TIme Independent):

Aerosol ( $\mathrm{ZnS}$ ) Flowrate

Aerosol Mass Median Diameter (AMMD)

Geometric Standard Deviation (GSD)
$0.030 \mathrm{~kg} / \mathrm{s}$

$3.5 \times 10^{-6} \mathrm{~m}$

2.0

Ice Condenser (Heat Structure) Massess:

\begin{tabular}{cc} 
Ice Condenser Lecation (Heat Structure\#) & Initial lce Mass (kg) \\
\hline Lower (HS300) & 821.00 \\
Middle (HS310) & 821.00 \\
Upper (HS320) & 821.00
\end{tabular}




\section{MELCOR Computer Model}

Generally speaking, both MELCOR and CONTAIN are lumped-parameter, control volumes computer codes and thus do not have knowledge concerning dimensionality. In the following discussion, however, reference will be made to one- and two-dimensional geometries. This is in reference only to the flow paths that connect the control volumes. If a control volume is represented as a six-sided box, then a one-dimensional model would have flow only in/out a maximum of two of these sides (and the sides do not have to be opposite one another), a two-dimensional model would flow out a maximum of four sides, and three-dimensional flow could flow out all six sides.

Guidance for the MELCOR model was obtained from the CONTAIN model $[9,10]$ for these two PNL experiments. One major departure from the CONTAIN model was that it was two-dimensional, whereas the MELCOR model was one-dimensional. It is believed that most MELCOR modelers will use the ice condenser model in a one-dimensional configuration to simulate nuclear power plants. Thus, the most useful assessment will result from modeling the experiment in a manner most closely associated with a typical modeler's approach, i.e., in a one-dimensional geometry.

The MELCOR hydrodynamic nodalization which models the experiment is shown in Figure 3.1. There are a total of ten control volumes in the MELCOR model. Control Volumes 10 and 20 represent the injection and mixing regions. Control Volume 100 is the cylindrical-to-cartesian transition region as well as representing the transition from vertical downward flow to horizontal flow. Control Volume 200 is the diffuser section. Control Volume 210 redirects the flow from horizontal to vertical upward. Control Volumes 300, 310 and 320 divide the 14.6 meter ice-condenser section into three equal vertical sections, as was done in the CONTAIN model. Control Volume 400 represents the outlet flow section, while the gas is exhausted to Control Volume 450, which represents the "environment". In the actual experiment, the flow was sent to a scrubber, which is ignored in both the CONTAIN and the MELCOR models.

Control Volume Hydrodynamic (CVH) mass and energy sources were used to simulate the injection of hot air and steam into Control Volume 10. These sources were time dependent. An additional source/sink pair was placed in Control Volumes 300 and 320. It was observed in the low flow test [7], Experiment 11-6, that some natural convection, or recirculation, occurred in the region from the diffuser outlet to the ice condenser sections. To model this "backflow" or recirculation, a mass/energy sink was placed in Control Volume 320; this same mass and energy was then sourced to Control Volume 300. An attempt to source this mass and energy further upstream to Control Volume 210 was unsuccessful because of the small size of Control Volume 210 relative to that of Control Volume 320 . The source/sink control function removed $20 \%$ of the mass and energy from Control Volume 320 every timestep, and transferred it to Control Volume 300 . The $20 \%$ value was used after conducting an informal sensitivity study ranging from $15 \%$ to $30 \%$. The MELCOR input for this recirculation was arranged so that, by changing one number, 


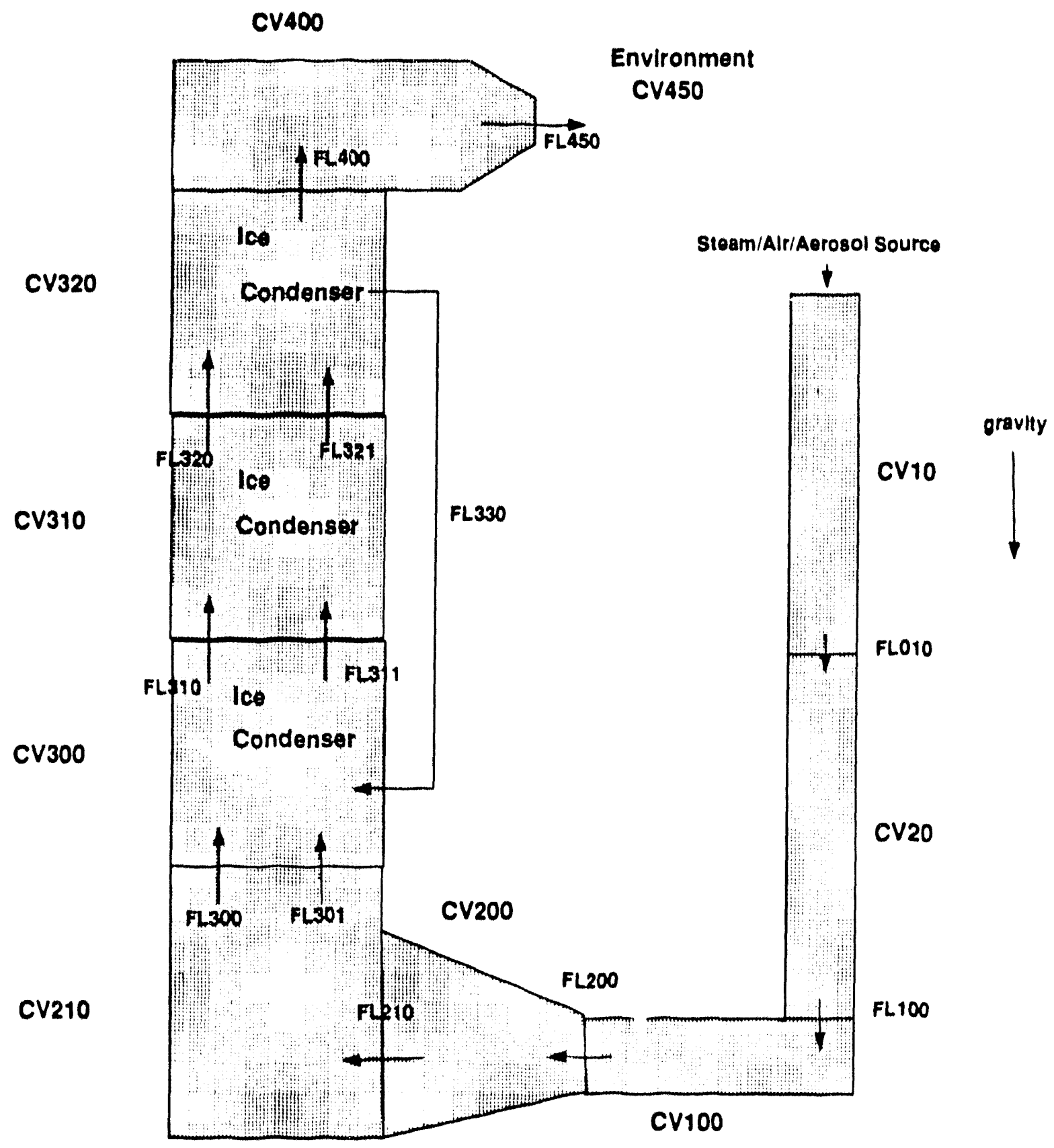

Figure 3.1 MELCOR Nodalization Diagram for the Ice Condenser Test Facility showing Control Volumes and Flow Paths (not to scale). 
the source/sink recirculation in the high flow Experiment 16-11 could be "zeroed out" of the simulation.

Another minor difficulty encountered was in setting the initial pressures. Initially, pressures in all the control volumes were set at the same value in the hope that the mass/energy source in Control Volume 10 would raise the pressure and set up a driving force to initiate flow. This proved unsuccesstul; fatal CVH convergence errors occurred. To alleviate this problem, a linear pressure gradient was set as initial conditions to "jump start" the flow in the proper direction and rate. This technique proved successful, and was used in the reference calculations. Pressure values for each control volume used to alleviate this minor problem may be found in Appendix $A$.

Flow paths shown in Figure 3.1 connected each control volume in succession. However, a further refinement was necessary in the ice-condenser sections. As water from melted ice in an ice condenser volume built up, it would compete with the upward moving hot gases flowing in a flow path. When enough liquid water built sufficient pressure head, the flow would reverse, a pressure build-up would occur, and either extreme time-step reductions would occur, or the code would shut down. To alleviate this problem, two flow paths were placed in the entrance and exit regions of the three ice-condenser control volumes. This allowed liquid water to flow downward in one flow path while simultaneously the steam/air/aerosol gas mixture could flow upward in the second flow path. No valves were placed in any of the flow paths, and $100 \%$ of the flow area for all flow paths was available during the entire simulation time. Loss coefficients were calculated from standard pipe friction factor correlations [11].

Heat structures were associated with each control volume to represent the piping, turning vanes, etc. Three heat structures were placed in each of the three ice condenser control volumes, as shown in Figure 3.2. One represented the ice itself; another represented the horizontal structural supports that could absorb heat and accept aerosol deposition; and a third structure represented the vertical supports that absorbed heat but did not allow aerosols to precipitate on them. Two heat structures--one representing the vertical portion, and another representing the horizontal portion-- were created for the ice condenser entry, located in Control Volume 210. Initially, only a vertical heat structure was placed in this control volume. However, substantial water from the ice condensers found its way down to this control volume, and $\mathrm{CVH}$ convergence problems were experienced with only a vertical heat structure in this location. The original heat structure was separated into a vertical and horizontal portion, alleviating the $\mathrm{CVH}$ convergence problem. A total of fifteen heat structures existed in the model. Control Volume 450 did not have a specific heat structure associated with it (nor is it necessary in MELCOR to place a heat structure in every control volume). However, the outside of the heat structures representing piping communicated with Control Volume 450. All of the heat structures contained only two nodes. The significance of number of nodes to resolve an ice condenser heat structure was examined in Section 8.4. The importance of radiation heat transfer, especially for the aerosol results, was examined in a sensitivity study in Section 8.5 . 
Heat Structures Assoclated With The

Three lce Condenser Control Volumes

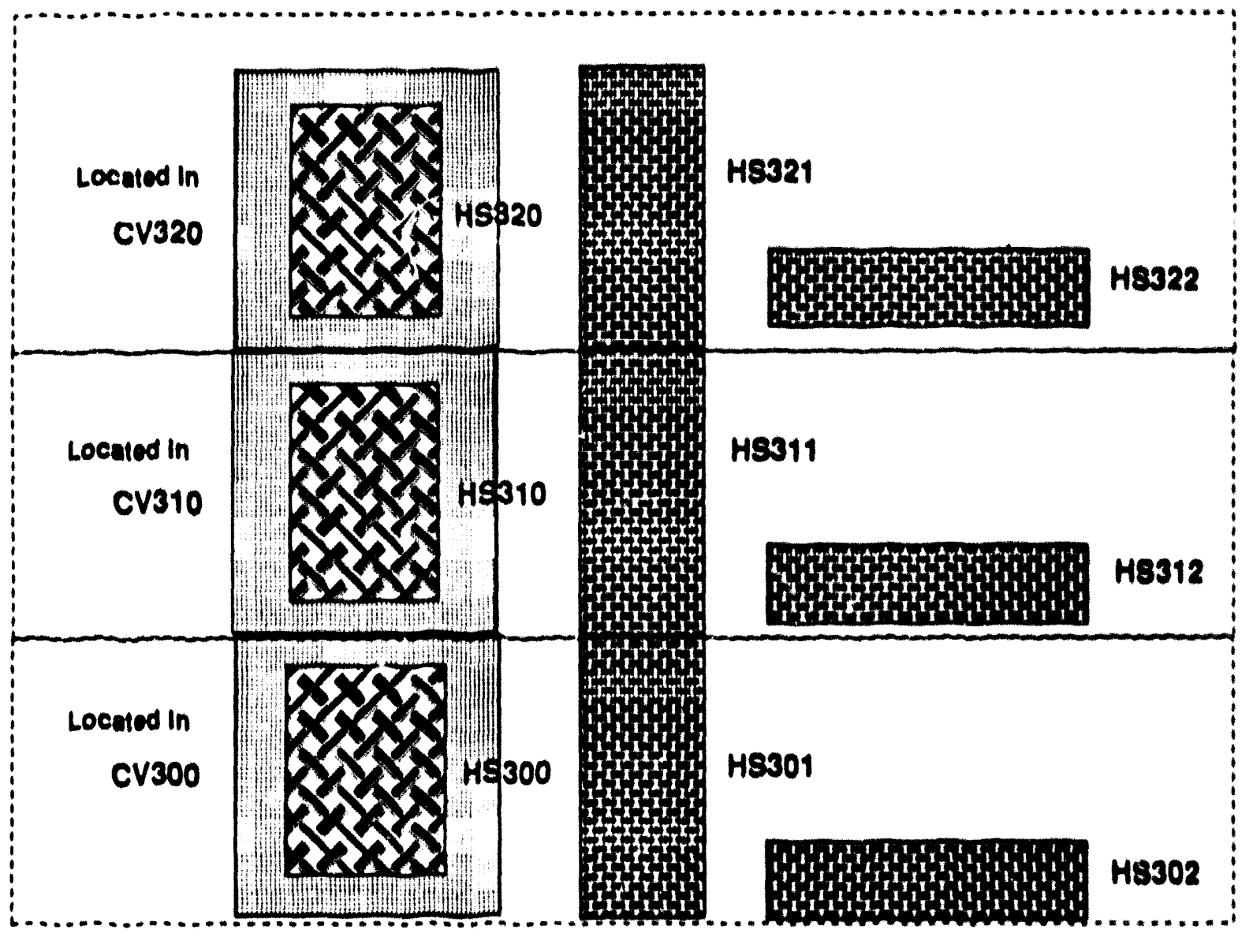

Figure 3.2 MELCOR Nodalization Diagram for the les Condenser Teat Facilly, showing Heat Structures (not to scalo). 
As discussed in Section 2, Experiment 11-6 was conducted after thirty minutes of preheating. which reduced the ice inventory from $2431 \mathrm{~kg}$ to $1361 \mathrm{~kg}$. An examination of the data revealed that ice melting during the preheat phase must have been primarily axial, i.e. most ice melt occurred at the bottom of the ice condenser. This melted ice was then replaced by ice falling down from higher regions of the ice condenser, and leaving the upper portion of the ice condenser devoid of ice. In fact, the data strongly indicated that the upper ice condenser control volume (Control volume 320) did not have any ice by the time Experiment 11-6 began (time "zero"). Further, at some point, ice melting changed from being primarily axial to being radia! because the ice in Control Volumes 300 and 310 disappeared at almost exactly the same time. If ice melt was axial during the experiment, then CV 310 would have lost all its ice much sooner than CV300. Since ice disappeared from CV300 and CV310 at about the same time, ice remaining from the preheat phase was equally apportioned between the ice condenser heat structures in these two control volumes

A MELCOR parameter that affected the melt rate of the ice is the adjustable heat transfer coefficient multiplier. In [8], a value of 1.2 for this parameter was used. For Experiment 16.11, the 1.2 value was adopted and agreed very well with experiment. However, the unique behavior of Experiment 11-6, with the pre-melting of ice and the recirculation, required an adjustment of this parameter. In the bottom control volume (CV300), a value of 1.8 was used for this parameter, and in the middle control volume (CV310) a value of 3.8 was necessary. These values were chosen based on the amount of time to melt the ice in each compartinent as indicated by the experimental results. Since ice was absent in the uppermost compartment for Experiment 11-6, a third value was unnecessary. These values were still well within accepted values for this parameter, as CONTAIN used a value of 5.0 for this parameter [8]. In addition, a sensitivity study was conducted for this parameter for both experiments in Section 8.2.

The aerosol input specified two components, water vapor and $\mathrm{ZnS}$, because previous studies [6] have shown a distinct benefit in doing so. The default number of components in MELCOR is one. However, the default number of classes (fifteen) and default number of sections (five) were used. The minimum and maximum diameters for the size distribution were $0.1 \times 10^{-6} \mathrm{~m}$ and $100.0 \times 10^{-6} \mathrm{~m}$, respectively These non-default choices were based on the data given in [7]. The aerosol particle density was unavailable, so the value used in the reference calculation was $2500 \mathrm{~kg} / \mathrm{m}^{3}$. Most of these parameters -- number of components, number of sections, the minimum diameter, the allowable range of particle diameter, and the aerosol particle density -- were examined in sensitivity studies discussed in Section 6. The source aerodynamic mass mean diameter (AMMD) was given as $3.5 \times 10^{.6} \mathrm{~m}$ for Experiment 11-6. Since a value for Experiment 16-11 was unavailable, the same value was used. The geometric standard deviation (GSD) used in both simulations was 2.0. The AMMD and GSD were providen in [7].

In Experiment 11-6, initial temperatures were taken from data that was available. Some $\mathrm{CVH}$ and heat structure temperatures were interpolated. One assumption was that the 30 minutes of pretreatment with hot gas flow in Experiment 11-6 had warmed the piping 
almost to the same temperature as the gas flowing inside. In Experiment 16-11, difficulty was encountered when an attempt was made to model the entry piping heat structures at room temperature and hot gas was flowed into the control volumes containing these structures. Condensate would form on these heat structures and cause the problem to become, numerically, extremely stiff. The timestep would be reduced so far as to cause shutdown of the simulation. This problem was alleviated by slightly raising the initial temperatures of the heat structures in MELCOR that represented the piping and diffuser. This minor deviation from actual experimental conditions produced temperatures at early time of the simulation that were somewhat too high. Section 4 discusses this observation further.

The reference MELCOR sirnulation was run with a maximum timestep of 1.04 second for Experiment $11-6$ and 0.45 second for Experiment 16-11 during the entire time of each simulation. In Experiment 11-6, the low flow case, MELCOR ran at the maximum timestep of 1.04 second. Experiment 16-11 was a high flow case; thus, with higher velocities it was expected that the timestep would be smaller. This was the case, as the observed timestep in Experiment 16-11 was usually 0.44 second. In both cases, the timestep would be decreased for short periods of time while the code stepped through some short, fast transients. The results of a timestep study are given in Section 5.2.

Running the MELCOR code involves two steps. Most user input is contained in a MELCOR Input GENerator file created by the user. The actual computation itself is invoked by a short MELCOR input file. A copy of the MELGEN and MELCOR input used for the reference calculation of Experiment 16-11 is given in Appendix A. Since the input to simulate the two experiments was so similar, the input to simulate Experiment 11-6 is not included. 


\section{Reference Calculation Results}

The MELCOR ice condenser aerosol assessment was performed as an open post-test calculation, with both the experimental data and also results from previous CONTAIN analyses available for reference. The results discussed in this section represent the MELCOR calculation that, in our judgment, the typical user would also produce. These results use the insights gained from a thorough examination of the experimental data and the CONTAIN analyses.

All of the experimental results presented have been digitized from figures in Reference [7]. Since many of the curves exhibited extreme oscillatory behavior, only major maxima and minima were captured in the digitizing process, and many small oscillations were ignored. The two reference calculations were performed on an IBM RISC 6000 Model 550 workstation using the IBM AIX 3.1.5 operating system.

\subsection{Experiment 11-6 Reference Calculation Results}

The experimental data for the ice condenser experiments consisted of temperature data and aerosol data (particle retention factor). In Experiment 11-6, the low flow rate induced a natural circulation flow between the diffuser outlet and the ice condenser. The MELCOR simulation only recirculated flow from the top of the ice condenser to the bottom, so there was only global agreement with gas temperatures exiting the diffuser. This agreement is discussed in Section 9. However, since this was an ice condenser aerosol experiment, it was assumed that the pertinent results to compare are ice condenser temperatures and particle retention of the aerosol. All temperature data displayed represents the temperature of the vapor (referred to in MELCOR as the "atmosphere") which is the temperature of the steam/air/aerosol mixture.

Both the experimental data and the MELCOR and CONTAIN models divided the ice condenser region into three vertical compartments. Figure 4.1.1 compares the experimental temperatures to those of the MELCOR model in the lowermost ice compartment, which is represented in the MELCOR model by Control Volume 300. Because Experiment 11-6 exhibited a recirculation loop, one flow path of the four major flow paths in ice condenser was about $25 \mathrm{~K}$ cooler than the other three flow paths. The temperature figures in this report will consistently display an "envelope" for the experimental data representing the thermocouple that registered the temperatures from the hottest of the four flow paths and the thermocouple that displayed the temperatures from the coldest flow path. The upper and lower temperature curves that defined the envelope tended to approach each other and make the envelope very small when all of the ice in compartments that contained ice was melted, of which Figure 4.1.2 is an excellent example. The slope of the temperature increase changed as well when all of the ice in a condenser section was melted. In general, as Figures 4.1.1 - 4.1.3 demonstrate, the MELCOR model did an excellent job of predicting temperatures within the data envelope. Further, the data showed that the ice 


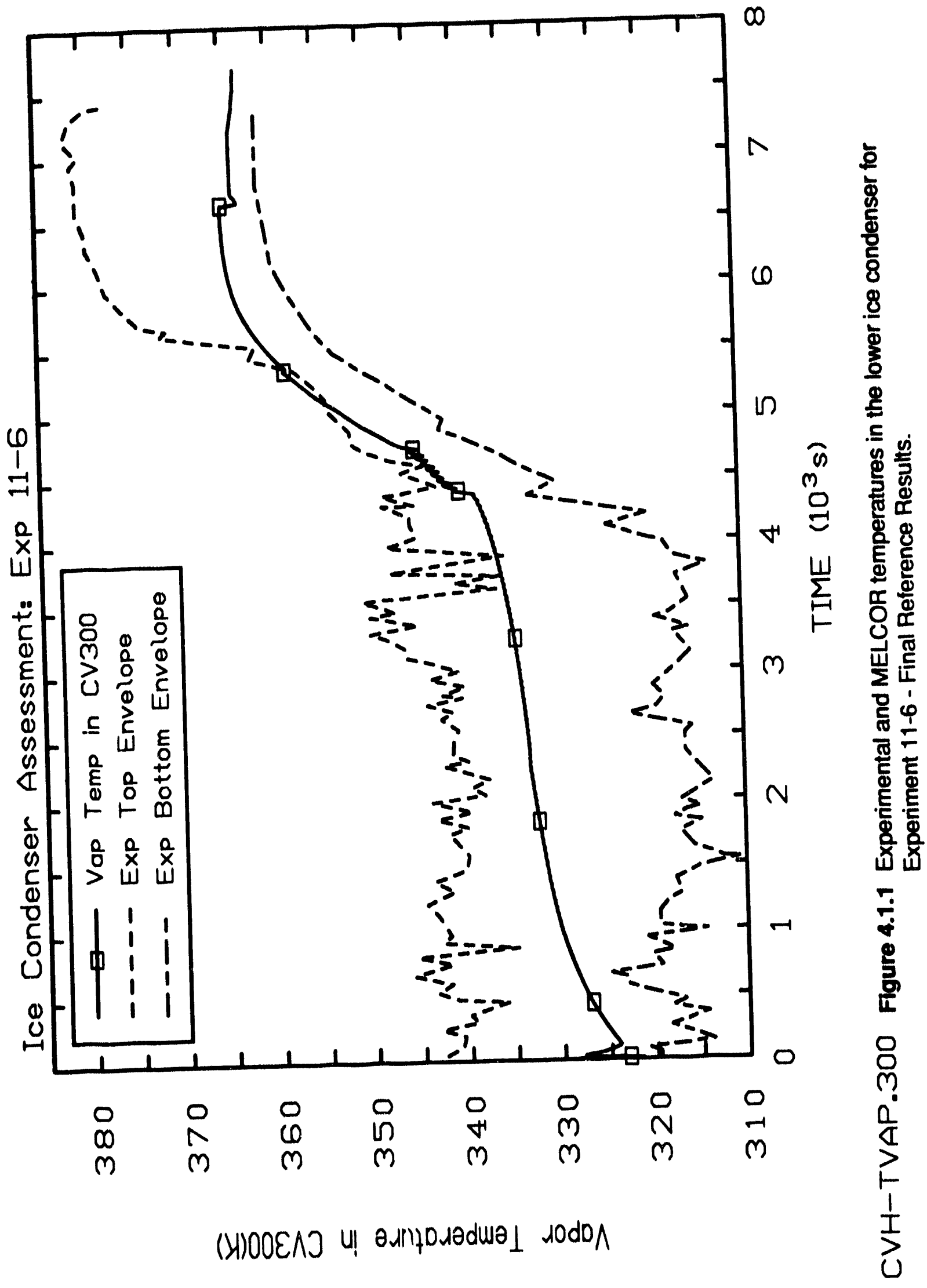




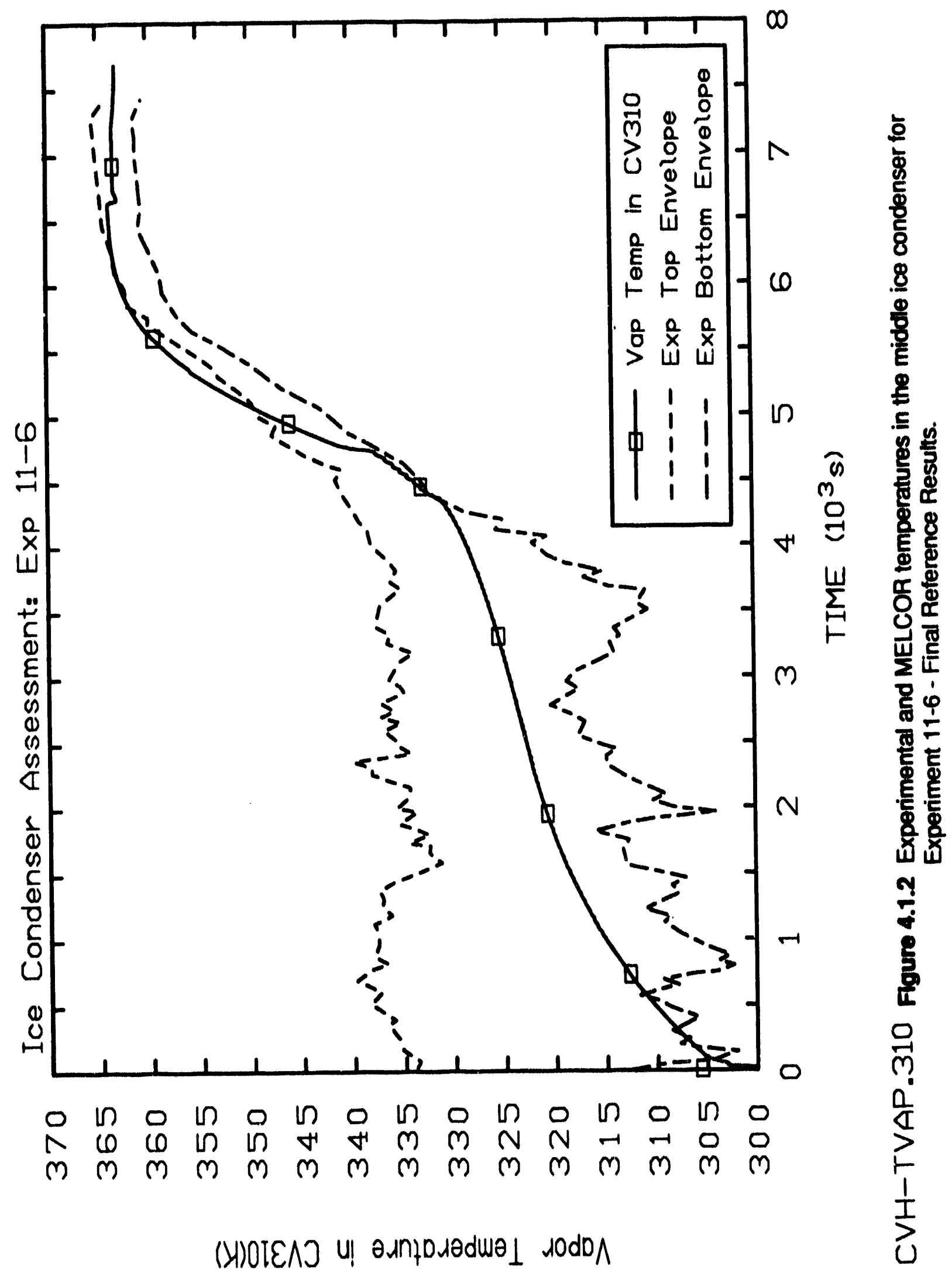




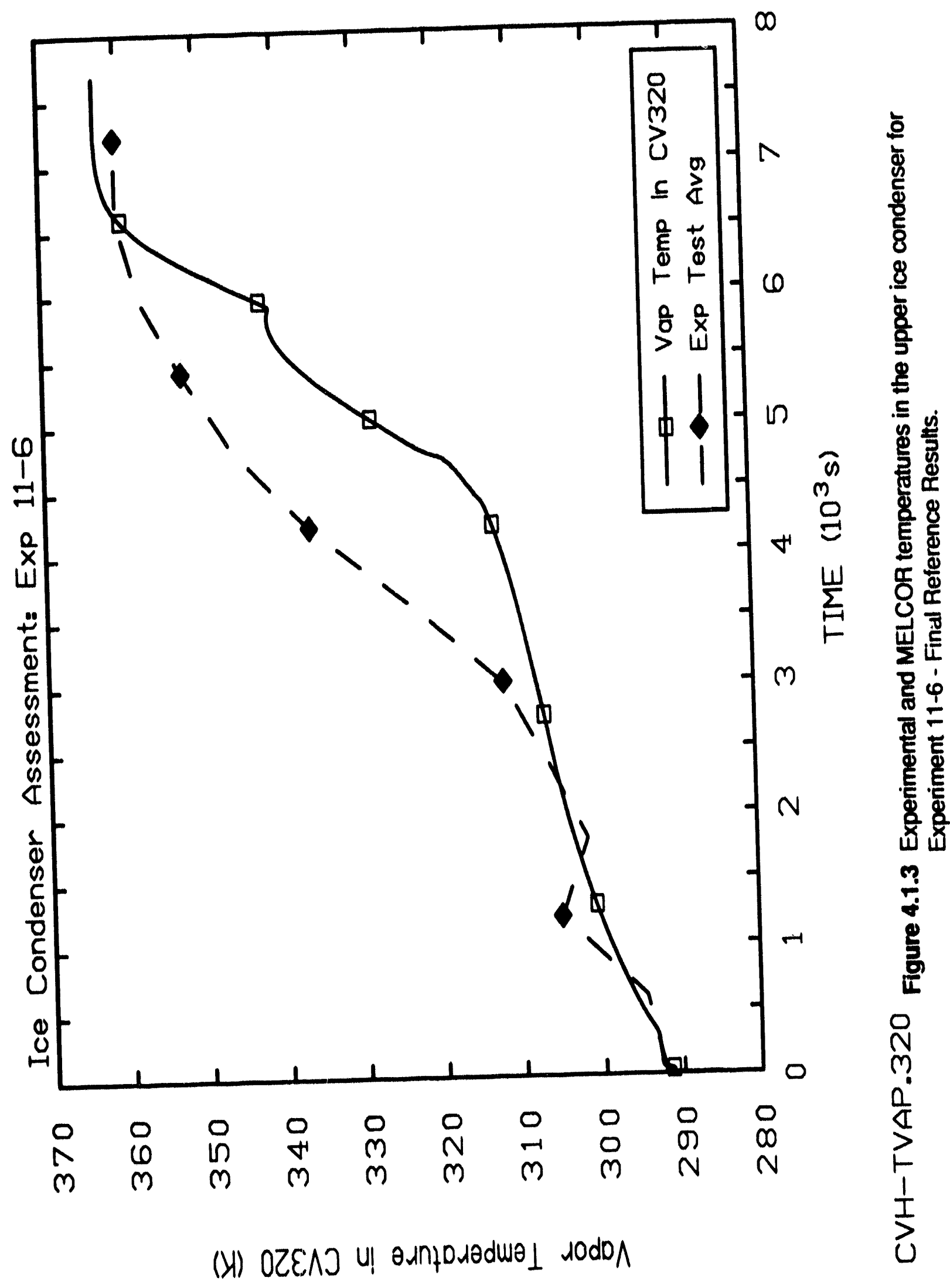


condenser sections lost all ice somewhere between 4000 and 5000 seconds, which was also well predicted by MELCOR.

Figure 4.1.2 compares the experimental results for the middle ice condenser compartment, which was in Control Volume 310, to the MELCOR model results. From initial time to about 4200 seconds, the MELCOR result fell within the experimental envelope. The melt time between 4000 and 5000 seconds was also well predicted. MEL.COR slightly overpredicted by as much as $3-4 \mathrm{~K}$ the temperature rise after the ice was melted, but again gave excellent agreement for the steady-state temperature in the condenser for the last 1600 seconds of the experiment. Overall, the agreement was considered excellent.

Figure 4.1.3 compares the experimental results for the uppermost ice condenser compartment, located in Control Volume 320, to the results of the MELCOR model. In this experiment, this compartment, at time zero, did not have any ice. The two thermocouples in this compartment, as a result of the lack of ice, predicted temperatures within a few degrees of one another. Thus, the experimental data was adequately represented by one curve. For the first 3000 seconds, MELCOR predicted the temperature fairly accurately. However, after this time, the experimental temperature profile rose more sharply, while the MELCOR results continued on the same slope until the lower control volumes lost their ice. Then, the MELCOR temperature curve rose sharply and caught up with the experimental result.

As discussed in the CONTAIN results, the most important result of the aerosol portion of the test can be obtained from the measured particle retention fractions. The experimental results for Experiment 11-6 concluded that the initial particle retention was 0.86 (or $86 \%$ ), the final particle retention was 0.73 , and that the average during the test was 0.78 . The MELCOR time-dependent result of particle retention is shown in Figure 4.1.4. Note that the curve quickly drops below 0.825 , and that the final value is about 0.71 .

Pressure build-up in the experiment was negligible. It was stated that the normal operating test section pressure never exceeded $13.8 \mathrm{kPa}$ gage, but did not state an average or typical value. In many instances it was probably less than this value. MELCOR results were such that the test section pressure did not exceed $2.0 \mathrm{kPa}$ gage. 

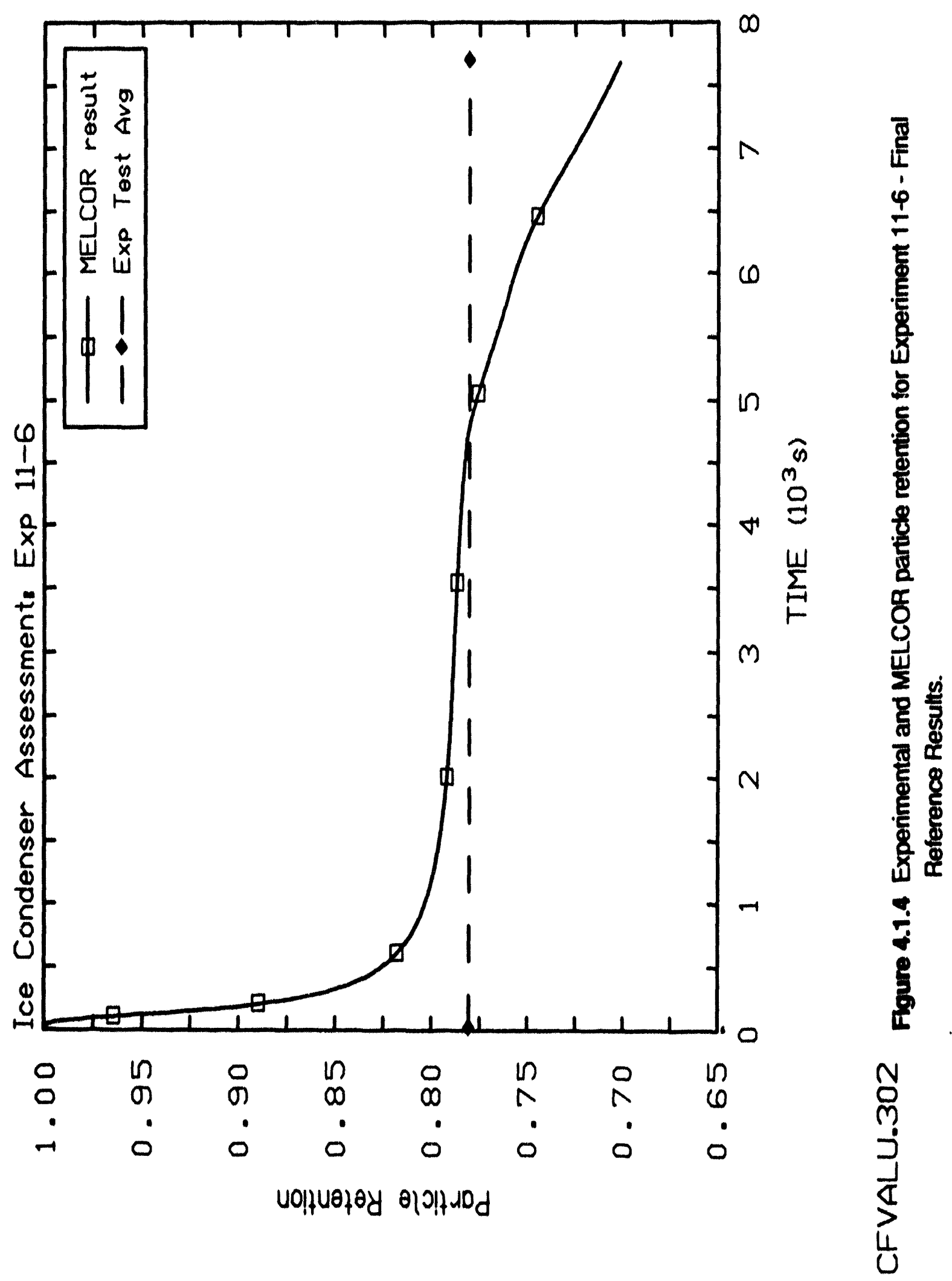


\subsection{Experiment 16-11 Reference Calculation Results}

In Experiment 16-11, only data for the top and bottom ice condenser regions was available. Data was not presented for the middle region. However, since this test was performed with every compartment full of $i c \theta$ and it was a high flow test with no recirculation [7], it is reasonable to assume that the temperatures for the middle ice condenser were intermediate to those of the top and bottom lce condenser.

Figure 4.2.1 compares the envelope of the experimental results for the lowermost ice condenser to the MELCOR prediction. In this experiment, the MELCOR data for this compartment tended to follow the upper experimental temperature envelope. During late time, MELCOR predicted temperatures that were as much as $5-10 \mathrm{~K}$ higher than the upper temperature envelope. However, an important observation is that the slope of the predicted temperature curve matches that of the data. The slight overestimation of temperature, especially in this compartment, may be attributed to the MELCOR limitation discussed in Section 3, where it was pointed out that it became necessary to set entry heat structures at temperatures artificially higher than experimental values to avoid condensation and consequent convergence difficulties. Still, overall agreement with the data was considered to be good.

Although the experiment data was not available, the MELCOR prediction for temperatures in the middle ice condenser are presented in Figure 4.2.2 for the sake of completeness.

Figure 4.2.3 compares the envelope of the experimental results for the uppermost ice condenser to the MELCOR prediction. In this case, the MELCOR prediction began too high, but then did reasonably well for the remainder of the experiment. Again, MELCOR initial and early-time temperatures were higher than the temperature in the uppermost compartment because of the initial high entry heat structure temperatures. Agreement between MELCOR and experiment in this compartment was also considered good.

The experimental results for the aerosol portion of Experiment 16-11 were as follows. The initial particle retention was given as $95.9 \%$, the final particle retention factor was 0.88 , and the average was 0.937 . The MELCOR prediction, along with the experimental average, is shown in Figure 4.2.4. The particle retention curve quickly dropped to a value around 0.94 , remained between $0.92-0.94$ for most of the test, and then dropped to a final value of about 0.91 . 


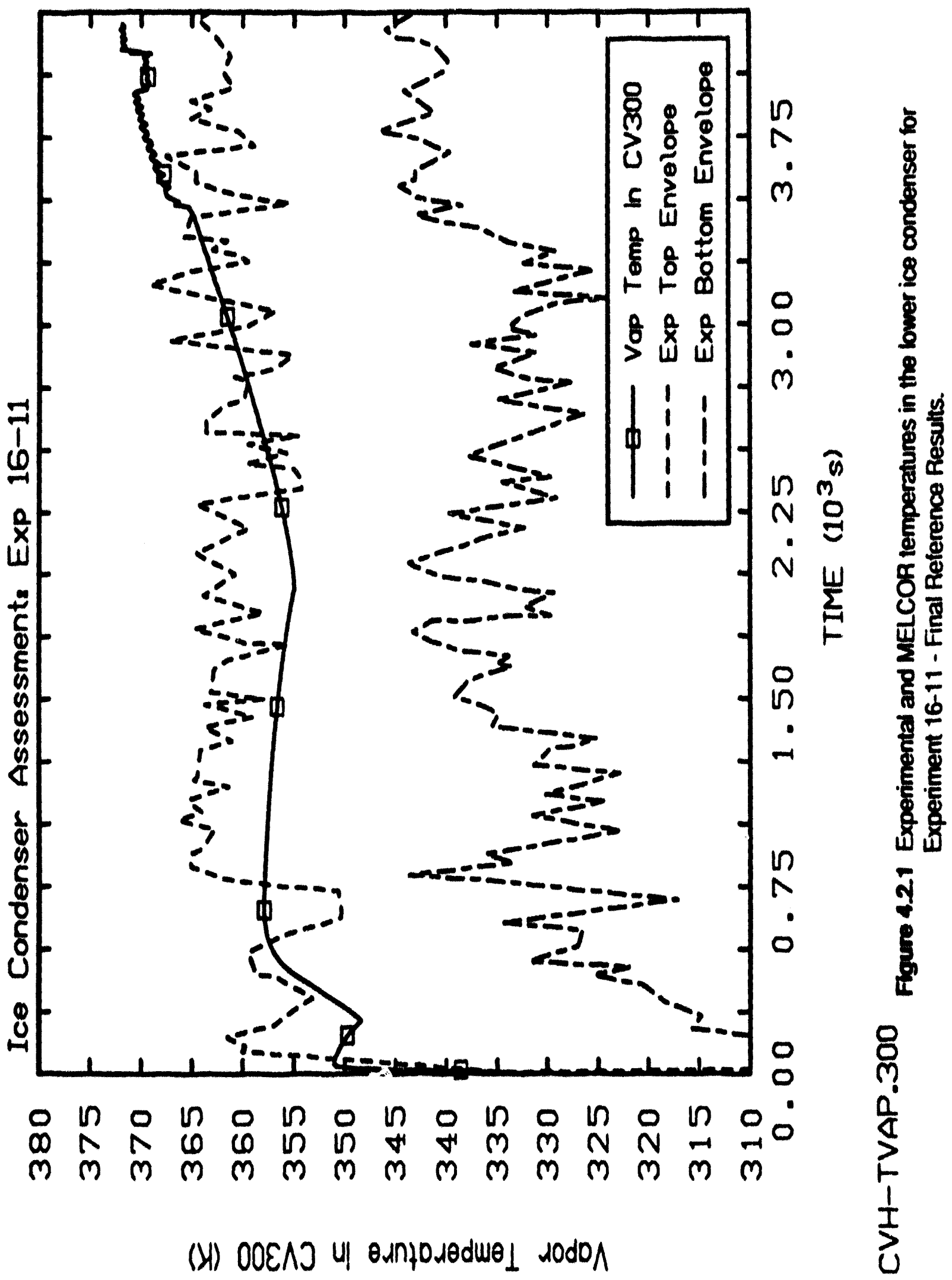




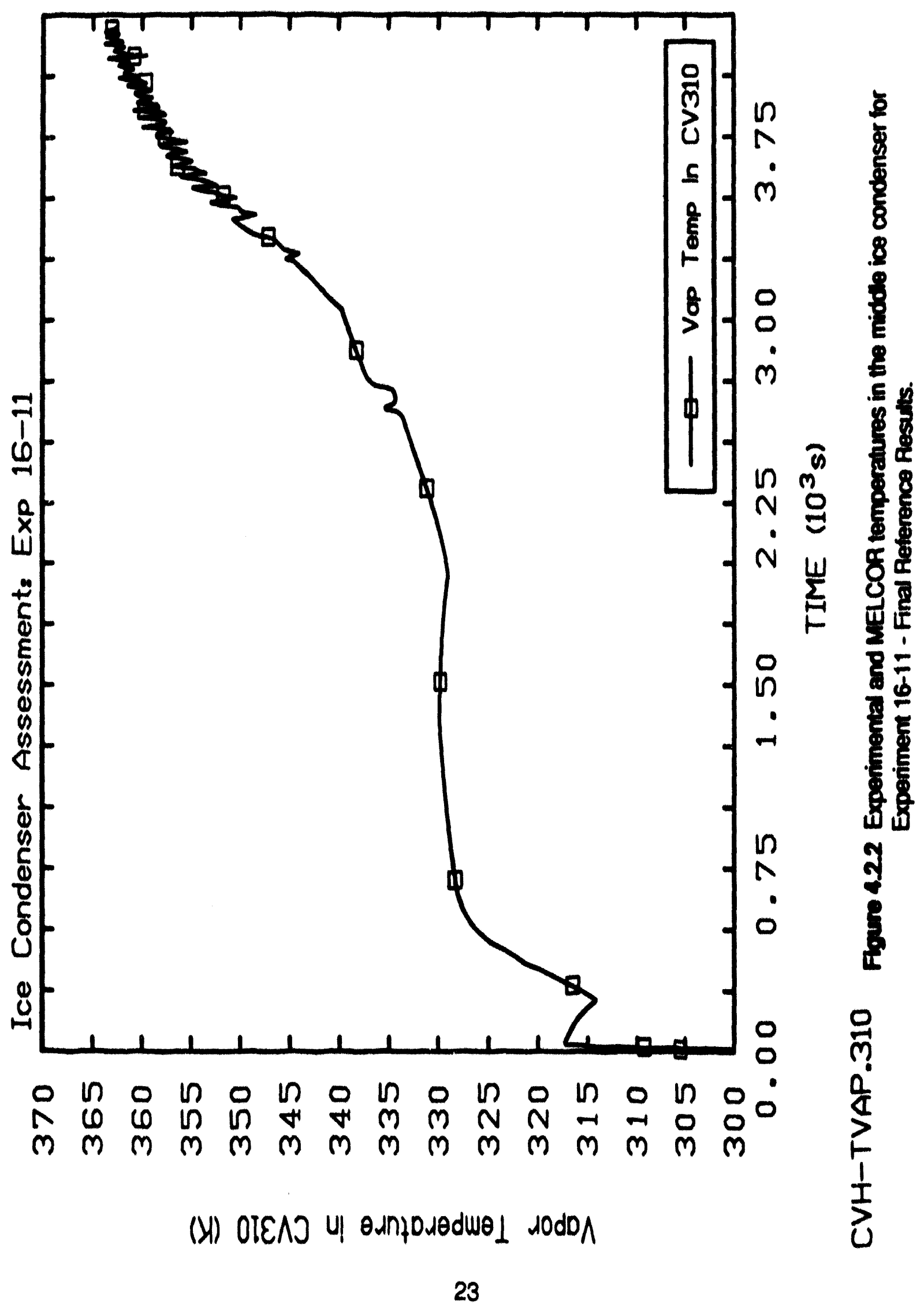




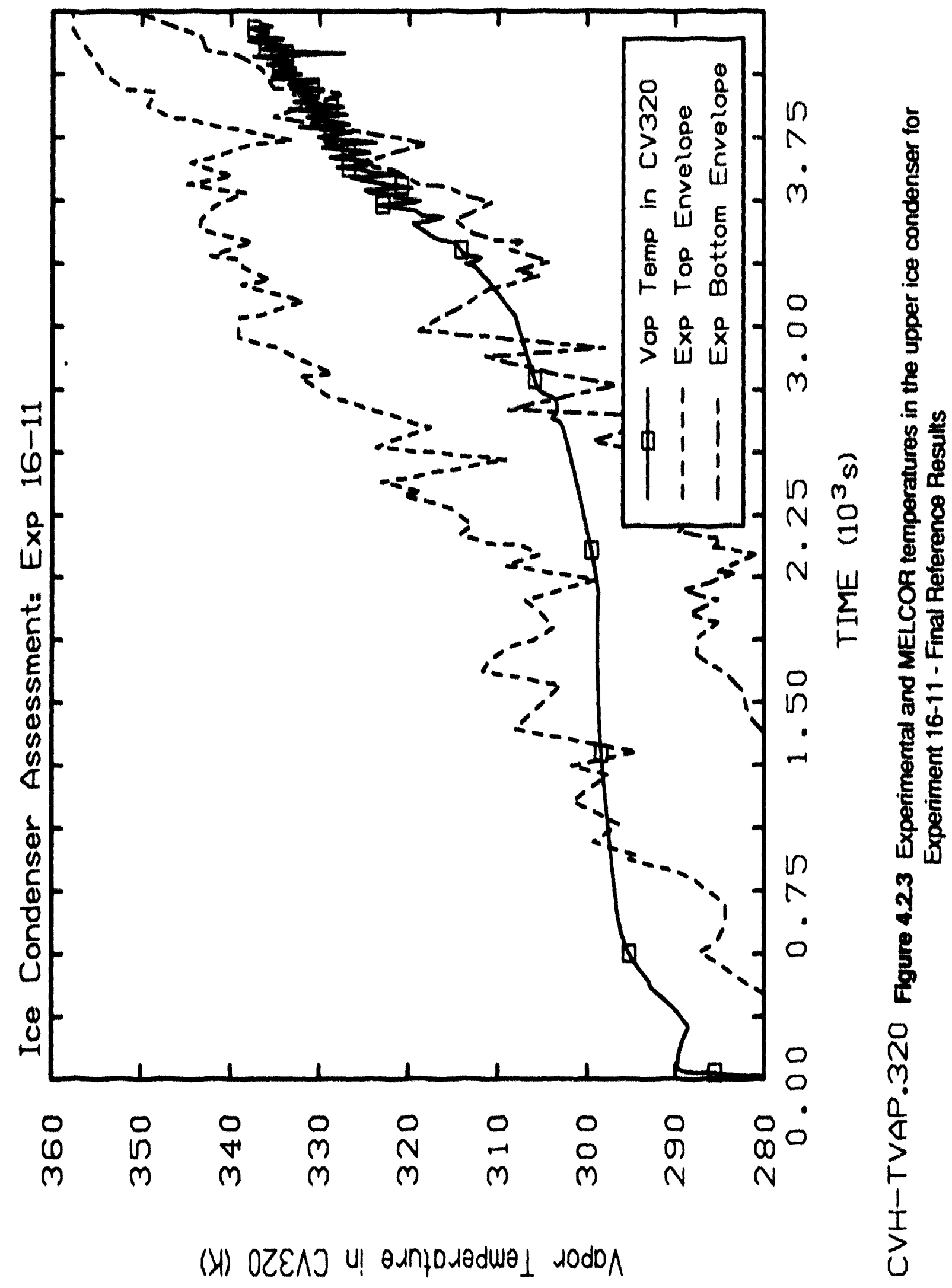




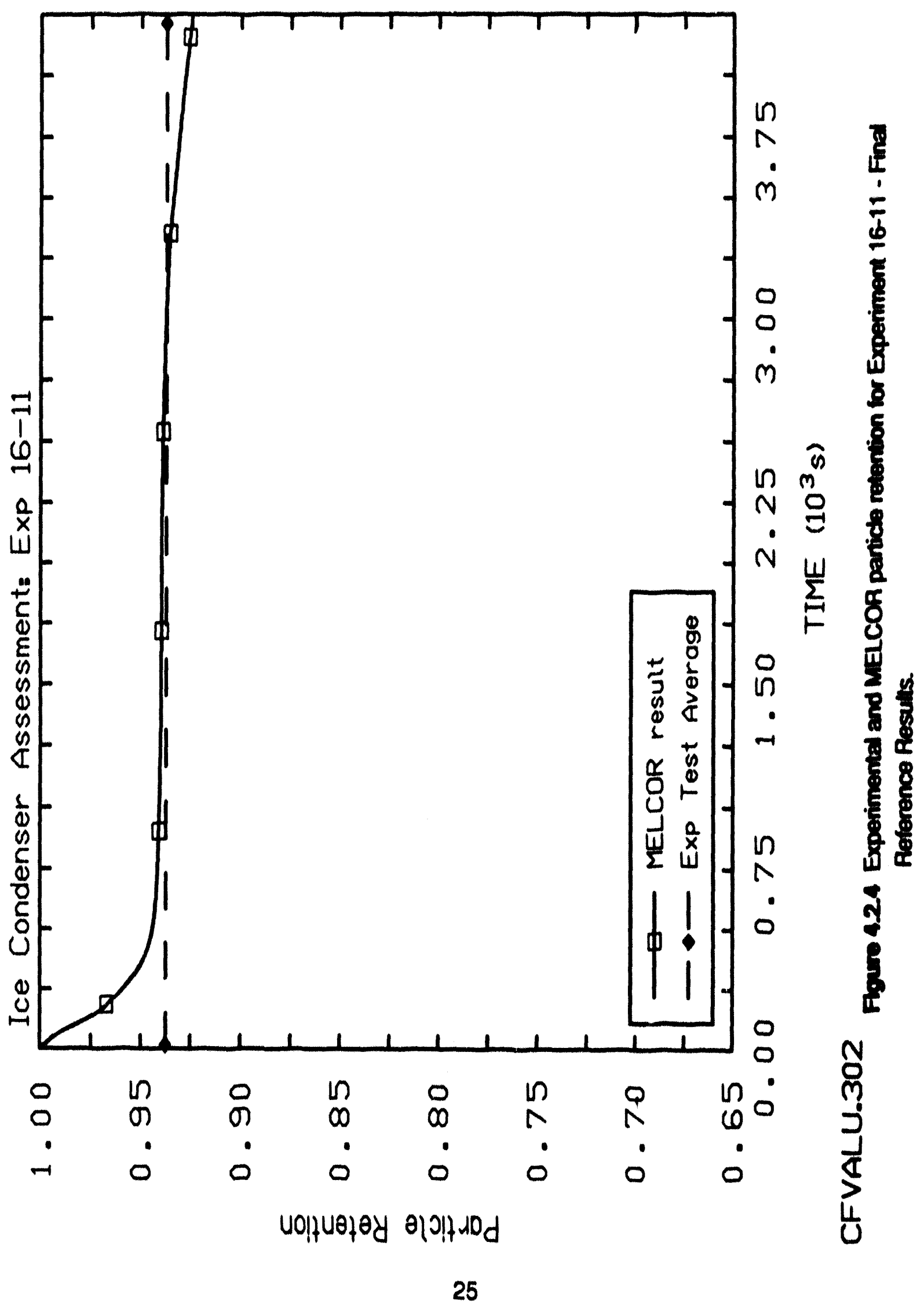




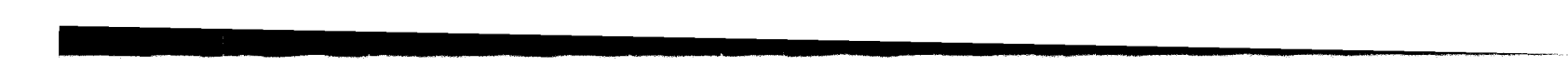




\section{Machine Dependency and Timestep Effects}

For identical input, differences in MELCOR results have been observed or reported on different computational platforms. In most instances, this has stemmed either from differences in FORTRAN compilers or in different interpretations of the ANSI FORTRAN standard. Thus, it was essential to perform the two reference calculations on different machines to determine whether the answers were consistent, especially on computational platforms with different operating systems and/or word length. Another concern was that varying the maximum timestep may possibly affect the results. The effect of varying the maximum timestep on one computing platform (the IBM workstation) was examined with respect to the MELCOR simulation of the PNL Ice Condenser experiments. In fact, all of the Sensitivity Studies with the exception of the Machine Dependency Sensitivity Study, including those of Sections 6, 7, and 8, were performed on the IBM workstation.

\subsection{Machine Dependency}

The reference calculations for both Experiment 11-6 and Experiment 16-11 were run on a CRAY XMP-24, a DEC VAX 8650, a Gateway 486/33 Personal Computer, and a Sun Microsystems SparcStation 2, as well as the IBM RISC 6000 Model 550 workstation. The results from the five machines differed in the last significant digit in the printed output results (of usually five significant digits), but when plotted all the results were such that no differences were visible.

Figure 5.1.1 shows the particle retention for both experiments as compared for the different computing platforms. Figure 5.1.2 shows the vapor temperature in Control Volume 300 and Figure 5.1.3 shows the vapor temperature in Control Volume 320 where the sensitivity study was compared to the experiment results (for both experiments). The figures show that there were no observable difference in the results. Although not shown, other hydrodynamic, flow, and aerosol parameters evinced the same characteristic, i.e. for all practical purposes the results were identical.

Figure 5.1 .4 shows the total cpu time used by the five different machines for each of the reference calculations. A result reported in another assessment [4] was that the IBM workstation virtually equalled the CRAY supercomputer in run time for these problems. Of course, the coding structure of MELCOR requires that the CRAY run for the most part in scalar mode; vectorization is not widely utilized. The PC required an order of magnifude more cpu than the IBM and the CRAY. Note that the PC "cpu time" is actually wall clock time and that the PC worked on a different task at about $35^{\mathrm{n} n}$ seconds. Thus, the uiscontinuity for the PC curve in Figure 5.1.4 for Experiment 16-1, should not exist, and the total cpu time should be closer to 12,000 seconds than just over 14,000 seconds. Although not shown, there was no difference in the proportionate cpu time that any one package of MELCOR used for the platforms. For instance, if the CVH Package used $50 \%$ 

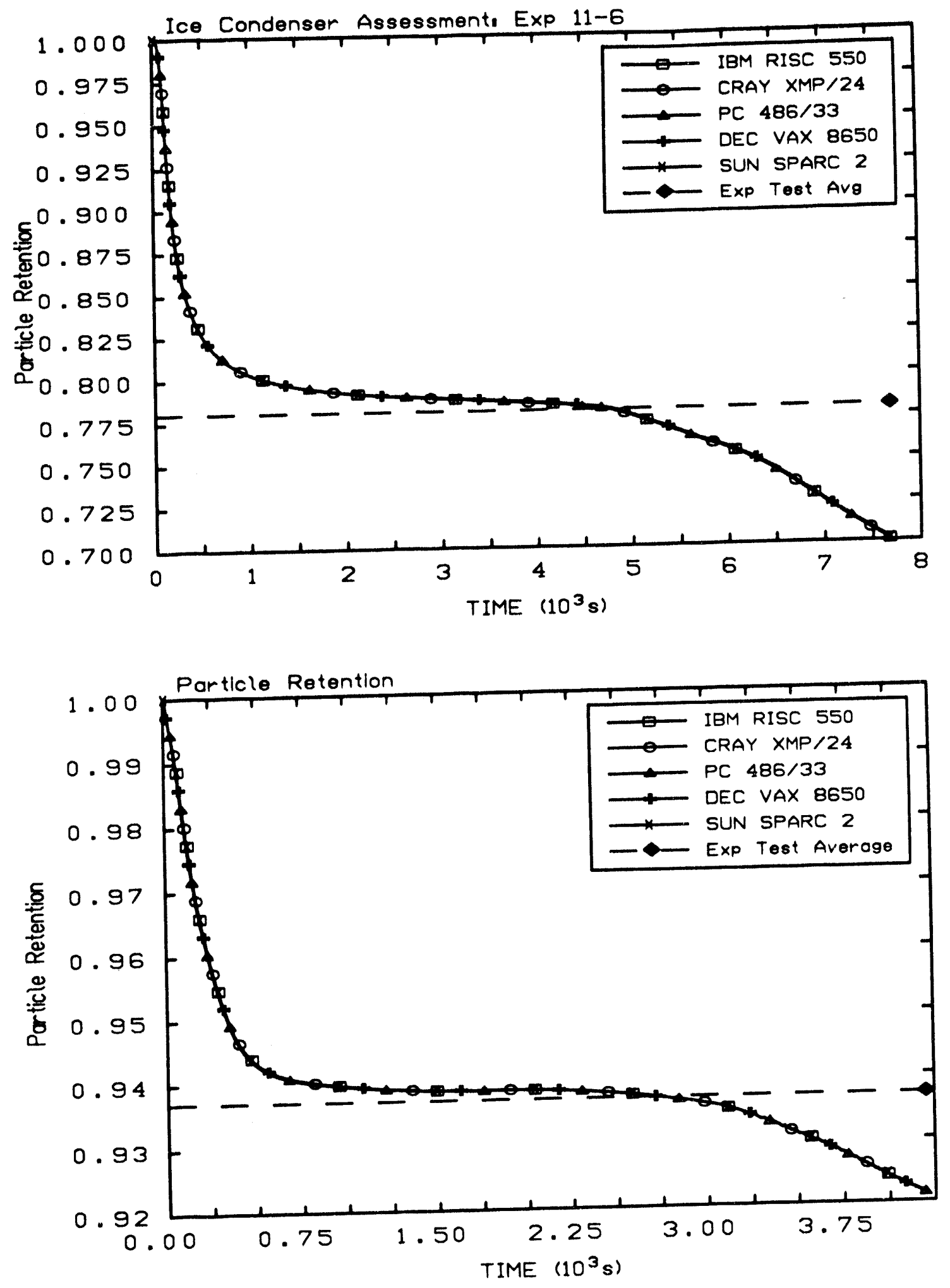

Figure 5.1.1 Particle Retention for Experiment 11-6 (top) and Experiment 16-11 (bottom). Machine Dependency Sensitivity Study. 

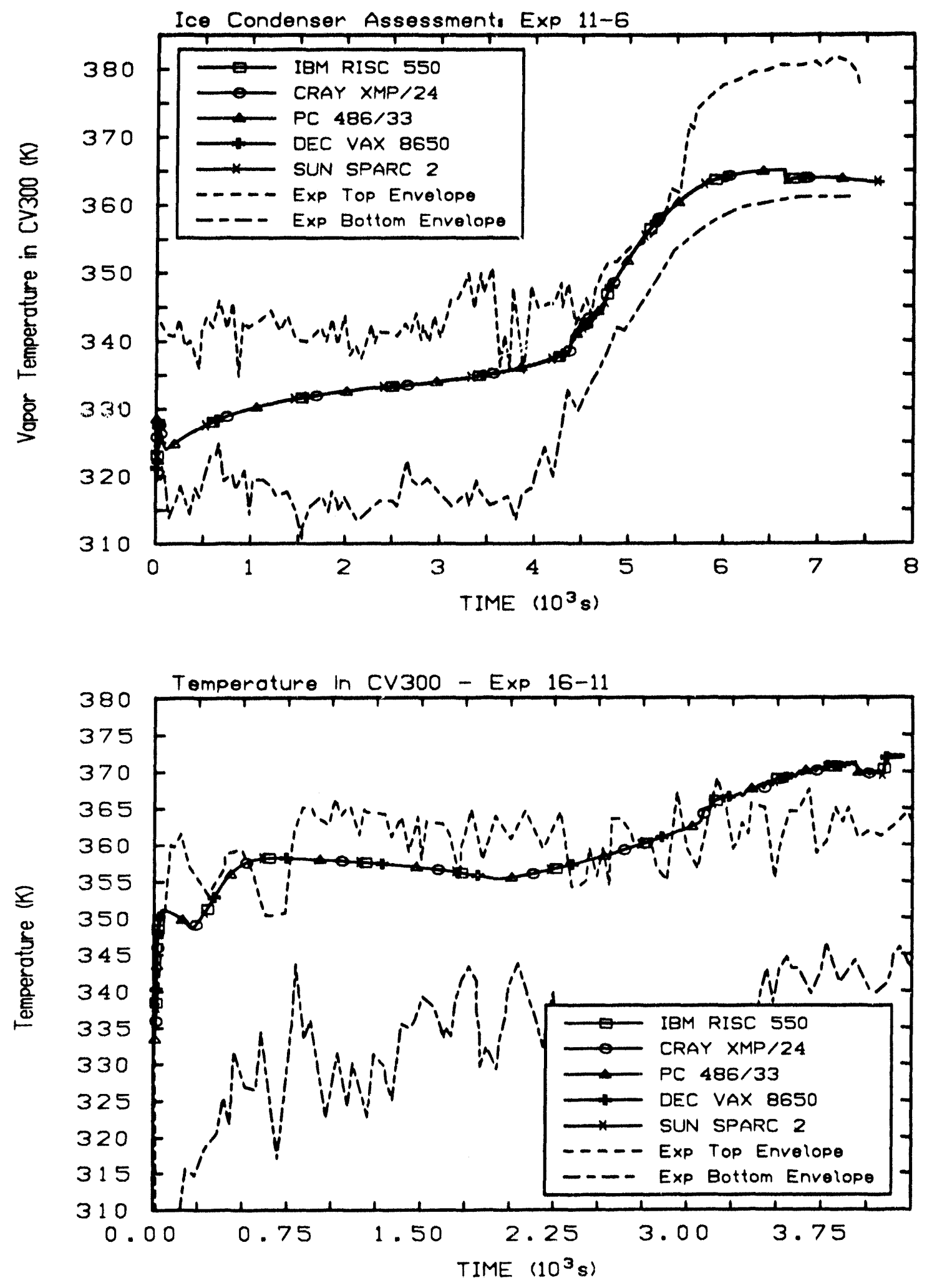

Figure 5.1.2 Vapor Temperature in CV300 for Experiment 11-6 (top) and Experiment 16-11 (bottom). Machine Dependency Sensitivity Study. 

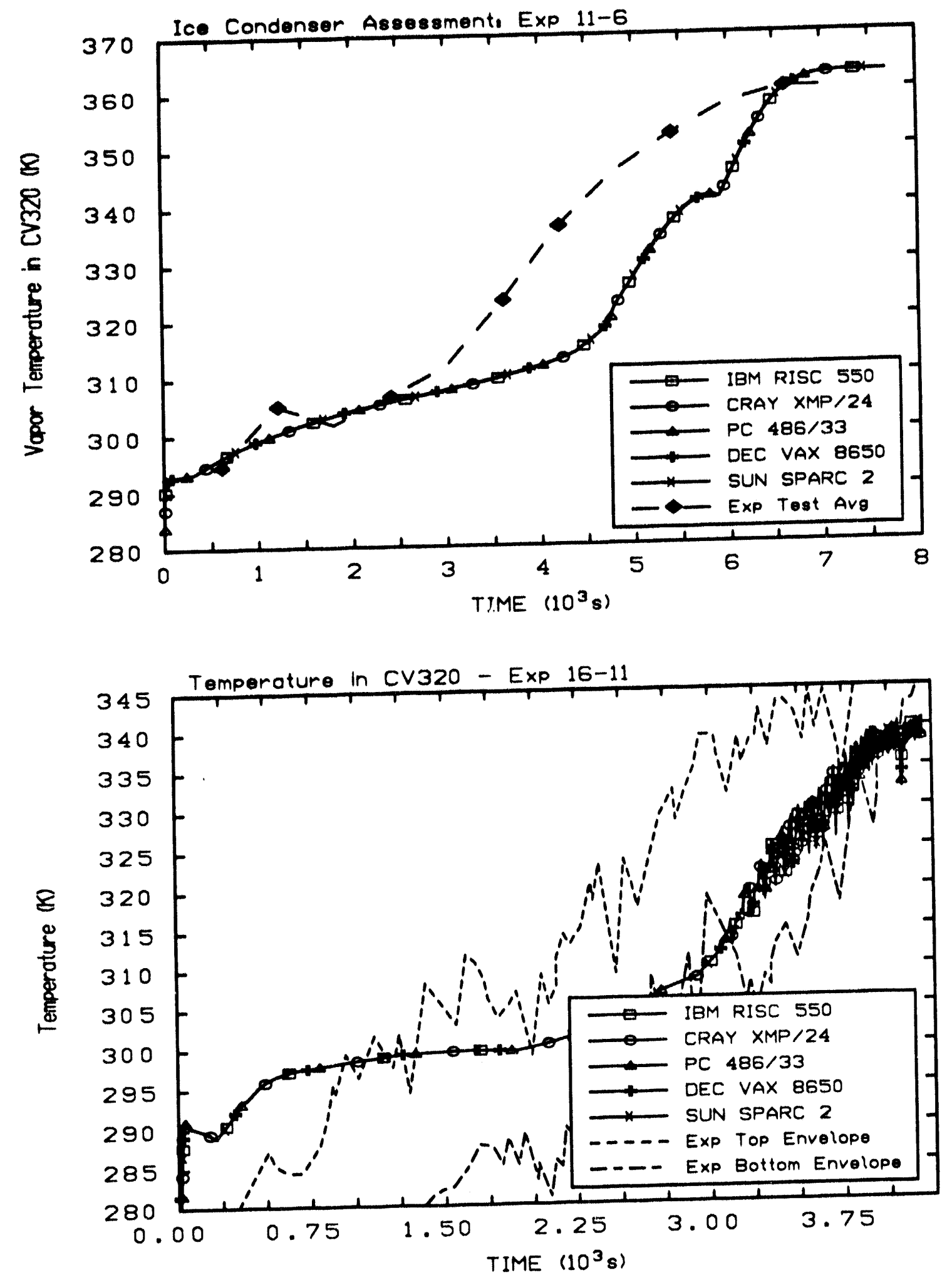

Figure 5.1.3 Vapor Temperature in CV320 for Experiment 11-6 (top) and Experiment 16-11 (bottom). Machine Dependency Sensitivity Study. 

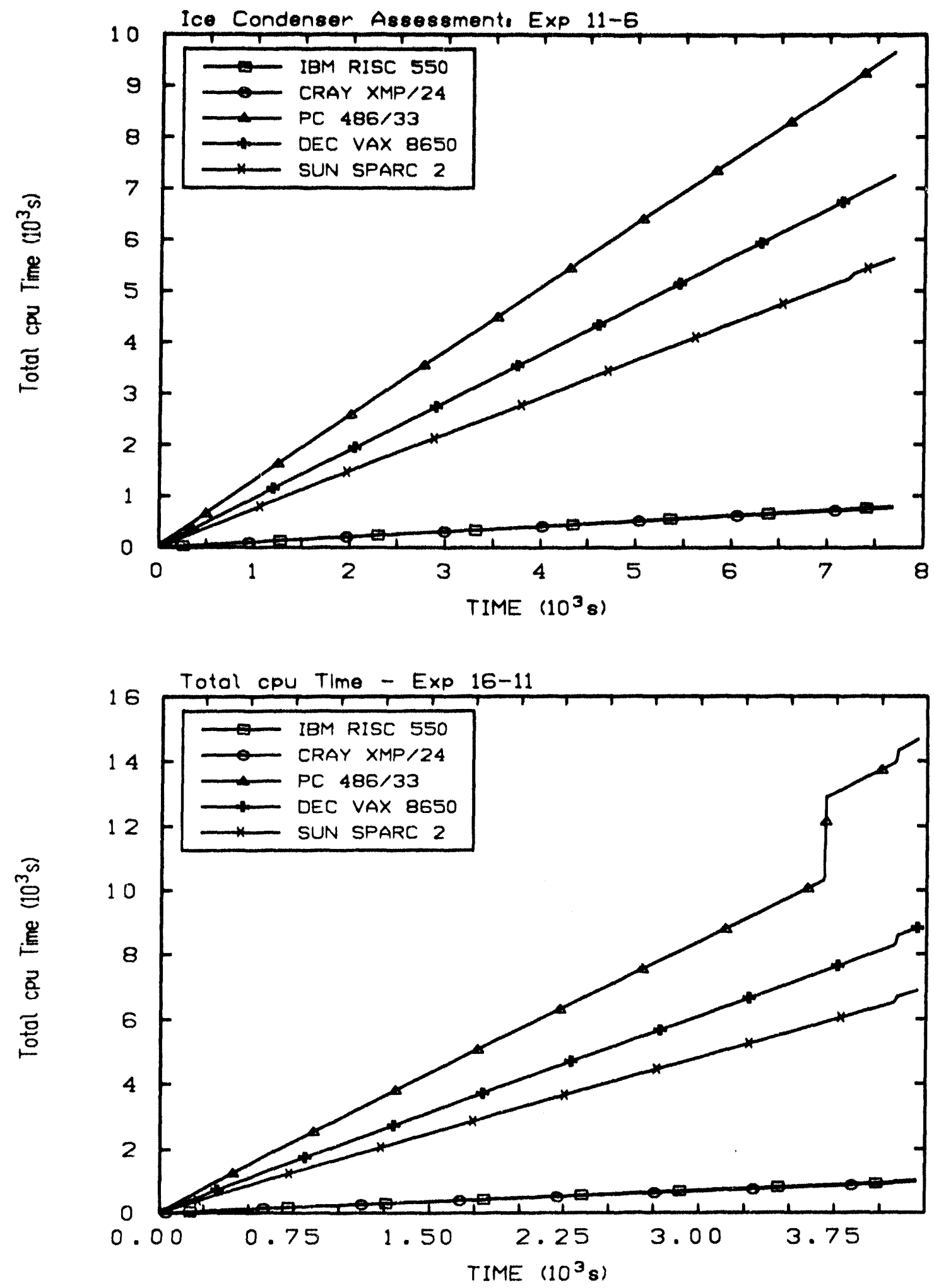

Figure 5.1.4 Computer Processor Unit time for Experiment 11-6 (top) and Experiment 16-11 (bottom). Machine Dependency Sensitivity Study. 
of the total cpu time on the IBM workstation, then approximately the same was the case for the remaining platforms.

The machine dependency sensitivity study was the only study performed using an earlier version of MELCOR other than 1.8LF. Because of time constraints, MELCOR 1.8KW was the version used in this study to show that there is essentially no machine dependency for the two ice condenser simulations. Previously, MELCOR version 1.8KQ had also been used to conduct a machine dependency study, with the same result that machine dependency was virtually nonexistent. Again, because of this redundency and the aforementioned time constrain, it was not deemed necessary to repeat the machine dependency sensitivity study for this class of problem.

\subsection{Timestep Effects}

The reference calculations for Experiment 11-6 described in Section 4 were run with a maximum timestep of 1.04 second. On the very first MELCOR run, a timestep of one second was used. Except for difficulties described elsewhere in this document, the calculation ran very smoothly using this value. Therefore, on subsequent runs, the maximum allowable timestep was refined (after two runs) to a value of 1.04 second, because it was observed that Experiment 11-6 usually ran at a $\mathrm{CVH}$-limited timestep of about 1.04 seconds.

In the timestep sensitivity study for Experiment 11-6, the reference calculation was run with the maximum timestep halved, decreased by a factor of five, decreased by one order of magnitude, and decreased by two orders of magniftude. Increasing the maximum allowable timestep made no sense because MELCOR would then run at the CVH limit of about 1.04 seconds and give results identical to those of the reference calculation. (This was actually verified, although results are not shown here.) Figure 5.2.1 compares particle retention for the base timestep and that using the other four maximum timestep values $-0.52,0.208,0.104$, and 0.0104 -- for Experiment 11-6. One observes that the difference between successive timestep calculations -- going from largest to smallest timestep -- is a monotonically decreasing function. Therefore, there is a great degree of confidence that the solution is converging. Furthermore, there is only about a difference of two percentage points in particle retention between the reference calculation at 1.04 seconds and the calculation using 0.0104 seconds. Figures 5.2 .2 to 5.2 .4 compare the temperatures in each of the three ice condenser control volumes for Experiment 11-6. The figures show that the timestep variation had a small, but observable effect on the temperatures - a few degrees. They also show that as the maximum timestep was reduced, that difference from the previous calculation was smaller, again implying that the results were converging.

The cpu required to simulate Experiment 11-6 is shown in Figure 5.2.5. For this problem, cpu time depended roughly linearly on the total simulation time. Thus, halving the maximum timestep doubled the cpu time and reducing it by an order of magnitude increased 


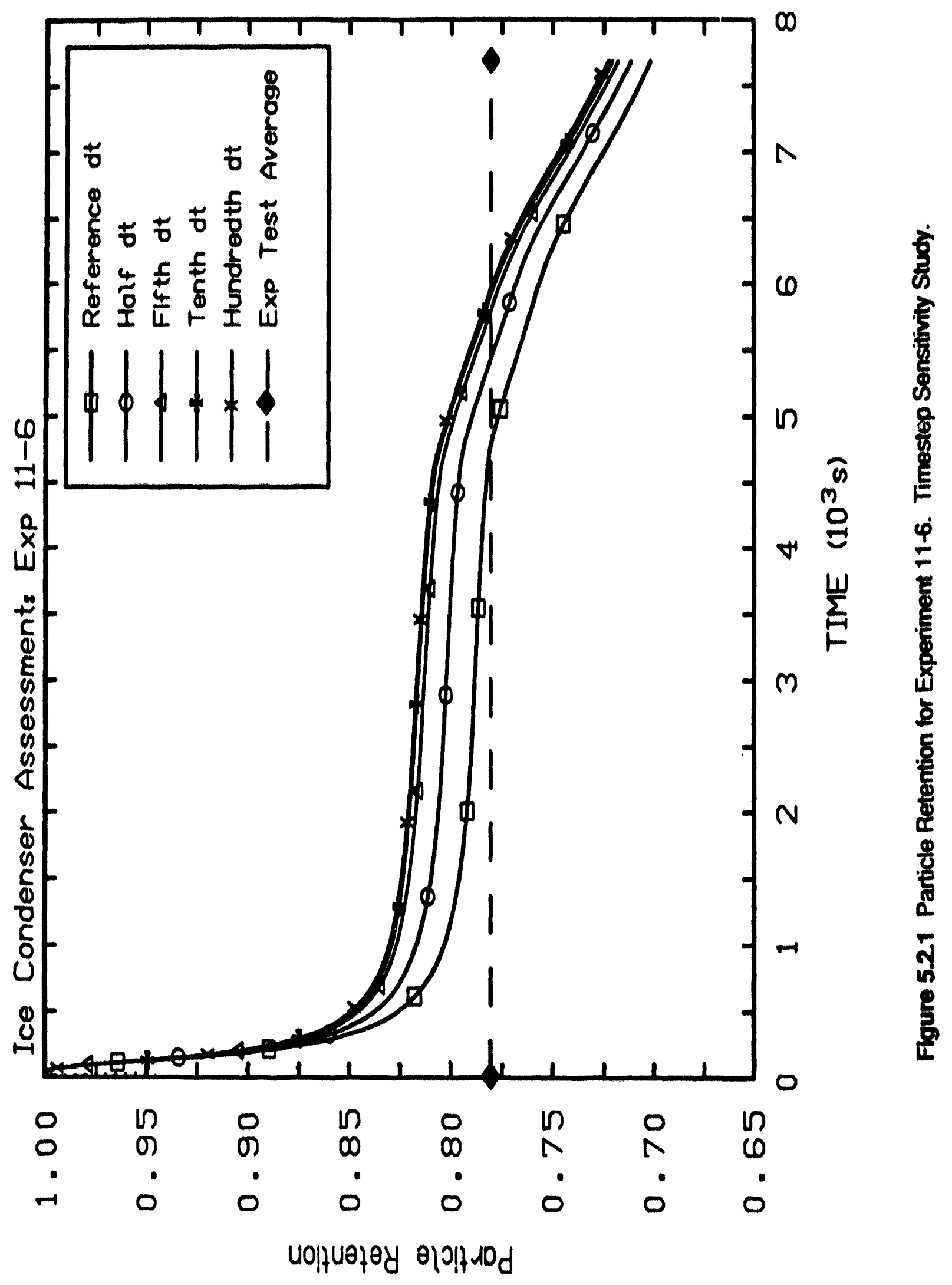




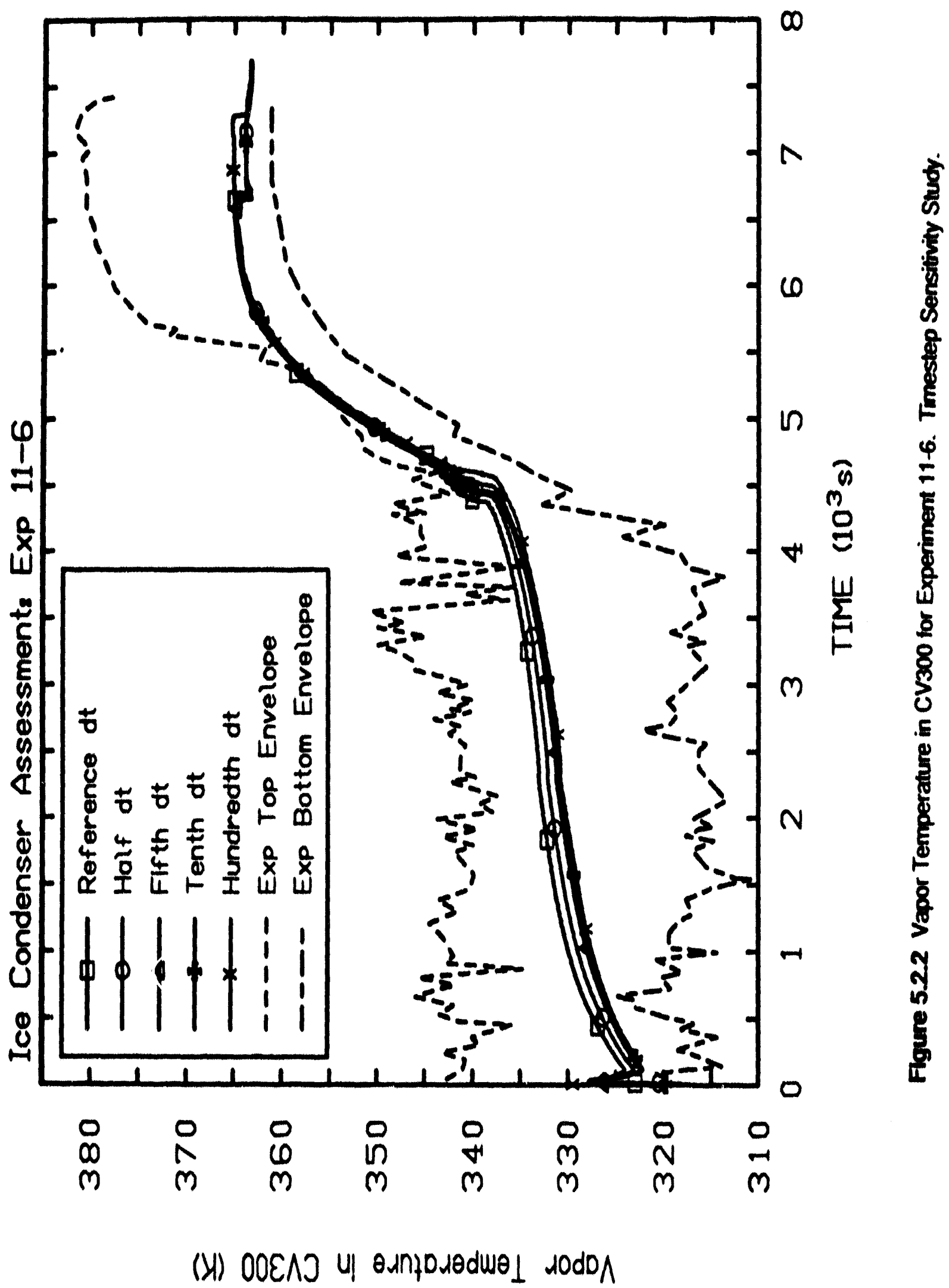




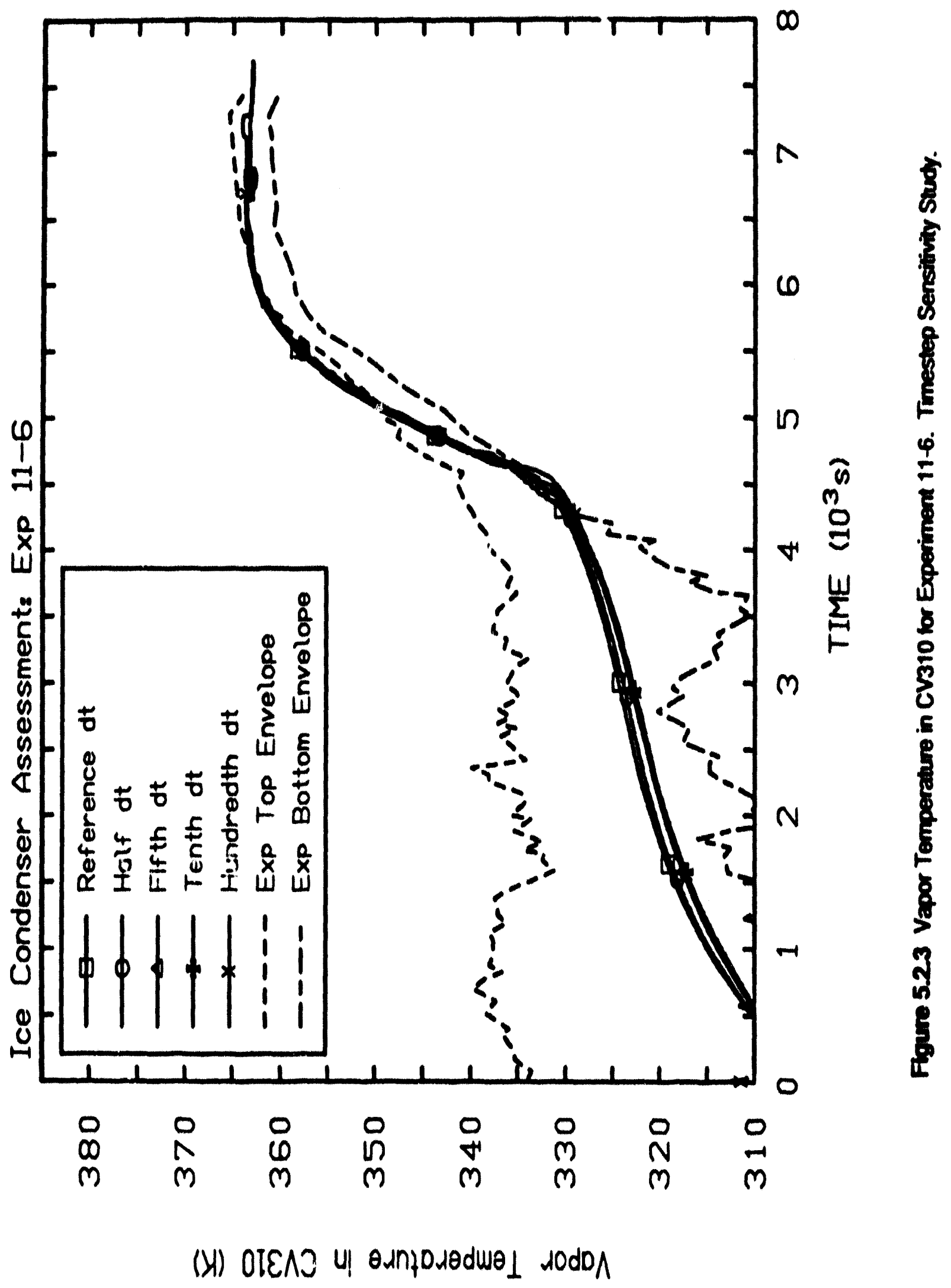




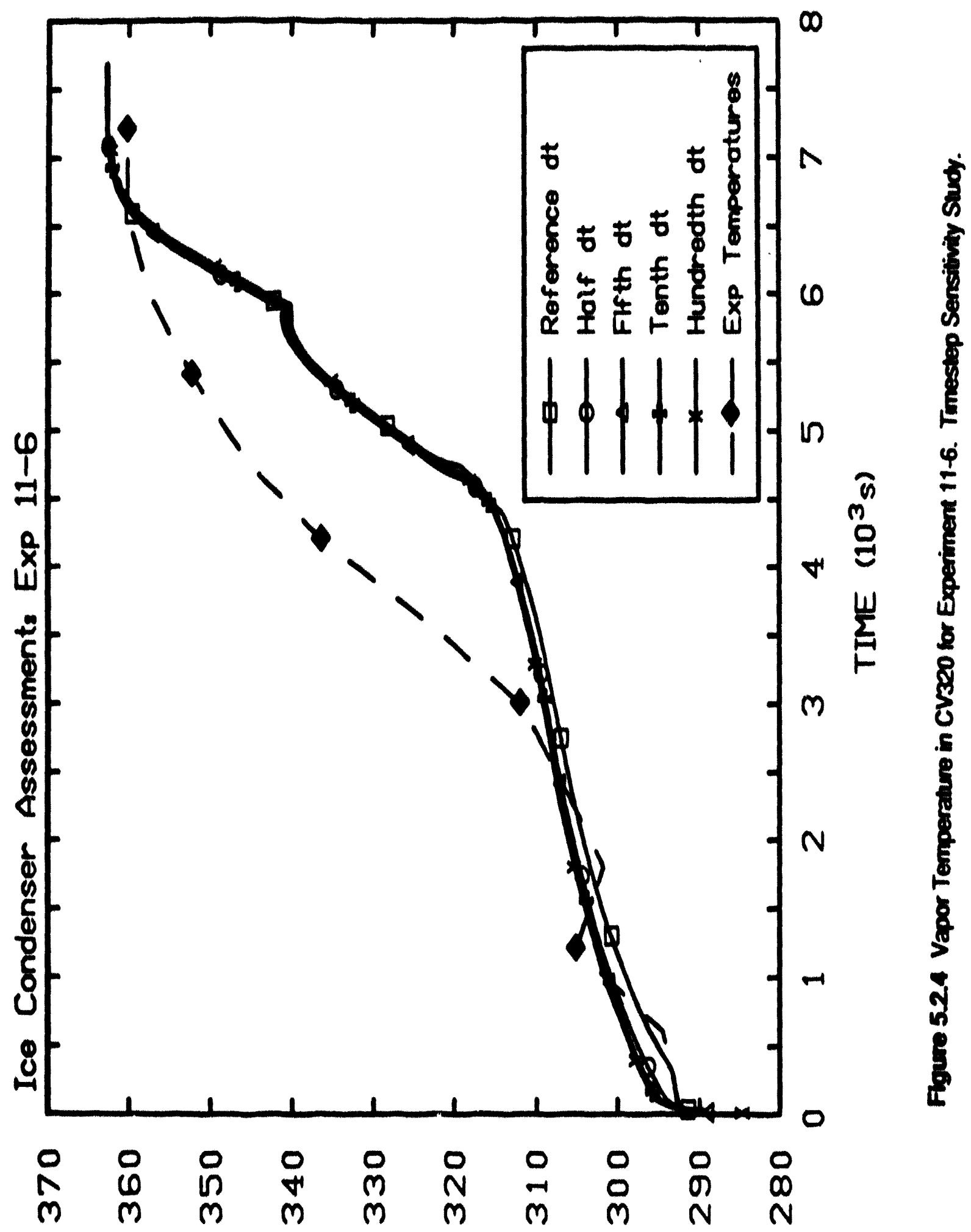

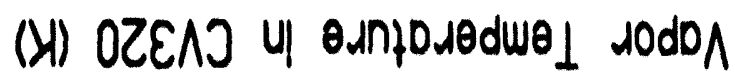




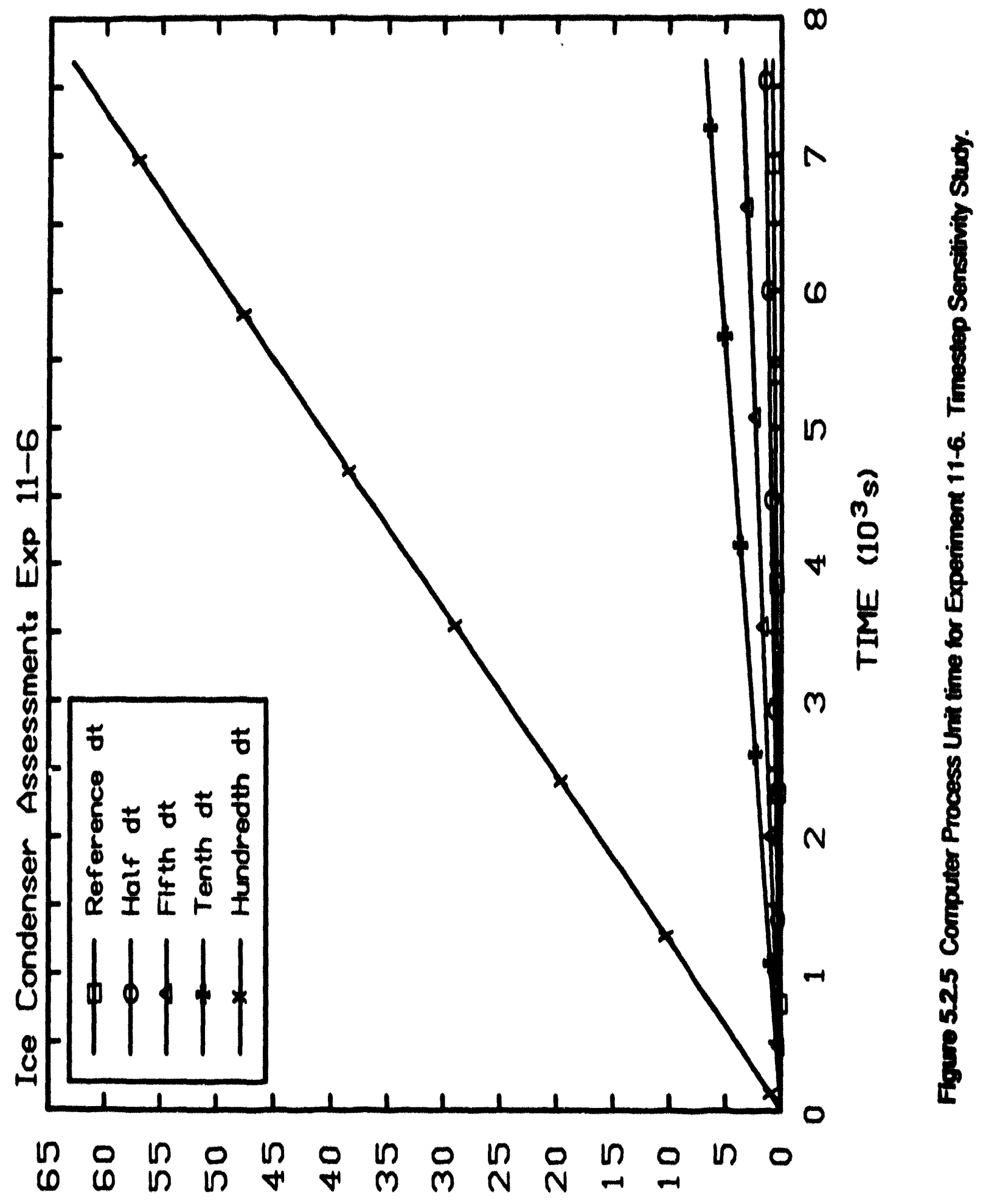

$\left(s_{\varepsilon} O I\right)$ oll I ndo 10201 
cpu time by about an order of magnitude. This implies that no significant subcycling occurred for any of the timestep runs for Experiment 11-6.

The same sensitivity study was pertormed for Experiment 16-11. In this experiment, the timestep was usually CVH-limited to a value around 0.44 seconds, although for simulating this experiment MELCOR decreased the timestep for short transients more often than for Experiment 11-6. Thus, the reference maximum timestep in this case was set to 0.44 seconds, and the sensitivity study was pertormed using values of $0.22,0.088$, and 0.044 seconds. A run with a timestep two orders of magnitude smaller was not pertormed for Experiment 16-11 since the results from the above runs showed minimal differences. Figure 5.2.6 compares the particle retention of the base timestep to that of the other sensitivity study values for Experiment 16-11. Figures 5.2 .7 to 5.2 .9 show the vapor temperatures in the ice condenser control volumes for each of the runs. The observed differences between runs were smaller for this high flow case as compared to the low flow case. In the particle retention plot, it was difficult to discern any differences, although the printed output definitely was different. Temperatures varied only a few degrees. Figure 5.2.10 shows the cpu required for the Experiment 16.11 simulation. Again, cpu time was commensurate with the value of the maximum timestep - the smaller the value, the more cpu time was required.

\subsection{Heat Structure Numerical Damping Coefficient}

The Heat Structure Package contains a model to stabilize numerical oscillations that can occur when heat is transferred to a control volume with small thermal inertia. Under the condition of small control volume thermal inentia, the control volume atmosphere temperature can oscillate about the heat structure surface temperature because the heat transfer rate is numerically explicit with respect to the control volume atmosphere temperature. Sensitivity coefficients 4070 have been provided in MELCOR to allow user control over the degree of numerical damping used by the Heat Structure Package [12].

The default values for the coefficients for the numerical damping were used throughout these studies, except in this sensitivity study where the damping was removed in a run simulating each experiment by inputting zero values for both of the 4070 sensitivity coefficients. Particle retention and Control Volume 300 (lowermost ice condenser region) temperatures are shown in Figures 5.3.1 and 5.3.2. The Experiment 11-6 results did show a difference in particle retention and control volume temperatures. Figure 5.3.3 displays the CV 300 heat transfer coefficient and demonstrates that, for Experiment 11-6, the MELCOR damping algorithm determined that damping was necessary. If damping was not necessary, then the two curves in Figure 5.3.3 would be identical. With damping, however, the heat transfer coefficient in this case was significantly smaller, thus leading to slightly slower melt rates, higher temperatures, and less particle retention.

The Experiment 16. 11 results for this sensitivity study were vintually identical, as demonstrated in Figures 5.3.1 and 5.3.2. There were some extremely sinall differences in the 


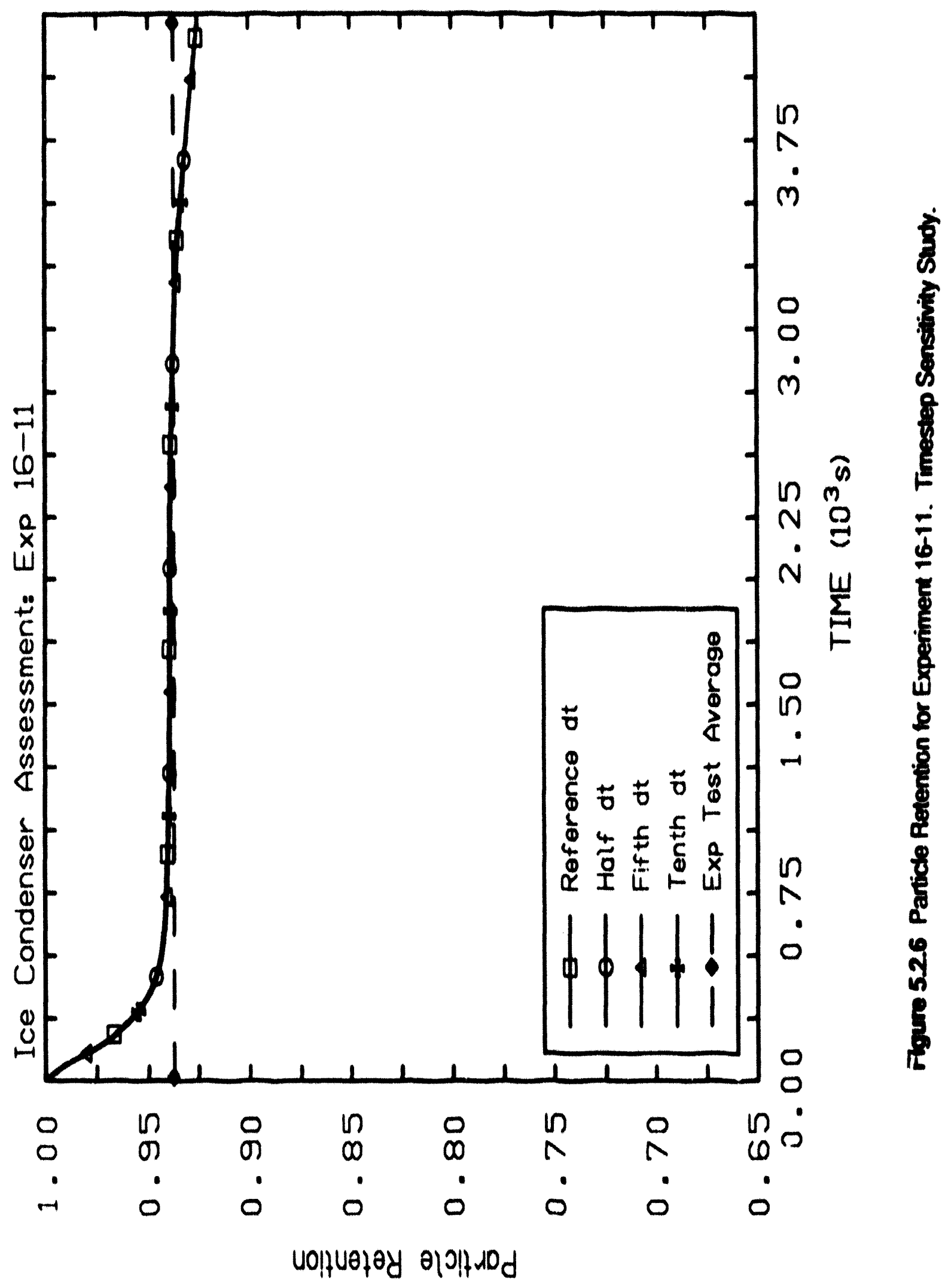




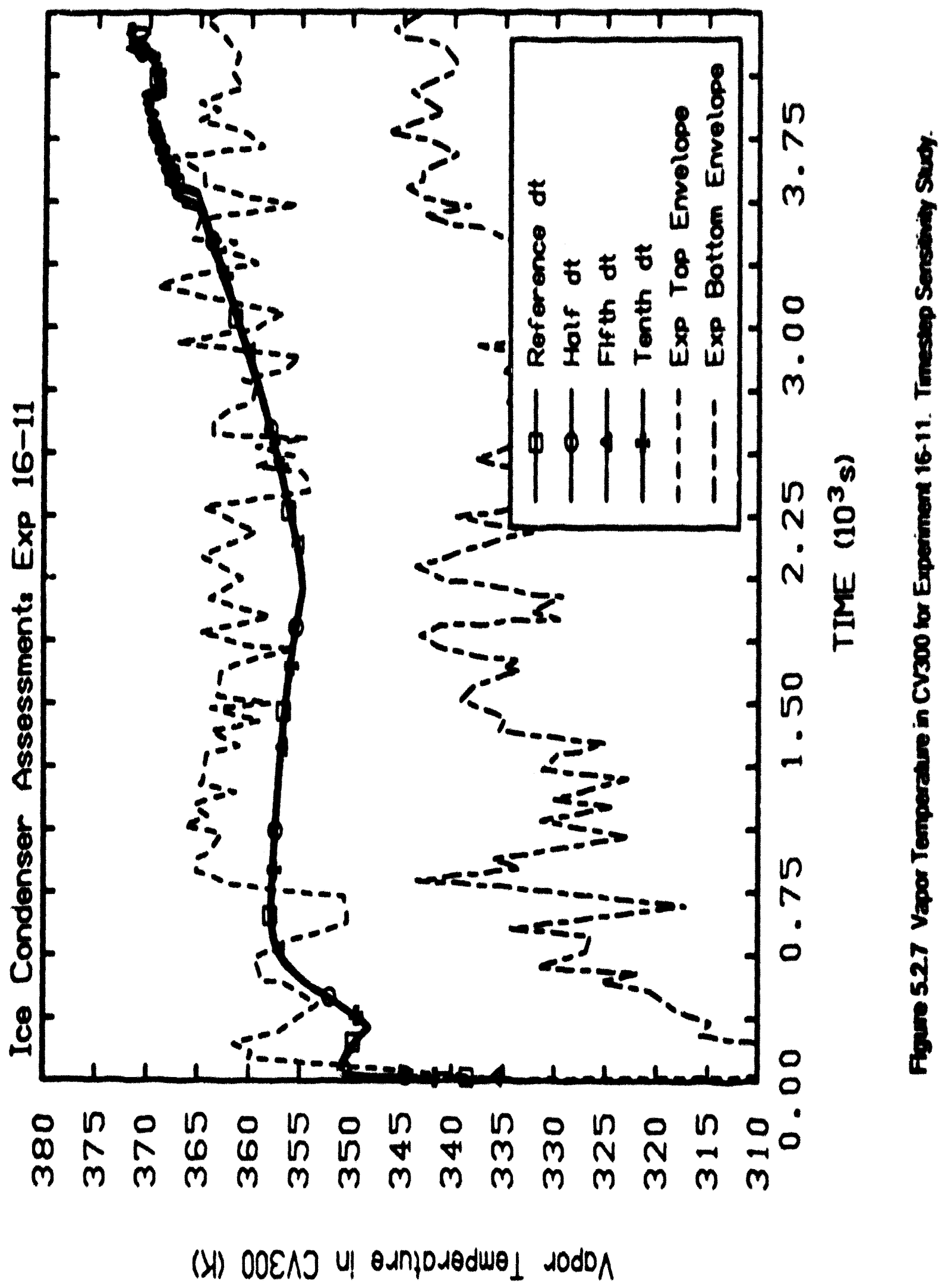




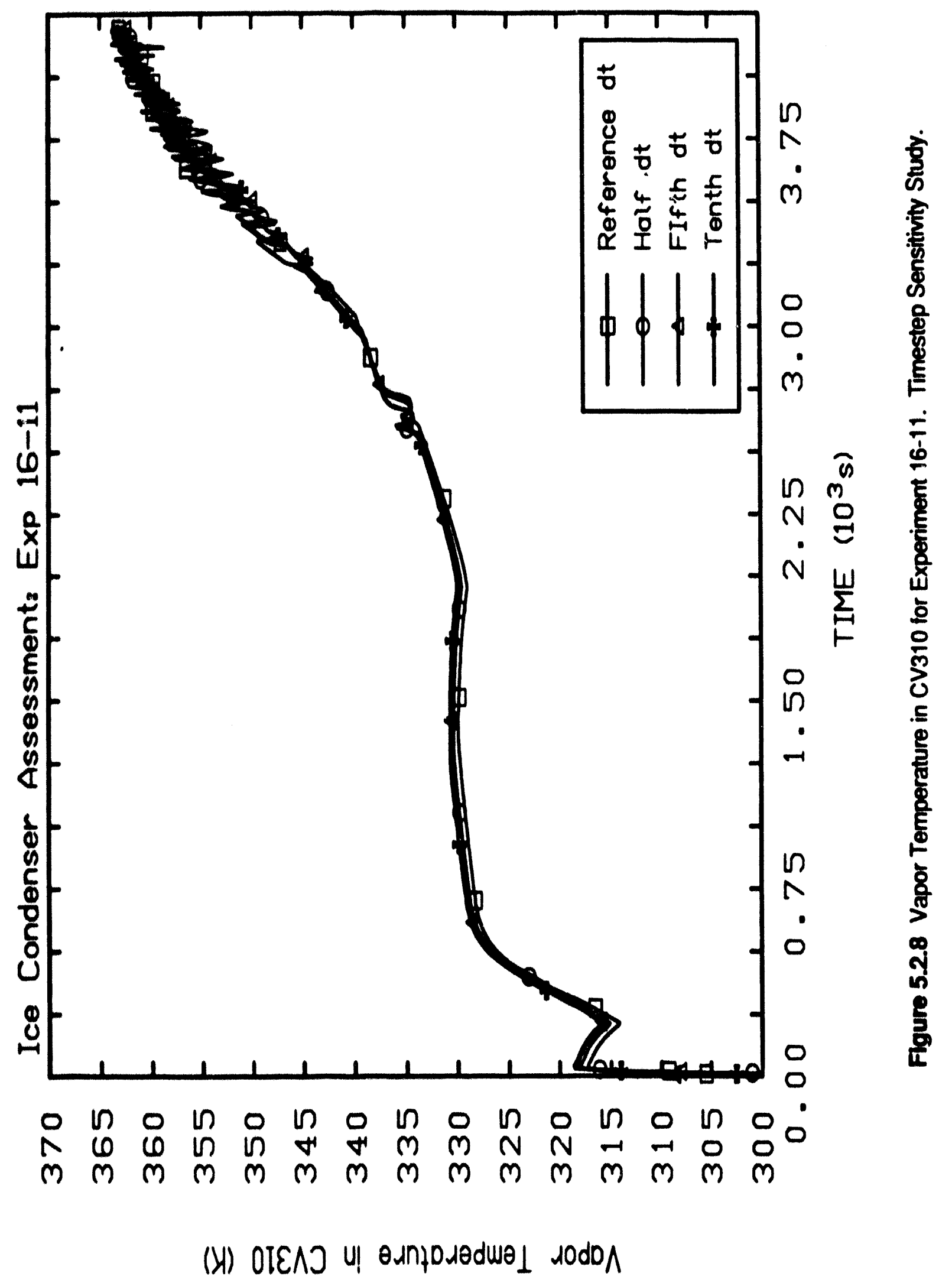




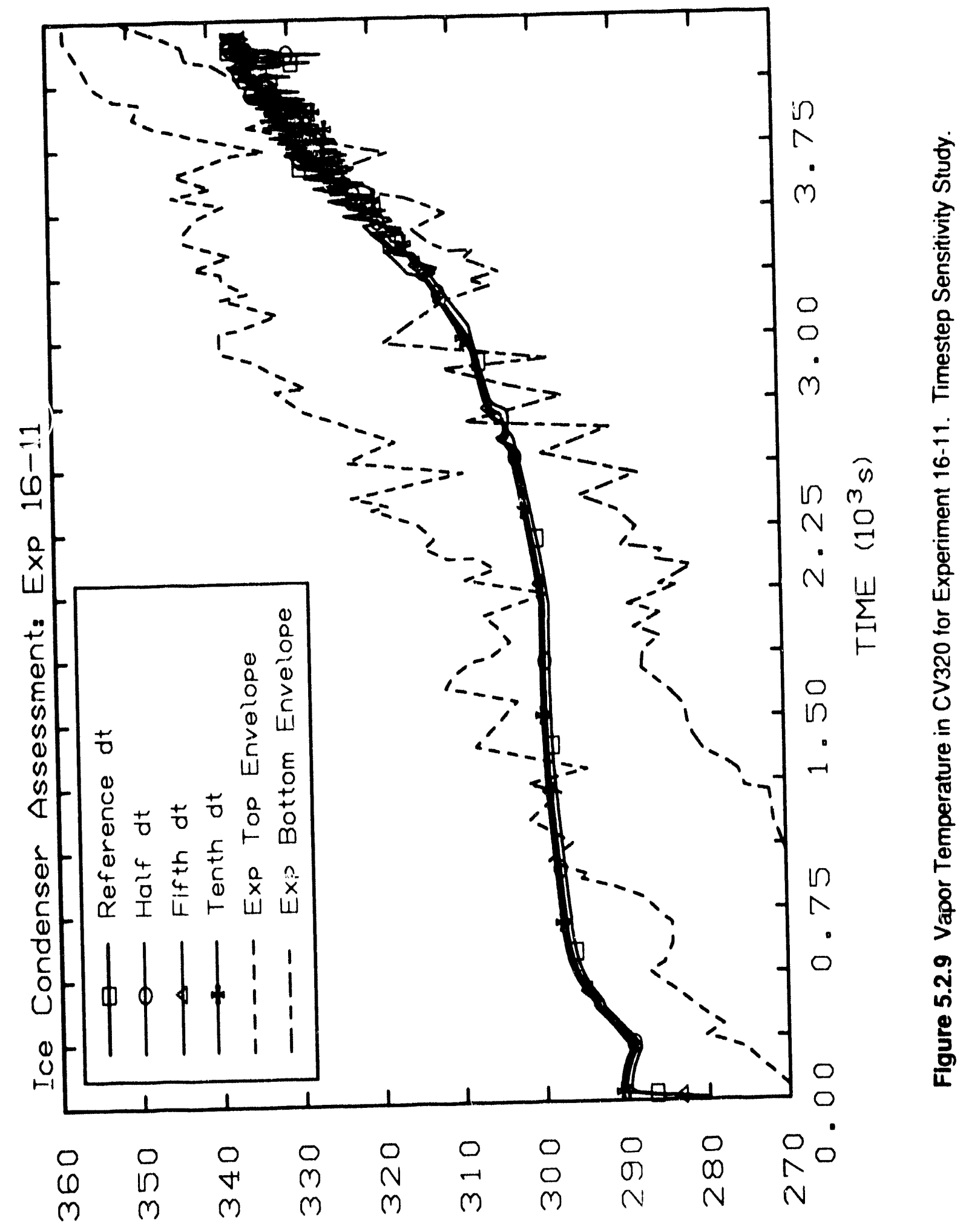

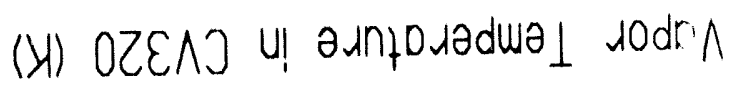




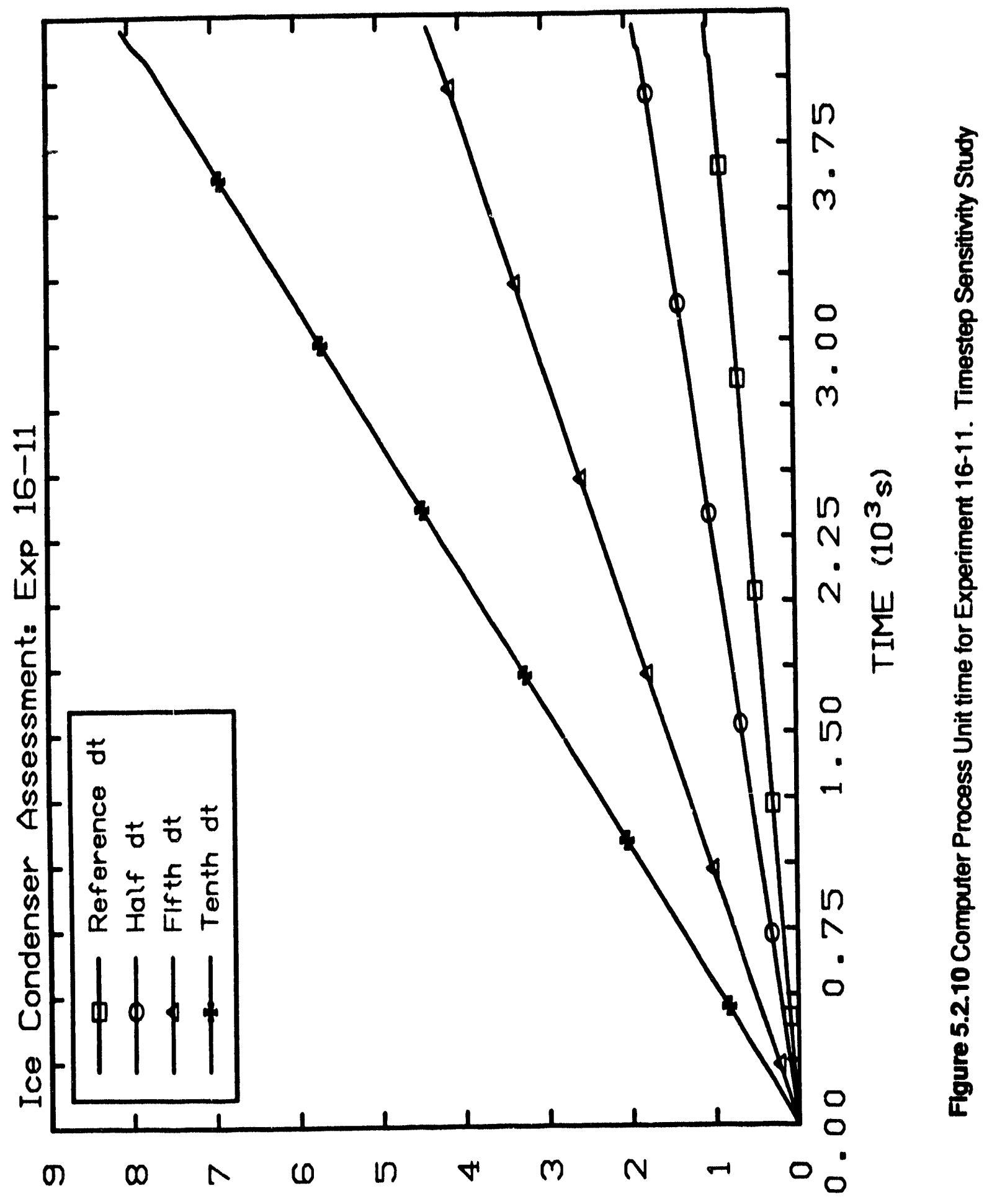

$\left(s_{\varepsilon} O L\right)$ aW! 1 ndo 10701 

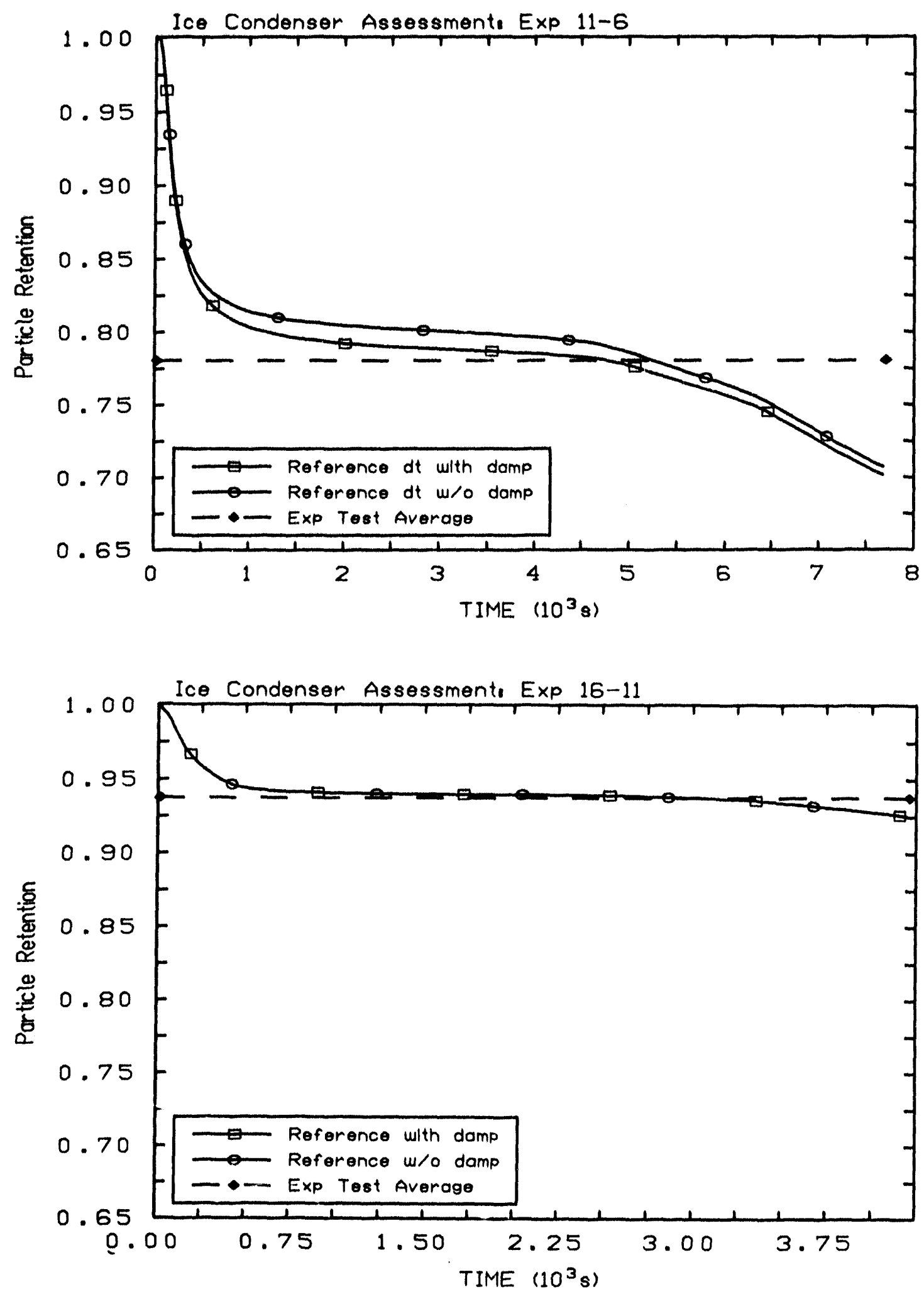

Figure 5.3.1 Particle Retention for Experiment 11-6 (top) and Experiment 16-11 (bottom). Heat Structure Damping Coefficient Sensitivity Study. 

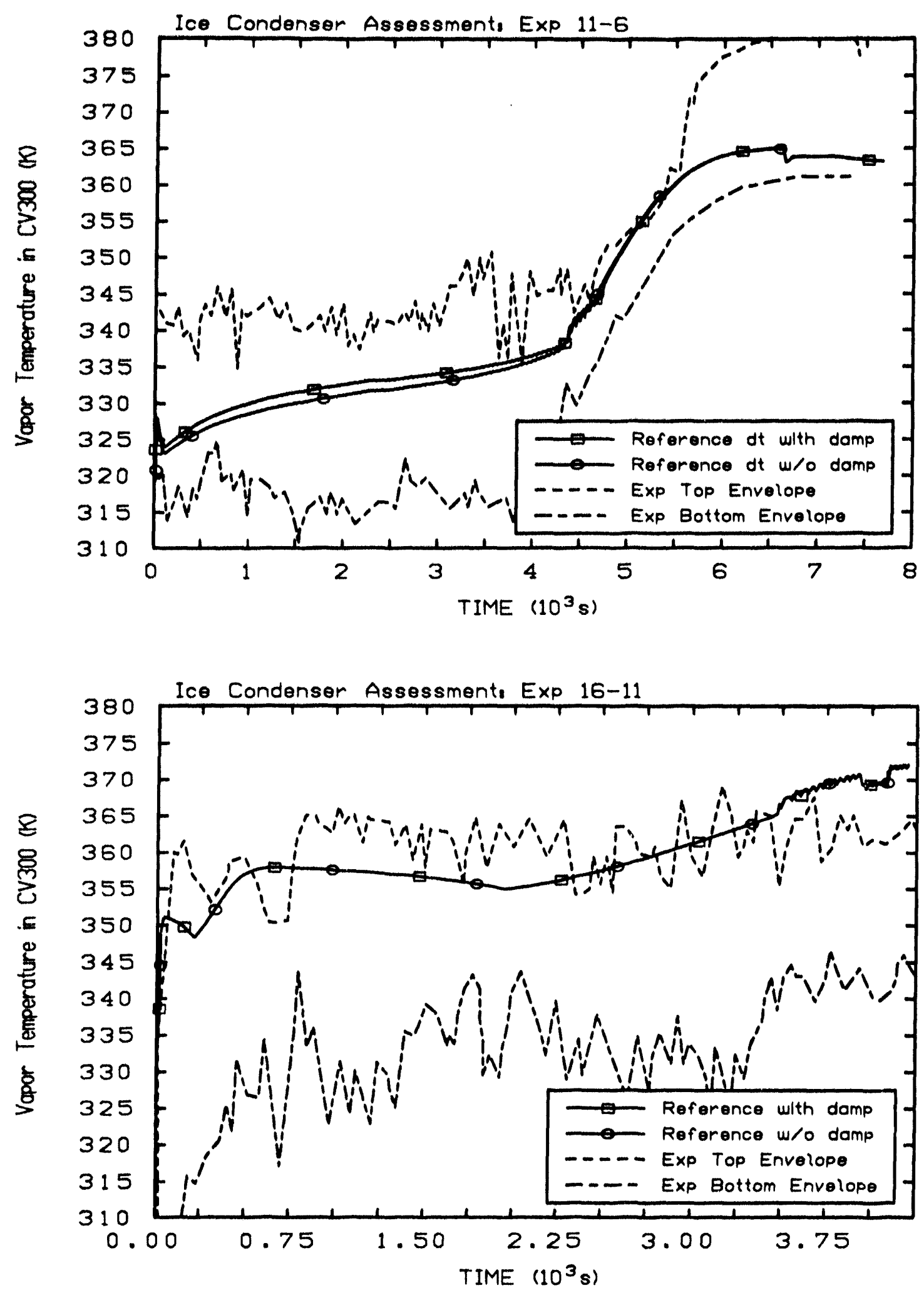

Figure 5.3.2 Vapor Temperature in CV300 for Experiment 11-6 (top) and Experiment 16-11 (bottom). Heat Structure Damping Coefficient Sensitivity Study. 

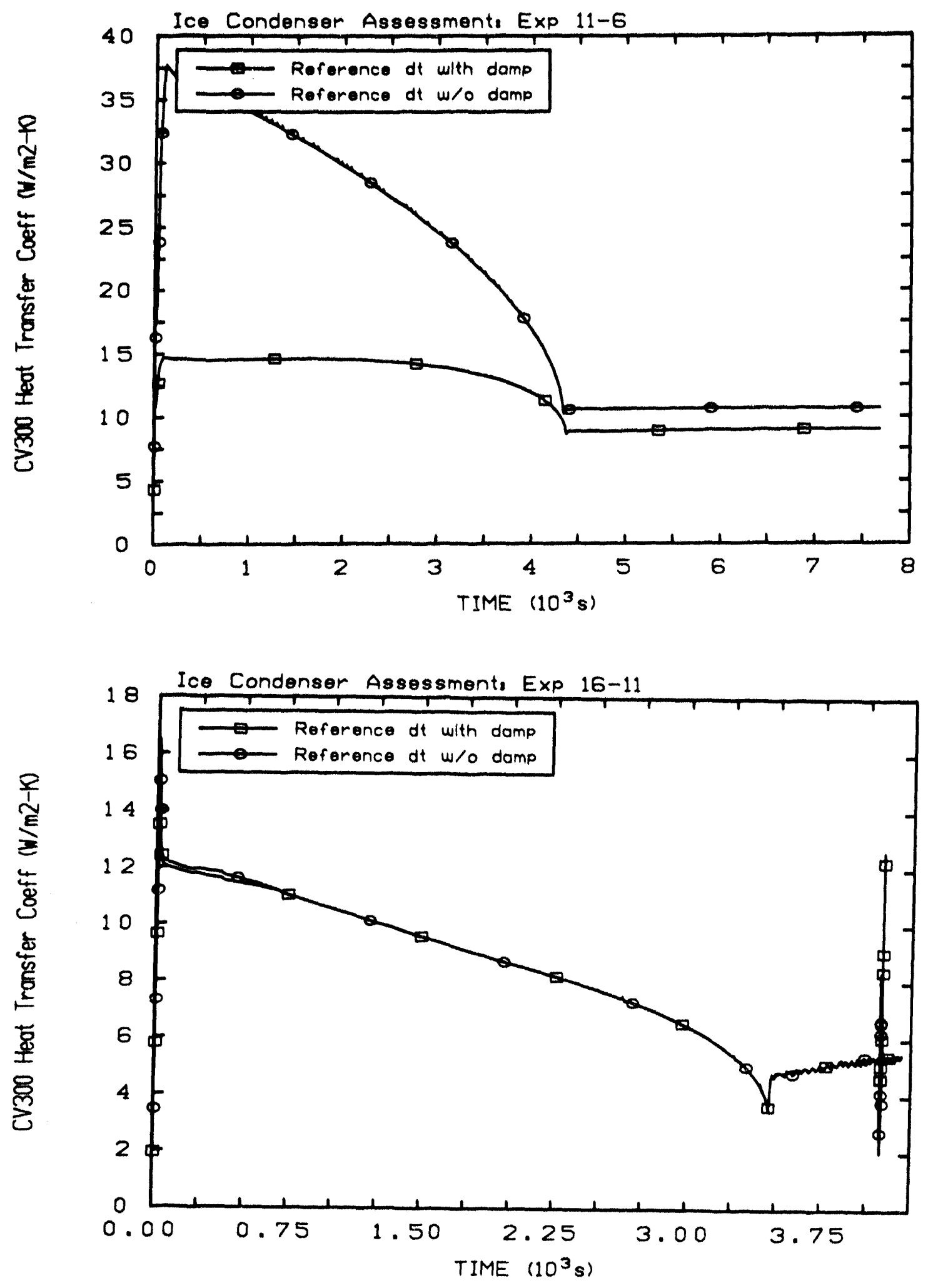

Figure 5.3.3 Heat Transfer Coefficient in CV300 for Experiment 11-6 (top) and Experiment 16-11 (bottom). Heat Structure Damping Coefficient Sensitivity Study. 
printed output. The reason for the identical results is clear from Figure 5.3.3, which shows that the heat transter coefficient for CV 300 was virtually identical for the two results. The other control volumes demonstrated this as well, although they are not displayed. A close examination of Figure 5.3.3 does reveal some differences, but they were not enough to cause observable differences on the particle retention and temperature plots.

Because the inclusion of the damping coefficient is a numerical artifice that is unnecessary in this problem, the calculation without the damping coefficient is probably a more accurate assumption. However, we have seen that the effect on the Experiment 16-11 results was nil and the effect on the Experiment $11-6$ results was fairly small.

Although not shown, the exclusion of damping slightly reduced the necessary cpu time for both cases. For example, for Experiment 11-6, for runs that required about 800 seconds of cpu time, there was a savings of about 30 seconds. 


\section{Aerosol Sensitivity Studies}

With respect to MELCOR aerosol results, at present there is interest in whether an aerosol needs to be represented by its own component, which was the case for the reference study (Section 4), or whether one component would be sufficient, which is the MELCOR default. Second, there was the question of whether five aerosol sections was sufficient. Perhaps using a larger number of sections would change MELCOR results. Thus, sensitivity studies were performed in which the number of aerosol components was varied (one or two), and the number of aerosol sections was varied from the default of five up to twenty sections. Third, although there are particles in the flow with varying solid density, MELCOR uses a single value. Thus, there was uncertainty as to the proper value. A value of $2500 \mathrm{~kg} / \mathrm{m}^{3}$ was used in the reference calculations. Again, to evaluate the significance of this parameter, it was varied in a third aerosol sensitivity study. The MELCOR default value of $1000 \mathrm{~kg} / \mathrm{m}^{3}$ was used, and the reference value was also doubled to $5000 \mathrm{~kg} / \mathrm{m}^{3}$ in this study. Fourth, the choice of diameter limits on the particle diameter can affect the results. To examine the significance of the water aerosol and the diameter at which it is created, as well as compressing and expanding the range for $\mathrm{ZnS}$, the minimum particle diameter was increased and decreased by an order of magnitude from the reference value of $0.1 \times 10^{-6} \mathrm{~m}$.

\subsection{Number of MAEROS Aerosol Components}

In the reference calculations, the injected $\mathrm{ZnS}$ aerosol was the second component while water aerosol was the first component. Another calculation was pertormed in which both the $\mathrm{ZnS}$ and water were combined into one component, which is the default choice of MELCOR. Figure 6.1.1 shows that the effect of combining the aerosols into one component decreased the resultant particle retention for both experiments by almost a constant. Agreement with experiment was not as good with the one-component calculations as it was with the two-component reference calculation. Figures 6.1.2 and 6.1.3 display two important aerosol parameters - the suspended aerosol mass and the aerodynamic mass median diameter (AMMD) for the lowermost region, Control Volume 300. The twocomponent case calculated slightly smaller suspended aerosol masses than the onecomponent case in both experiments. This implied that more particles were settled out, as the particle retention in Figure 6.1.1 proves. Figure 6.1.3 show that for the mass median diameter the one-and two-component results were virtually identical for both experiments. The AMMD of the $\mathrm{ZnS}$ in CV 300 was very close to the input value of $3.5 \mathrm{x}$ $10^{.6} \mathrm{~m}$ placed in the upstream mixing chamber. Since water aerosol is created in the smallest section, its AMMD was much smaller -- in the range of 0.75 to $1.0 \times 10^{-6} \mathrm{~m}$. The combination of the two AMMD's for the two-component case equalled that of the onecomponent case. Thus, all of the results were consistent. 

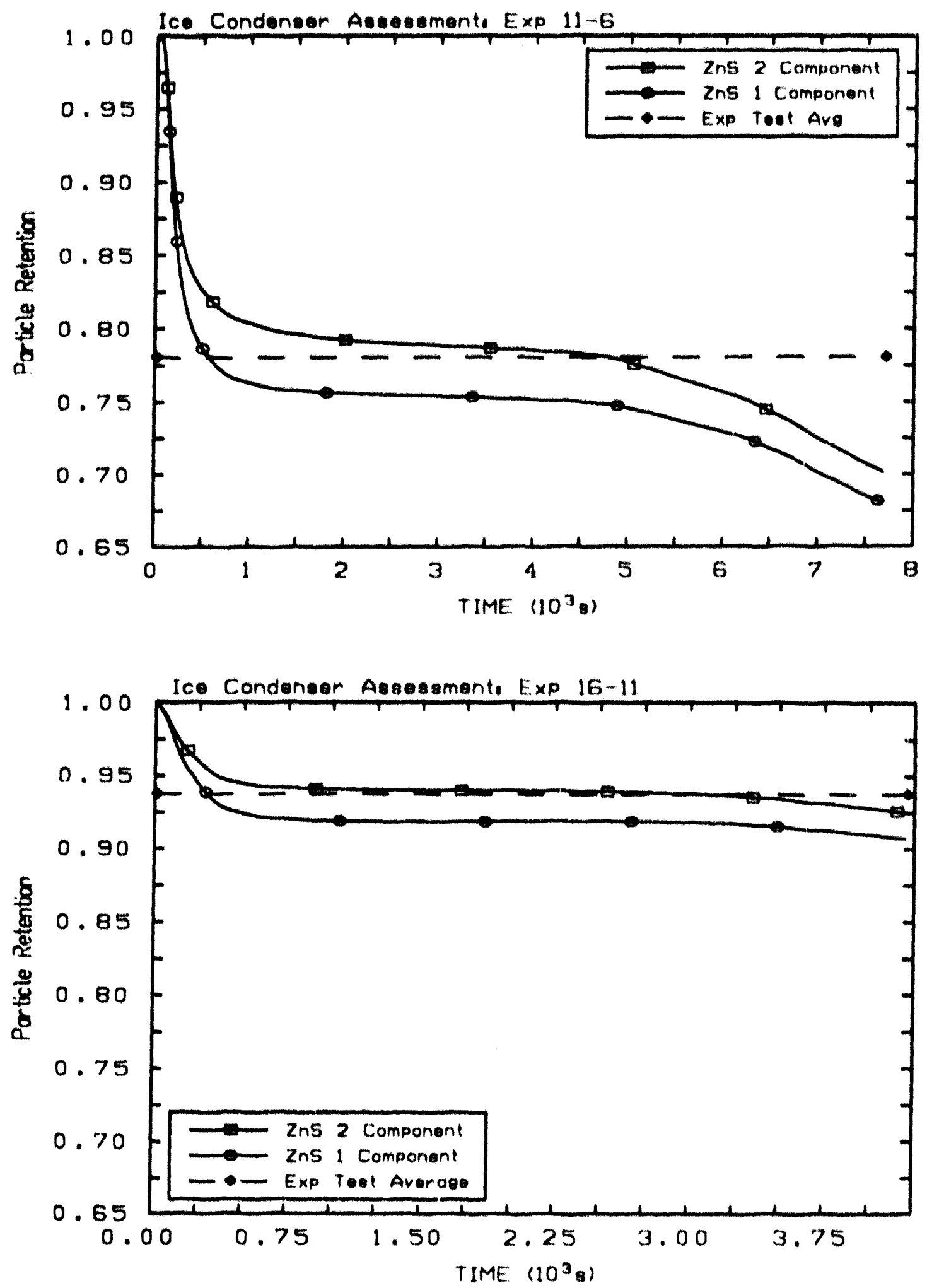

Figure 6.1.1 Particle Retention for Experiment 11.6 (top) and Experiment 16-11 (bottom). Aerosol Component Sensitivity Study. 

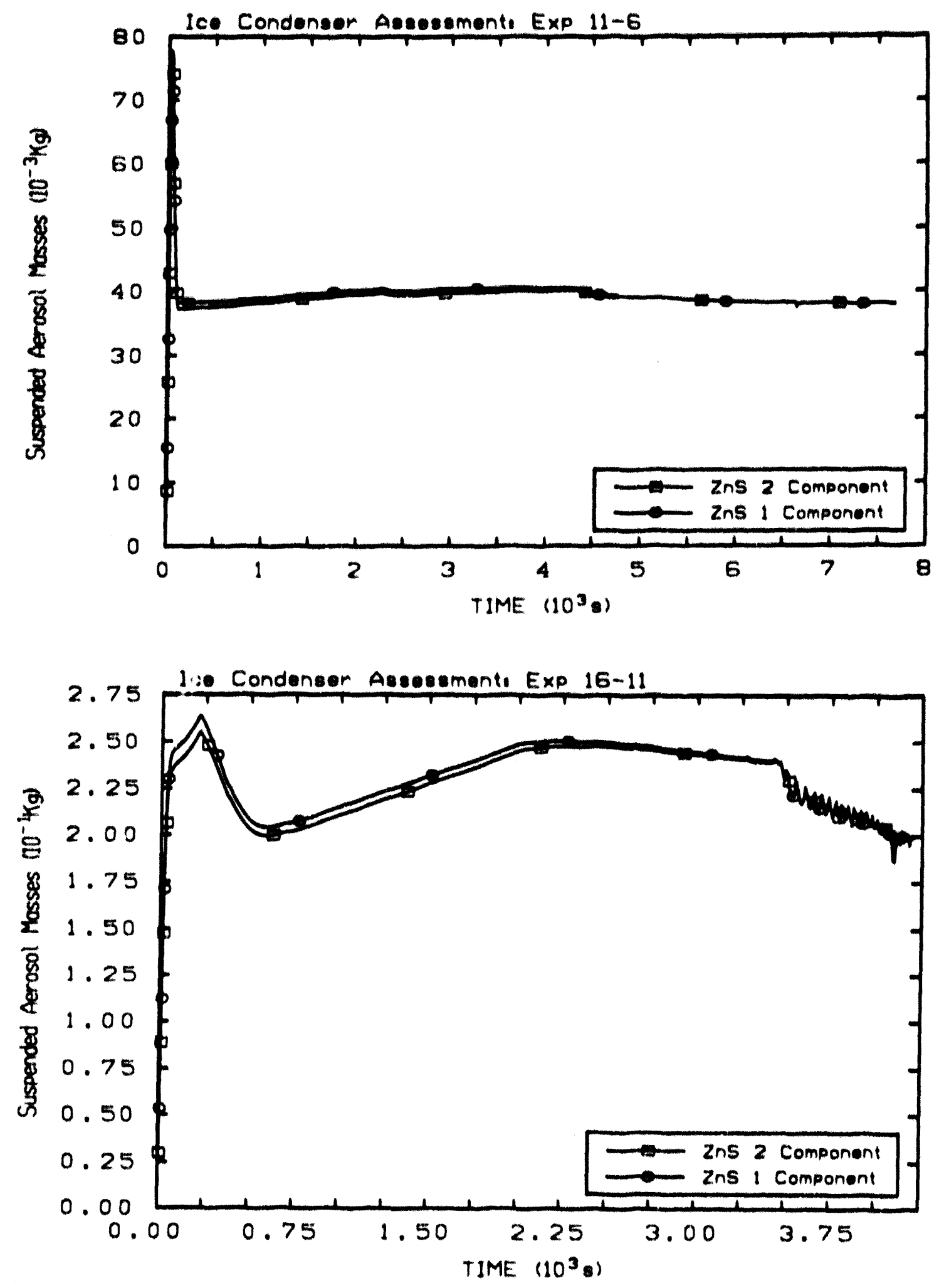

Figure 6.1.2 Suspended Aerosol Masses for Experiment 11.6 (top) and Experiment 16-11 (bottom). Aerosol Component Sensitivity Study. 

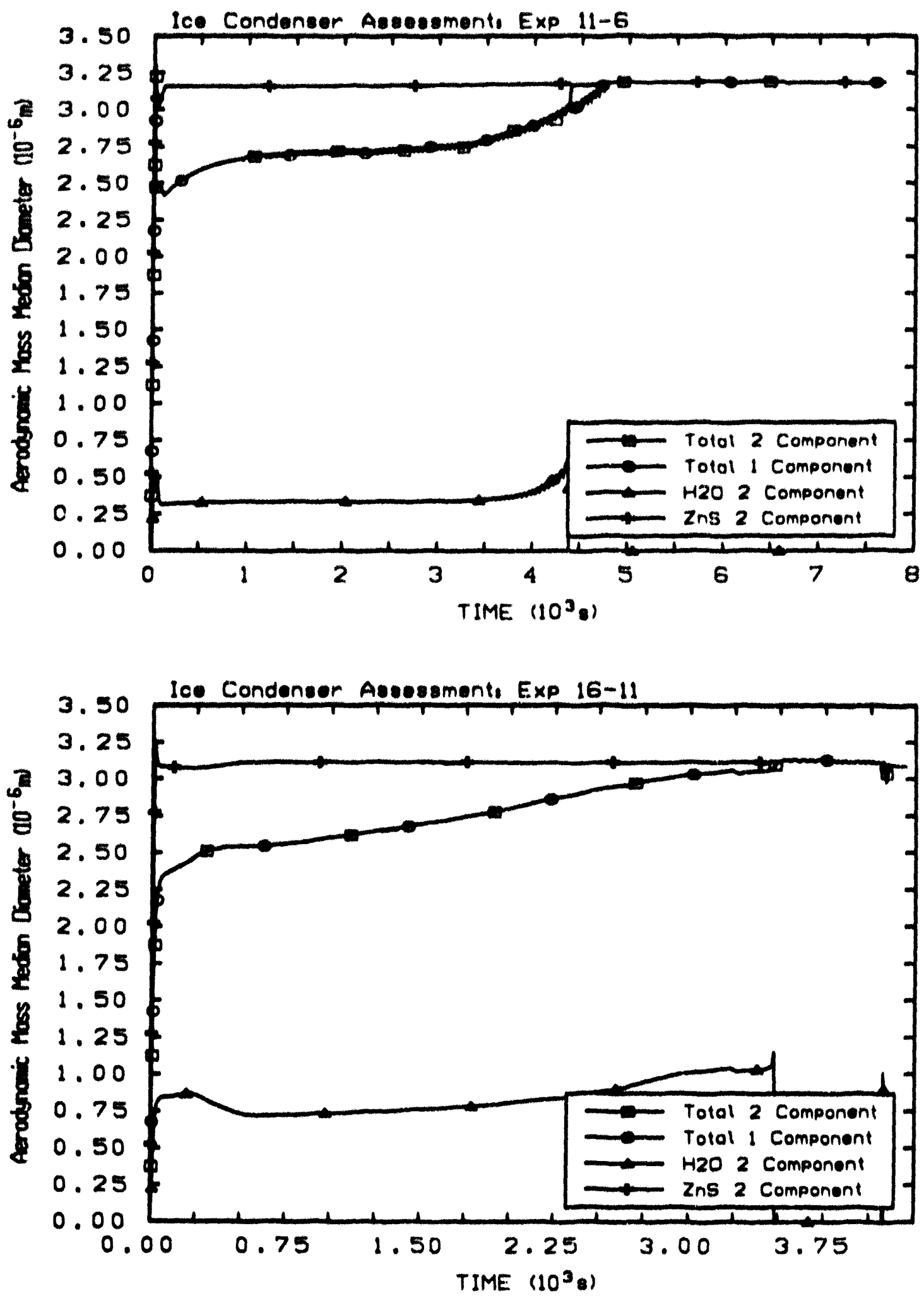

Figure 6.1.3 Aerodynamic Mass Median Diameter for Experiment 11.6 (top) and Experiment 16-11 (bottom). Aerosol Component Sensitivity Study. 
The point at which all of the lce from the ice condenser disappeared is evident in both experiments because it was the point in which the two results merge in Figures 6.1.2. This is verified in Figure 6.1.4 which shows that all of the ice in the lower ice condenser compartment (where Heat Structure 300 was located) was melted at about 4400 seconds in Experiment 11.6 and 3200 seconds in Experiment 16-11.

Figure 6.1.5 shows the vapor temperature in CV300 (the lower ice condenser region) for both experiments. The figure demonstrates that there were no observable differences in the thermal/hydraulic conditions being calculated between the one-component and twocomponent calculation. This included temperatures, flows, etc. in the remaining regions of the calculations where figures are not shown. It should be emphasized that this was the observation that was expected.

The iwo-component calculation took only about a minute extra cpu time for both experiments, as shown in Figure 6.1.6. Thus, the additional time used to separate the $\mathrm{ZnS}$ and water into separate components is recomme ided to treat aerosol effects more accurately in MELCOR.

\subsection{Number of MAEROS Aerosol Sections}

The reference calculations used the default number of MAEROS aerosol sections, which was five. For both Experiment 11.6 and 16.11, sensitivity studies were pertormed in which first ten and then twenty MAEROS aerosol sections were used. These sectlons represent the number of size bins into which the panticle size may fall. The minimum and maximum bin diameters were not changed, so this study only changed the total number of bins which lie between the minimum and maximum.

Figure 6.2.1 shows the effect that the sensitivity study had on particle retention for both experiments. In both cases, increasing the number of section from five to ten had the effect of decreasing particle retention, by less than one percentage point in Experiment 16-11, and by about 2.5 percentage points in Experiment 11-6. Since ten sections represents the spectrum of particle size better than five sections, it is belleved that the ten-section results were slightly more accurate. The trend of decreasing particle retention is coirect because it will require slightly more time for particles to agglomerate to the heaviest section and settle out when there are ten sections as opposed to five. However, as Figure 6.2.1 shows, when the number of sections was again doubled to twenty, a very small difference in particle retention was observed as compared to the ten section results. Thus, as with the timestep results, convergence is observed and the twenty section computation probably gives the most accurate results. Figure 6.2.2 shows the temperature in the bottom ice condenser for each of the experiments. As in the component sensitivity study, changing an aerosol parameter such as the number of sections had no effect on the temperatures. Although not shown, this conclusion applied to all of the control volumes and flow paths in the problem. 

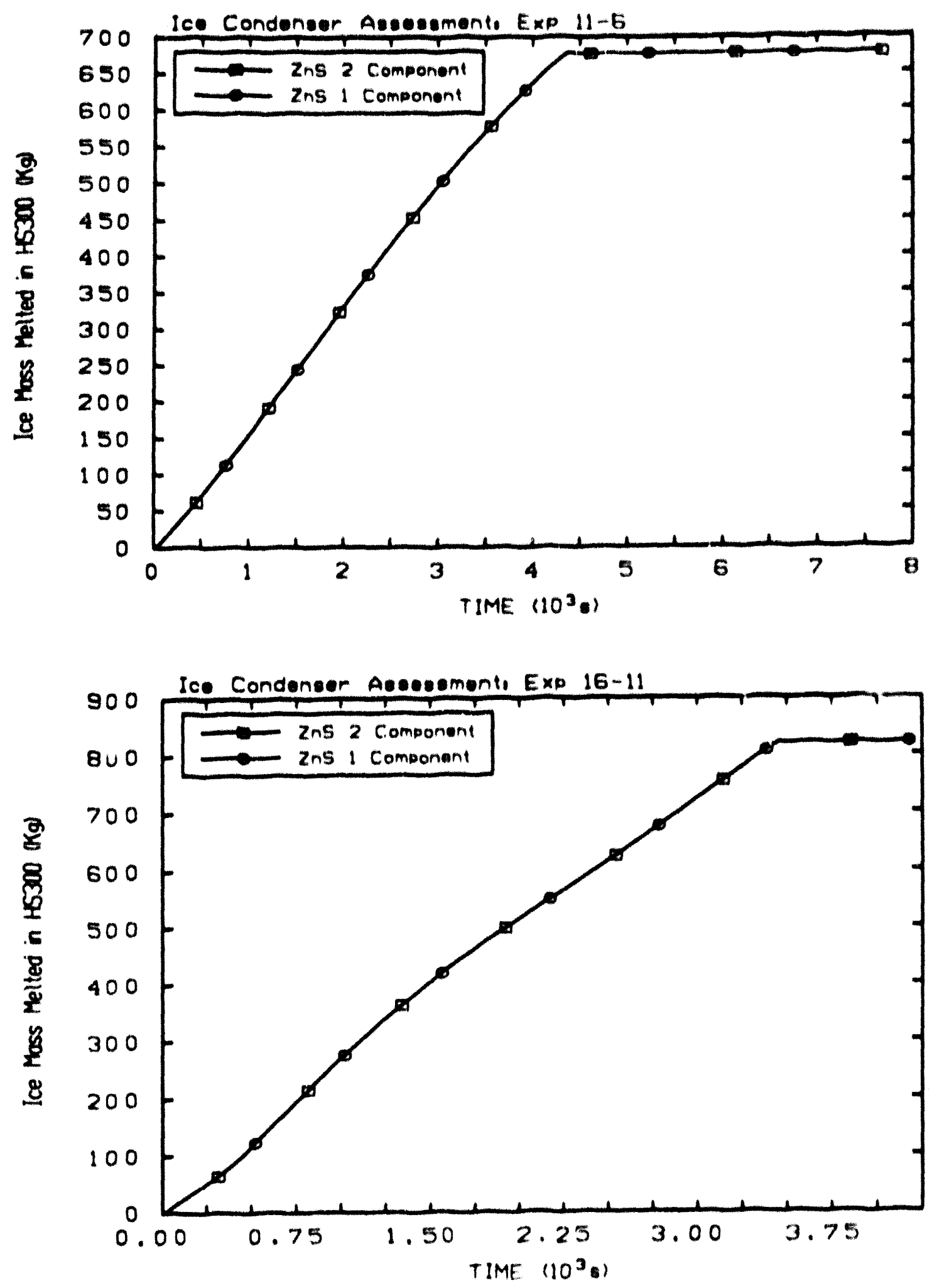

Figure 6.1.4 ICe Mass Melted in CV300 for Experiment 11.6 (top) and Experiment 16.11 (Bottom). Aerosol Component Sensitivity Study. 

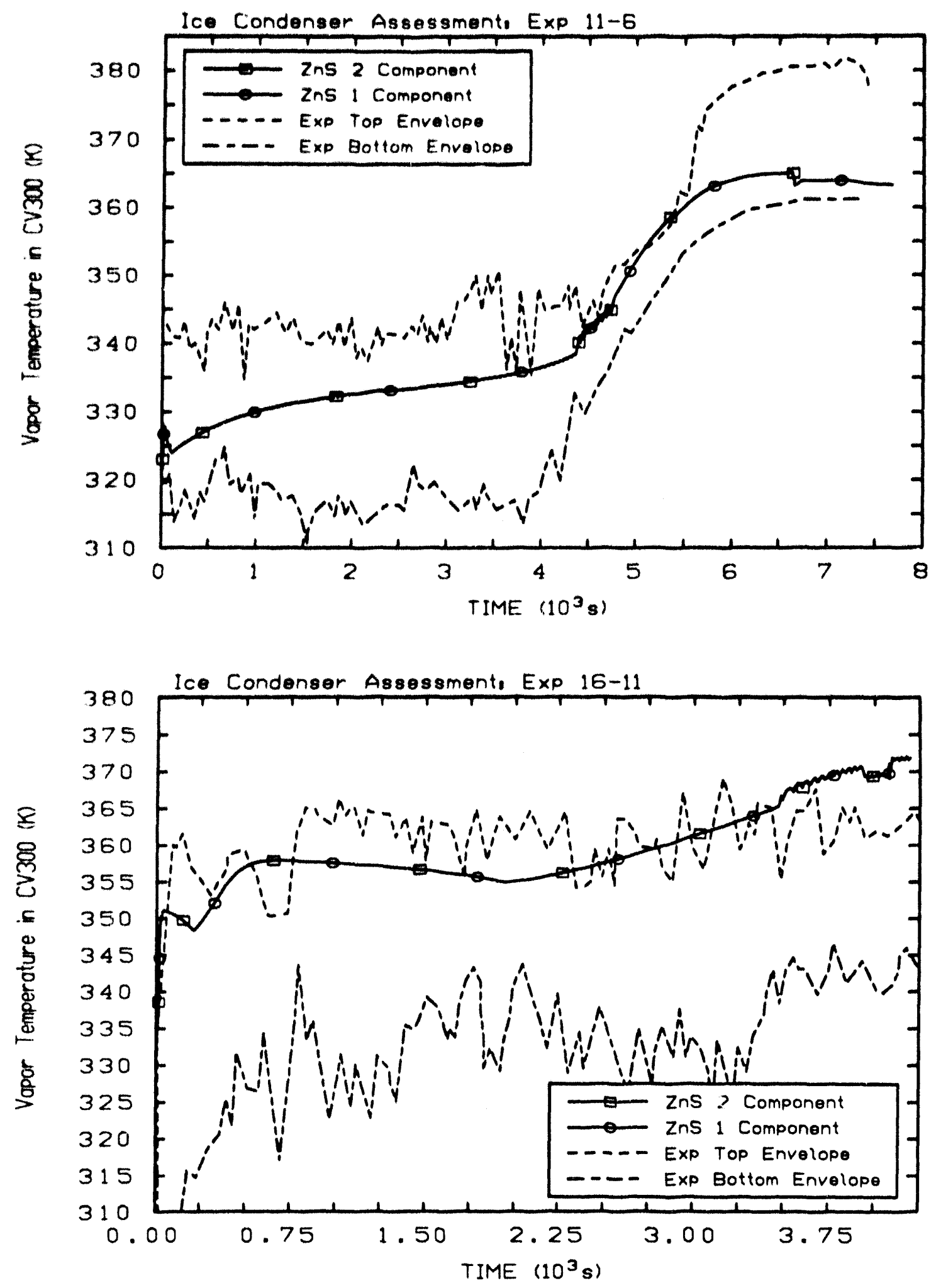

Figure 6.1.5 Vapor Temperature for CV300 for Experiment 11-6 (top) and Experimen 16-11 (bottom). Aerosol Component Sensitivity Study. 

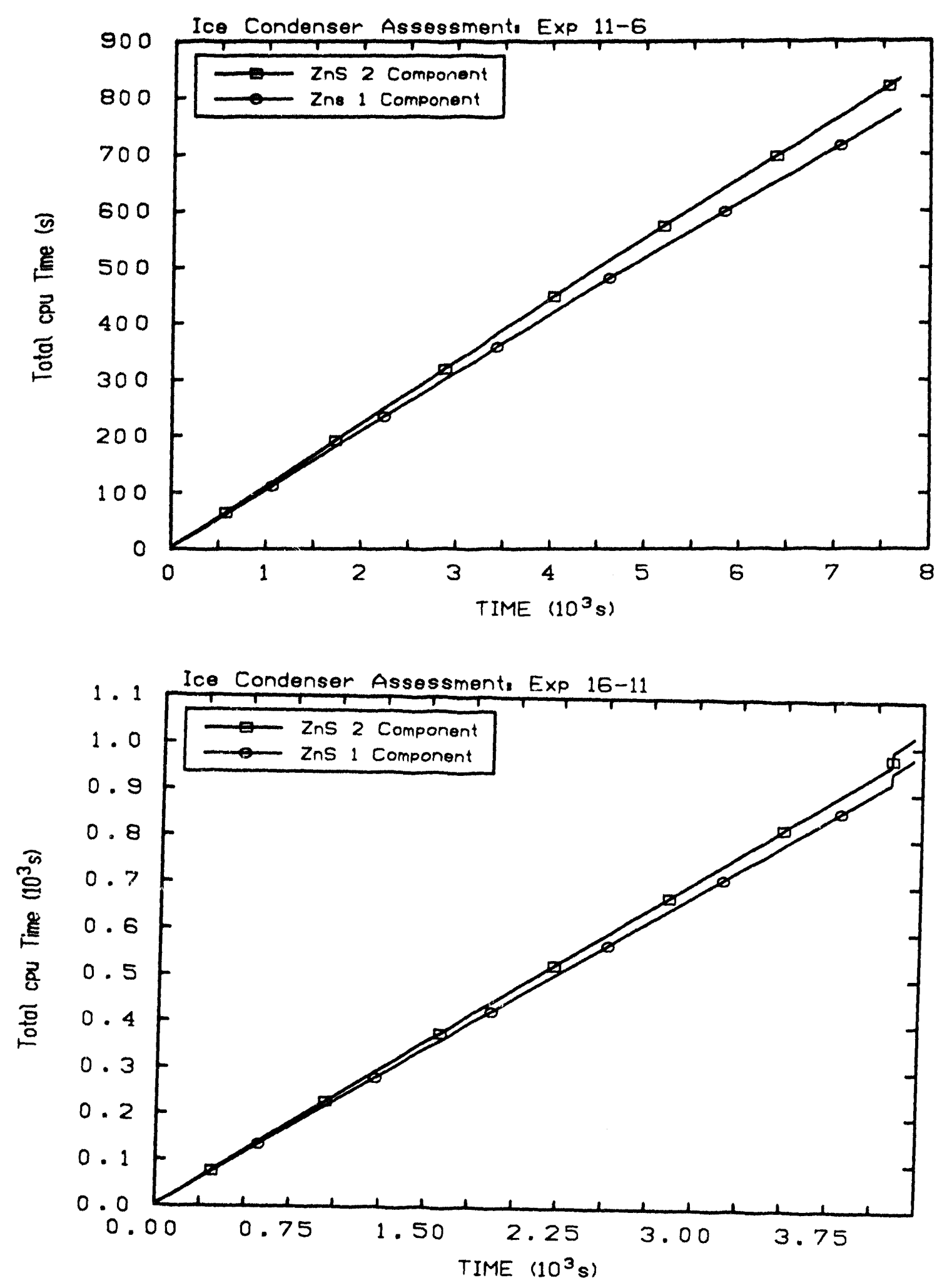

Figure 6.1.6 Computer Processor Time for Experiment 11-6 (top) and Experiment 16-11 (bottom). Aerosol Component Sensitivity Study. 

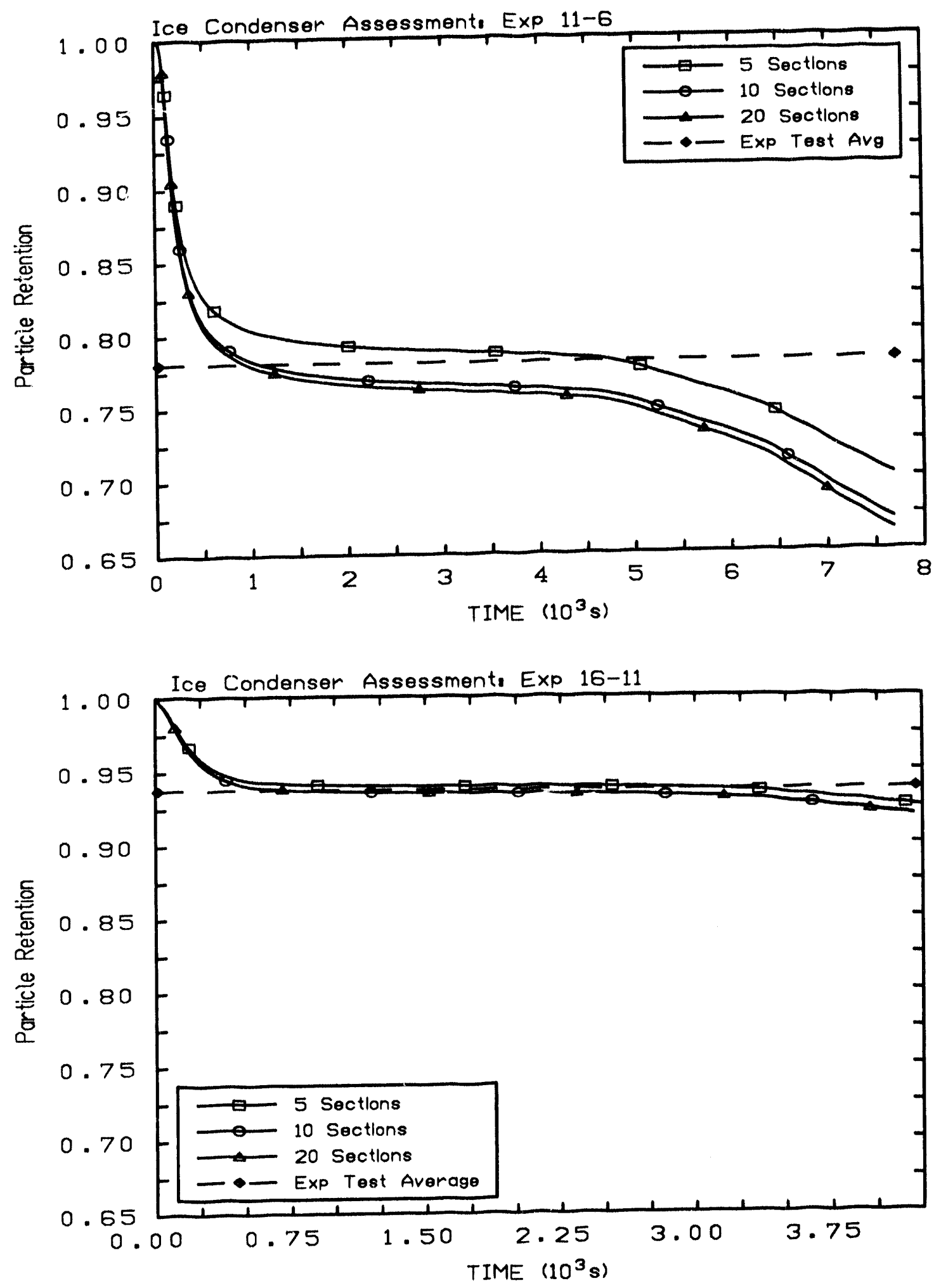

Figure 6.2.1 Particle Retention for Experiment 11-6 (top) and Experiment 16-11 (bottom).Aerosol Section Sensitivity Study. 

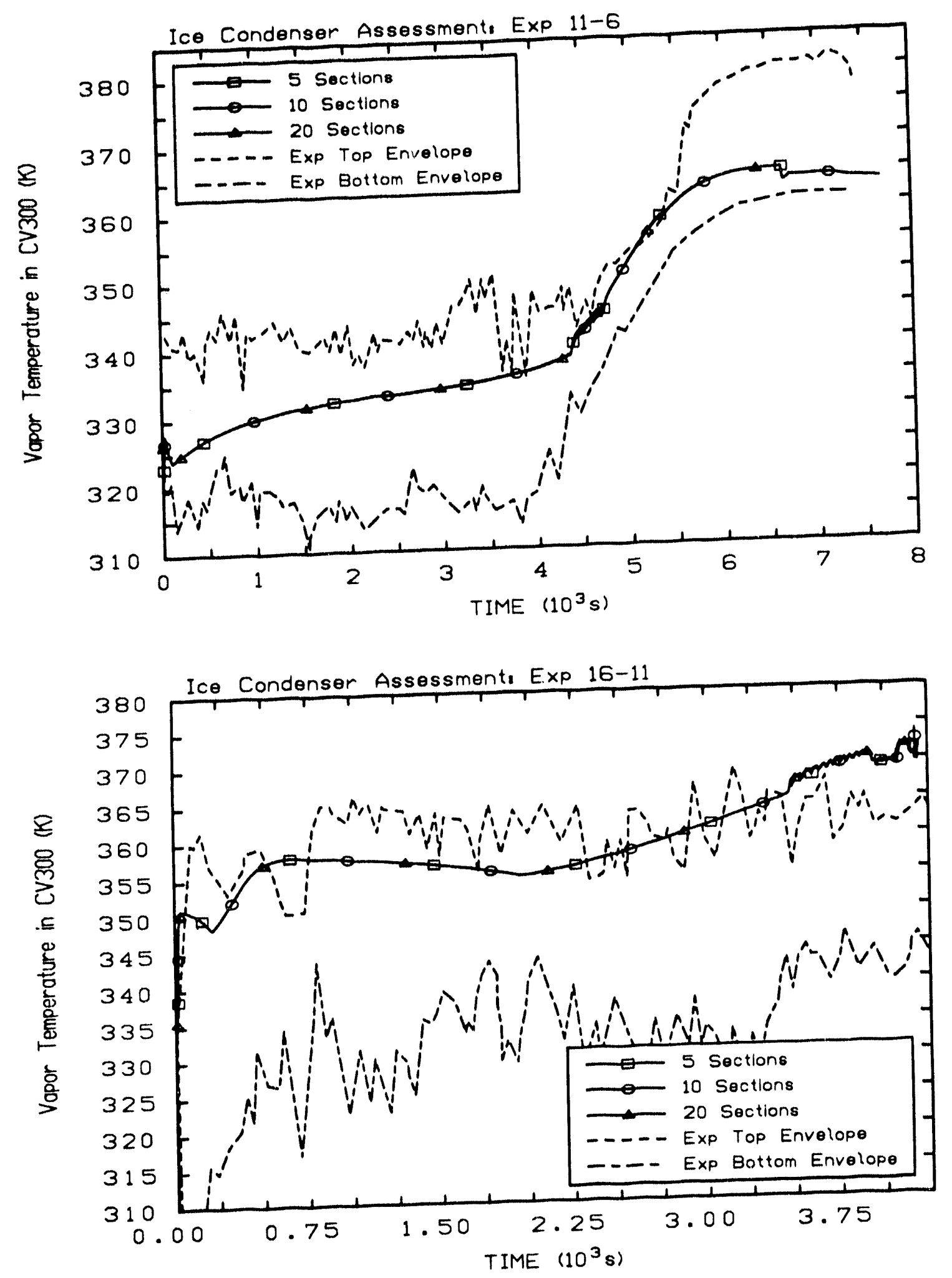

Figure 6.2.2 Vapor Temperature for CV300 for Experiment 11-6 (top) and Experiment 16-11 (bottom). Aerosol Section Sensitivity Study. 
Figure 6.2.3 shows the cpu time required for each run for each of the experiments. Doubling the number of sections to ten required roughly an increase of $25 \%$ in the necessary cpu time for both experiments. Using twenty sections required more than double the cpu time. Using five sections for these calculations gave aerosol results that were within $5 \%$ of the twenty section results; it is an individual judgment call as to whether the ten section or twenty section calculations were worth the additional accuracy compared to the cpu cost.

\subsection{Particle Density}

The particle density is a value chosen to represent every aerosol particle in the aerosol calculations. It is used in several correlations within the RN Package [12]. Obviously, if there is more than one kind of particle, this is a simplifying assumption. The MELCOR default value is $1000 \mathrm{~kg} / \mathrm{m}^{3}$, which was representative of inater aerosol. With $\mathrm{ZnS}$ also present as an aerosol particle in the experiments, a larger value was necessary, but there is some uncertainty as to the "correct" value. The value of $2500 \mathrm{~kg} / \mathrm{m}^{3}$ was chosen from previous experience and from an informal sensitivity study.

Figure 6.3.1 shows the effect of varying the particle density on particle retention for both experiments. Changing the density had a large effect on particle retention. For Experiment 11-6, the lower density decreased particle retention by about ten percentage points, while the higher density raised particle retention by ten percentage points. For Experiment 16-11, the trends were the same, but the corresponding decrease or increase was about 2.5 percentage points instead of ten. Physically, these trends were correct in that heavier particles settle out faster and to a greater degree than light particles. Figure 6.3.2 shows that the suspended aerosol mass data was consistent with the particle retention. Higi ier suspended masses implied lower particle retention. Figure 6.3.3 shows the aerodynamic mass median diameter in CV300 for both the ZnS and water for both experiments (all three ice condenser regions showed the same trends). The smaller densities had larger diameters because the larger, less dense particles could remain as aerosols for longer periods of time. The point at which the ice and water disappeared from CV 300 is apparent, especially in the Experiment 11-6 plot, because it is the time in which all the water densities become zero. Thus, all of the MELCOR data were consistent.

Figure 6.3.4 and 6.3.5 show the temperature in the bottom and top ice condenser for each of the experiments. As in the previous two sensitivity studies, changing an aerosol parameter such as the particle density had no effect on the temperatures, flow path parameters or other CVH variables. Figure 6.3.6 shows that varying the density had a very small impact on the cpu time, for both experiments. 

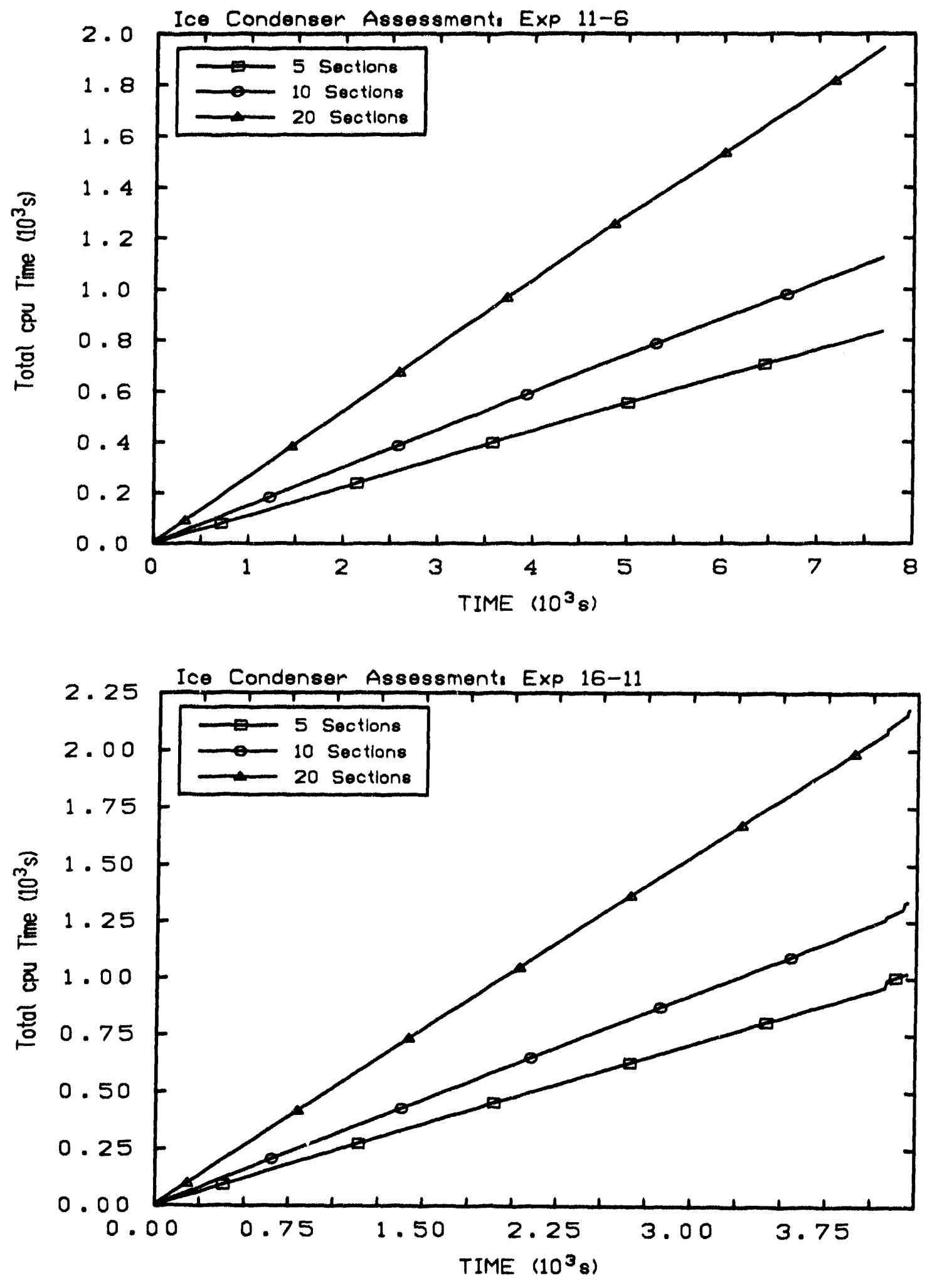

Figure 6.2.3 Computer Processor Time for Experiment 11-6 (top) and Experiment 16-11 (bottom). Aerosol Section Sensitivity Study. 

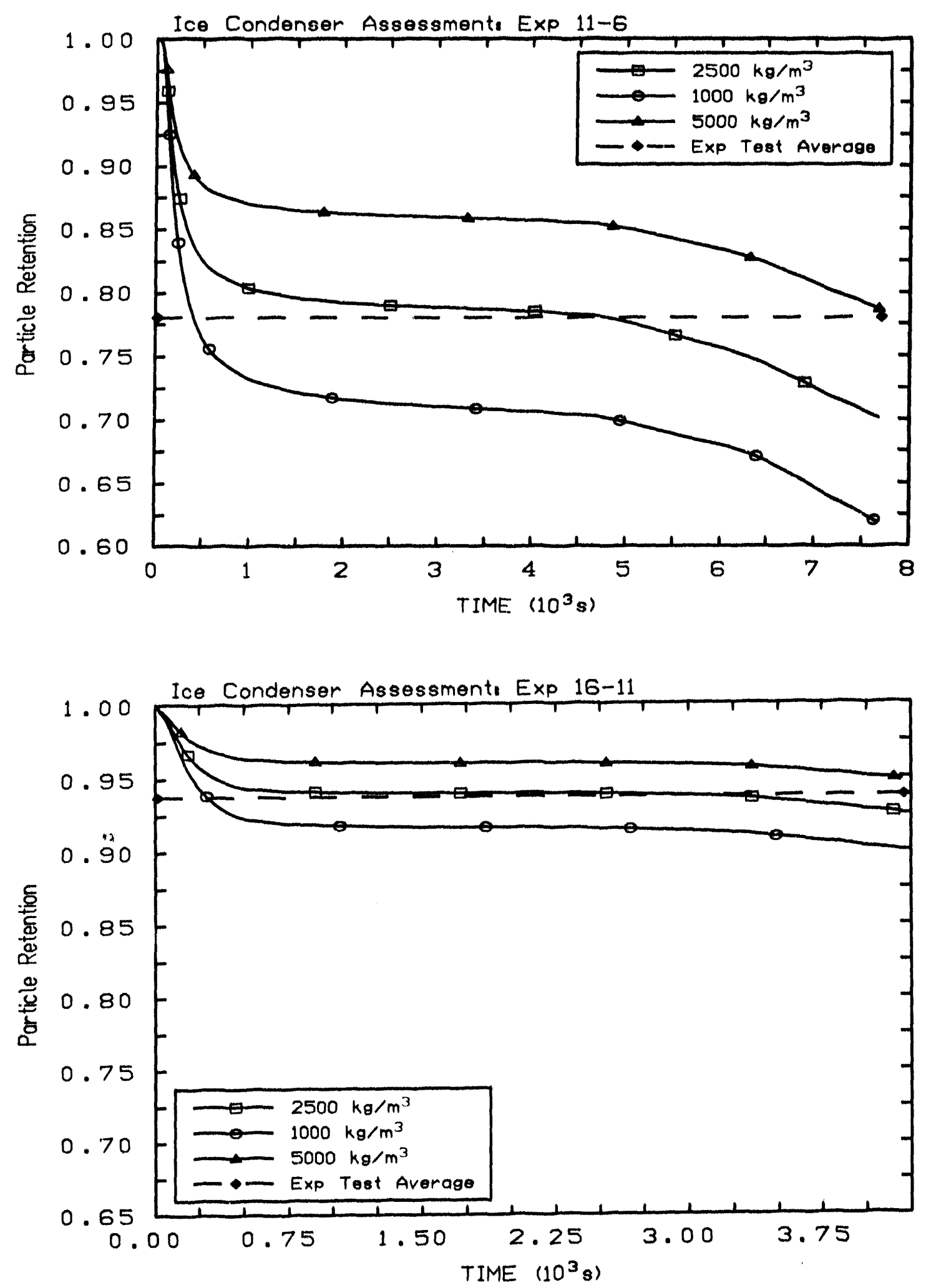

Figure 6.3.1 Particle Retention for Experiment 11-6 (top) and Experiment 16-11 (bottom). Aerosol Density Sensitivity Study. 

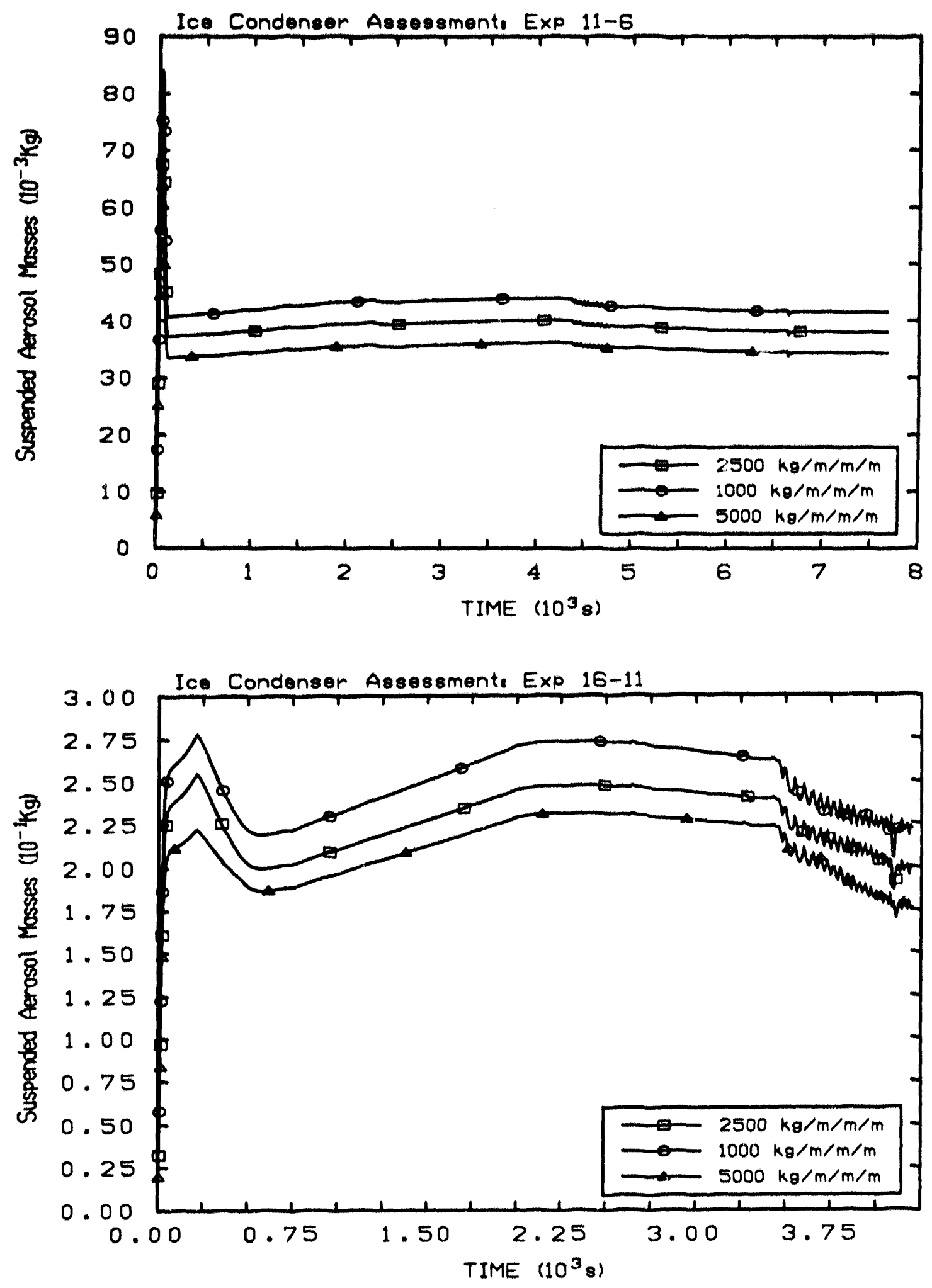

Figure 6.3.2 Suspended Aerosol Masses for Experiment 11-6 (top) and Experiment 16-11(bottom). Aerosol Density Sensitivity Study. 

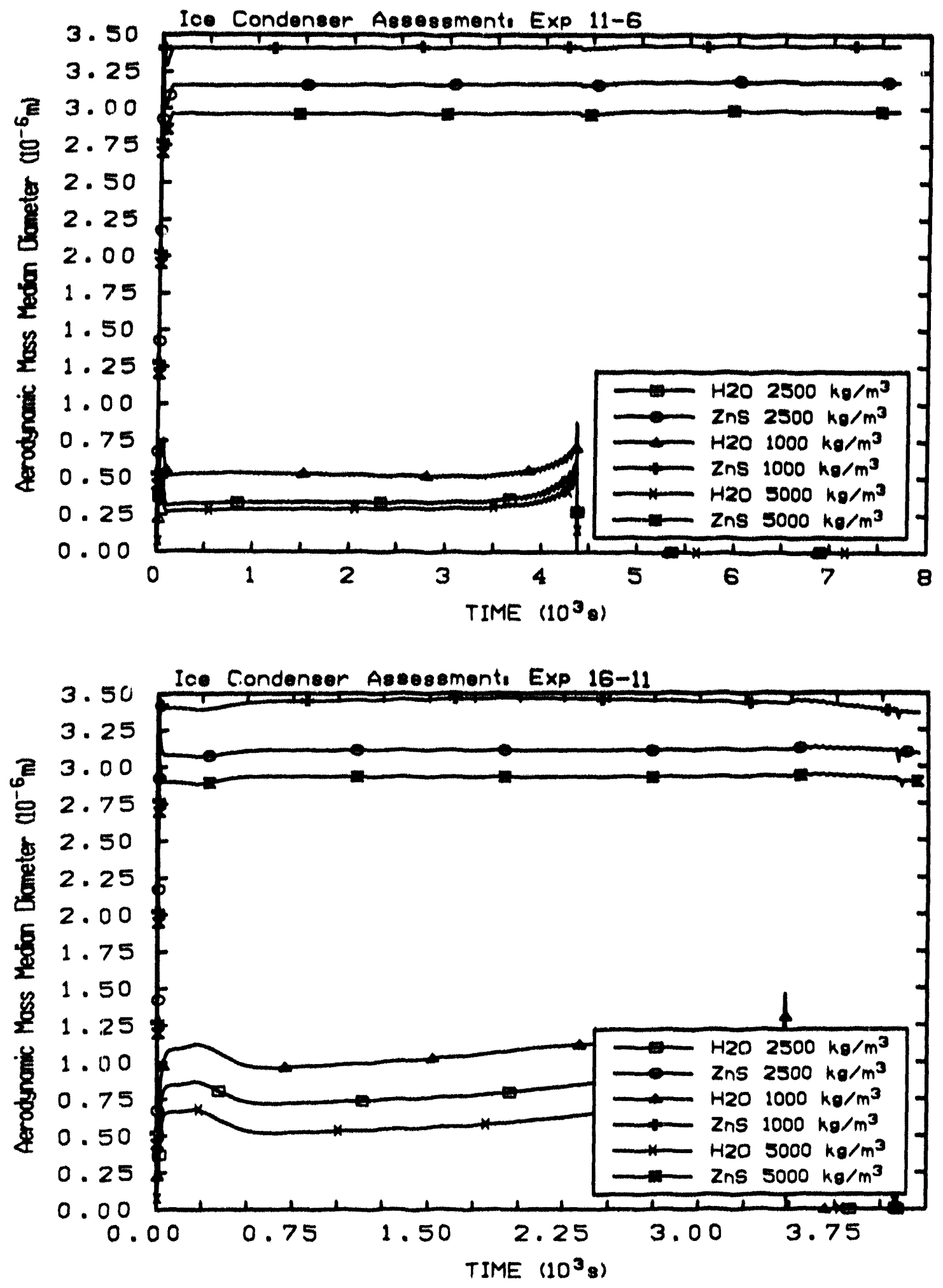

Figure 6.3.3 Aerodynamic Mass Median Diameter for Experiment 11-6 (top) and Experiment 16-11 (bottom). Aerosol Density Sensitivity Study. 

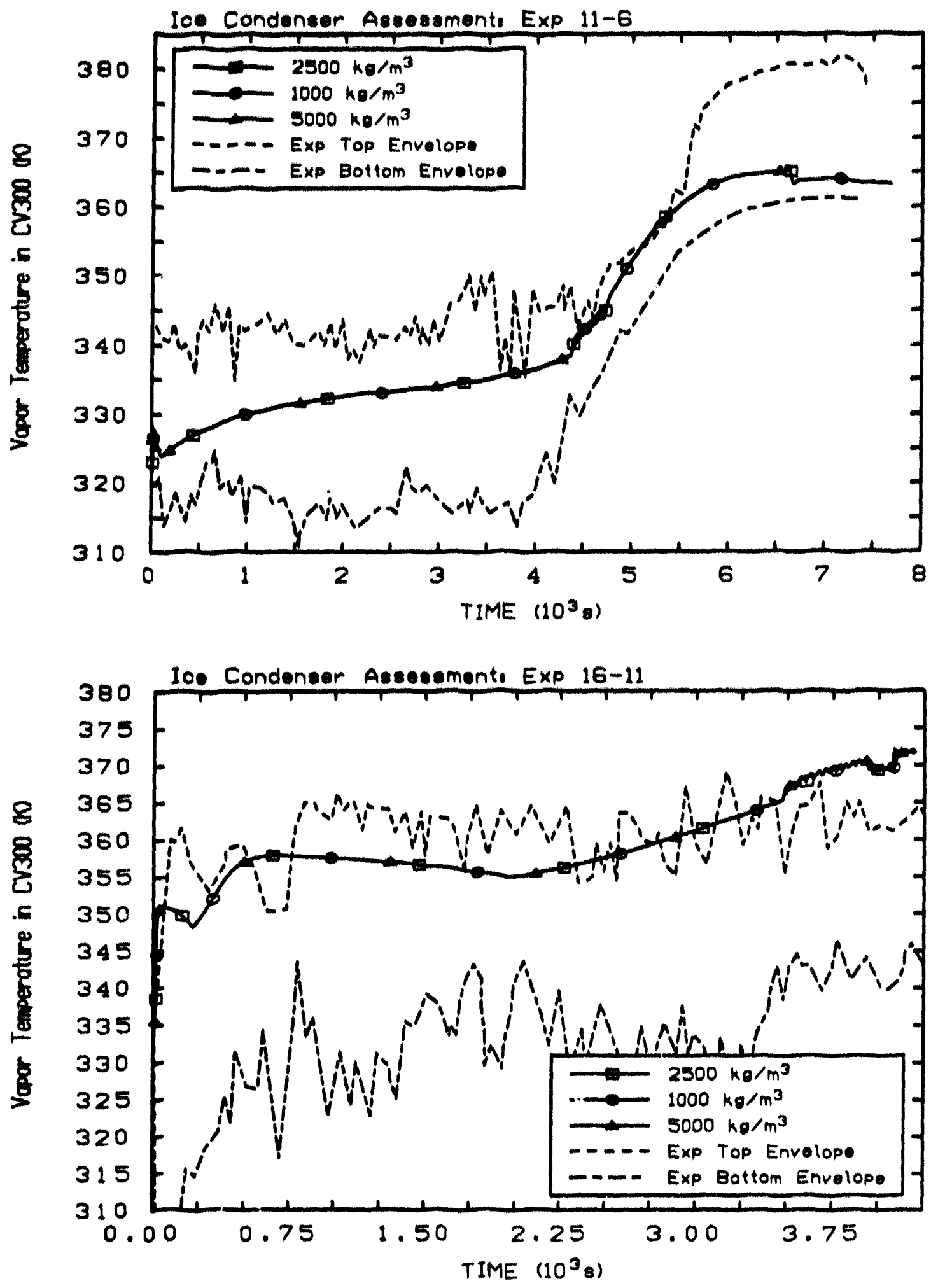

Figure 6.3.4 Vapor Temperature for $\mathrm{Cl}^{\prime} 300$ for Experiment 11-6 (top) and Experiment 16-11 (boitom). Aerosol Density Sensitivity Study. 

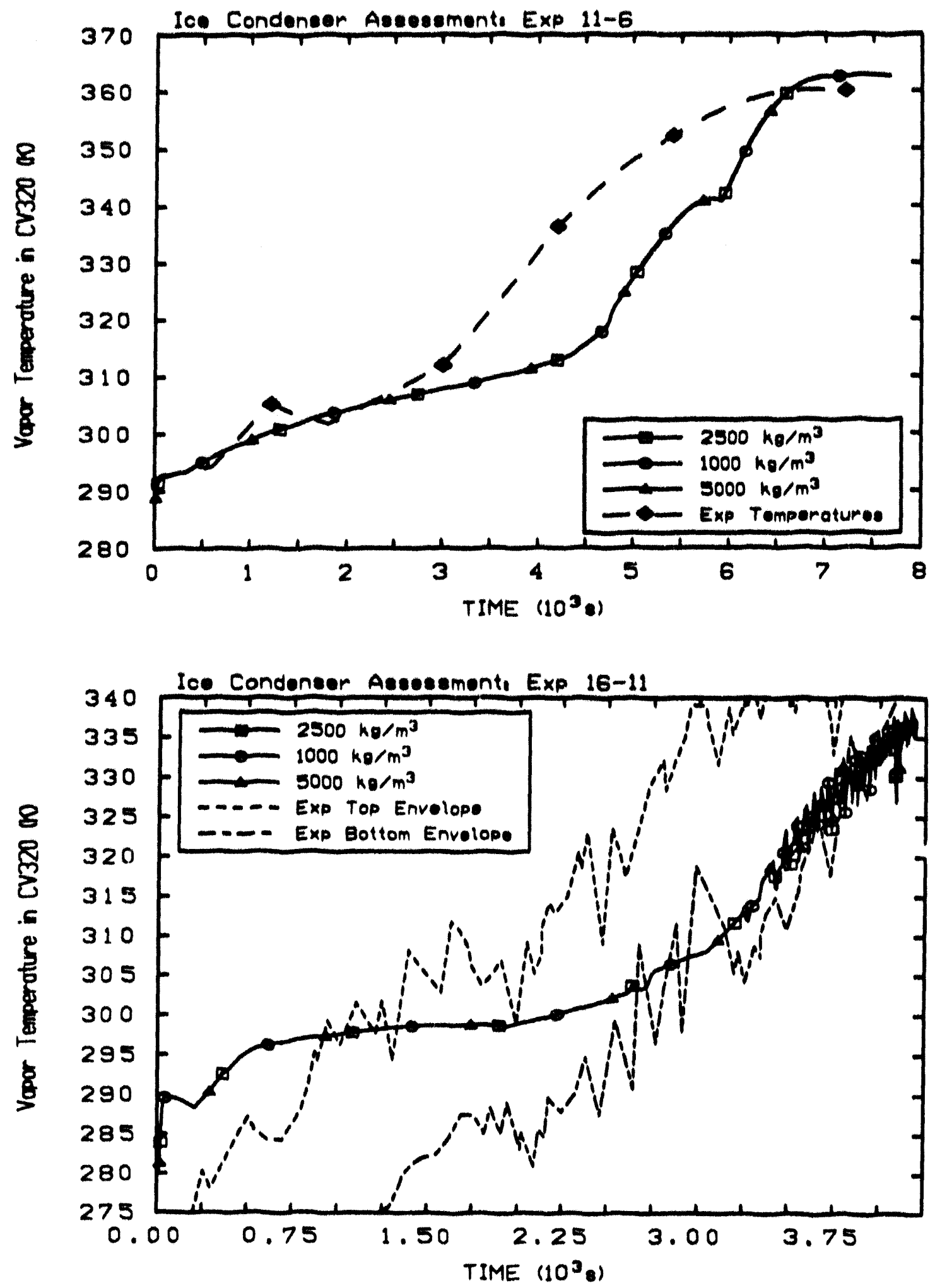

Figure 6.3.5 V/apor Temperature for CV320 for Experiment 11.6 (top) and Experiment 16-11 (bottom). Aerosol Density Sensitlvity Study. 

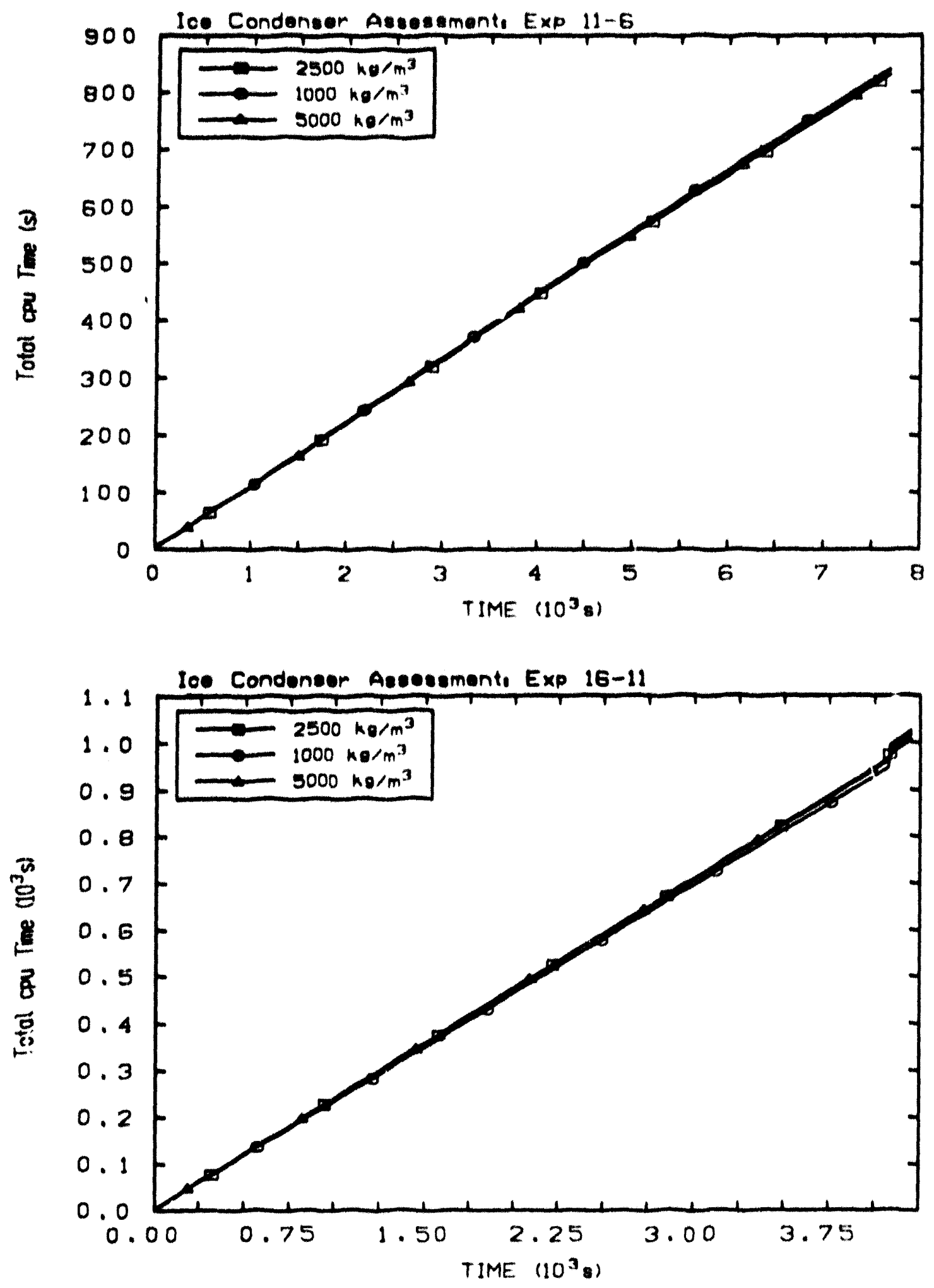

Figure 6.3.6 Computer Processor Time for Experiment 11.6 (top) and Experiment 16-11 (bottom). Aerosol Density Sensitivity Study. 


\subsection{Minimum Partlcle Diameter}

Values for the minimum and maximum particle diameters, as discussed in Section 3, were obtained from data given in [7]. However, one facet of the aerosol modeling in the RN Package is that the water aerosol can be created at a different diameter which is partly a function of the allowable diameter range. This will affect the speed at which the aerosol components settle out of the atmosphere. Also, if the range is changed and an aerosol is injected at the same diameter, this distribution of the aerosol in the various sections may change. This in turn may affest the rate and/or quantity of the aerosol settling out. In this study, the minimum reterence dlameter of $0.1 \times 10^{.6} \mathrm{~m}$ was decreased to $0.01 \times 10^{.6} \mathrm{~m}$ and also increased to $1.0 \times 10^{.6} \mathrm{~m}$.

It should be emphasize that only the minimum particle diameter was changed; the maxlmum particle diameter was always fixed at $100.0 \times 10^{.6} \mathrm{~m}$. There was substantikl experimental evidence that particles larger than $100.0 \times 10^{.6} \mathrm{~m}$ always settled out. Therefore, this value was not changed in this study.

Figure 6.4.1 shows that raising the minimum diameter affected the particle retention marginally, but that lowering the minimum diameter raised the particle retention in Experiment 11.6 by about six percentage points and in Experiment 16-11 by about 2.5 percentage points. The cause was not thermal/hydraulic. Figure 6.4.2 demonstrates that the temperature of Control Volume 300 for both experiments did not vary by changing the particle diameter range. Although not shown, the same was true for the remaining control volumes. Figure 6.4.3 shows that the ice melt rate was also not affected.

The choice of minimum particle diameter did affect the particle retention by redistributing particles in the five aerosol sections. Figure 6.4 .4 shows an approximate time-averaged variation of mass in each section of the $\mathrm{ZnS}$ component for Experiment 11-6. Clearly, the aerosol boundaries given the reference aerosol minimum and maximum diameters are such that most of the aerosol, with an AMMD of $3.5 \times 10^{.6} \mathrm{~m}$ was initially placed in Saction 3. This was veritied by examining the written output. Increasing or decreasing the minimum diameter, however, shifted the section boundaries, and the section that the majority of $\mathrm{ZnS}$ aerosol was initially placed. Figure 6.4.4 shows that when the minimum diameter was increased to $1.0 \times 10^{\circ} \mathrm{m}$, thereby decreasing the allowable aerosol range, the majority of the $\mathrm{ZnS}$ is initially placed in Section 2. Conversely, when the minimum diameter was decreased, the majority of the $\mathrm{ZnS}$ aerosol was placed in Section 4. For the case of minimum diameter equal to $1.0 \times 10^{.6} \mathrm{~m}$ and the majority of $\mathrm{ZnS}$ aerosol mass in Section 2 , it took longer to migrate to the largest section and settle out. Thus, this case should have a lower particle retention, which is verified by Figure 6.4.1. Conversely, the case of minimum diameter equal to $0.01 \times 10^{.6} \mathrm{~m}$ placed the majority of $\mathrm{ZnS}$ mass in Section 4 , which resulted in faster settling and higher particle retention

Figure 6.4.5 shows that varying the allowable diameter range had an observable but not significant effect on cpu usage. 

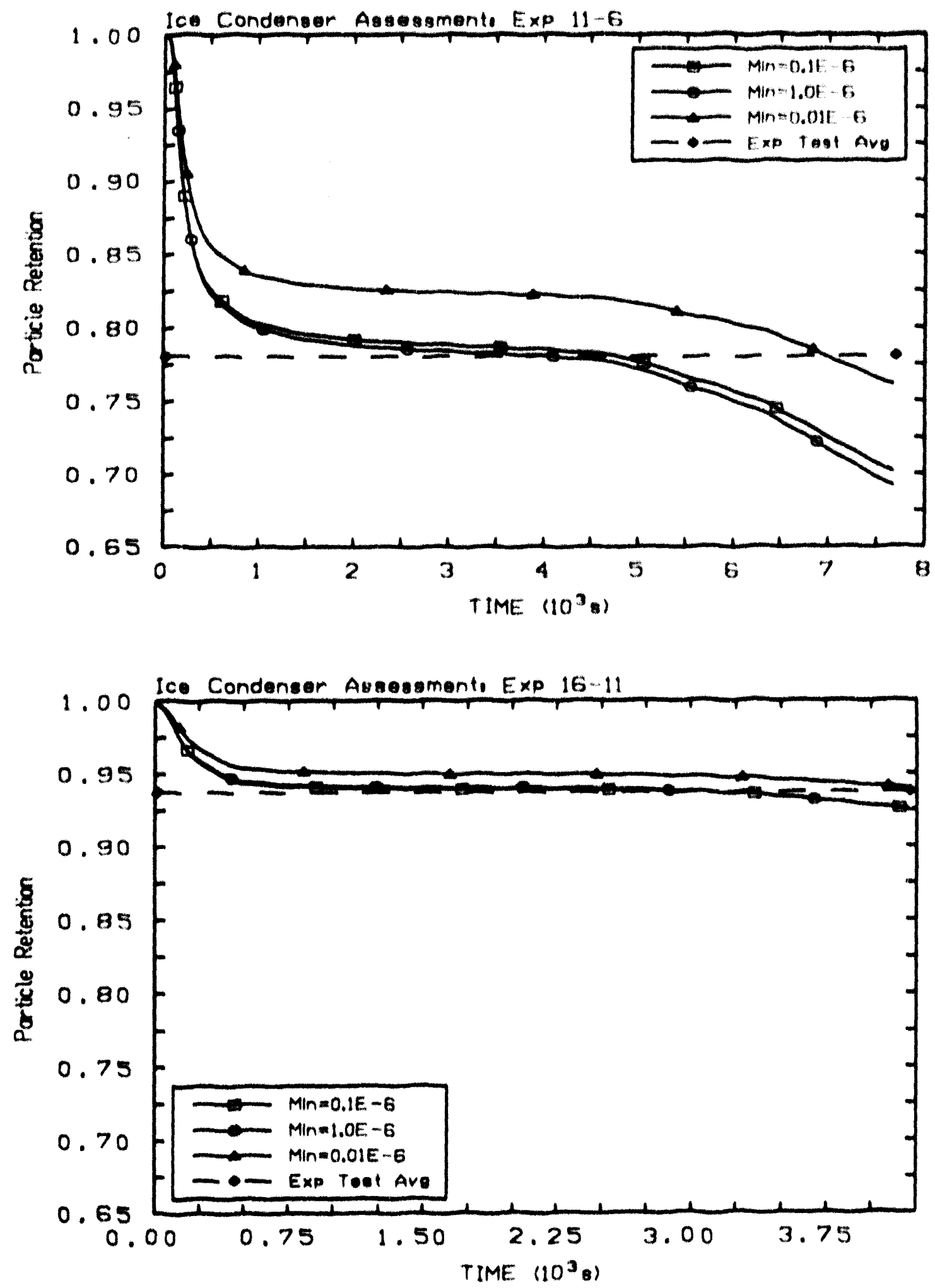

Figure 6.4.1 Particle Retention for Experiment 11.6 (top) and Experiment 16.11 (bottom). Minimum Aerosol Particle Diameter Sensitivity Study. 

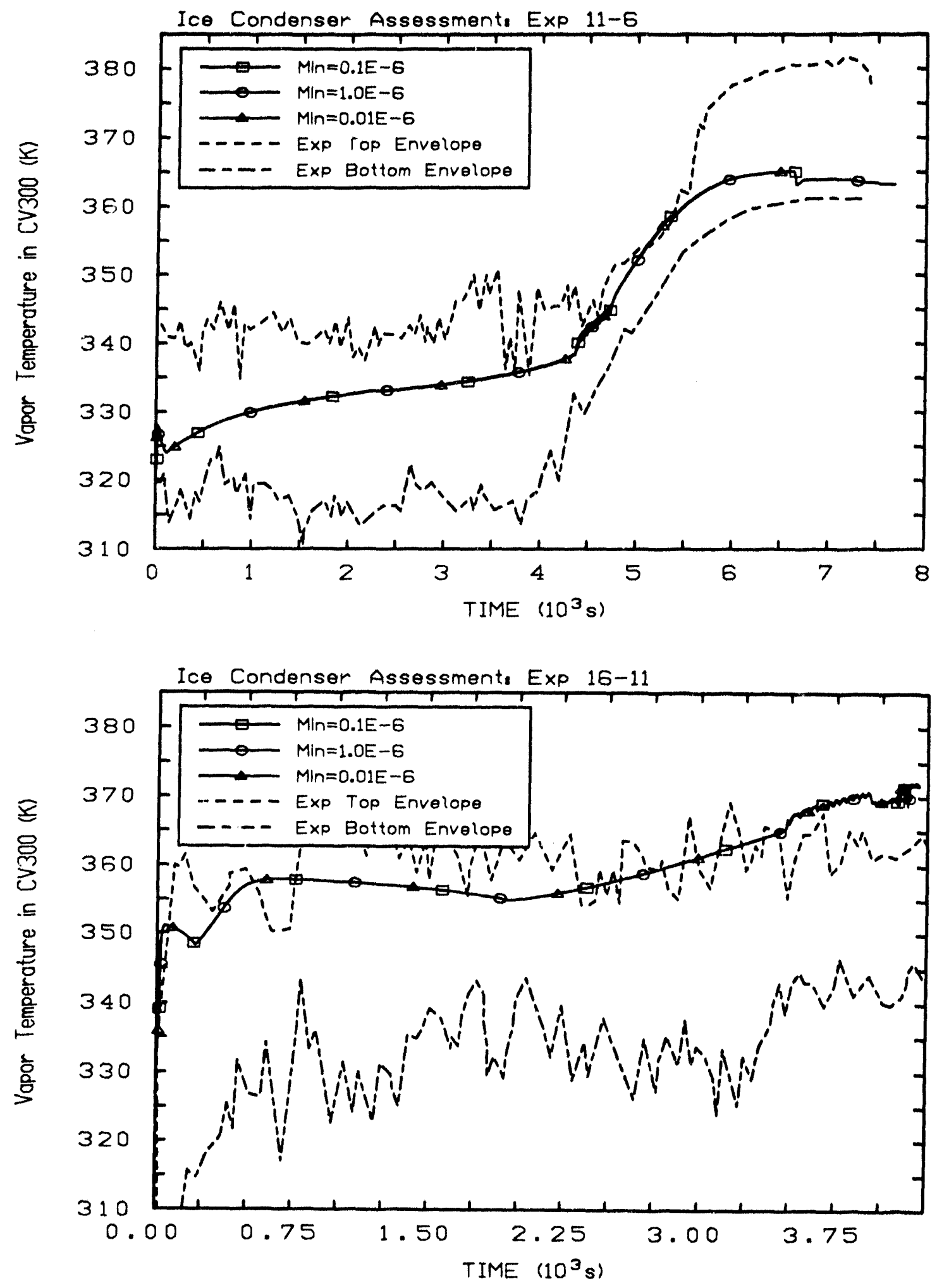

Figure 6.4.2 Vapor Temperature for $\mathrm{CV} 300$ for Experiment 11-6 (top) and Experiment 16-11 (bottom). Minimum Aerosol Particle Diameter Sensitivity Study. 

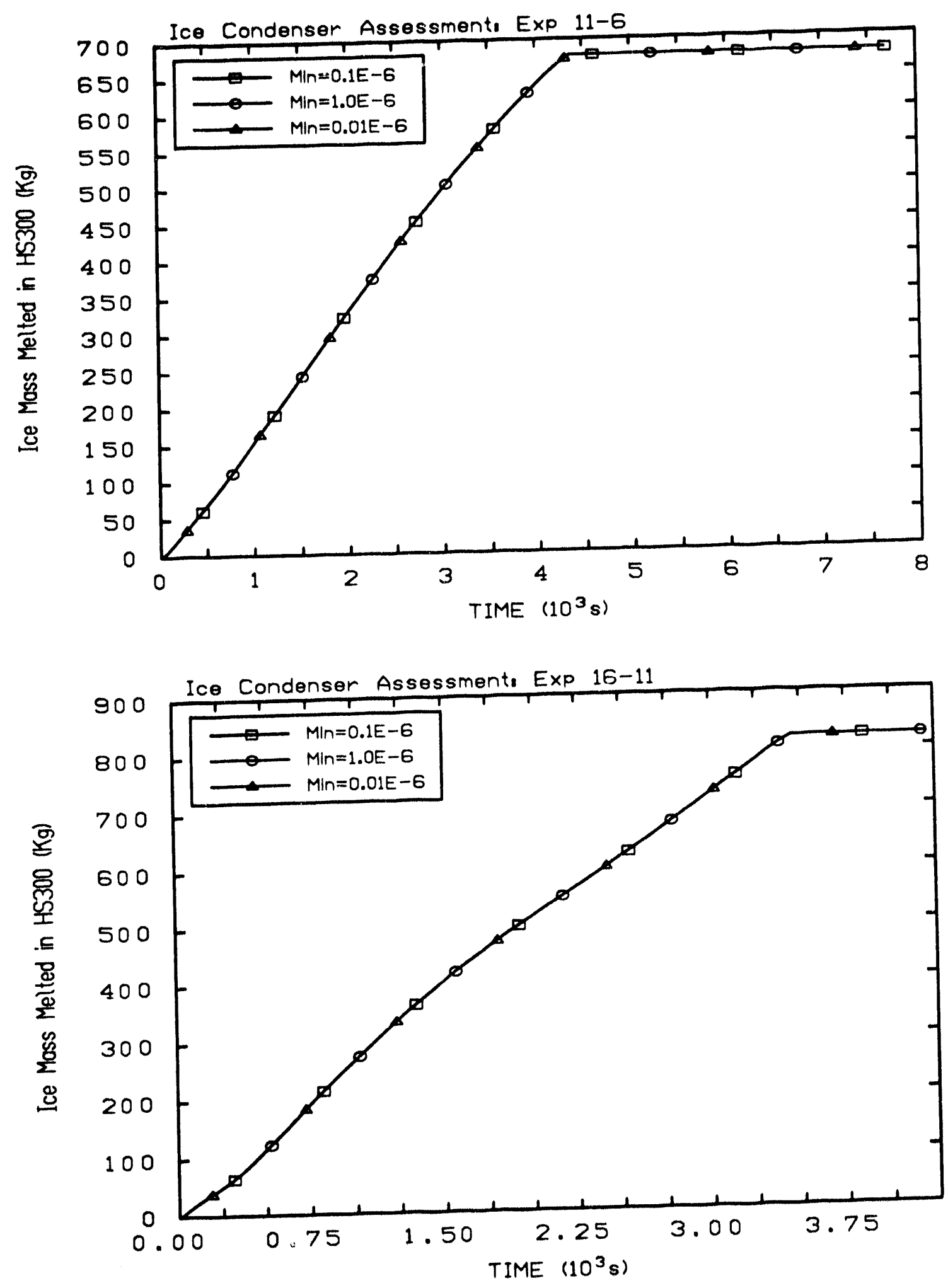

Figure 6.4.3 Ice Mass Melted in CV300 for Experiment 11-6 (top) and Experiment 16-11 (Bottom). Minimum Aerosol Particle Diameter Sensitivity Study. 


\section{Min Diameter $\mathbf{=} 0.1$ micron}

Average ZnS Mass in

Each Class (gm)

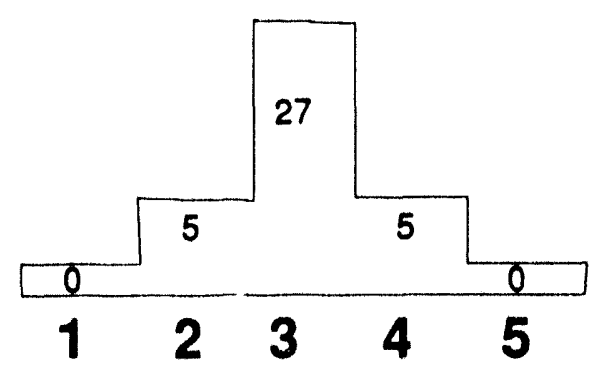

\section{Min Diameter $=1.0$ micron}

Average $\mathrm{ZnS}$ Mass in

Each Class (gm)

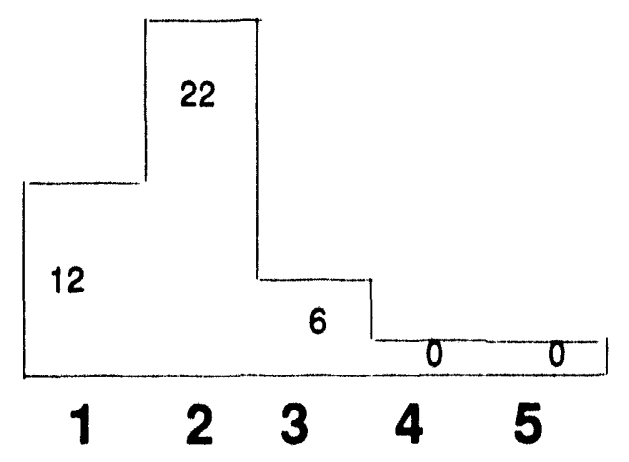

\section{Min Diameter $=0.01$ micron}

Average ZnS Mass in

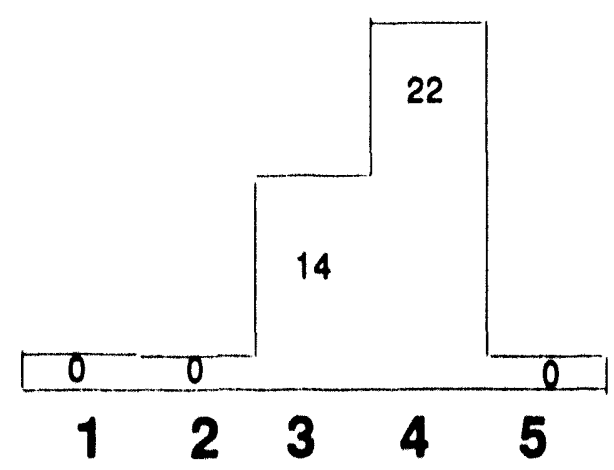

Figure 6.4.4 Distribution of ZnS Particles in the Five Sections for Experiment 11-6. Minimum Aerosol Particle Diameter Sensitivity Study. 

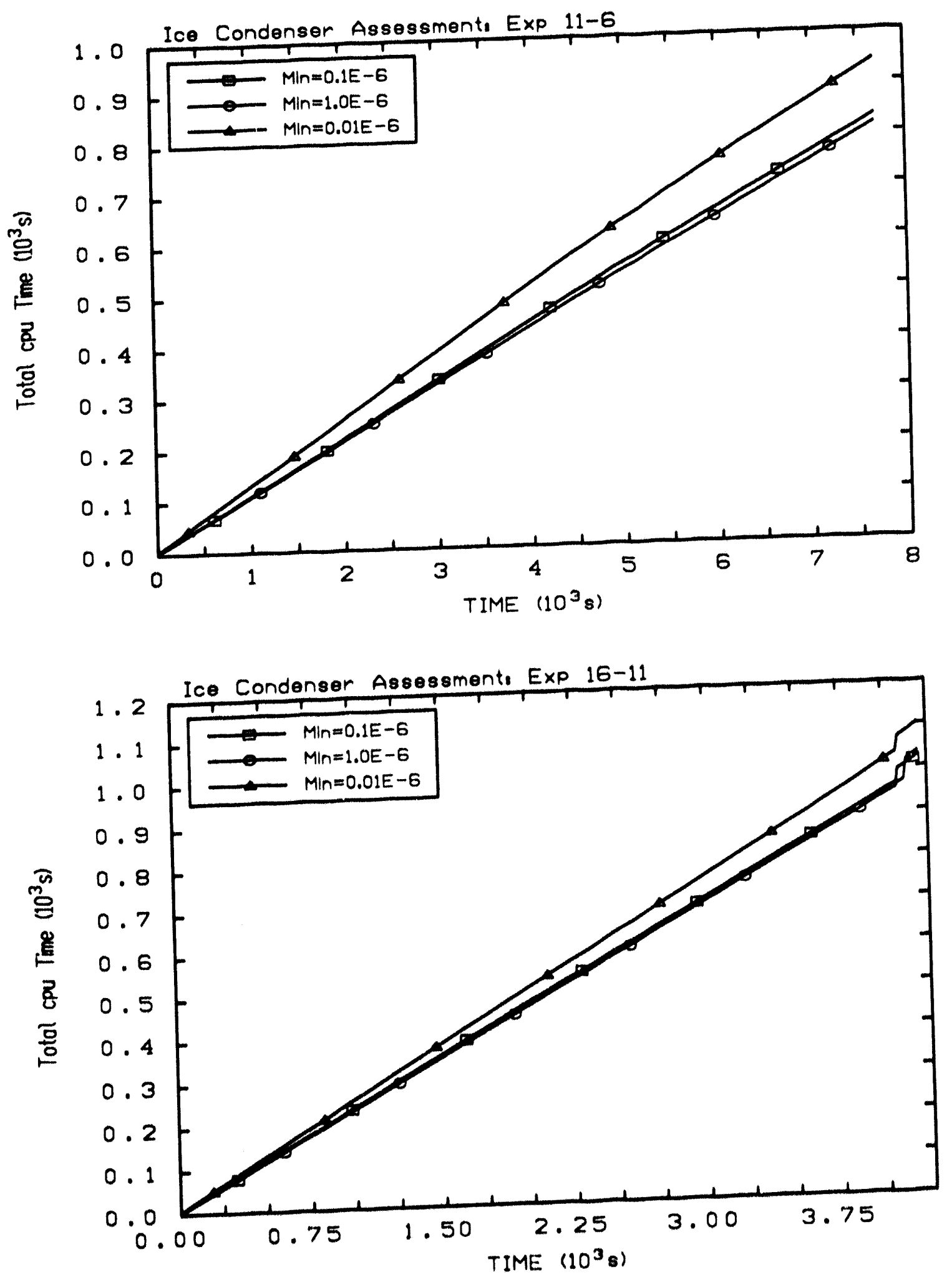

Figure 6.4.5 Computer Processor Time for Experiment 11.6 (top) and Experiment16-11 (bottom). Minimum Aerosol Particle Diameter Sensitivity Study. 


\section{Thermal/Hydraulic \& Flow Sensitivity Studies}

Sensitivity studies were also conducted on parameters that affected the control volume hydrodynamics and the flow. Because of the geometry of this problem, there was uncertainty concerning the values of the flow loss coefficients used in the MELCOR FL Package. Thus, the loss coefficients for all flow paths were first halved and then doubled to examine the importance of this parameter. CVH input requires that the user make a choice between equilibrium and non-equilibrium thermodynamics (pool and atmosphere at the same or different temperatures). The reference calculation used non-equilibrium thermodynamics for all control volumes because it usually is a more accurate assumption. However, a sensitivity study using equilibrium thermodynamics was also performed. Another CVH sensitivity study was performed to determine if the inclusion of physics for bubble rise through an accumulation of pool (liquid water) in any control volume was important.

\subsection{Flow Loss Coefficients}

Assigning flow loss coefficients to flow paths is a difficult task. This particular experimental geometry contained turning vanes, diffusers, a change from cylindrical to cartesian piping, and complex lce condenser baskets. Although the best engineering judgment possible was used for all of the MELCOR input, computation of the flow loss coefficients exhibited some uncertainty. Thus, a sensitivity study was conducted on the flow loss coefficients to determine the impact that the flow loss coefficients have on the MELCOR results. In this study, the reference loss coefficients for all the flow paths were both doubled and halved. Figure 7.1.1 displays the results of this sensitivity study on particle retention for both Experiments $11-6$ and 16-11. There were small observable differences in the results, but it is obvious than $\theta$ ven a poor choice of flow loss coefficients for these problems did not significantly affect the aerosol results. Figures 7.1.2 to 7.1.4 display temperatures in the three ice condenser control volumes for both experiments. Again, although there were small deviations from the reference calculation results, it was apparent that, because pressure drop in this problem was small, the variation in flow loss coefficients did not significantly change conditions within the ice condenser. Although not shown, changing the flow loss coefficients had a negligible effect on the cpu time to solve the problem for both experiments.

\subsection{Equilibrium / Non-equilibrium Thermodynamics}

The term "equilibrium/non-equilibrium thermodynamcis" refers to a choice in the Control Volume Hydrodynamics (CVH) Package that the user must make (no default value is coded). Equilibrium forces the liquid water, or pool, in a control volume to be in thermodynamic equilibrium with the atmosphere, in this case the steam/air/aerosol mixture. In a practical sense, equilibrium forces the pool and atmosphere to be at the same temperature (a poor choice in most MELCOR applications). Nonequilibrium allows the two quant- 

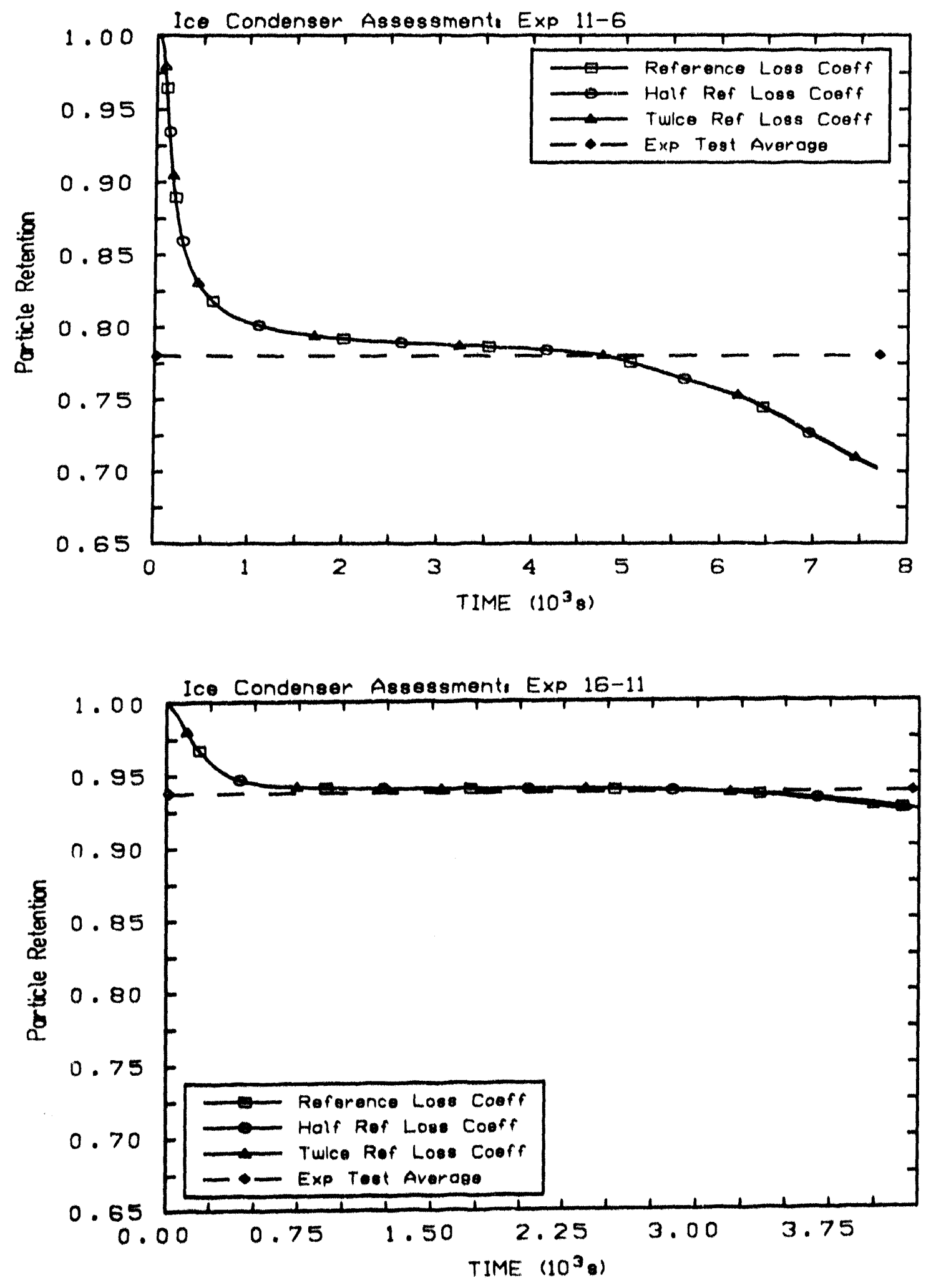

Figure 7.1.1 Particle Retention for Experiment 11-6 (top) and Experiment 16-11 (bottom). Flow Loss Coefficient Sensitivity Study. 

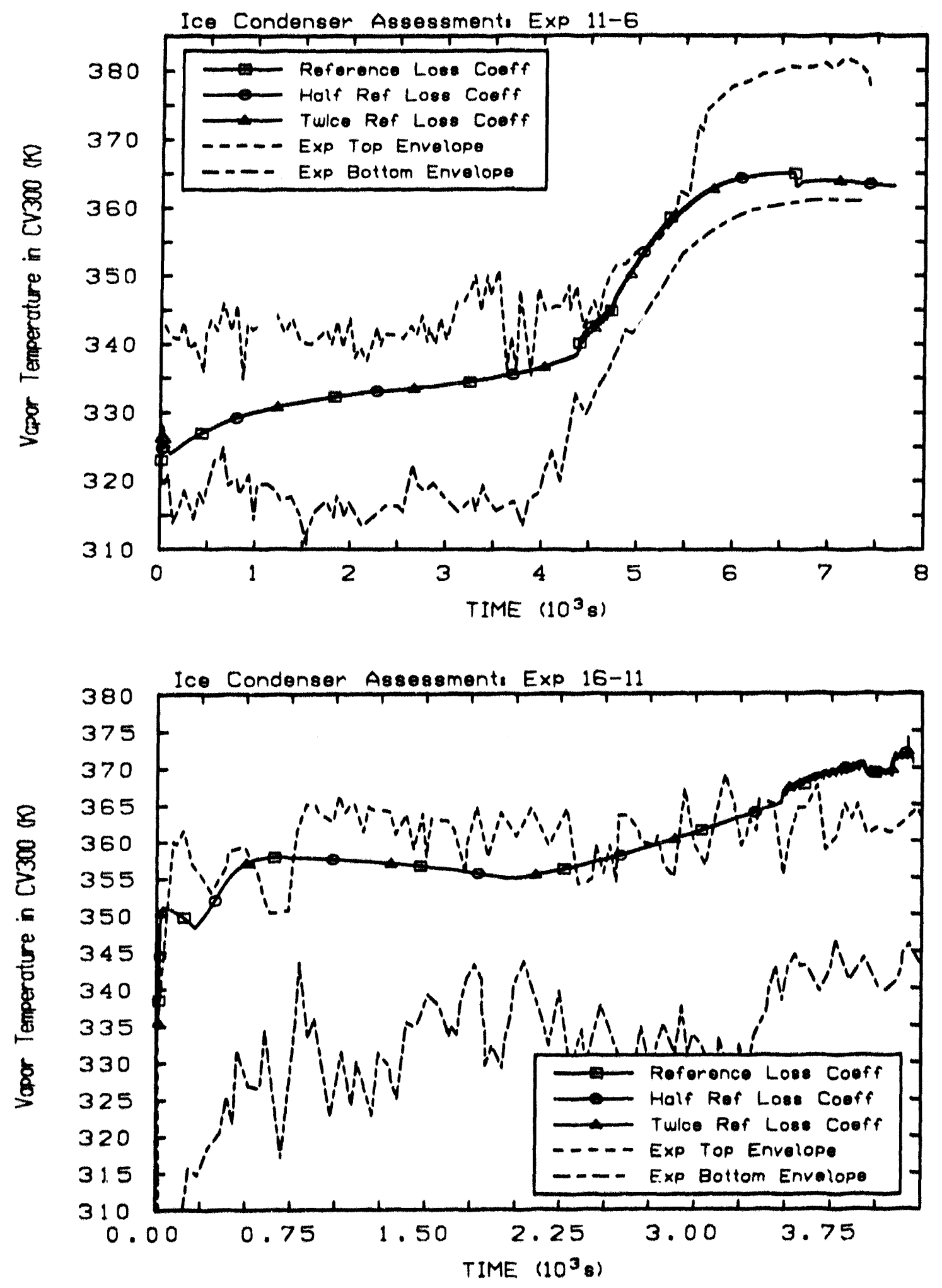

Figure 7.1.2 Vapor Temperature for CV300 or Experiment 11-6 (top) and Experiment 16-11 (bottom). Flow Loss Coefficient Sensitivity Study. 

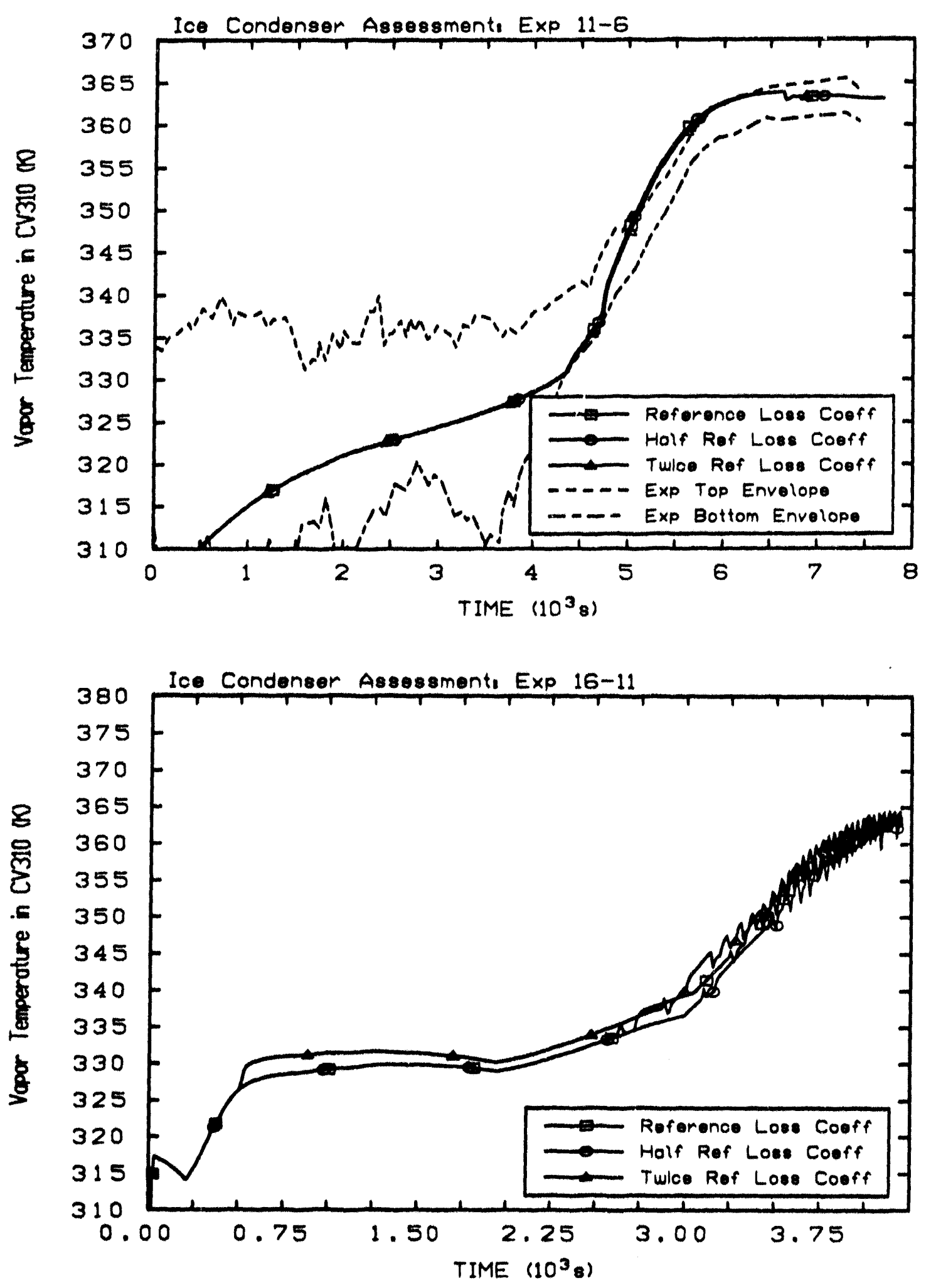

Figure 7.1.3 Vapor Temperature for CV310 for Experiment 11-6 (top) and Experiment 16-11 (bottom). Flow Loss Coefficient Sensitivity Study. 

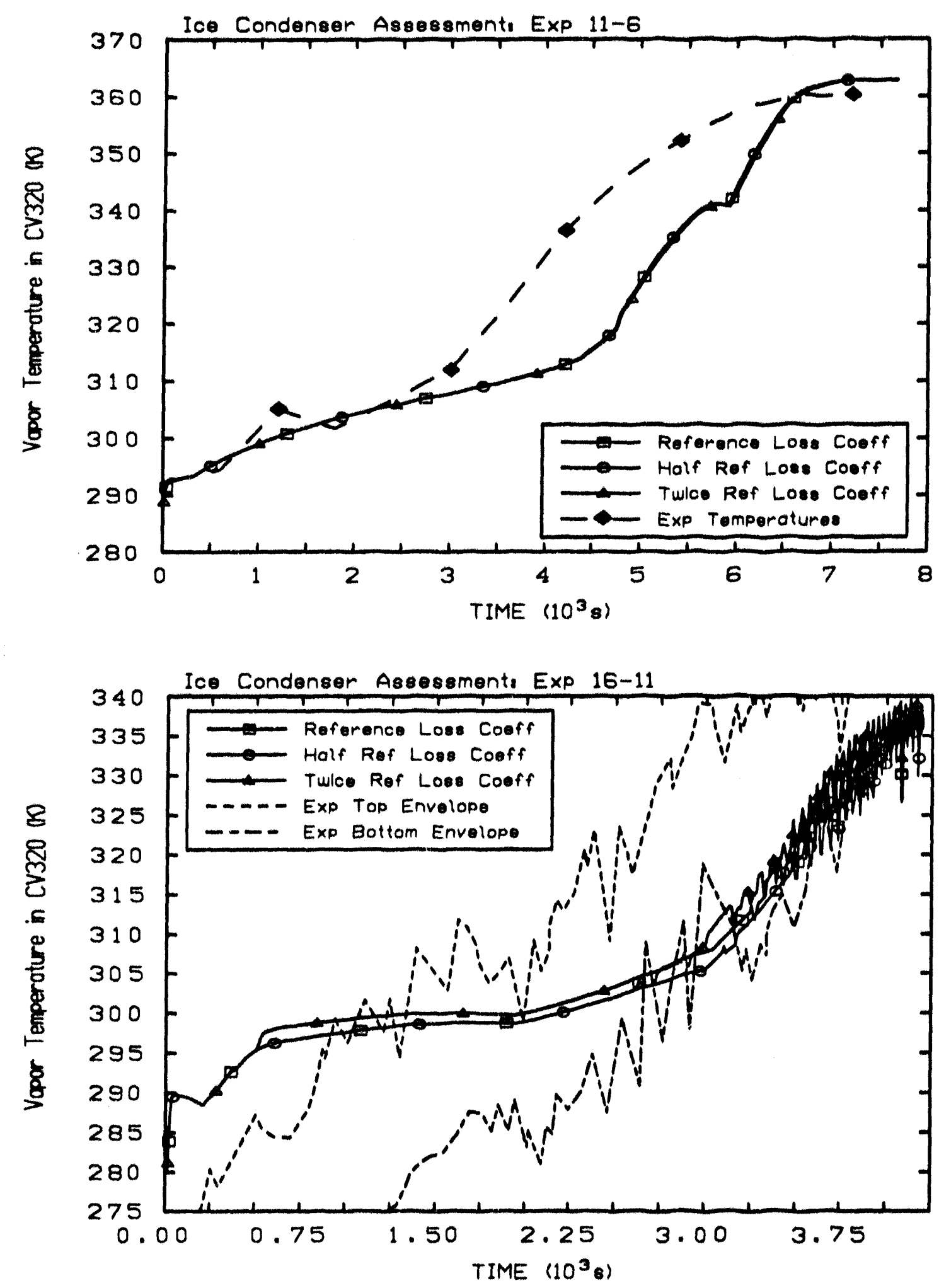

Figure 7.1.4 Vapor Temperature for CV320 for Experiment 11-6 (top) and Experiment 16-11 (bottom). Flow Loss Coefficient Sensitivity Study. 
ities to be in different thermodynamic states. The reference calculation was performed using non-equilibrium thermodynamics option in the CVH Package. Figure 7.2.1 to 7.2.3 shows predicted temperatures in the three ice condenser regions of the non-equilibrium calculation compared to those of an equilibrium calculation for both experiments. Because the vapor temperature must now equal that of the pool (and a very small pool usually does exist in each control volume, especially in Experiment 11-6) and the pool temperature was always cooler, the vapor temperatures for the equilibrium calculation were, not surprisingly, cooler than the non-equilibrium vapor temperatures.

Figure 7.2.4 shows that the lower temperatures slowed the ice melt rate. Until the ice melted, this tended to decrease the particle retention, especially for Experiment 16-11 with its higher flow rate, as Figure 7.2.5 shows. However, since the ice lasts longer, and even after the ice was melted, temperatures stayed lower, particle retention for later times for both experiments were higher for the equilibrium cases. Figure 7.2.5 is misleading in that it may appear to some that the equilibrium case for Experiment 11.6 is more accurate. However, recall that the final experimental value was 0.73 for Experiment 11.6 and 0.88 for Experiment 16-11. Only averages are shown in the figure.

Figure 7.2.6 shows that the equilibrium calculation required moderately less cpu time than the non-equilibrium calculation.

\subsection{SPARC Physics}

Since MELCOR calculations placed a small amount of pool in each of the three ice condenser control volumes, an additional calculation was performed with the FL Package bubble rise model turned on. SPARC is an acronym for Suppression Pool Aerosol Bemoval Code [12].

The temperature results for the three ice condenser regions for both experiments are depicted in Figures 7.3.1 - 7.3.3, which compare the reference calculation to the calculation with SPARC physics In Experiment 16-11, the pool was so small that temperatures were not significantly affected. Although the plots show the curves to be identical, there were differences in the printed output results. Temperatures in Experiment 11.6 were cooler by a few degrees for the SPARC simulation.

Figure 7.3.4 compares SPARC and non-SPARC results for particle retention for the two experiments. Again, Experiment 16-11 showed very little difference because of the small pool volumes. However, as observed in Section 7.2. Experiment 11.6 contained, at times, large enough masses of pool for the SPARC physics to cause a significant increase in particle retention compared to the reference calculation. It is apparent that the SPARC code was removing an additional significant amount of aerosol from the flow in Experiment 11-6, about ten percentage points more. In Experiment 16-11, pool was formed at the end of the experiment, which caused the particle retention at late times to 

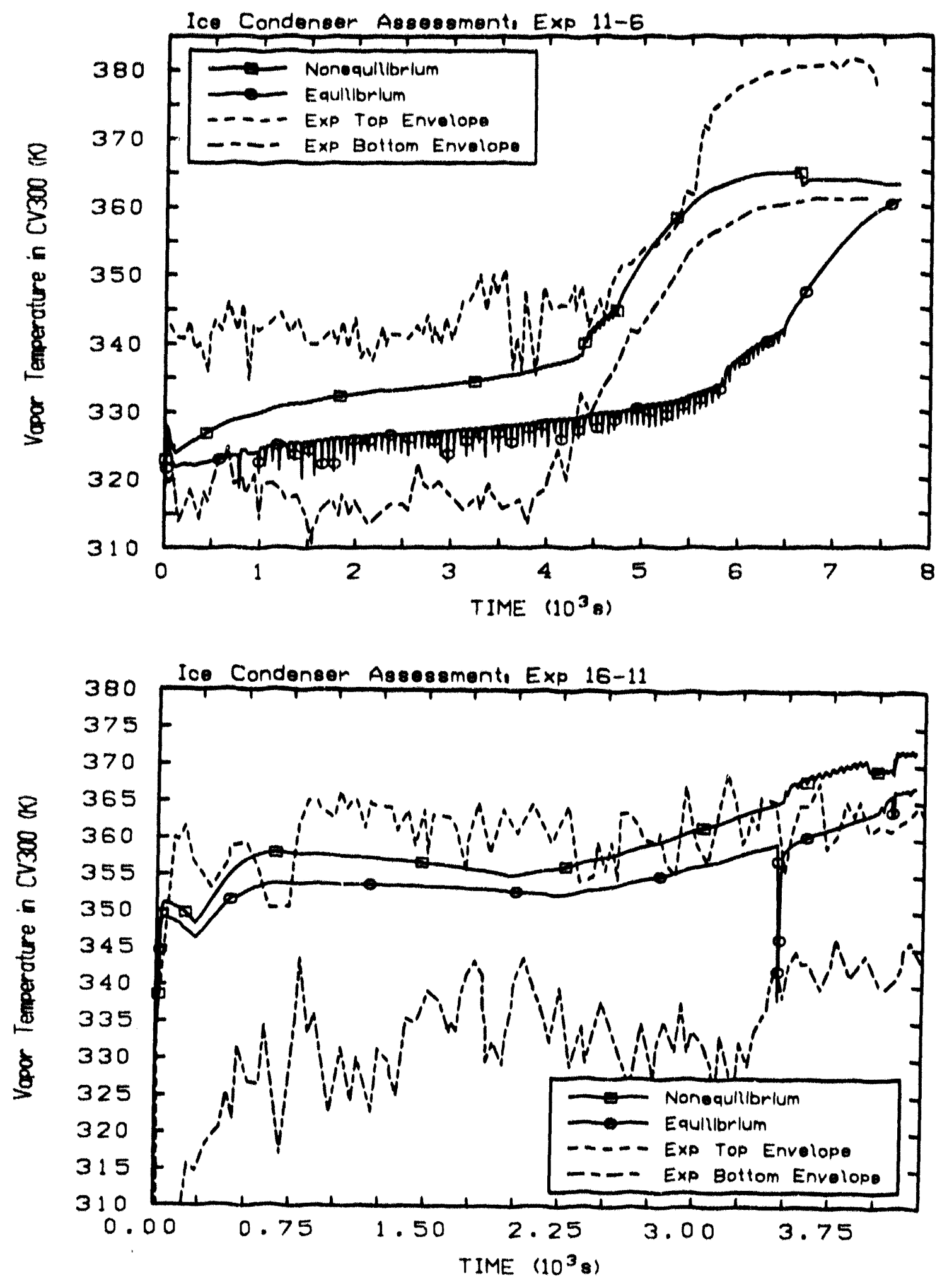

Figure 7.2.1 Vapor Temperature for CV300 or Experiment 11-6 (top) and Experiment 16-11 (bottom). Equilibrium/Nonequillibrium Sensitivity Study. 

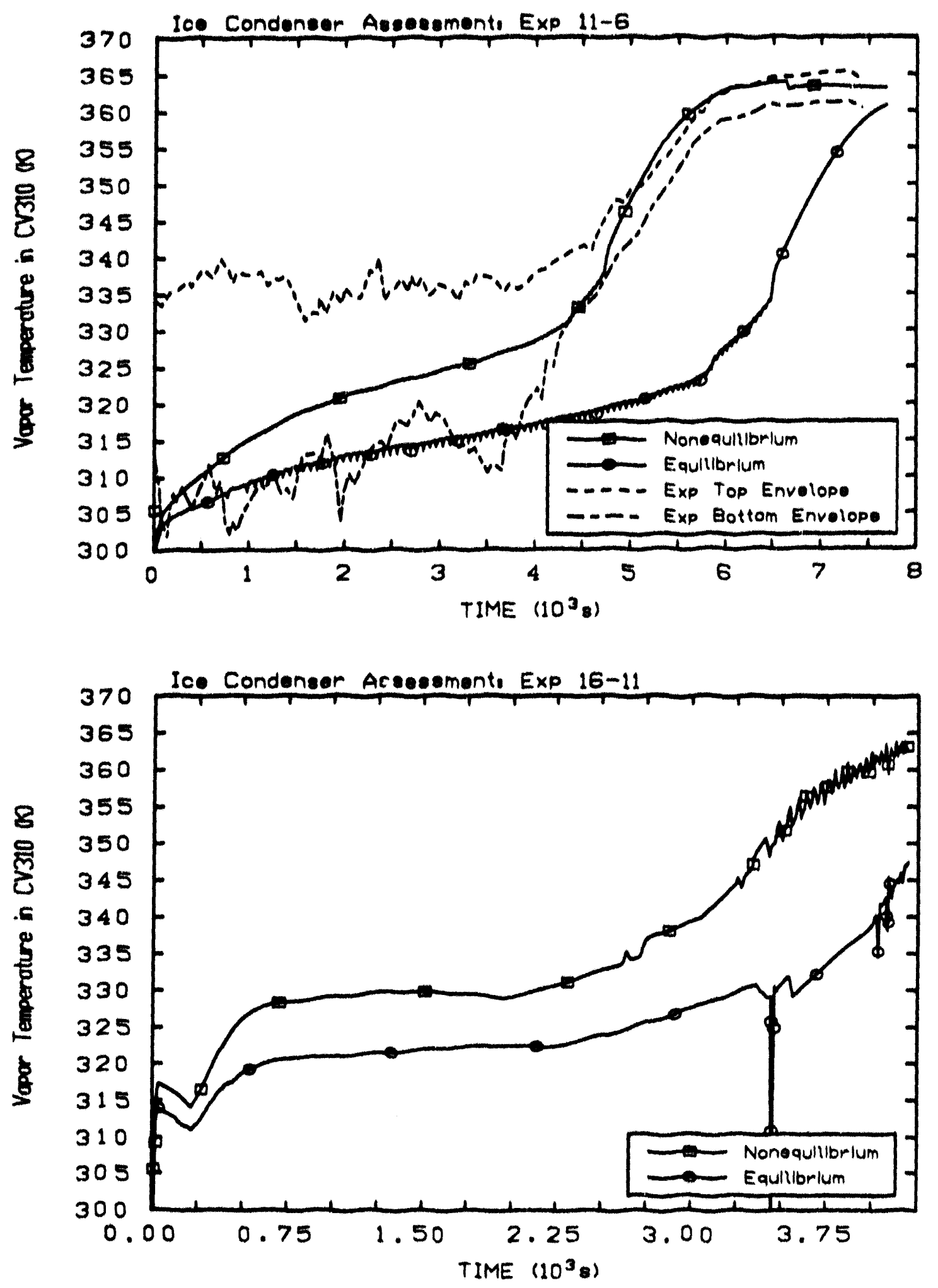

Figure 7.2.2 Vapor Temperature for CV310 for Experiment 11.6 (top) and Experiment 16-11 (bottom). Equilibrium/Nonequilibrium Sensitivity Study. 

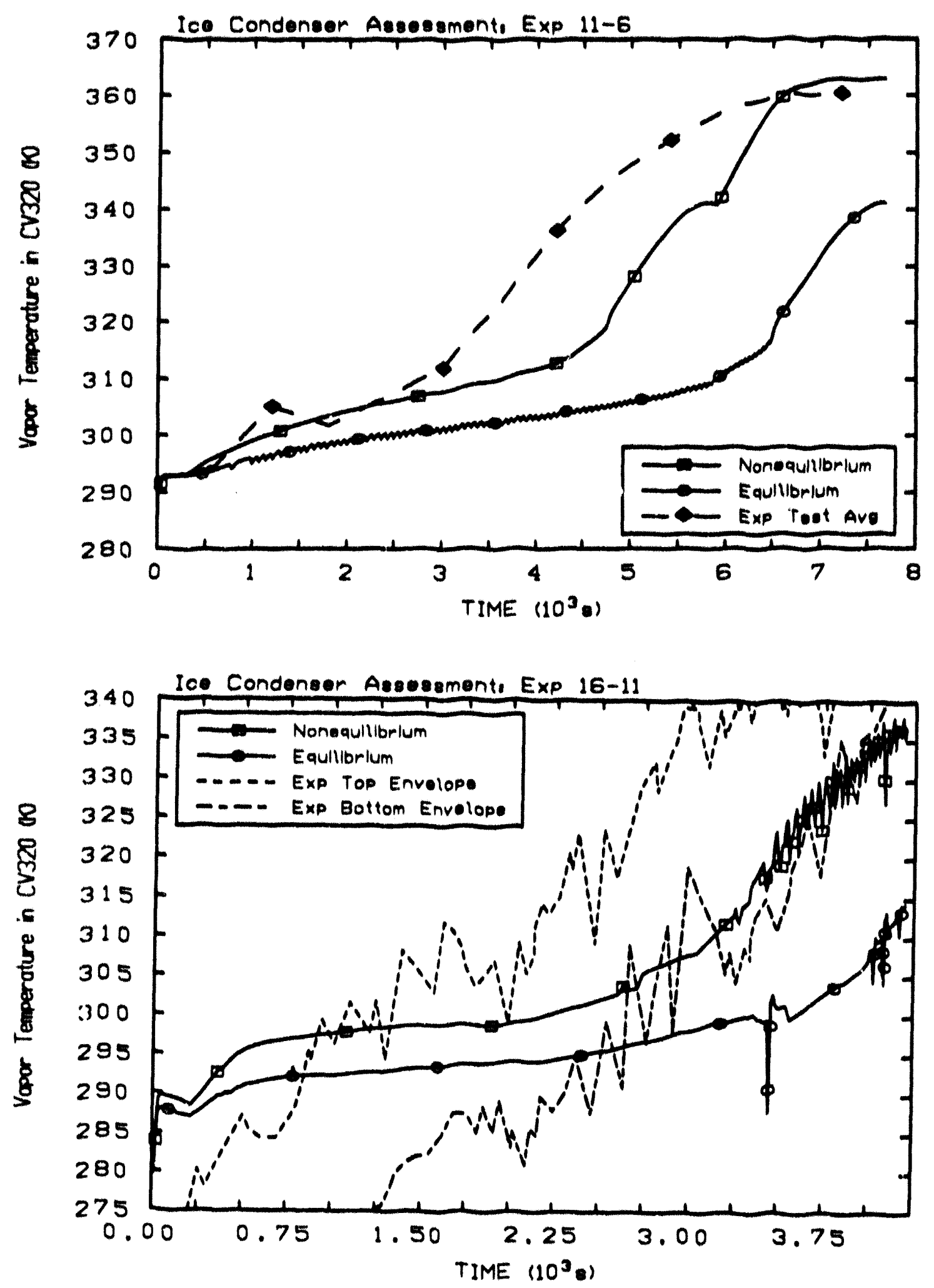

Figure 7.2.3 Vapor Temperature for CV320 for Experiment 11.6 (top) and Experiment 16-11 (bottom). Equilibrium/Nonequilibrium Sensitivity Study. 

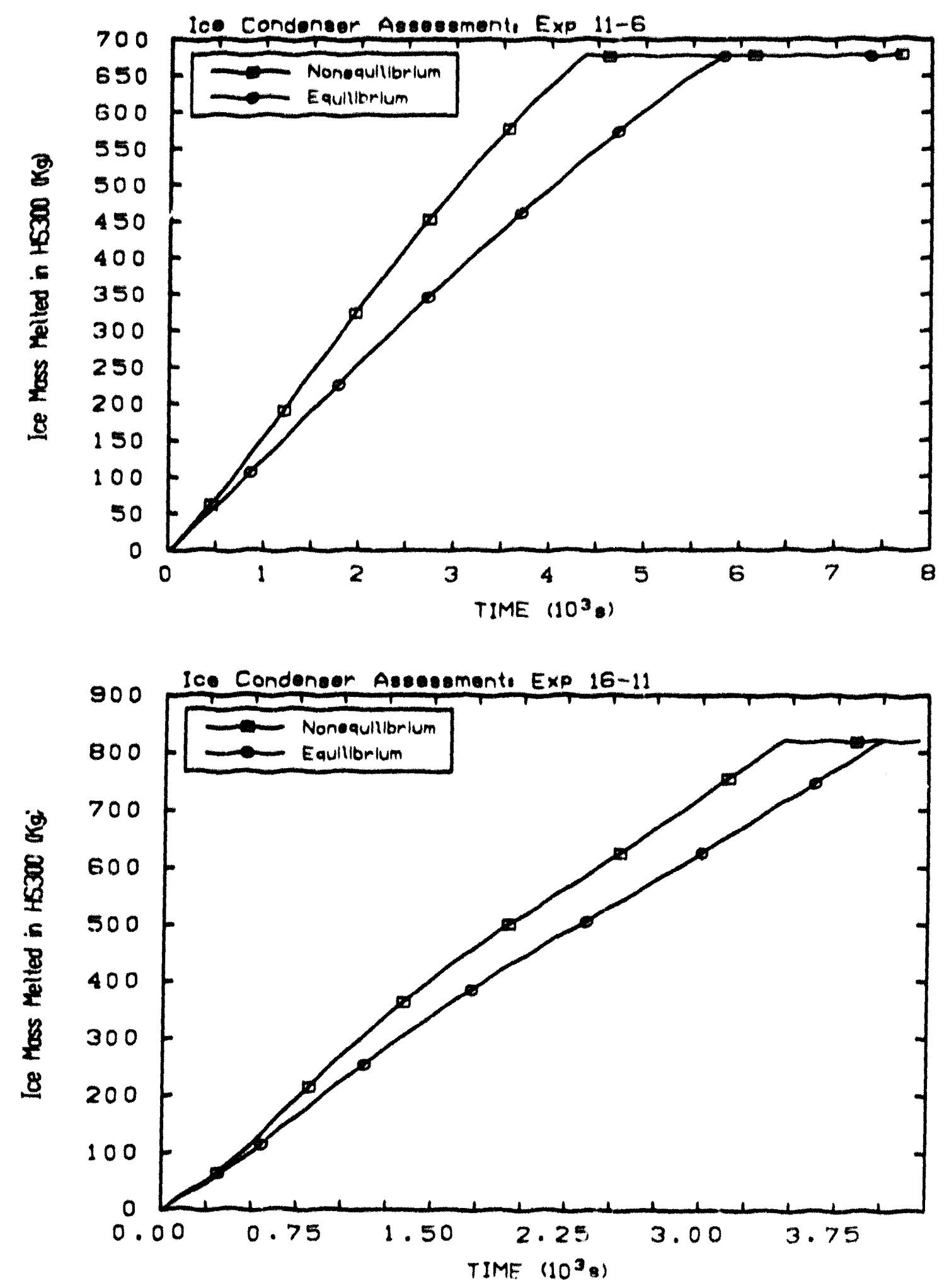

Figure 7.2.4 ICe Mass Melted in CV300 for Experiment 11-6 (top) and Experiment 16-11 (Bottom). Equllibrium/Nonequilibrium Sensitivity Study. 


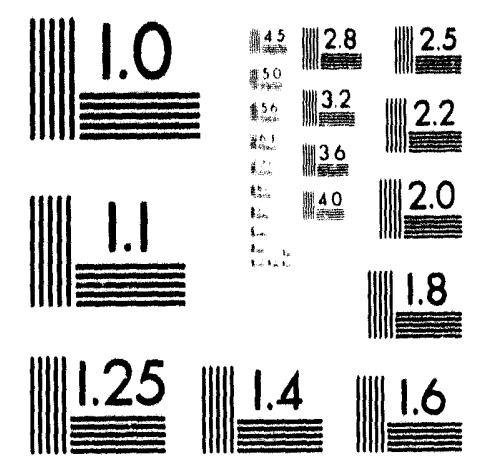



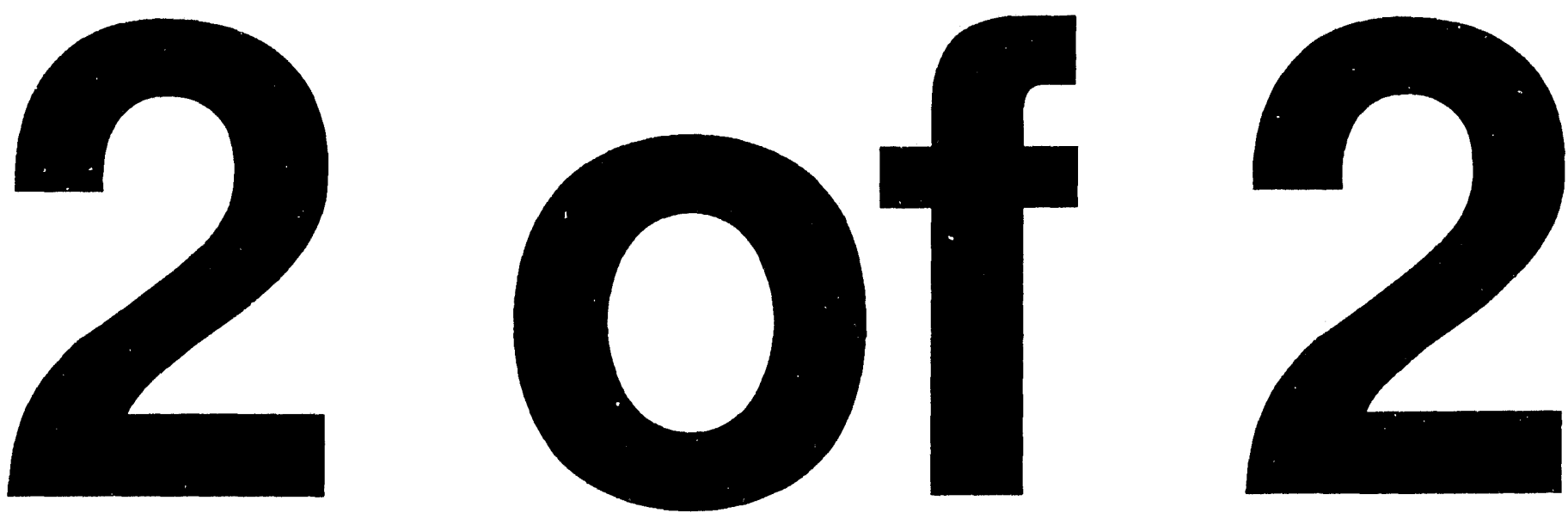

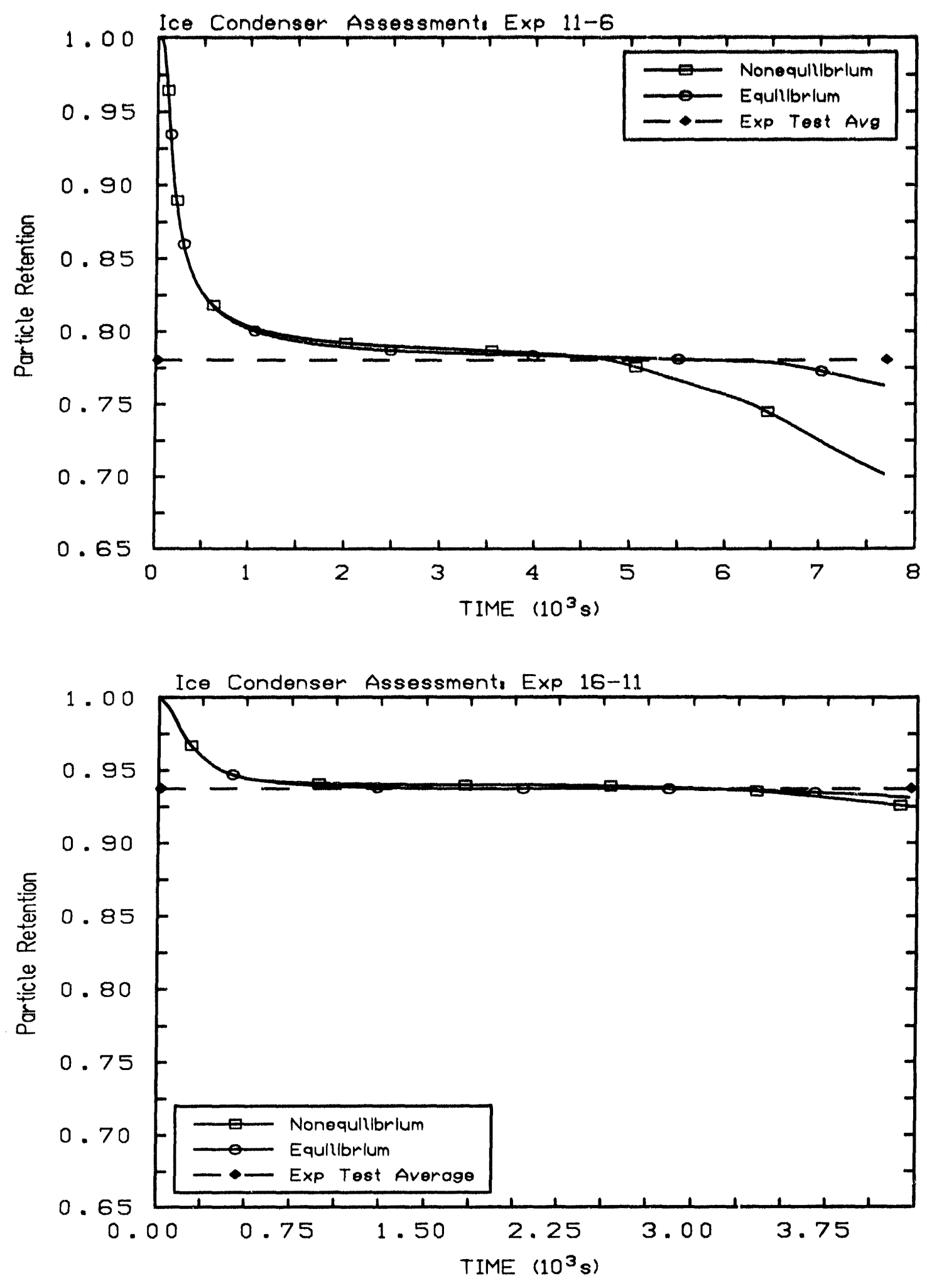

Figure 7.2.5 Particle Retention for Experiment 11-6 (top) and Experiment 16-11 (bottom). Equilibrium/Nonequilibrium Sensitivity Study. 

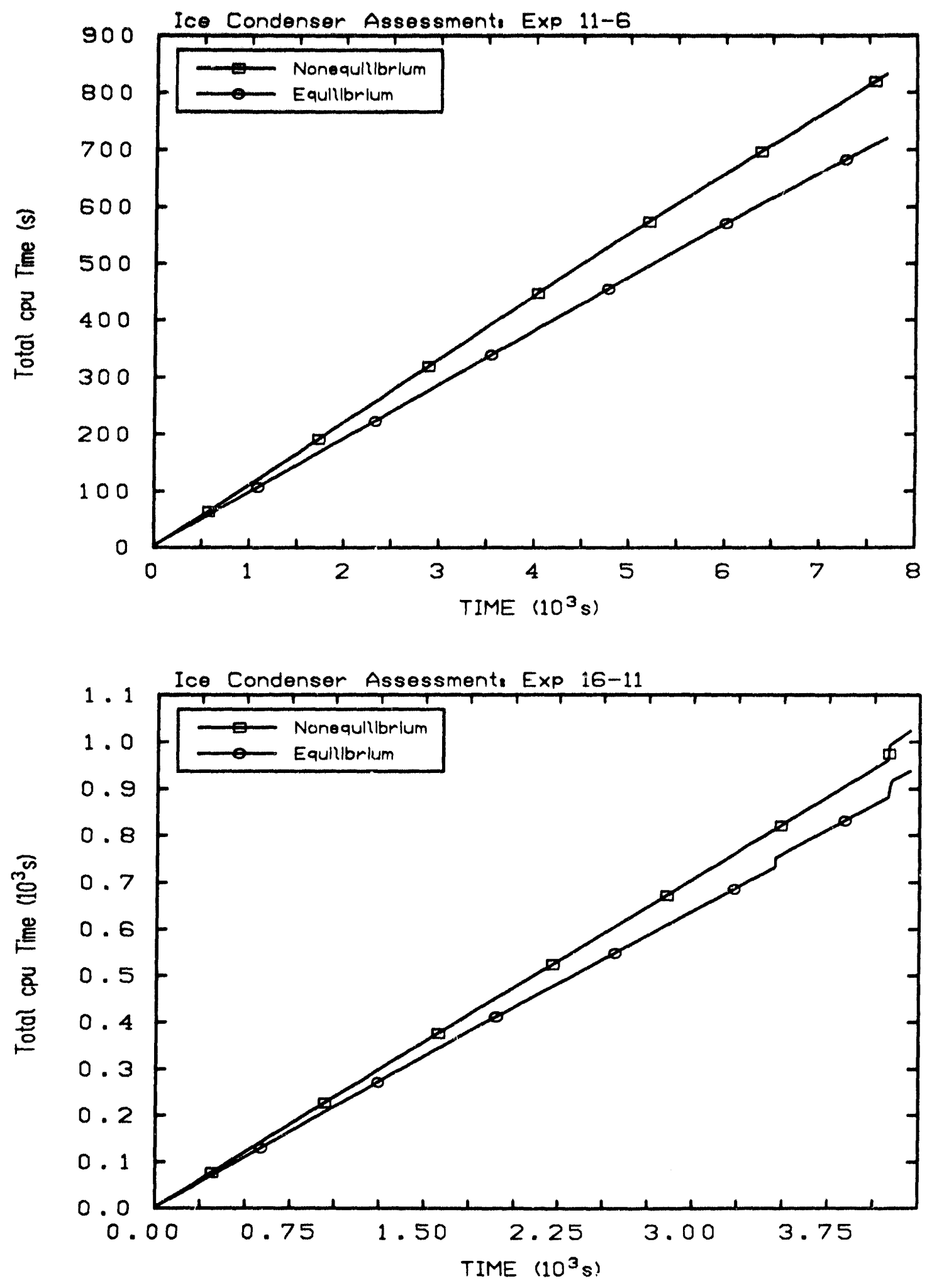

Figure 7.2.6 Computer Processor Time for Experiment 11-6 (top) and Experiment 16-11 (bottom). Equilibrium/Nonequilibrium Sensitivity Study. 

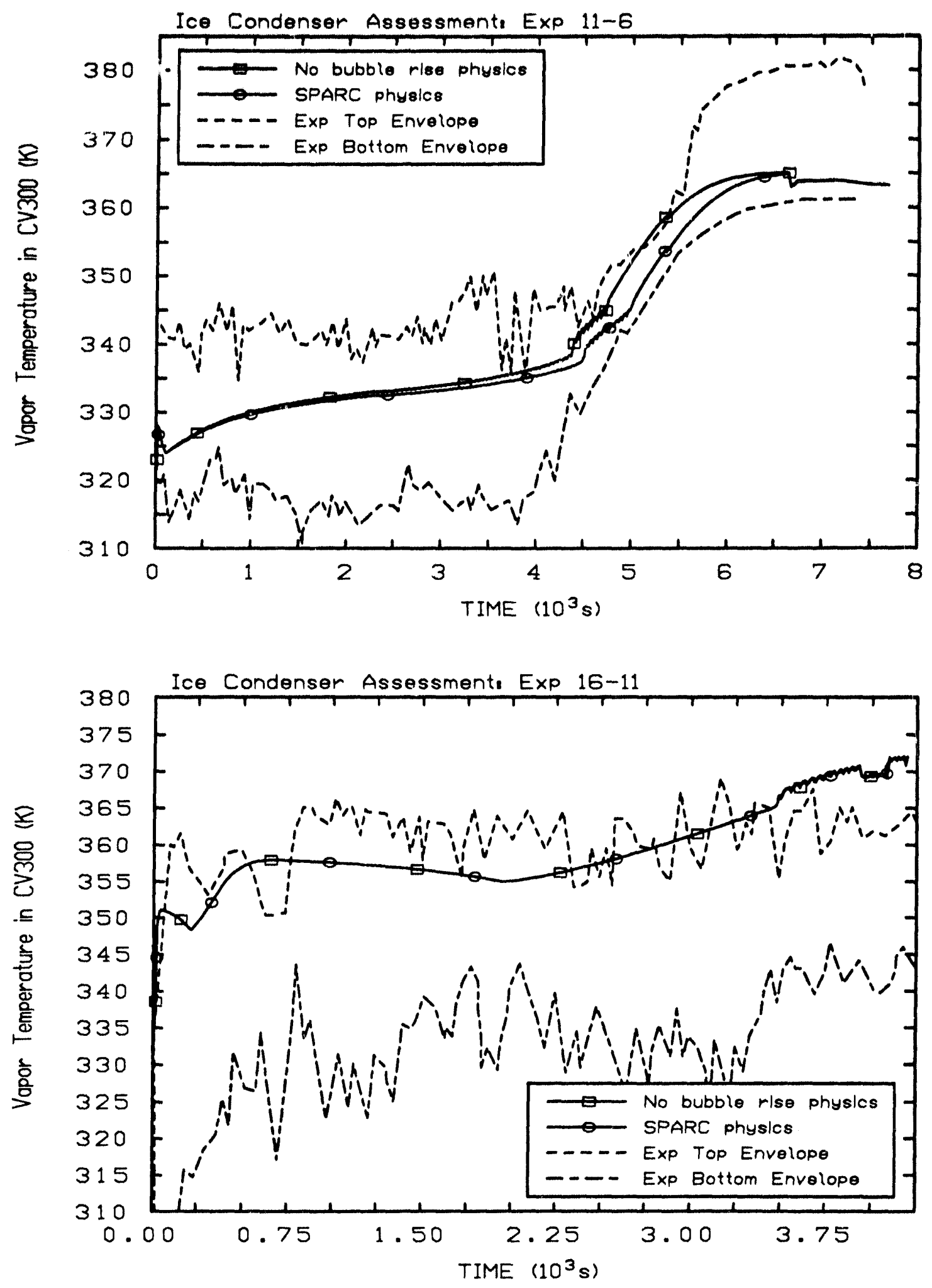

Figure 7.3.1 Vapor Temperature for $\mathrm{CV} 300$ or Experiment 11-6 (top) and Experiment 16-11 (bottom). SPARC Physics Sensitivity Study. 

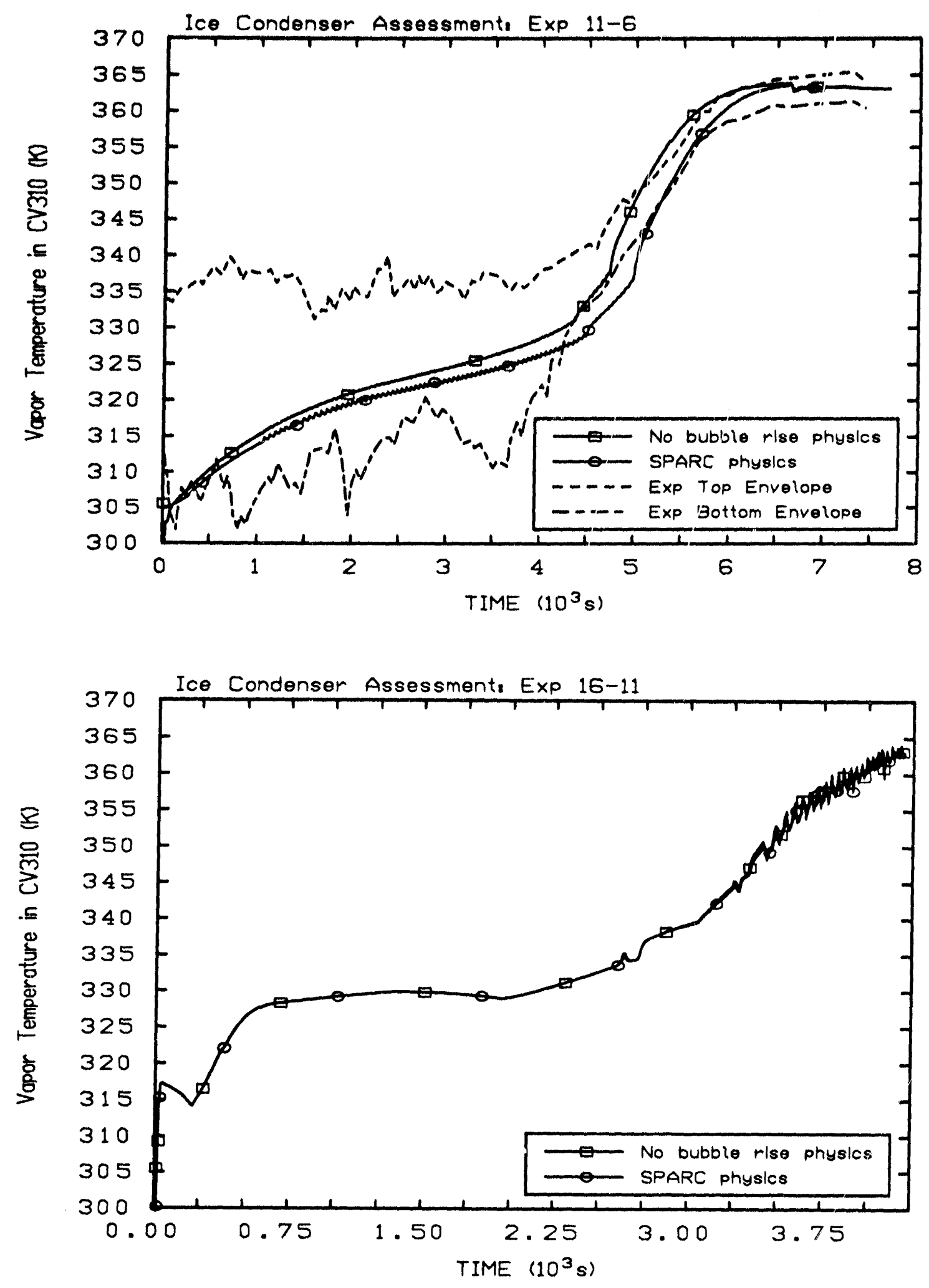

Figure 7.3.2 Vapor Temperature for CV310 for Experiment 11-6 (top) and Experiment 16-11 (bottom). SPARC Physics Sensitivity Study. 

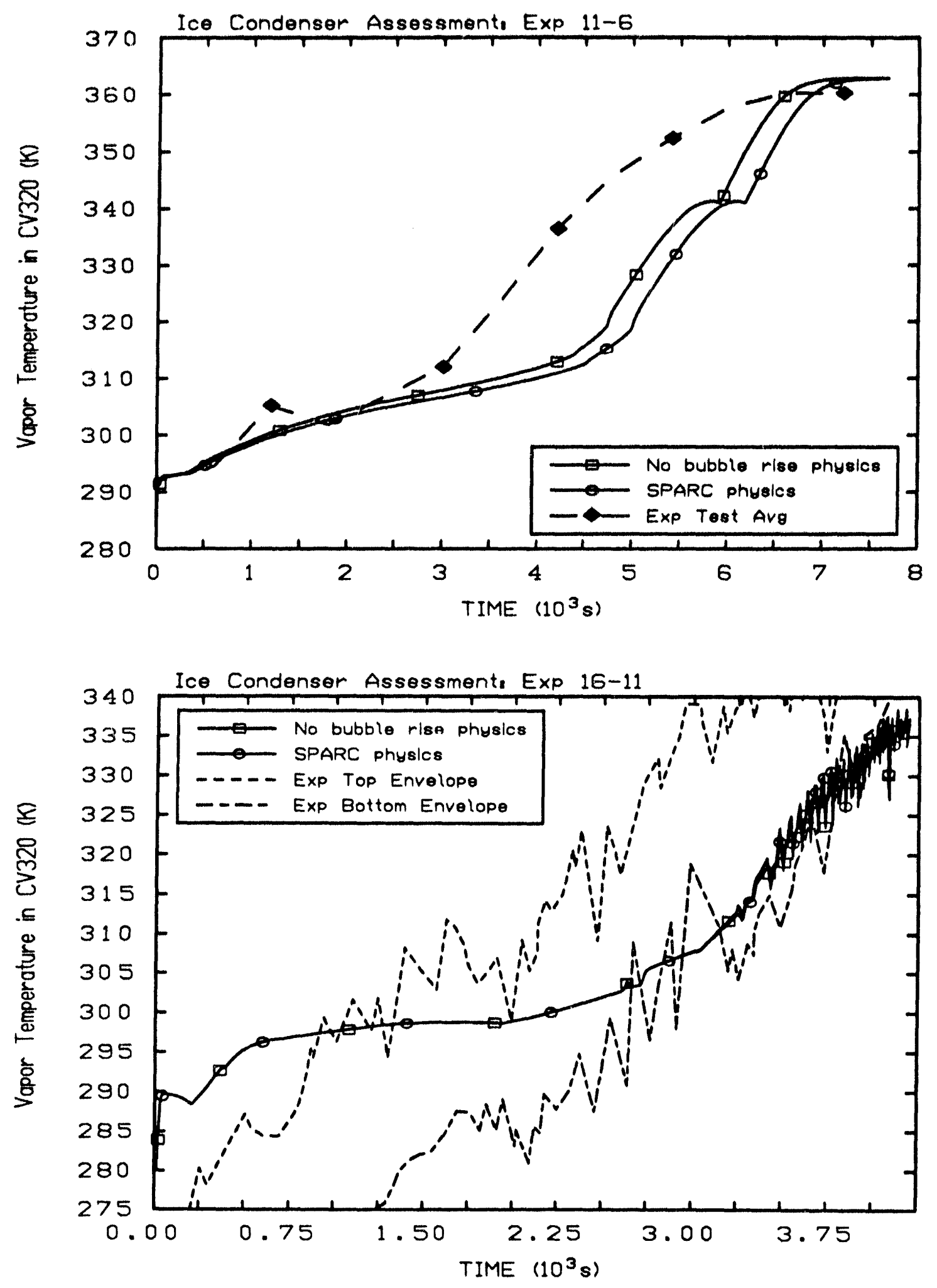

Figure 7.3.3 Vapor Temperature for CV320 for Experiment 11-6 (top) and Experiment 16-11 (bottom). SPARC Physics Sensitivity Study. 

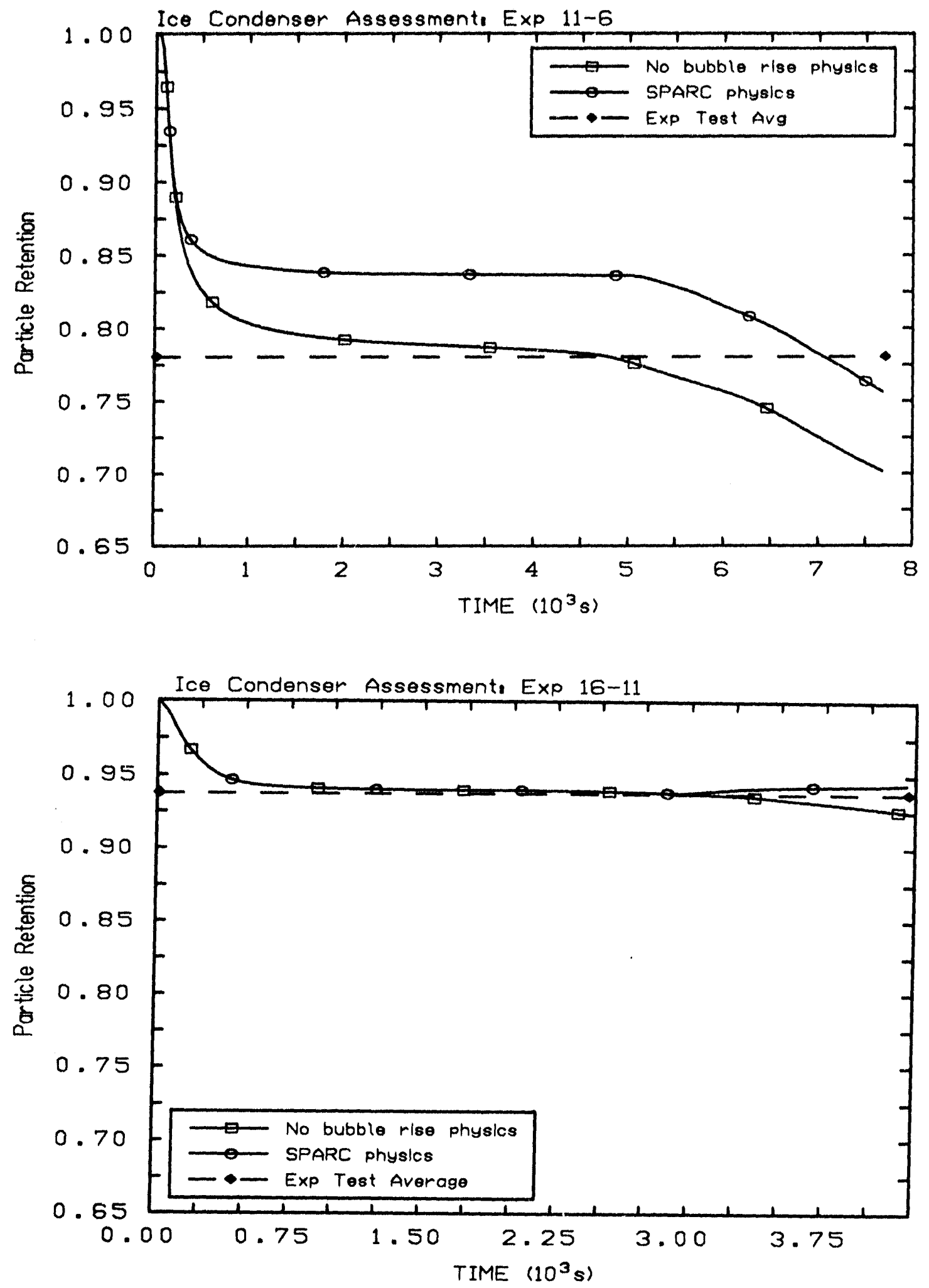

Figure 7.3.4 Particle Retention for Experiment 11-6 (top) and Experiment 16-11 (bottom). SPARC Physics Sensitivity Study. 
actually rise slightly. Figure 7.3 .5 shows that the addition of the SPARC physics model added a small, but noticeable amount of cpu time to the problem simulation for both experiments.

It should be pointed out that, although in the experiments there was probably fog and certainly liquid water present in regions of the ice condenser, it did not congregate in a liquid pool at the bottom of "control volumes" as assumed by MELCOR. Although one can certainly obtain different results, as demonstrated here, by activating the SPARC physics, for ice condenser control volumes it is not recommended. We maintain that the reference calculation without SPARC physics is the more accurate and more appropriate result. 

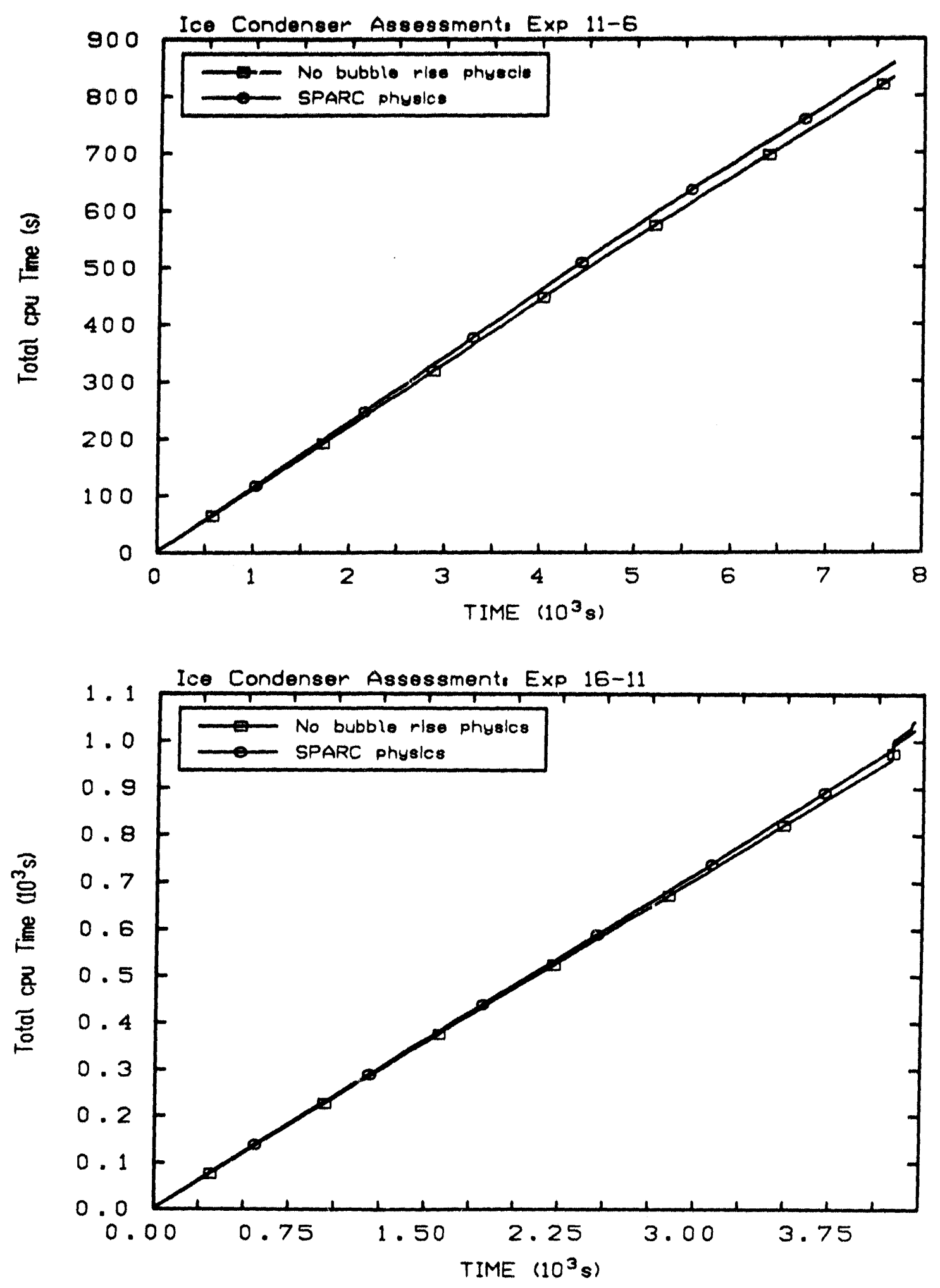

Figure 7.3.5 Computer Processor Time for Experiment 11-6 (top) and Experiment 16-11 (bottom). SPARC Physics Sensitivity Study. 


\section{Ice Condenser Sensitivity Studies}

Since the ice condenser model was new, emphasis was placed on conducting several studies on the importance of several of the ice condenser parameters. For the ice condenser input, two parameters -- the temperature range of melting, and the effective heat of reaction -- were varied to determine their importance. An adjustable heat transter coefficient also exists in the ice condenser model to account for details lacking in the modeling. In [8], a value of 1.2 was used, but CONTAIN used a value of 5.0. A sensitivity study was conducted on this parameter. Third, a characteristic length for the ice condenser heat structure was not well-known. This parameter was also varied in a study. Also, most of the heat structures in the critical ice condenser region were very thin, usually $9 \mathrm{~mm}$ and the reference study was conducted using only two nodes for these structures. To determine the effect of heat structure nodalization, an additional calculation was performed in which ten nodes were placed in all of the heat structures. Finally, another study was performed in which the inclusion of radiation heat transfer to and from the structures on aerosol results was examined.

\subsection{Energy Capacity and Temperature Range of the Ice}

The total energy capacity of the ice and the temperature range over which melting is allowed are coupled in the present ice condenser model. In [8], the temperature range used was 274-373 K, and this was one of the ranges used in this sensitivity study. However, especially for Experiment 11-6, this produced temperatures in the ice condenser that were too high. Also, the study in [8] assumed one control volume for the ice condenser rather than the three used in this study. The reason the large temperature range was used in [8] was that, as the melted water runs down the control volume, its temperature is increasing to the boiling point, and this energy must be accounted for in the ice condenser model. For the three control volume model, then, it appeared reasonable to divide the temperature range by three. Thus, another run in this sensitivity study used a range of $274-307 \mathrm{~K}$ to account for the latent heat of melting of the water as it traveled from the upper ice condenser control volume to the bottom. However, it was obvious from the results of [7] that the ice in Experiment 11-6 completely melted in the 4000-5000 second time span, and the 274-307 $\mathrm{K}$ temperature range allowed the ice to melt too slowly. The temperature range of $274-284 \mathrm{~K}$ was chosen for the reference calculation because it gave the most consistent agreement with the particle retention, temperature, and ice condenser melt data.

The results of this study are presented in Figures 8.1.1 to 8.1.6. Figures 8.1.1 to 8.1.3 display the resulting temperatures in the three ice condenser control volumes for both experiments. The results predicting Experiment 11-6 were more sensitive to the allowed temperature range and energy capacity of the ice than were those predicting Experiment 16-11, probably because Experiment 11-6 started out with only about half the ice as Experiment 16-11. For Experiment 11-6, using the 274-373 $\mathrm{K}$ temperature range resulted in higher temperatures that gave poorer agreement with data than the reference calculation. 

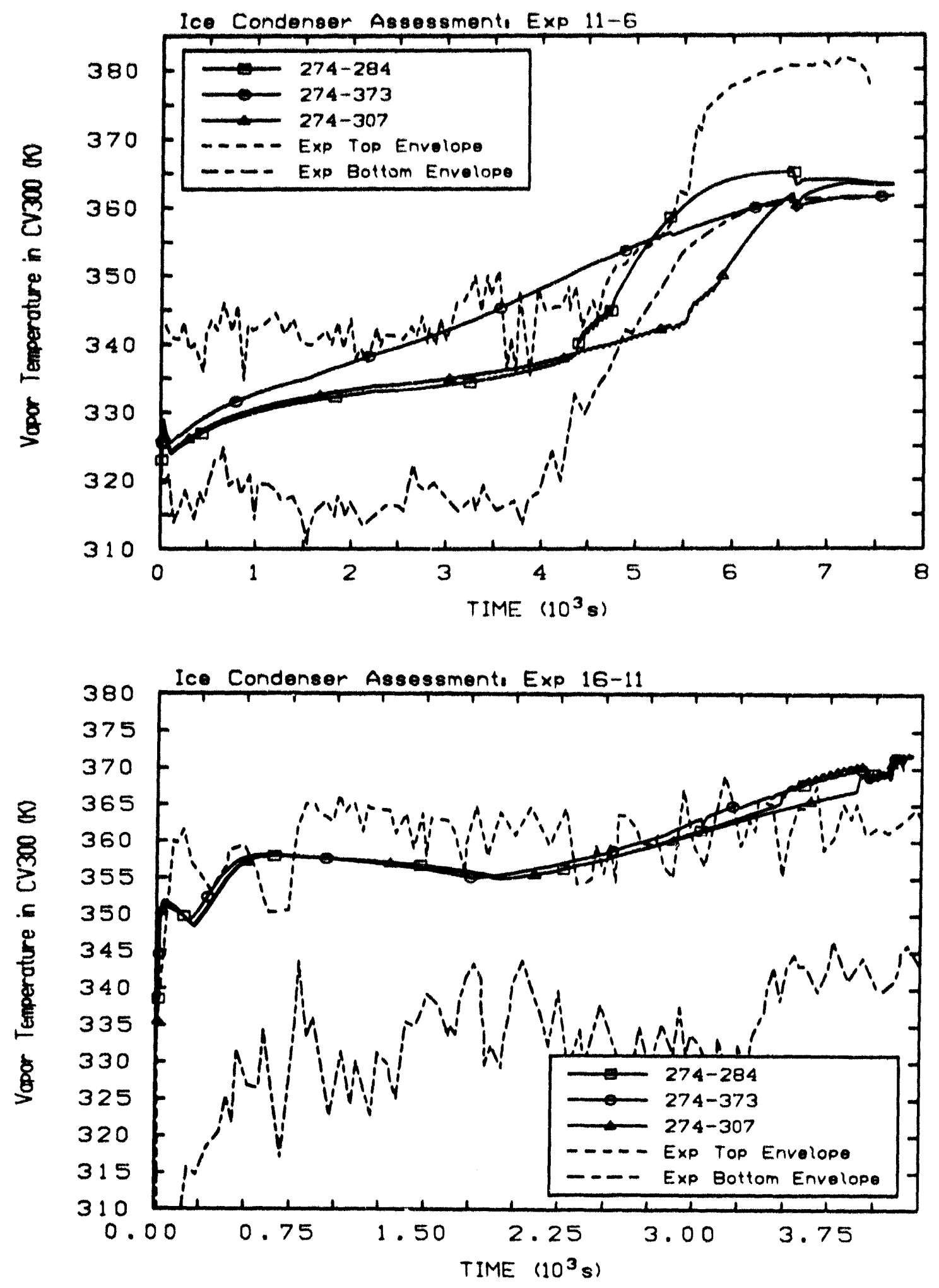

Figure 8.1.1 Vapor Temperature for CV300 for Experiment 11-6 (top) and Experiment 16-11 (bottom). Energy Capacity of Ice Sensitivity Study. 

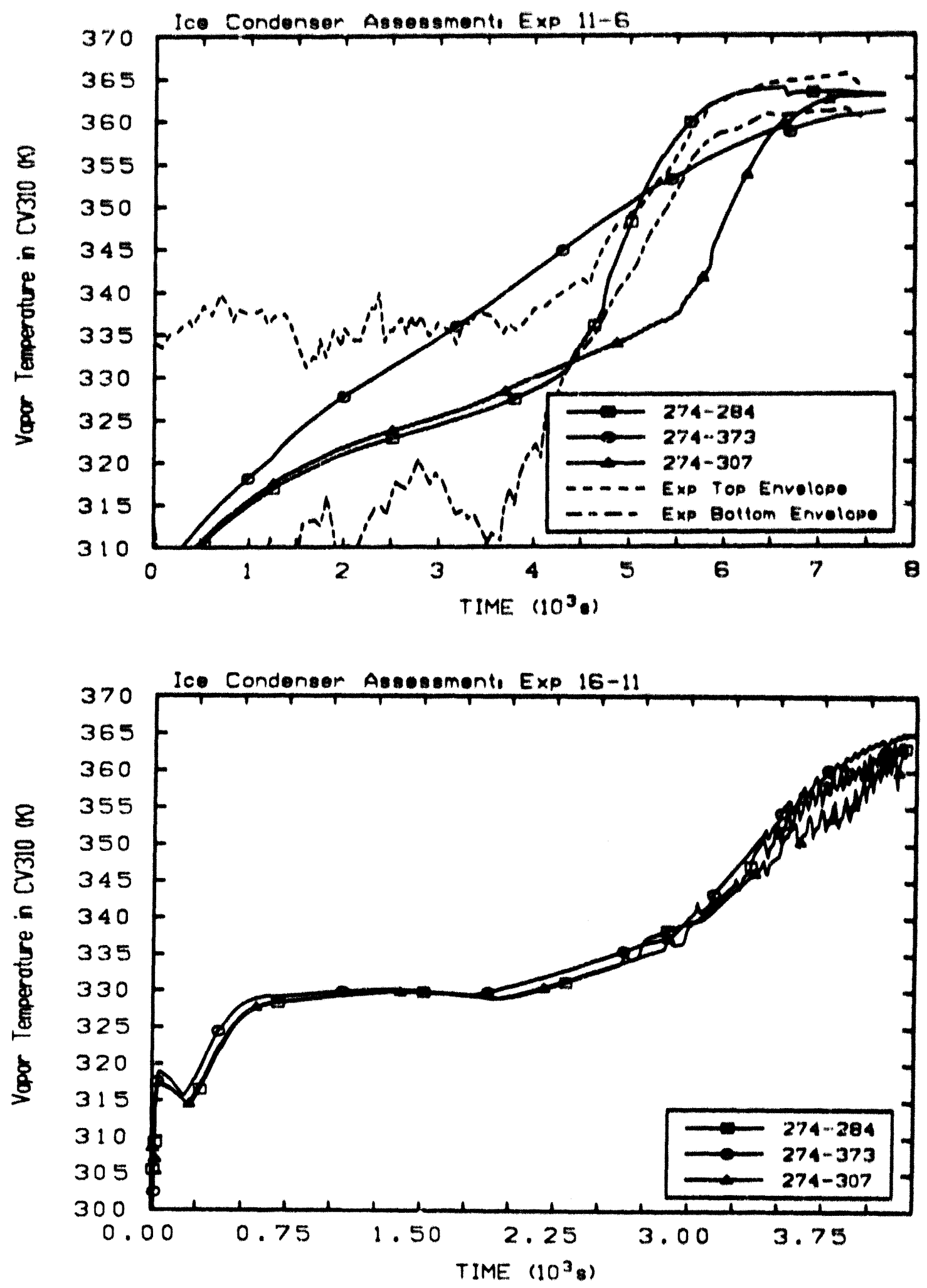

Figure 8.1.2 Vapor Temperature for CV310 for Experiment 11.6 (top) and Experiment 16-11 (bottom). Energy Capacity of lce Sensitivity Study. 

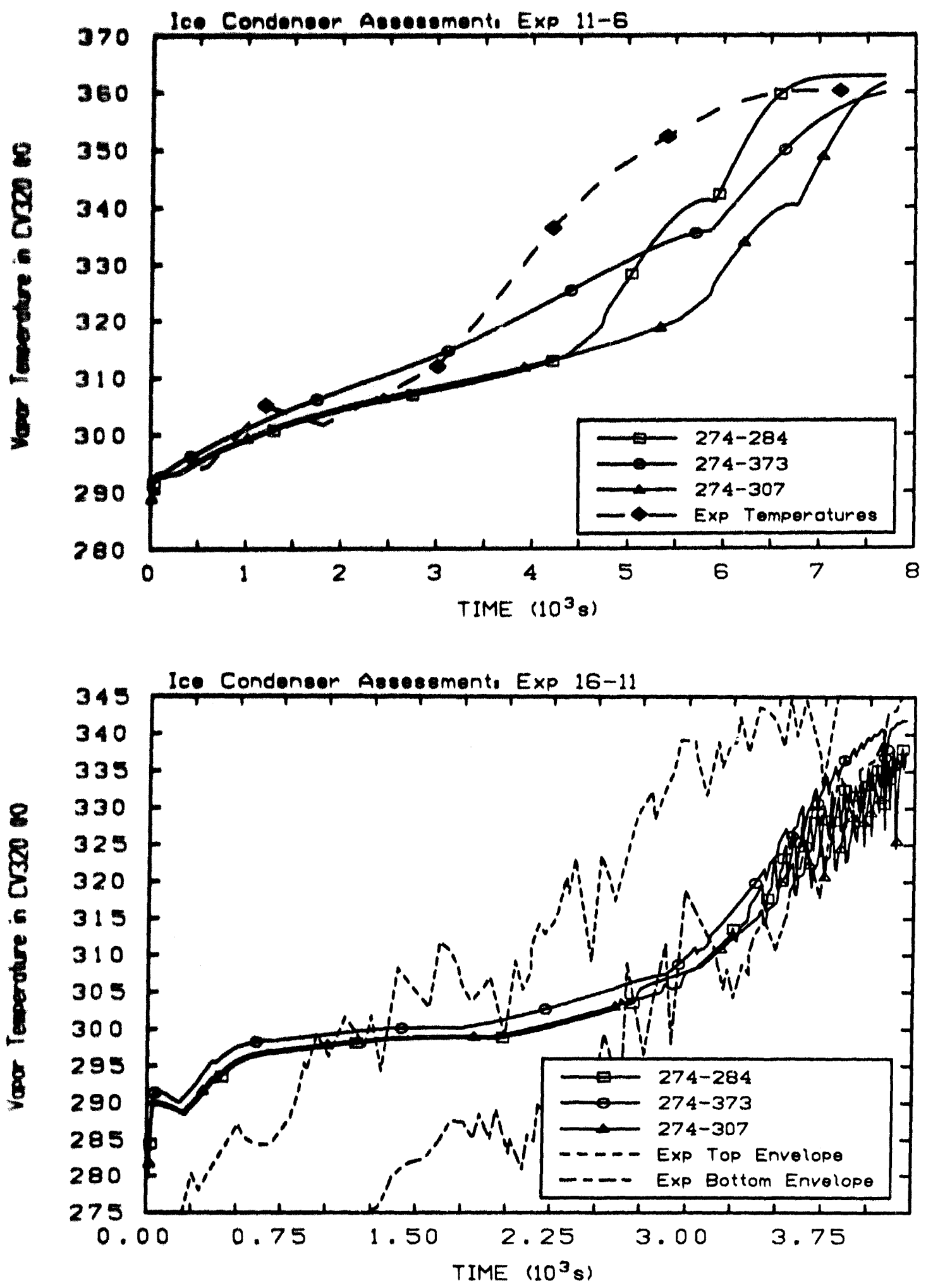

Figure 8.1.3 Vapor Temperature for CV320 Experiment 11-6 (top) and Experiment 16-11 (bottom). Energy Capacity of Ice Sensitivity Study. 

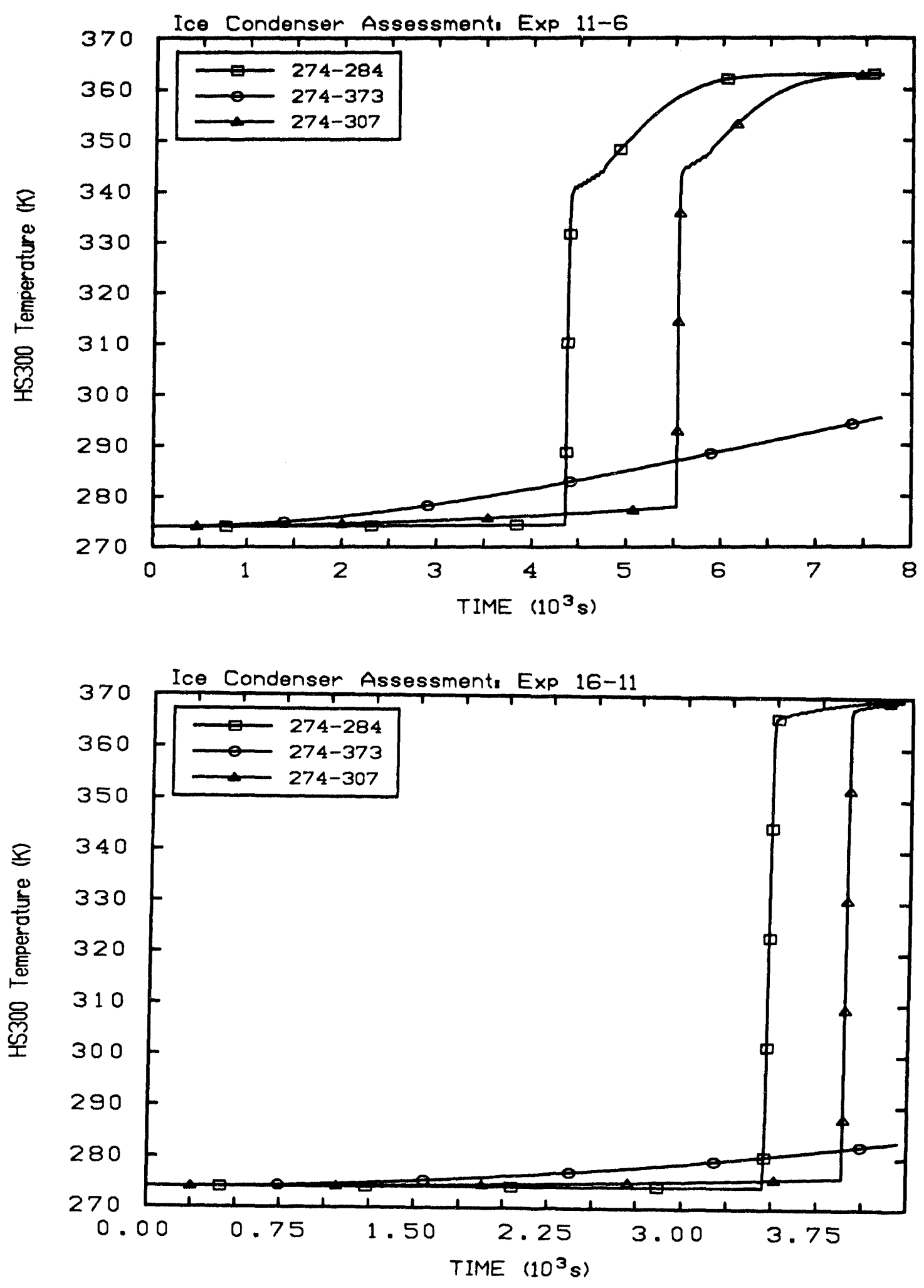

Figure 8.1.4 Temperature of HS300 for Experiment 11-6 (top) and Experiment 16-11 (bottom). Energy Capacity of lce Sensitivity Study. 

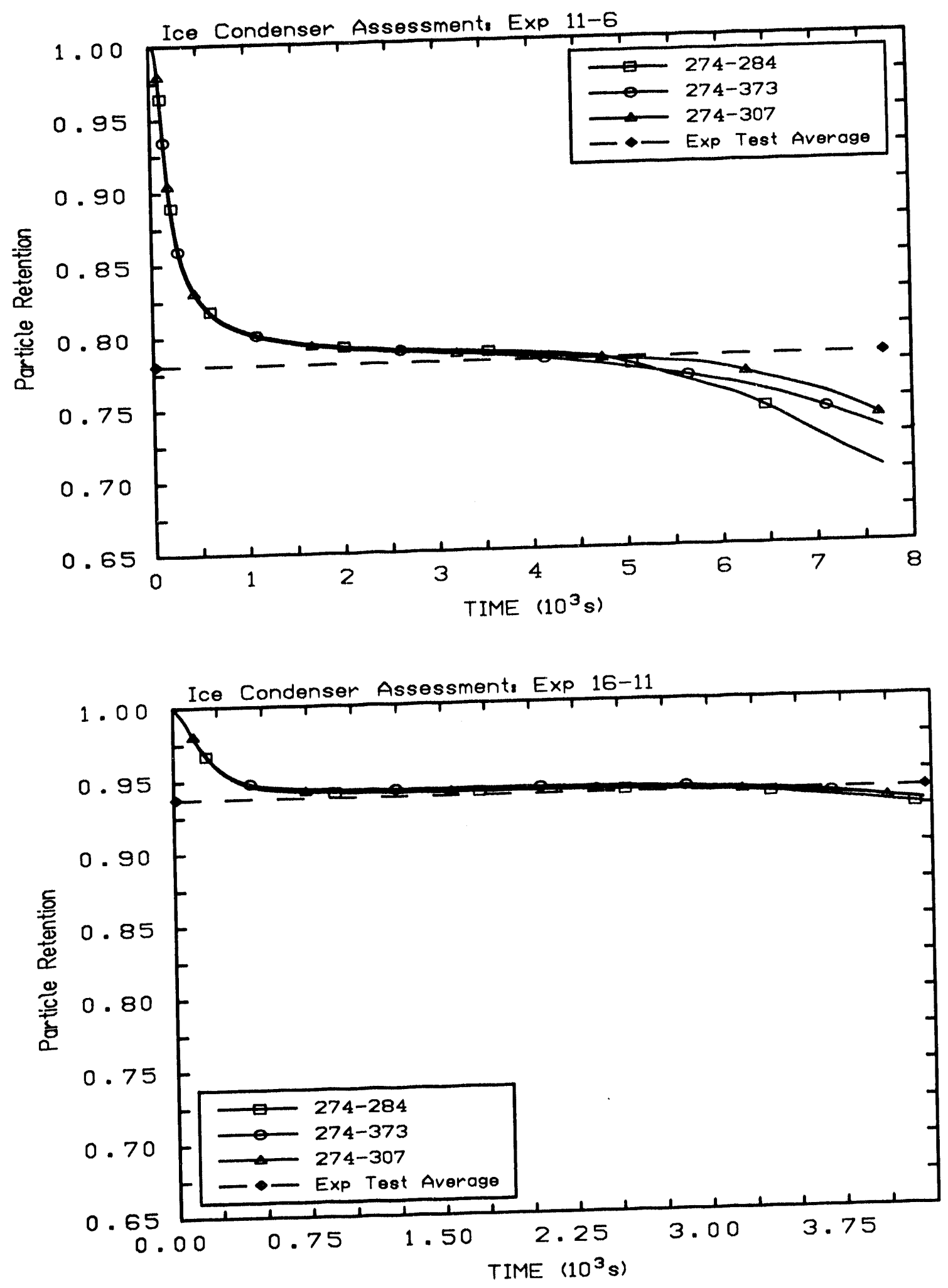

Figure 8.1.5 Particle Retention for Experiment 11-6 (top) and Experiment 16-11 (bottom). Energy Capacity of Ice Sensitivity Study. 

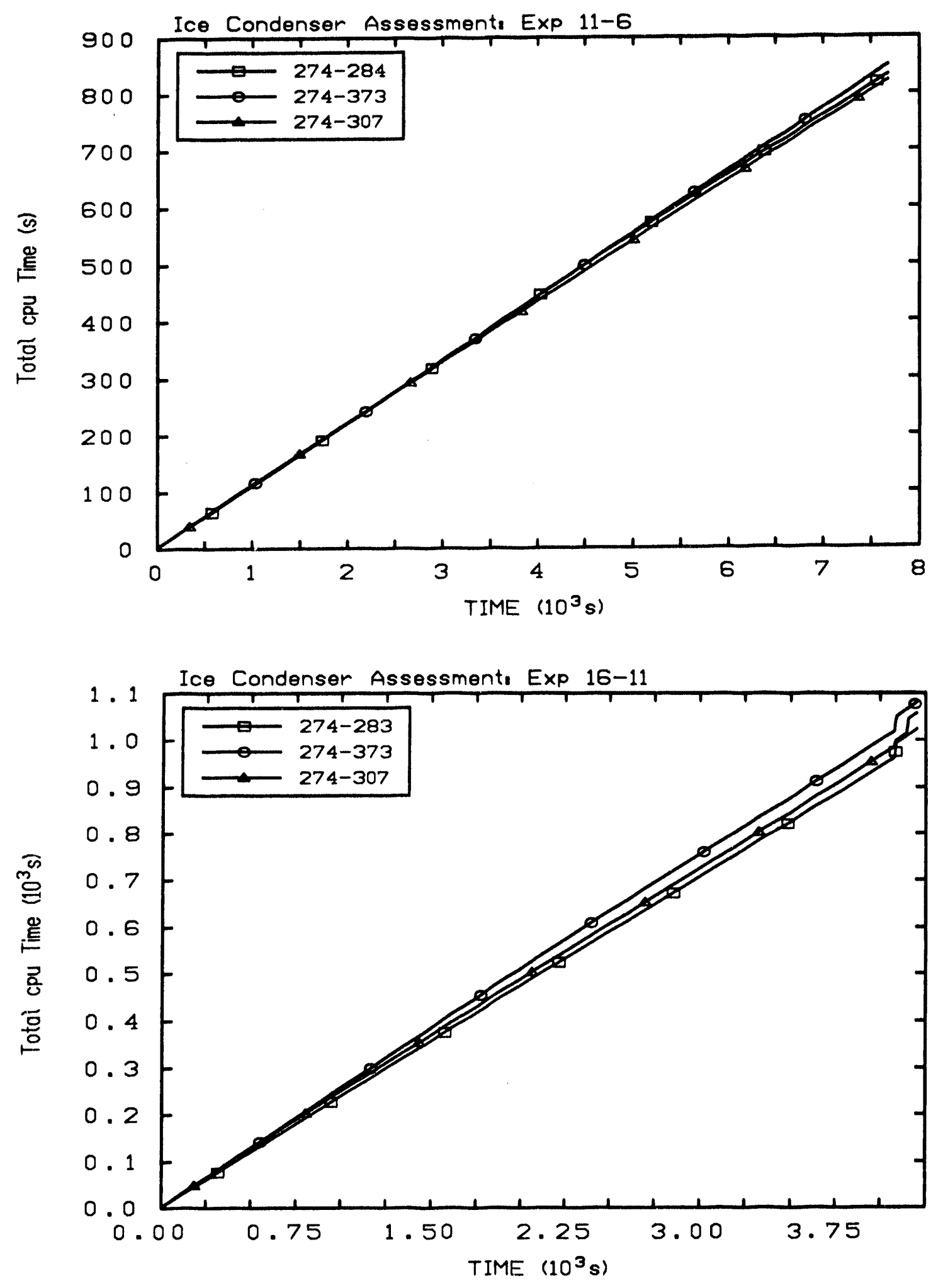

Figure 8.1.6 Computer Processor Time for Experiment 11-6 (top) and Experiment 16-11 (bottom). Energy Capacity of Ice Sensitivity Study. 
Temperatures in the results for Experiment 16-11 were relatively insensitive to ice energy capacity.

Figure 8.1.4 displays heat structure temperatures. The time at which ice disappeared from a control volume was clearly indicated by the jumps in temperature. For Experiment 11-6, ice clearly disappeared between 4000-5000 seconds using the 274-284 temperature range, while the 274-307 $\mathrm{K}$ temperature range had the ice disappearing between 5500-6000 seconds. The experimental temperature curves clearly indicated that this was too late. For both experimental cases, a choice of $274-373 \mathrm{~K}$ for the temperature range resulted in a calculation for which the ice never completely melted.

Figure 8.1.5 displays the particle retention. The aerosol results exhibited small variations from reference values in this study, but they were not significant. Finally, Figure 8.1.6 displays the cpu time required for each run. Again, the choice of ice energy capacity did not affect run time significantly.

\subsection{Ice Heat Transfer Coefficient Multiplier}

In [8], a value of 1.2 was used for the ice heat transfer coefficient multiplier, while CONTAIN calculations used a value of 5.0. (To this author's knowledge, the mathematical model for the ice condenser is the same in MELCOR and CONTAIN and thus the coefficient multiplier for the two codes performs the same function.) For the Experiment 16-11 reference calculation (See Section 3), the recommended value of 1.2 was used. However, as discussed earlier, this proved unsatisfactory for the Experiment 11-6, and values in the 1.8-3.8 range were used. This was one of three differences in the input decks for simulation of the two experiments. Another was different initial and boundary conditions (an obvious necessity). The third was the inclusion of the recirculation phenomenon in the Experiment 11-6 input.

For Experiment 16-11, this sensitivity study used the reference value of 1.2 , the CONTAIN value of 5.0, and the intermediate value of 3.1 to determine the significance of the heat transfer coefficient multiplier. For Experiment 11-6, the reference value of multiplier averaged 2.8, so the sensitivity study for this experiment used the lower value of 1.2 and the upper value of 5.0 as the sensitivity range.

Figure 8.2.1 to 8.2.3 shows the variation in temperatures in the ice condensers for both experiments. Not surprisingly, a larger multiplier lowered the temperatures, but increased the melting rate, as shown in Figure 8.2.4. Although the variation in the multiplier varied temperatures, its most significant effect was on the melt rate of the ice and the resulting point at which the slope in the temperature curves changed. For Experiment 11-6 in Figure 8.2.4, a multiplier value of 5.0 melted the ice about 1600 seconds earlier than the reference case, causing a corresponding jump in vapor temperature at an inappropriate time (See Figure 8.2.1). Because the multiplier affected temperatures in the ice condenser, particle retention was also affected, as Figure 8.2 .5 shows, but the effect was 

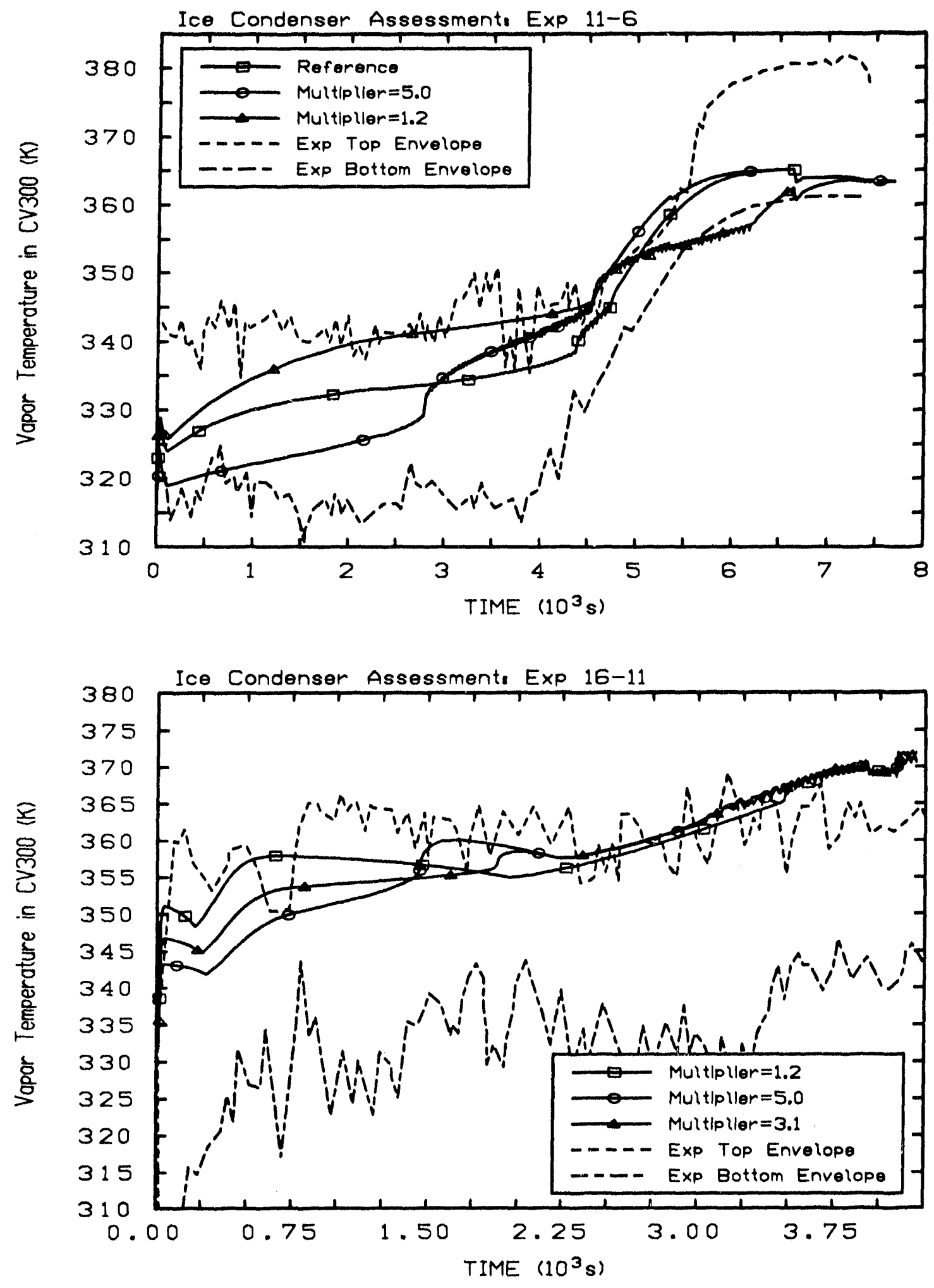

Figure 8.2.1 Vapor Temperature in CV300 for Experiment 11-6 (top) and Experiment 16-11 (bottom). Ice Heat Transfer Coefficient Multiplier Sensitivity Study. 

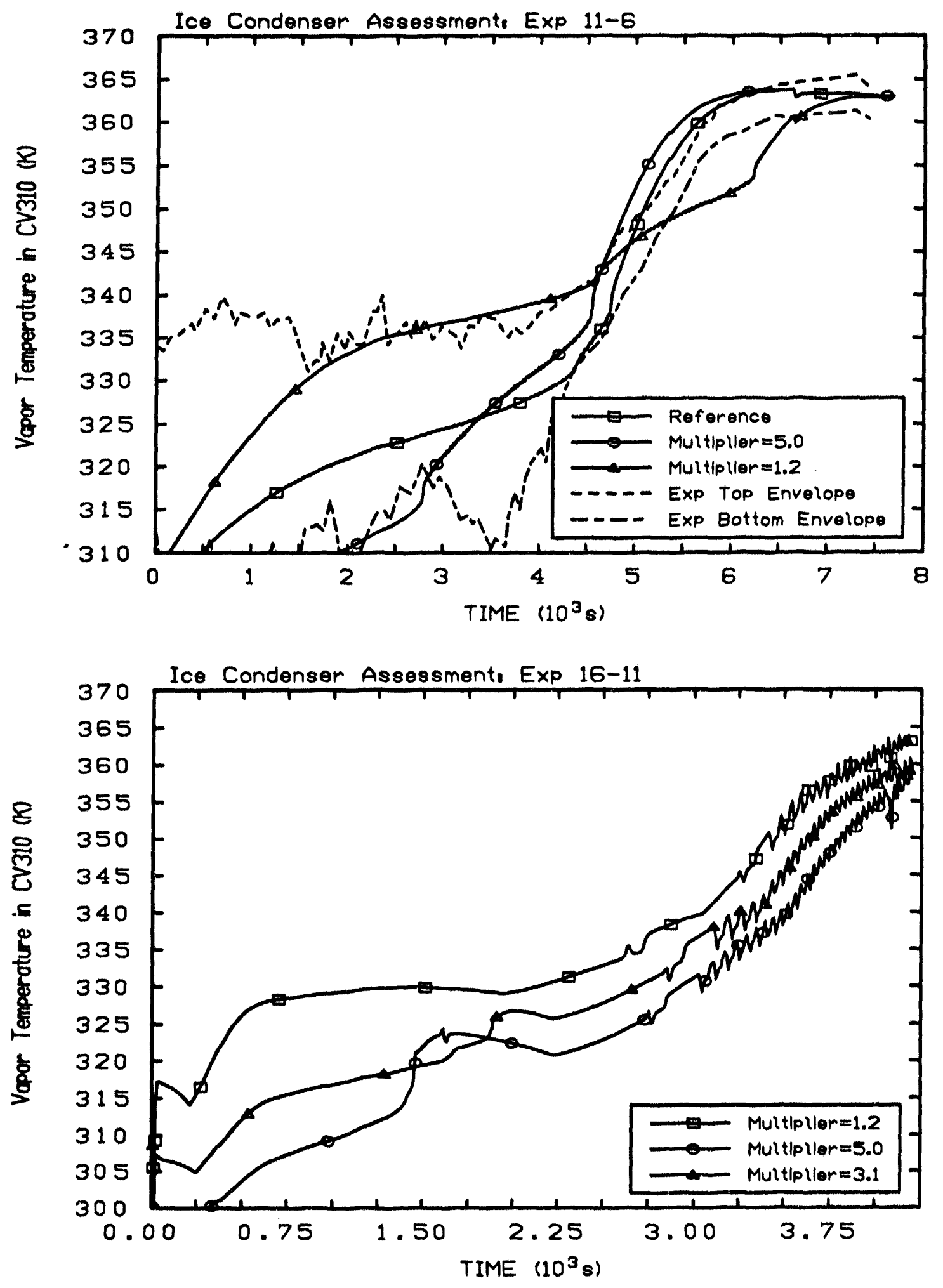

Figure 8.2.2 Vapor Temperature in CV310 for Experiment 11-6 (top) and Experiment 16-11(bottom). Ice Heat Transfer Coefficient Multiplier Sensitivity Study. 

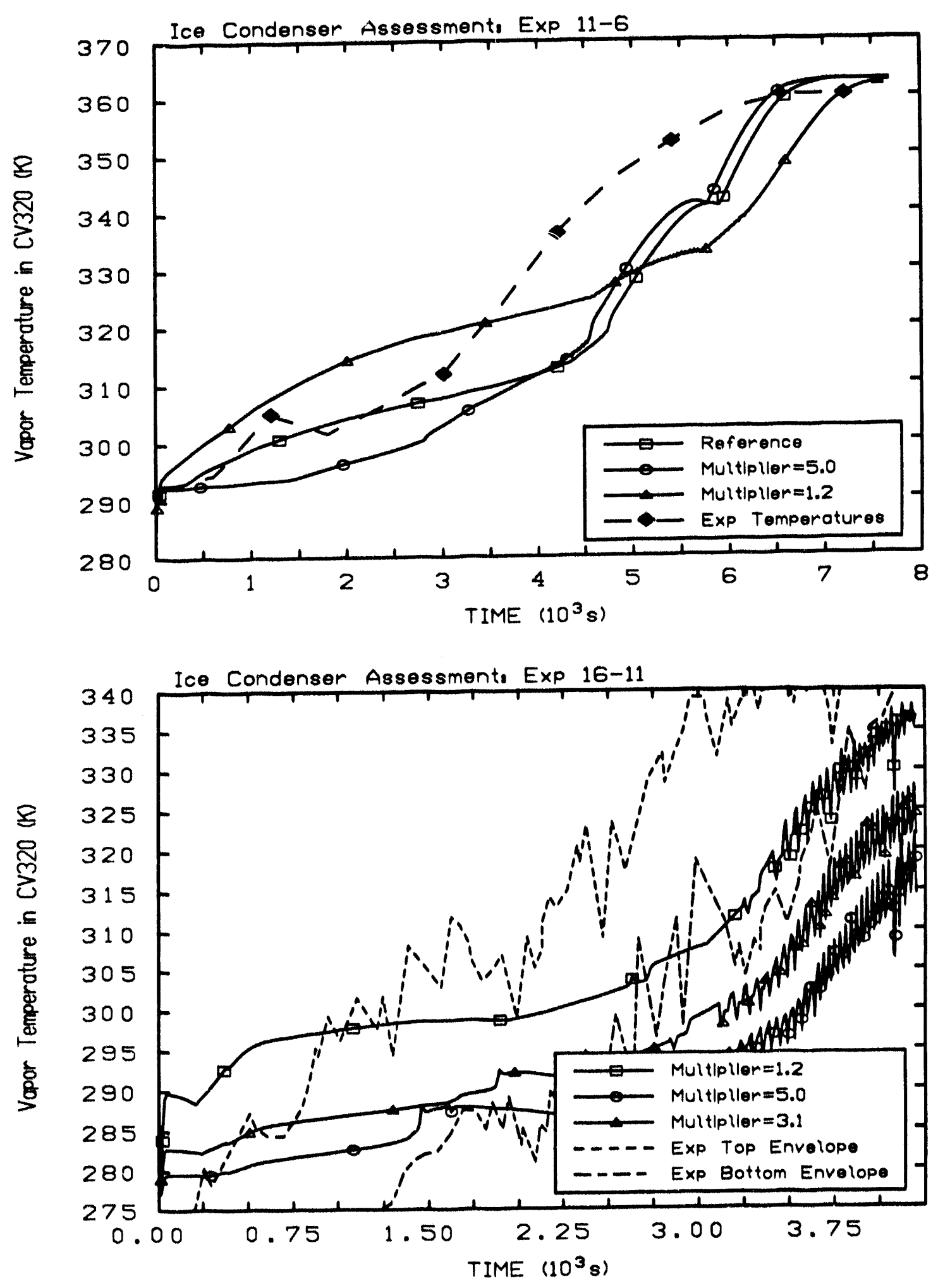

Figure 8.2.3 Vapor Temperature in CV320 for Experiment 11-6 (top) and Experiment 16-11(bottom). Ice Heat Transfer Coefficient Multiplier Sensitivity Study. 

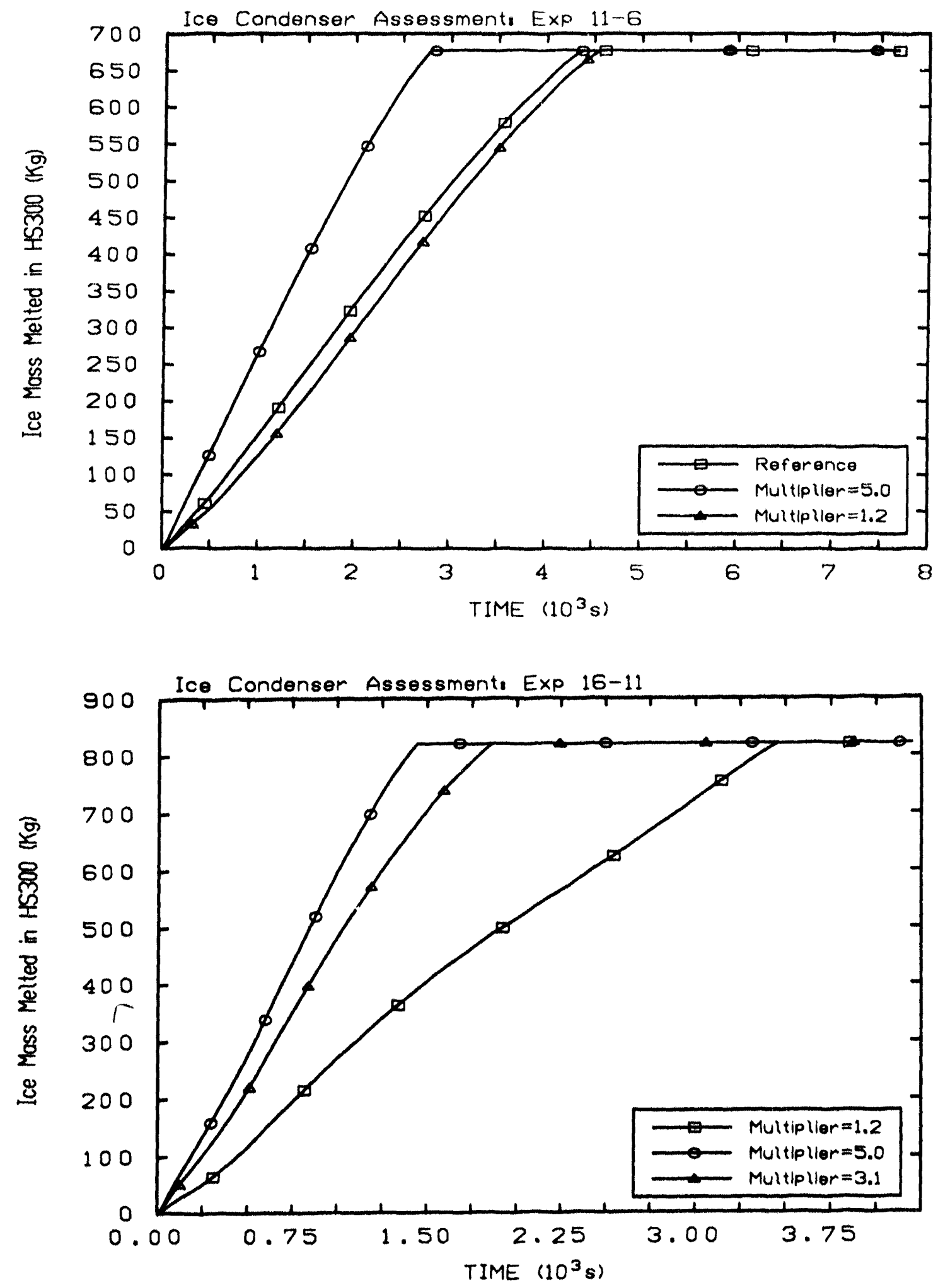

Figure 8.2.4 Mass of lce Melted in CV300 for Experiment 11.6 (top) and Experiment 16-11 (bottom). Ice Heat Transfer Coefficient Multiplier Sensitivity Study. 

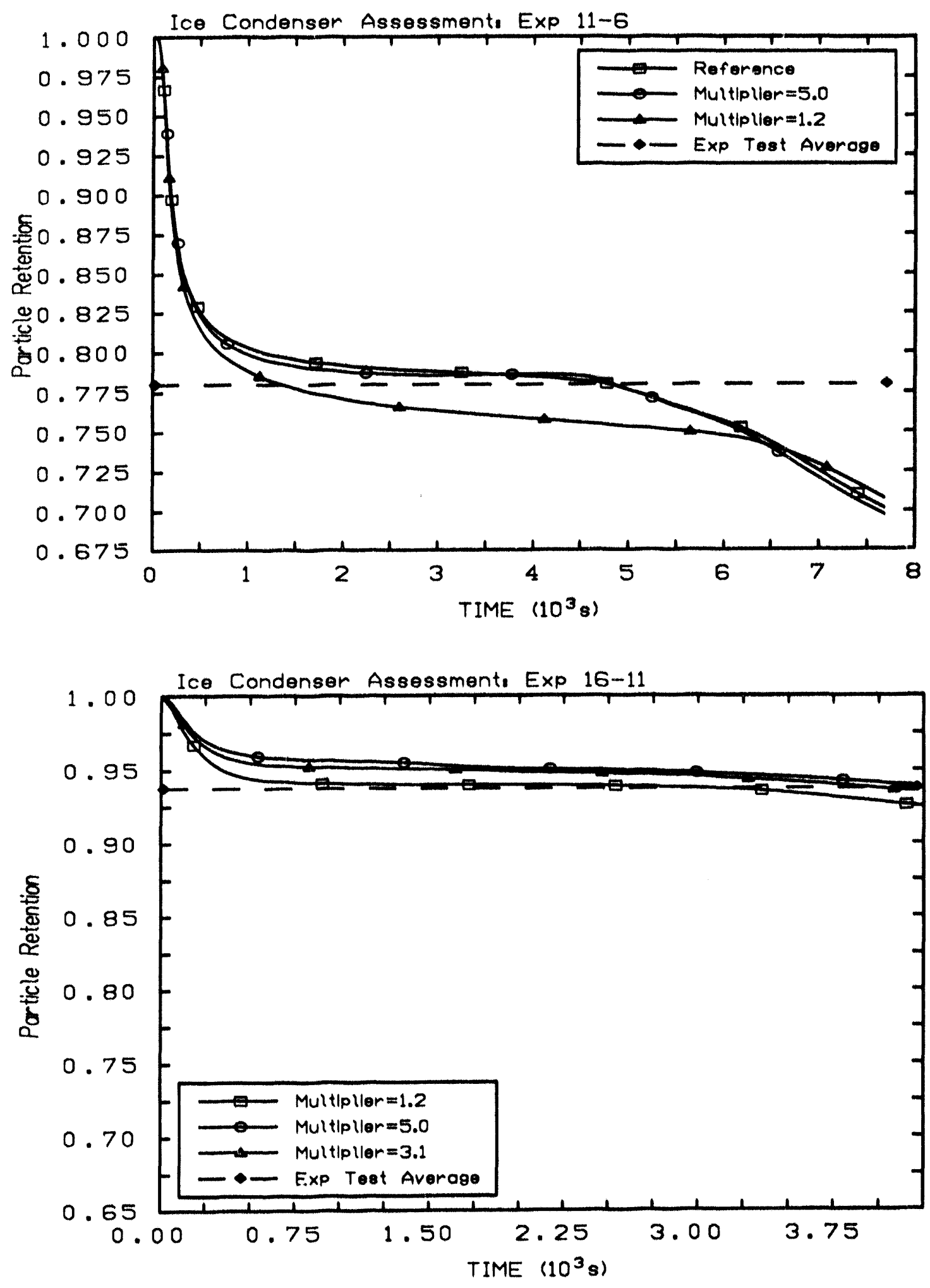

Figure 8.2.5 Particle Retention for Experiment 11-6 (top) and Experiment 16-11 (bottom). Ice Heat Transfer Coefficient Multiplier Sensitivity Study. 
small and predictable. The smaller multiplier resulted in higher temperatures and thus a lower particle retention. A higher multiplier in early time resulted in lower temperatures and higher particle retention. For Experiment 11-6, in the last 1000 seconds a multiplier value of 1.2 allowed the condenser to actually still retain some ice while the other two studies at this point had all ice melted. Thus, at this time, the multiplier $=1.2$ case actually had a higher particle retention.

The ice heat transfer coefficient multiplier did not significantly affect cpu time, as shown in Figure 8.2.6.

\subsection{Ice Heat Structure Characteristic Length}

The characteristic length of 0.032 meters for the ice condenser heat structures was representative of the diameter of a typical ice cube. However, there were large open spaces in the structure, there was considerable variation in ice cube size, and consequently there was uncertainty as to the correct value of the characteristic length. In this sensitivity study, the reference characteristic length for the three ice condenser heat structures was essentially halved and doubled (values of 0.015 and $0.060 \mathrm{~m}$ were actually used), and also increased and decreased by an order of magnitude.

Figures 8.3.1 to 8.3.3 show the resultant effect on the ice condenser temperatures for the two experiments. Figure 8.3.4 shows the temperature of the lower ice condenser region. It can be observed that the characteristic length was an important parameter in predicting the melt rate of the ice (from Figure 8.3.4, the point at which all ice melted is readily evident), which in turn significantly affected temperatures in that region. In this respect, the characteristic length parameter affected the results in a manner almost identical to that of the ice heat transfer coefficient multiplier. As Figure 8.3.5 shows, the effect on particle retention was again similar to the Multiplier Study result. Variation of a few percentage points was observed in the expected trend. Although not shown, the characteristic length did not significantly affect cpu time; all ine runs lie within $60 \mathrm{cpu}$ seconds of one another.

\subsection{Heat Structure Nodalization}

In this study, a case was run in which the number of nodes in all the heat structures was changed from two to ten. Figure 8.4.1 compares particle retention for this input variation to the reference case for both experiments. As seen in previous sensitivity studies, the variation affected the low flow case more than the high flow case. In both cases, early time behavior was unchanged. Figure 8.4.2 displays the reason for this behavior. At early time, ice mass melted for the two cases was identical. For Experiment 11-6, it wasn't until about 1000 seconds that the ice mass melt curves differed. For Experiment 16-11, particle retention never differed by more than one percentage point; for Experiment 11-6, the difference was about two and one-half percentage points. 

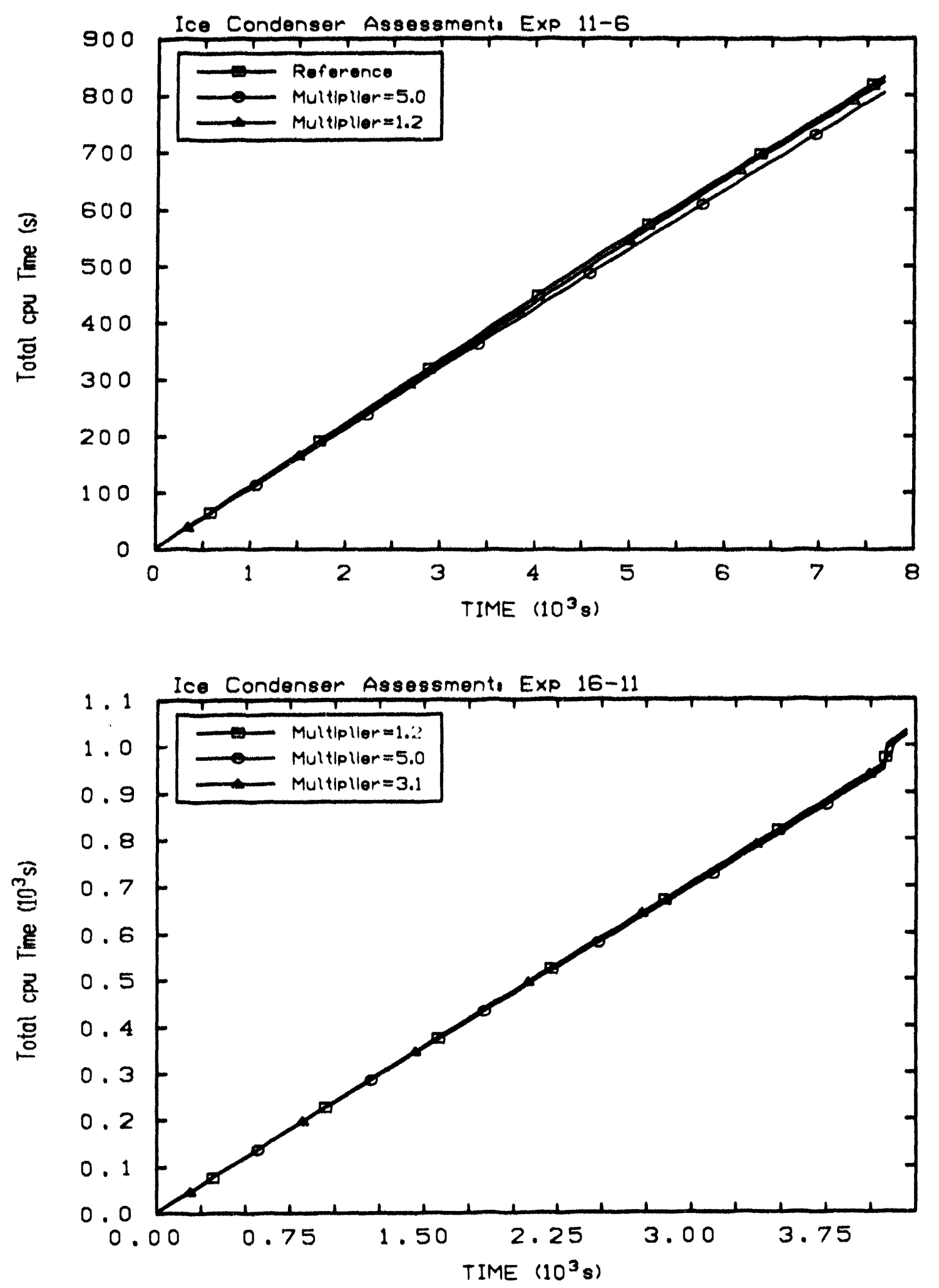

Figure 8.2.6 Computer Processor Time lor Experiment 11-6 (top) and Experiment 16-11 (bottom). Ice Heat Transfer Coefficient Multiplier Sensitivity Study. 

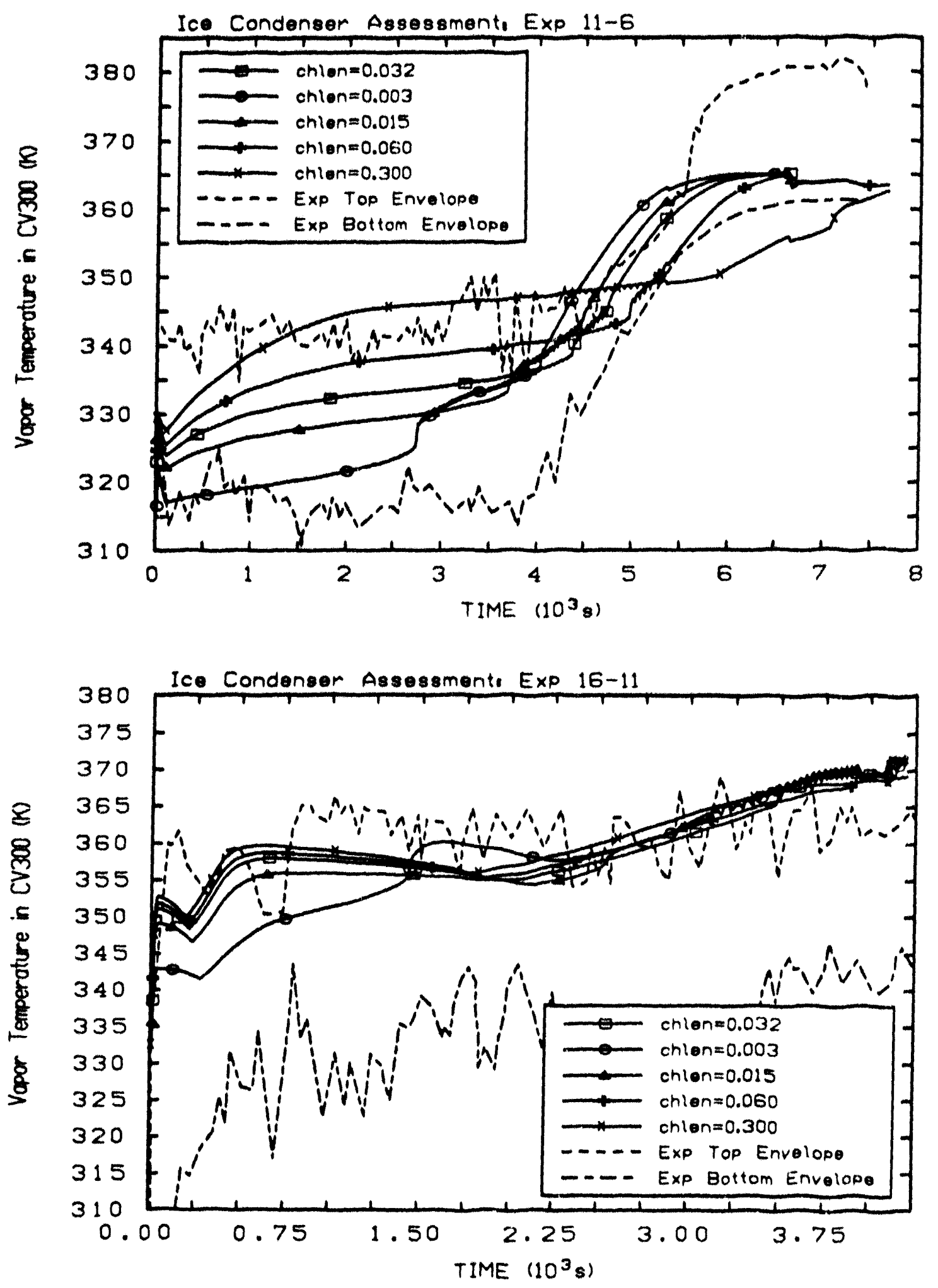

Figure 8.3.1 Vapor Temperature for CV300 or Experiment 11.6 (top) and Experiment 16.11 (bottom). Ice Heat Structure Characteristic Length Sensitivity Study. 

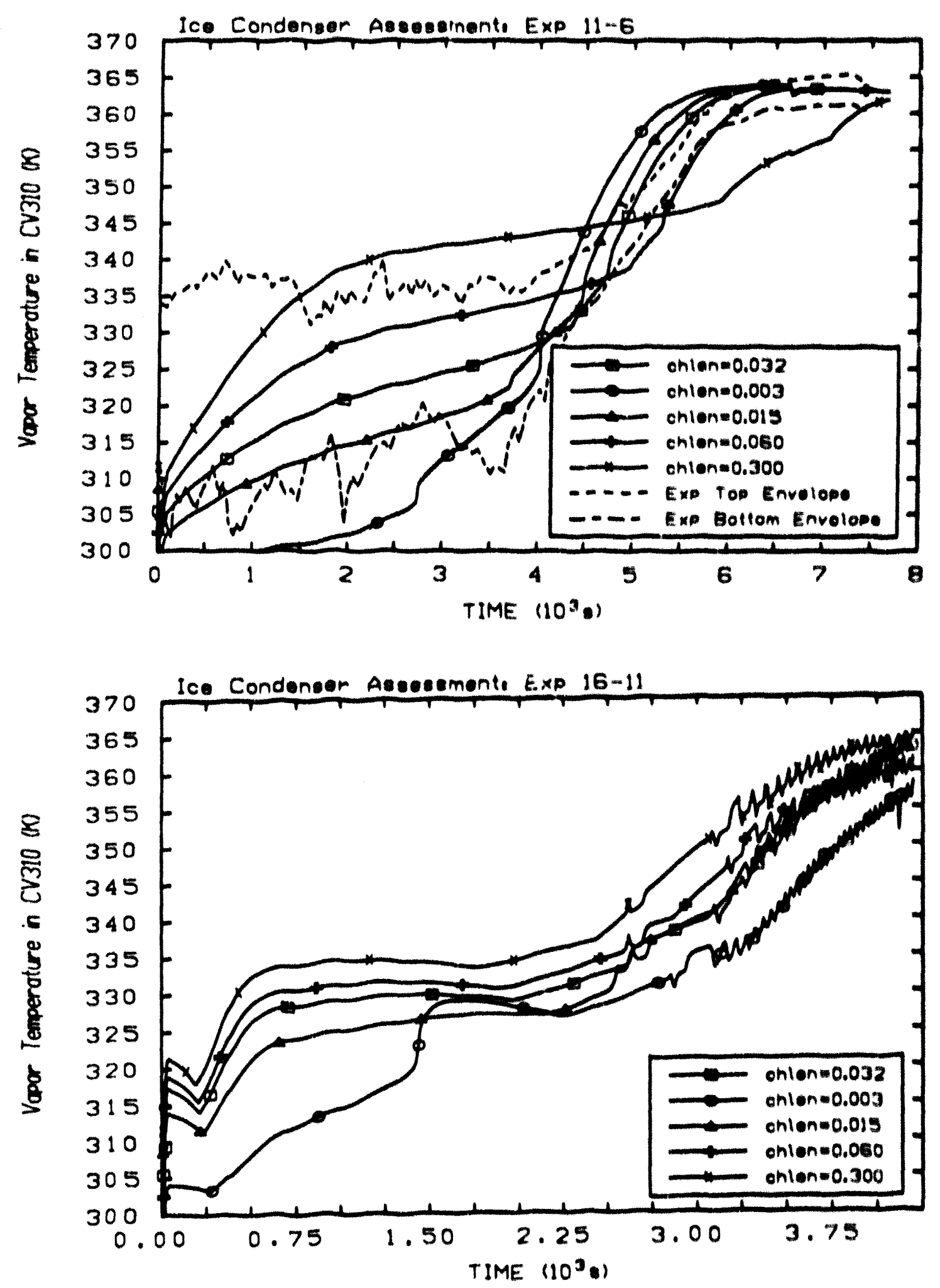

Figure 8.3.2 Vapor Temperature for CV310 tor Experiment 11.6 (top) and Experiment 16-11 (bottom). Ice Heat Structure Characteristic Length Sensitivily Study. 

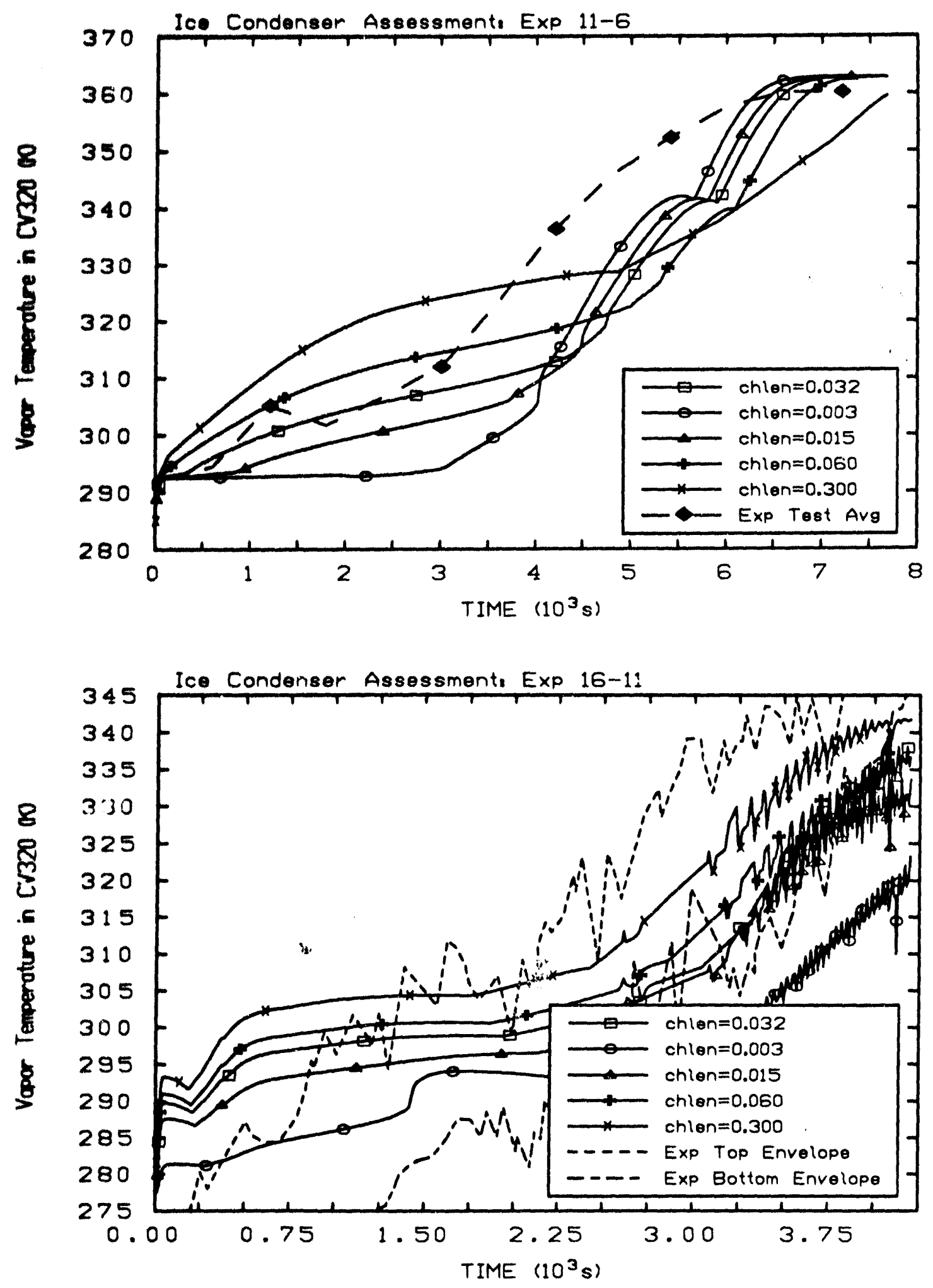

Figure 8.3.3 Vapor Temperature for CV320 for Experiment 11-6 (top) and Experiment 16-11 (bottom). Ice Heat Structure Characteristic Length Sensitivity Study. 

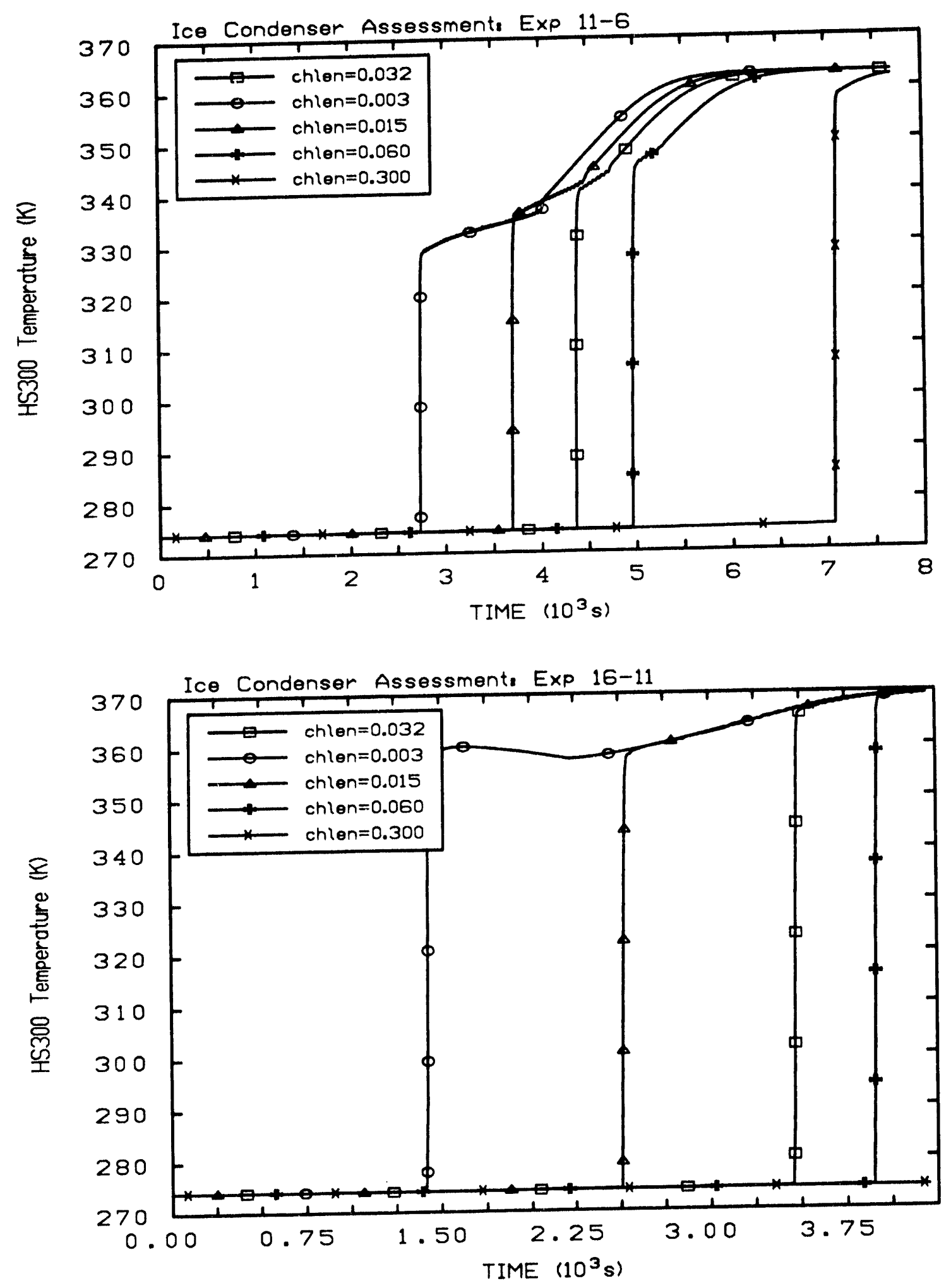

Figure 8.3.4 Heat Structure Temperatures of HS 300 for Experiment 11-6 (top) and Experiment 16-11 (bottom). Ice Heat Structure Characteristic Length Sensitivity Study. 

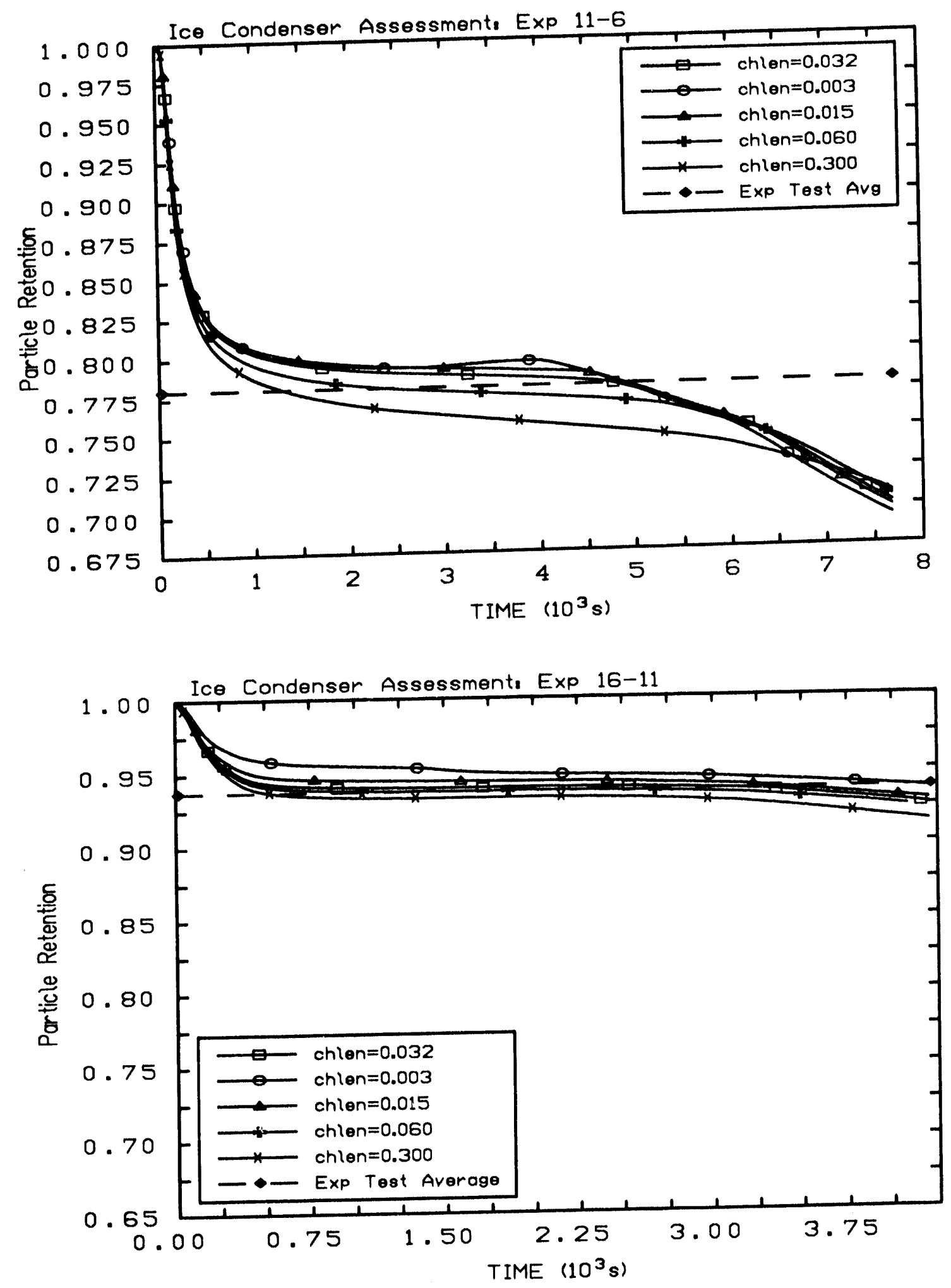

Figure 8.3.5 Particle Retention for Experiment 11-6 (top) and Experiment 16-11 (bottom). Ice Heat Structure Characteristic Length Sensitivity Study. 

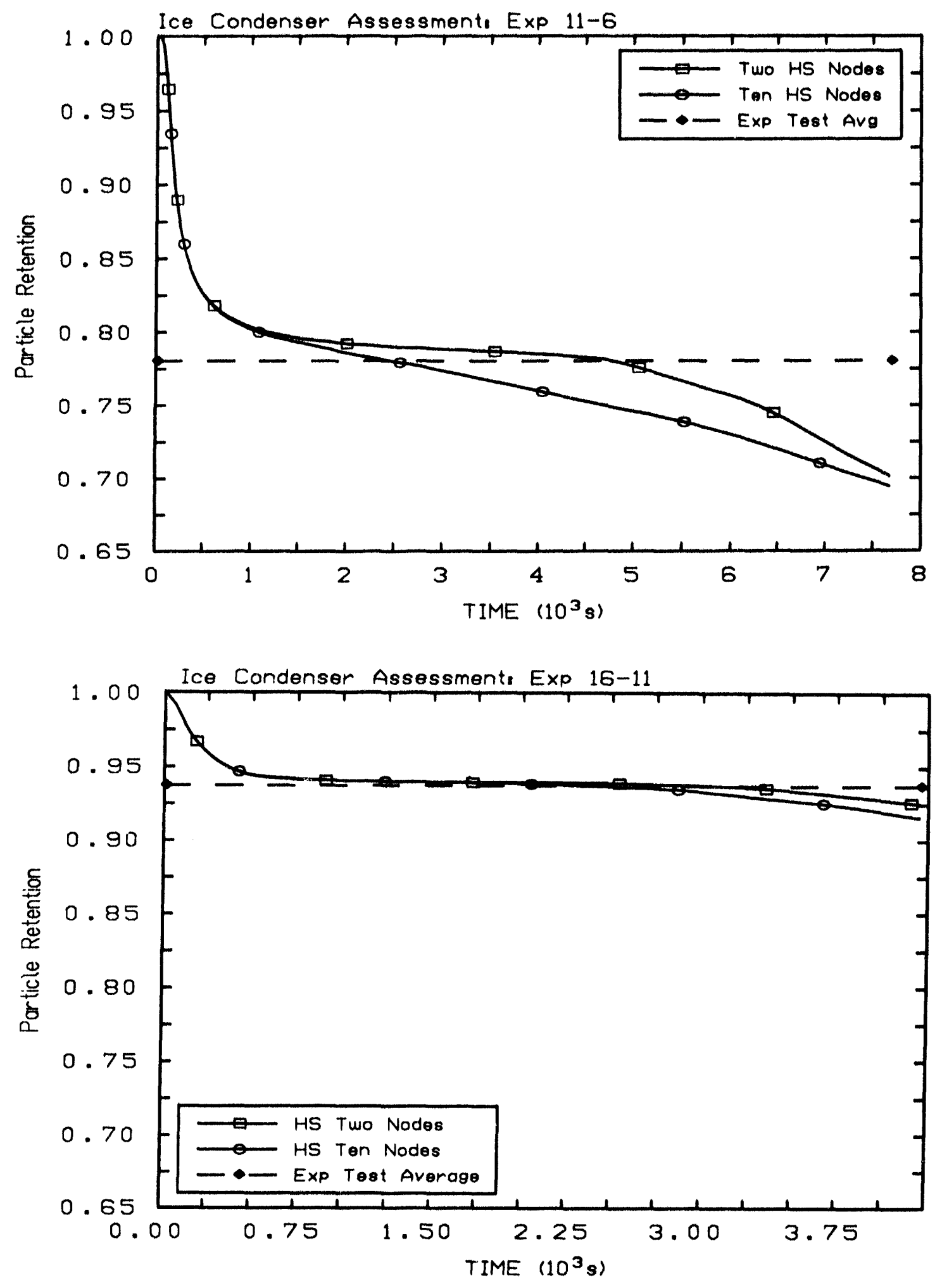

Figure 8.4.1 Particle Retention for Experiment 11-6 (top) and Experiment 16-11 (bottom). Heat Structure Nodalization Sensitivity Study. 

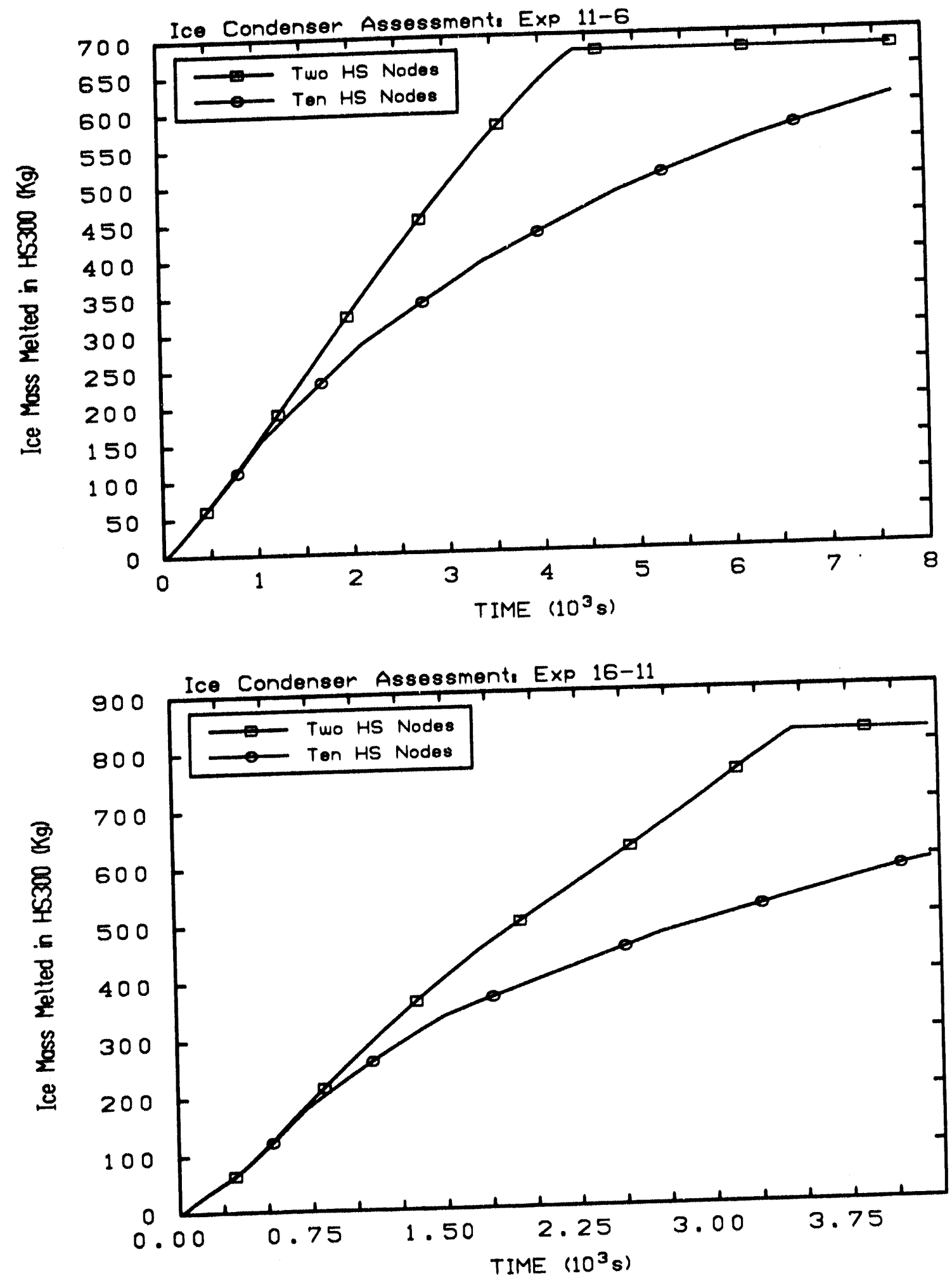

Figure 8.4.2 Mass of Ice Melted in CV300 for Experiment 11-6 (top) and Experiment 16-11 (bottom). Heat Structure Nodalization Sensitivity Study. 
Figures 8.4.3 to 8.4.5 display the effect on temperatures for both experiments. Again, for early times, temperatures for the two and ten nodes cases were almost identical. Then, results differed significantly, with the ten node case consistently much higher than the two node case. By closely examining Figure 8.4.6, the points at which ice finishes melting in a cell can be observed in the ten node case by the sudden temperature jumps. Thus, for Experiment 16-11, the ice in the outermost cell melted at about 1000 seconds. Once ice is removed from a cell, the Heat Structure Package replaces the ice with a material specified in the input for that ice heat structure. This, as recommended in [8], was a low density, high heat capacity material which tended to somewhat insulate the remaining ice from the high temperature control volume and raise the temperature of the outer ice condenser temperature node. Thus, the ice is melted at a slower rate and the control volume has higher temperatures. This explains the higher control volume temperatures, slow ice melt rate, and lower particle retention in the ten node case.

Because the ice condenser melt mechanism operates in the manner described above, temperature behavior at the outer node in an ice condenser heat structure is unpredictable and thus may give unexpected results. Using only two nodes not only gives a much more predictable temperature response (Figure 8.4.6), but creates a more simple model. As Figure 8.4.7 shows, there was also a significant cpu advantage in using few nodes.

\subsection{Radiation Heat Transfer}

The reference calculation did not include radiation heat transfer between heat structure surfaces and adjacent control volumes because it was believed that temperatures were too low to have a significant impact on the calculation. However, it was found in [6] that inclusion of radiation could have a dramatic effect on aerosol behavior, even at low temperatures, because of saturation ratio differences and its resulting effect on water droplet suspension.

In this study, another run was made that included radiation in the ice condenser regions. An emissivity value of 0.9 was used. Particle retention for both experiments is shown in Figure 8.5.1. The inclusion of radiation did not affect particle retention significantly. The temperatures of the control volumes of the three ice condenser regions are shown in Figures 8.5.2 to 8.5.4. Again, although there are small differences, the effect for these ice condenser problems was unimportant. Finally, in Figure 8.5.5, the results of suspended aerosol masses in the lower ice condenser region show small but insignificant differences. Although not shown, the inclusion of radiation increased cpu usage by just a few seconds. 

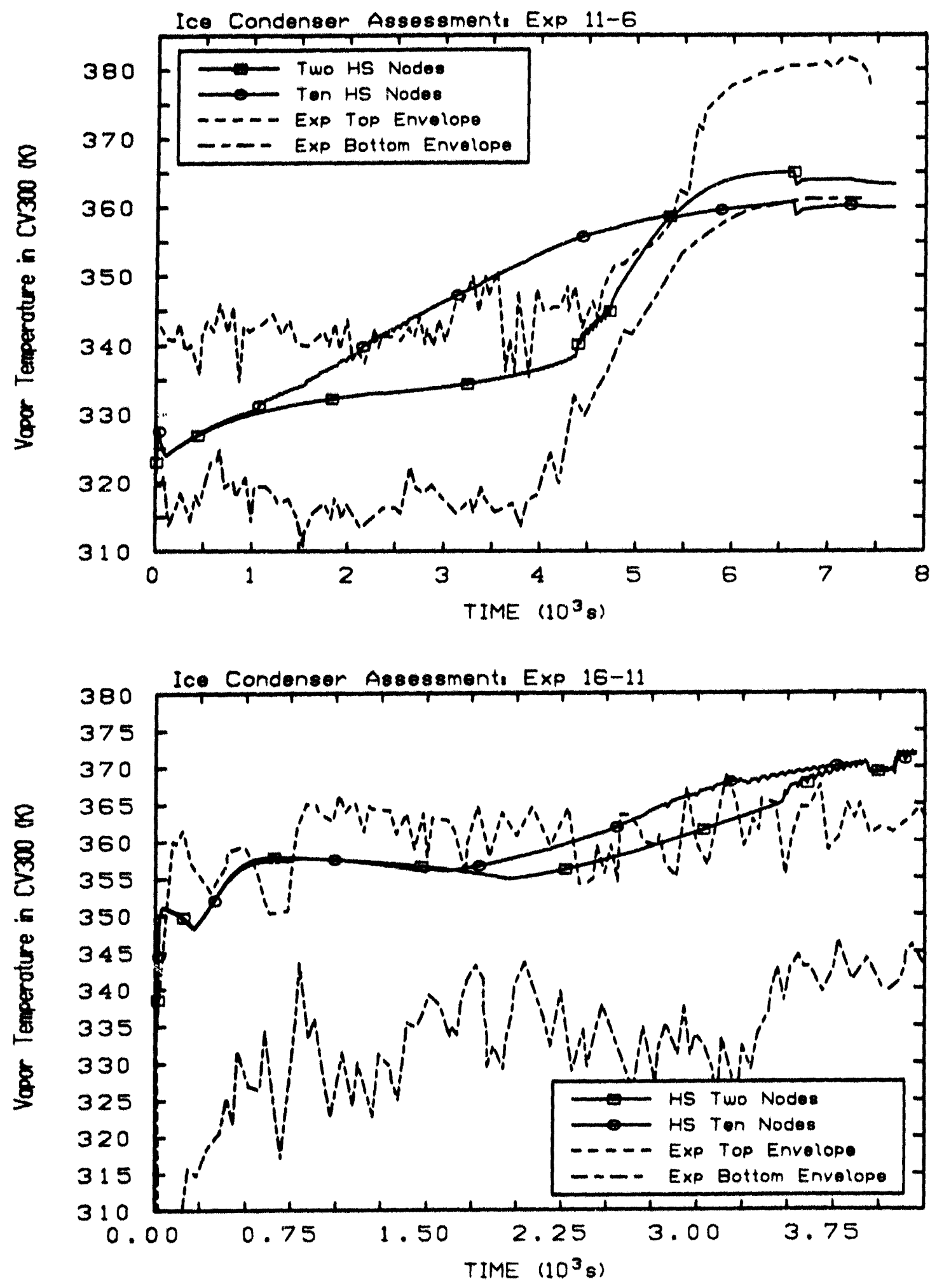

Figure 8.4.3 Vapor Temperature in CV300 for Experiment 11.6 (top) and Experiment 16-11 (bottom). Heat Structure Nodalization Sensitivity Study. 

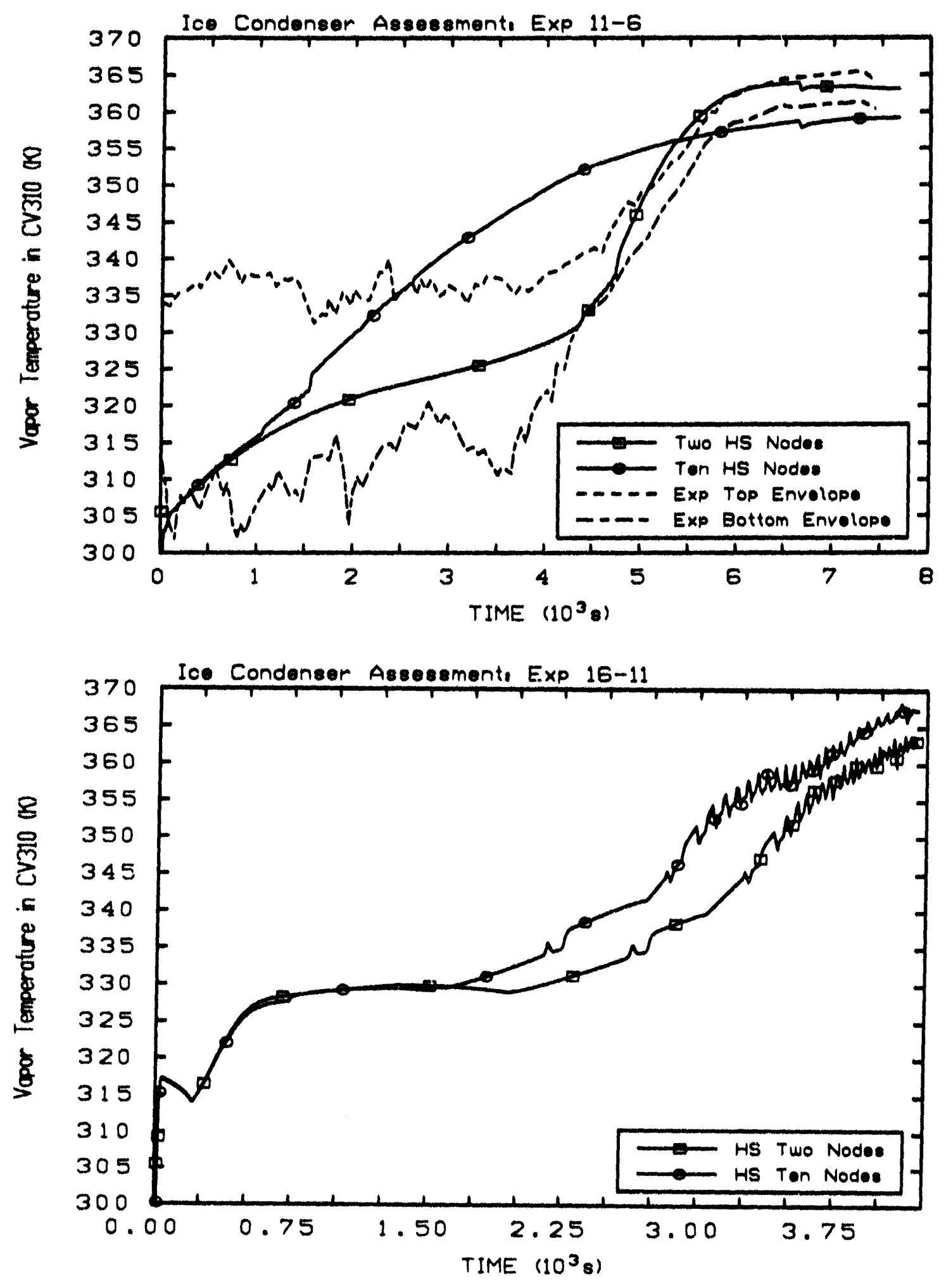

Figure 8.4.4 Vapor Temperature in CV310 for Experiment 11.6 (top) and Experiment 16-11 (bottom). Heat Structure Nodalization Sensitivity Study. 

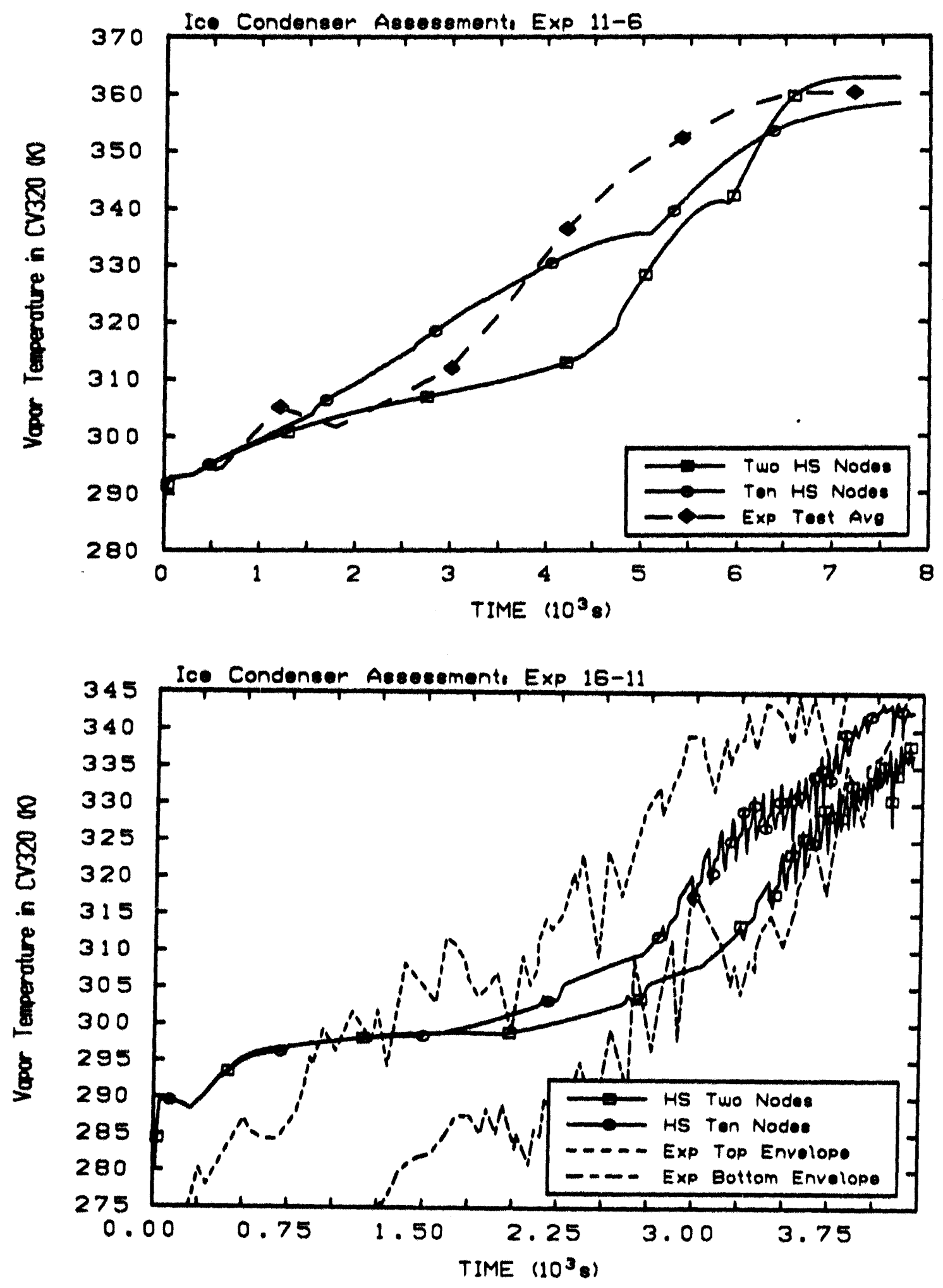

Figure 8.4.5 Vapor Temperature in CV320 for Experiment 11-6 (top) and Experiment 16-11 (bottom). Heat Structure Nodalization Sensitivity Study. 

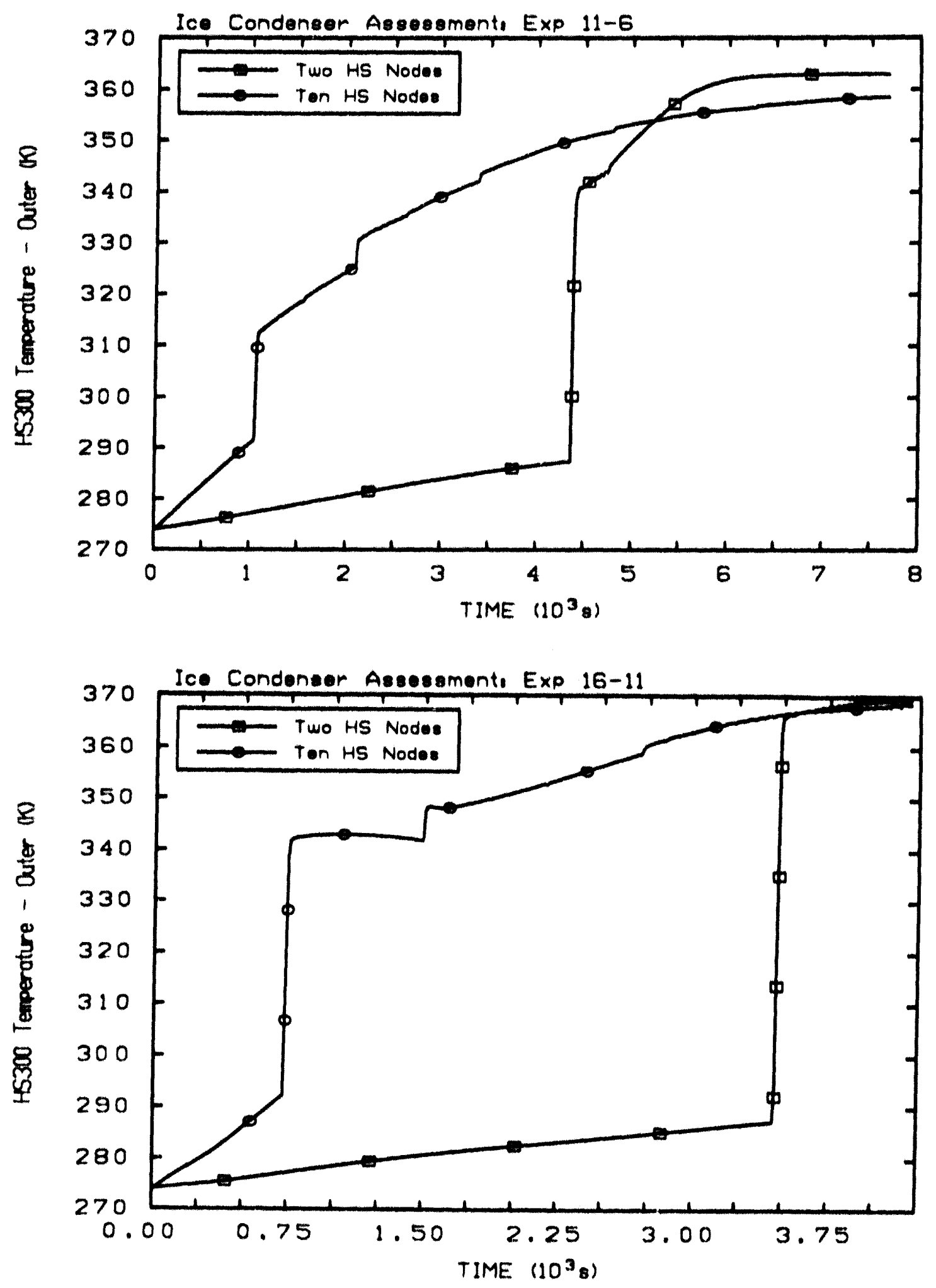

Figure 8.4.6 Heat Structure Temperatures of HS 300 for Experiment 11.6 (top) and Experiment 16-11 (bottom). Heat Structure Nodalization Sensitivity Study. 

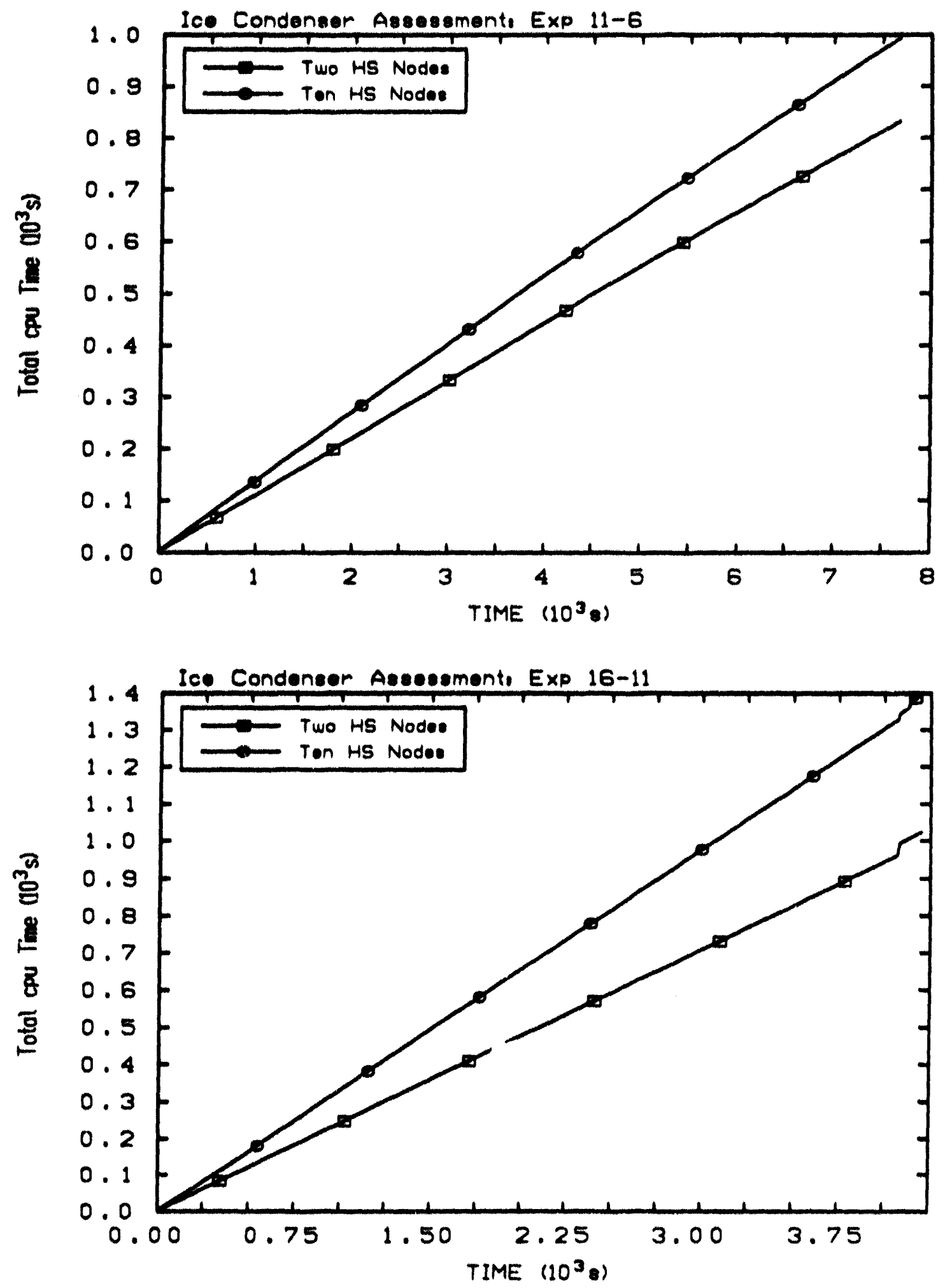

Figure 8.4.7 Computer Processor Time for Experiment 11-6 (top) and Experiment 16-11 (bottom). Heat Structure Nodalization Sensitivity Study. 

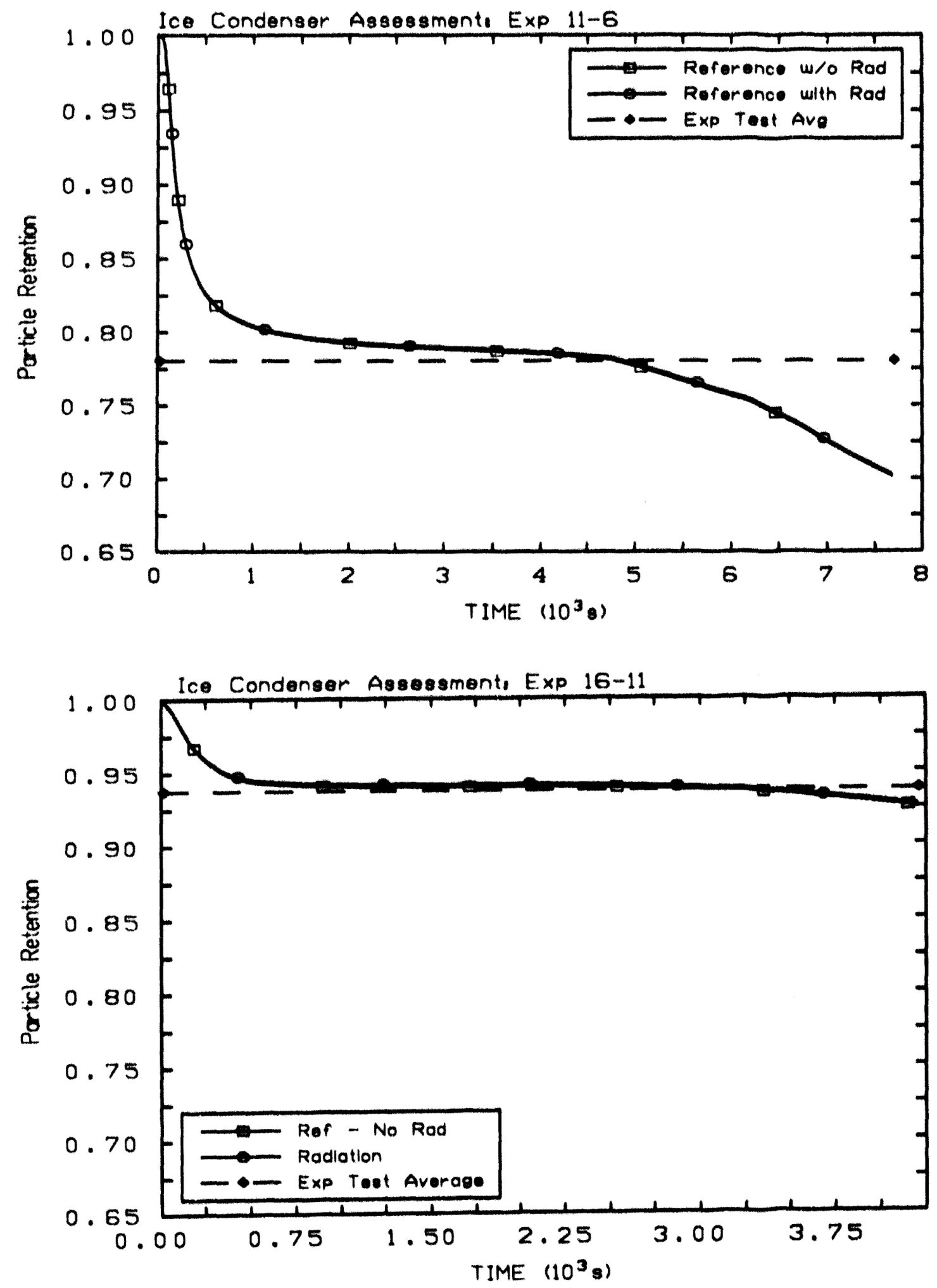

Figure 8.5.1 Particle Retention for Experiment 11-6 (top) and Experiment 16-11 (bottoln). Radiation Heat Transfer Sensitivity Study. 

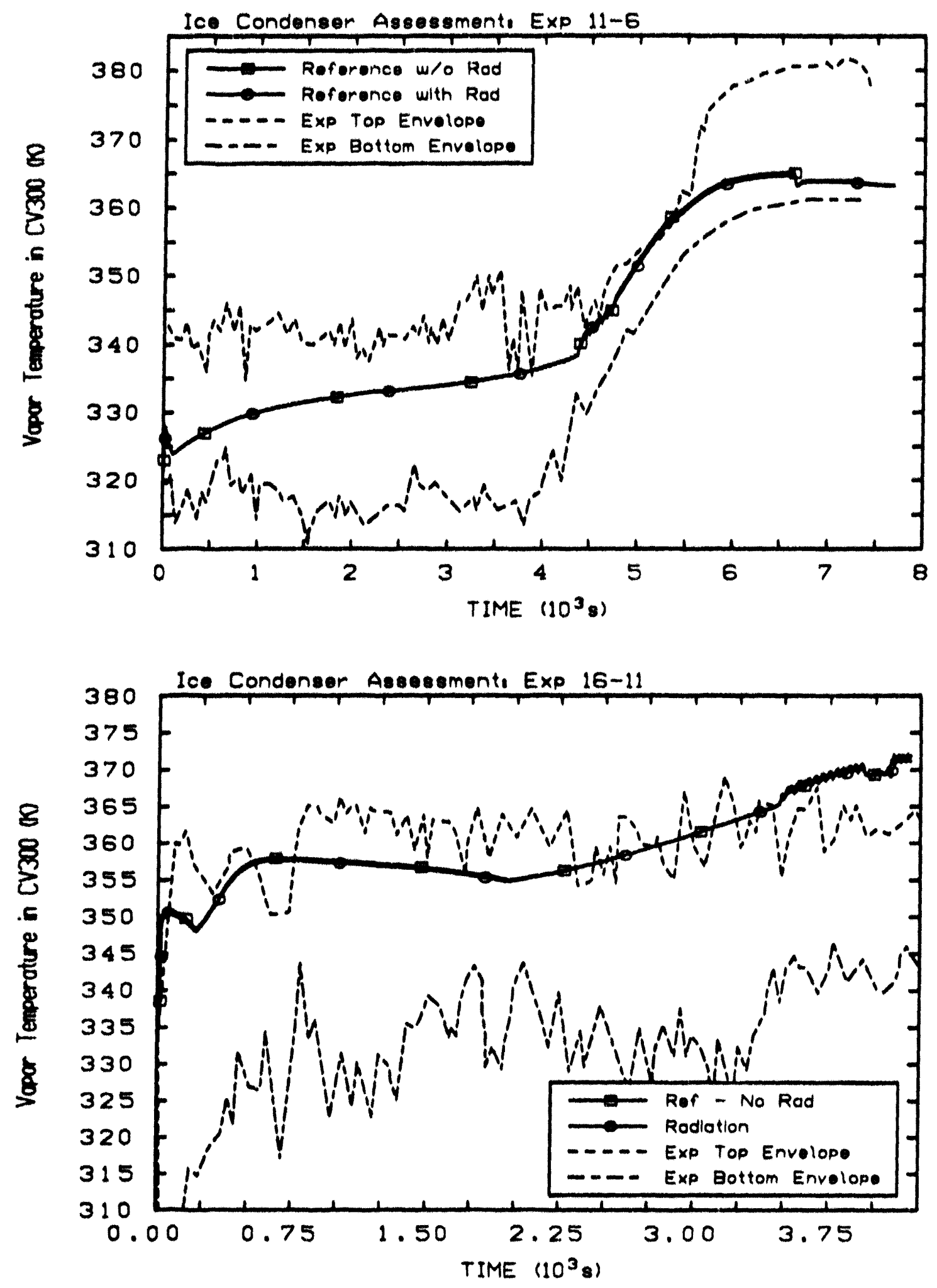

Figure 8.5.2 Vapor Temperature in CV300 for Experiment 11-6 (top) and Experiment 16-11 (bottom). Radiation Heat Transfer Sensitivity Study. 

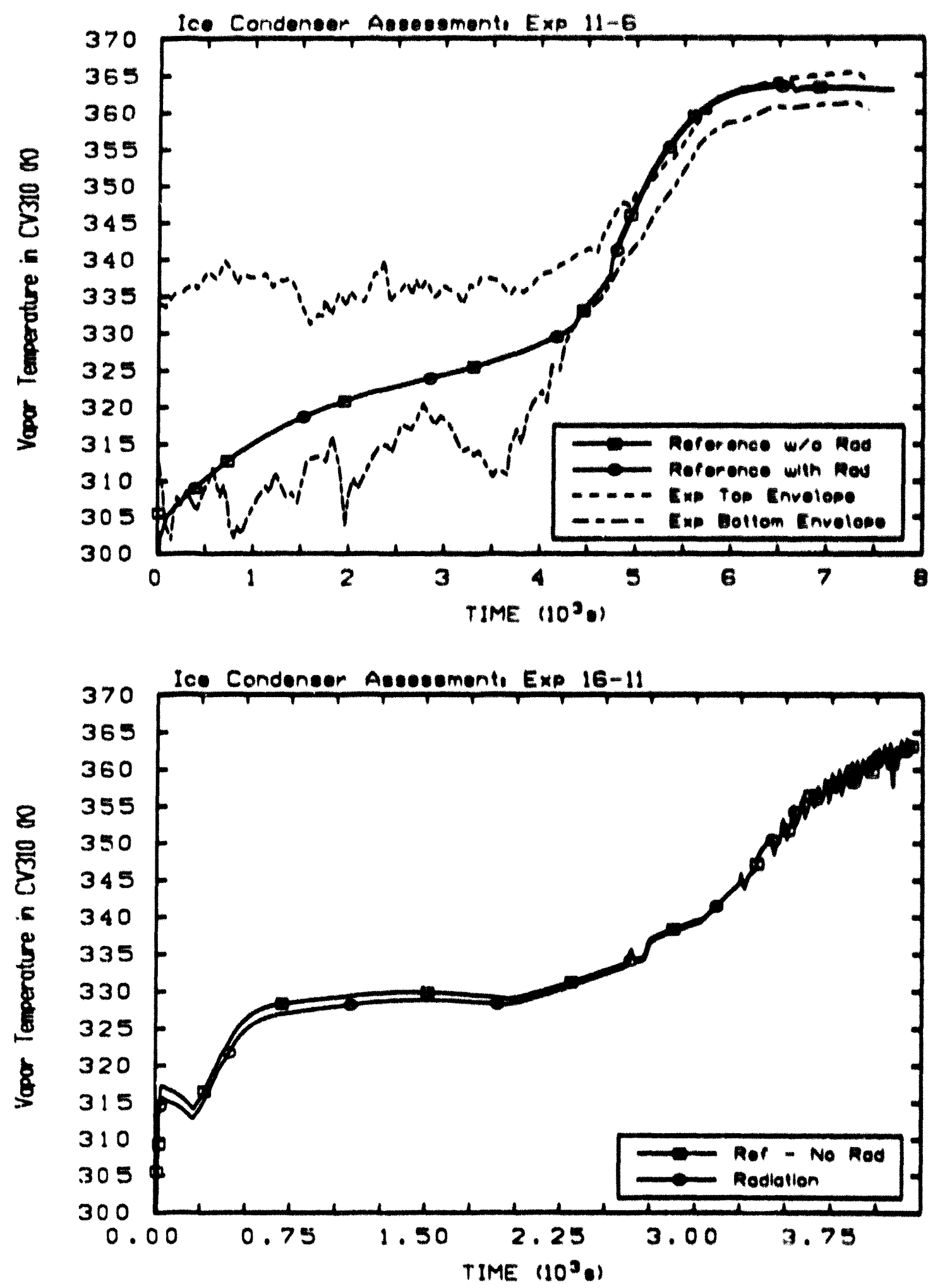

Figure 8.5.3 Vapor Temperature in CV310 tor Experiment 11.6 (top) and Experiment 16-11 (bottom). Radiation Heat Transter Sensitivity Study. 

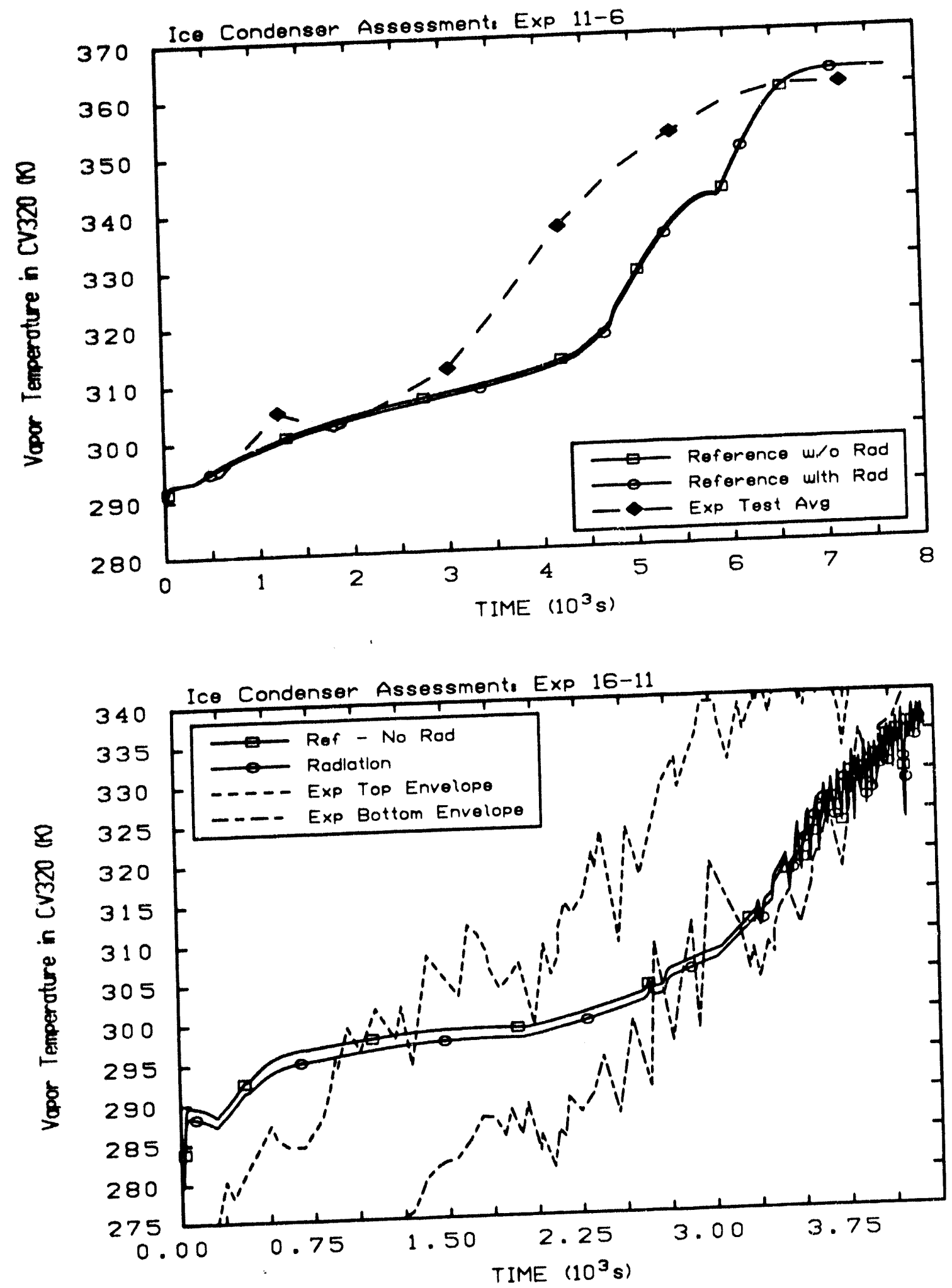

Figure 8.5.4 Vapor Temperature in CV320 for Experiment 11-6 (top) and Experiment 16-11 (bottom). Radiation Heat Transfer Sensitivity Study. 

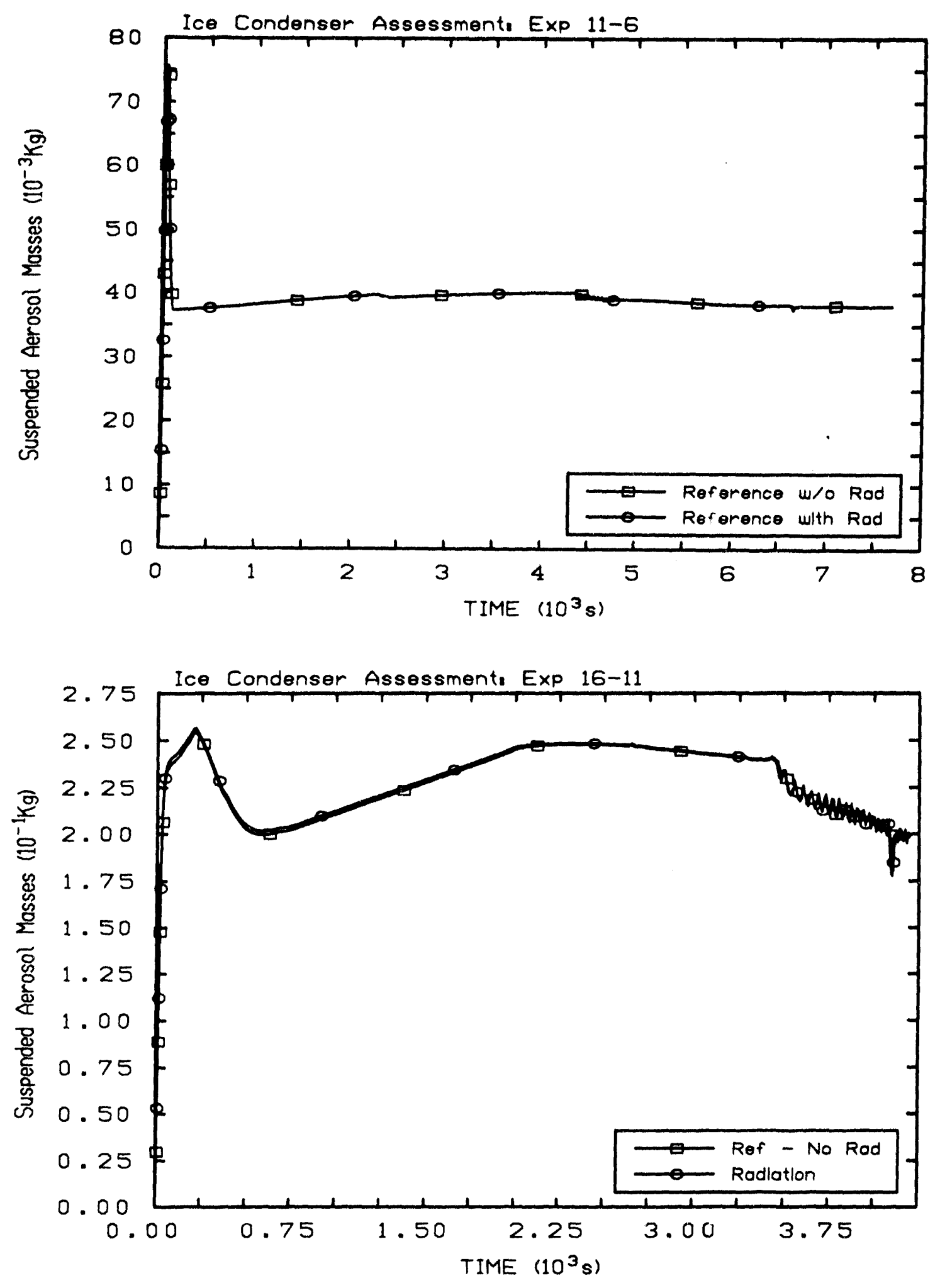

Figure 8.5.5 Suspended Aerosol Masses for Experiment 11-6 (top) and Experiment 16-11 (bottom). Radiation Heat Transfer Sensitivity Study. 


\section{Comparison to CONTAIN}

CONTAIN has also beer, used to simulate these two PNL experiments $[9,10]$. Although all of the data for Experiments 11.6 and $16-11$ were available at the time that the CONTAIN calculations were performed, they were performed before the PNL final report [7] was written. The CONTAIN calculations placed emphases on the recirculation in the diffuser rather than events occurring within the ice condenser. In contrast to the onedimensional MELCOR flow model, the CONTAIN model used a two-dimensional flow model to approximate the recirculation that occurred within the ice condenser in Experiment 11-6. The same CONTAIN nodal model was also used to simulate Experiment 16125-11. CONTAIN predictions for the temperatures within the ice condensers themselves were not presented, so comparisons between MELCOR and CONTAIN temperatures in the ice condenser are not possible. As discussed in Section 3, both MELCOR and CONTAIN are "zero dimensional" control volume codes; the dimensionality discussed here refers only to the flow network that connected the control volumes.

The CONTAIN reports did publish diffuser inlet and outlet temperatures. No figures are shown because both the MELCOR and CONTAIN results are straight lines, so figures would not enhance the cilscussion. For Experiment 16-11, the experimental data indicate that the diffuser inlet began at a temperature of about $365 \mathrm{~K}$ and linearly increased to about $385 \mathrm{~K}$ at the end of the experiment. MELCOR Control Volume 200 (See Figure 3.1) began and ended at a temperature of about $372 \mathrm{~K}$. Since the MELCOR model was onedimensional, the $372 \mathrm{~K}$ value was an average value of the diffuser inlet during the test, and since the focus of the MELCOR model was in modeling the ice condensers accurately while only peripheral attention was given to upstream conditions, we were pleased with this agreement. CONTAIN data [10], because it was two-dimensional, showed three curves from three cells for the diffuser inlet. The single experimental temperature at the diffuser inlet was $375 \mathrm{~K}$ after 35 minutes. One CONTAIN temperature prediction began at $355 \mathrm{~K}$ and ended at about $365 \mathrm{~K}$. Another began at about $360 \mathrm{~K}$ and ended at $370 \mathrm{~K}$, while the third curve consistently ran about $2 \mathrm{~K}$ hotter than the second curve. Thus, the CONTAIN predictions were slightly cooler than the experimental results. For the temperatures at the diffuser outlet for Experiment 16-11, the experimental data was always between 365 and $370 \mathrm{~K}$ (except at early time, when the heater was settling to steadystate). MELCOR Control Volume 210 was always between 370 and $378 \mathrm{~K}$ for the entire 4200 seconds, so it predicted results a few degrees high. The coldest of the three CONTAIN cells ran linearly from a starting temperature of $345 \mathrm{~K}$ to a final temperature of about $360 \mathrm{~K}$. The hottest curve ran from $360 \mathrm{~K}$ to $365 \mathrm{~K}$. Thus, CONTAIN again predicted temperatures a few degrees on the cold side. CONTAIN temperatures were only plotted out to about 35 minutes for a 75 minute experiment in which significant ice melt occurred in the 35-75 minute range, while particle retention was plotted out to about 70 minutes. It would have been useful for CONTAIN publications to include temperatures in the 35-70 minute time period, resulting in a more complete comparison to MELCOR.

For Experiment 11.6, the data was more interesting because there was recirculation, and as previously discussed, there was considerable temperature variation within a control 
volume because of the three-dimensional stratified flow. The diffuser inlet temperature "envelope" fell within $315 \mathrm{~K}$ and $395 \mathrm{~K}$. Again, the three cells representing the CONTAIN results were straight lines. One curve began at $325 \mathrm{~K}$ and ended at $331 \mathrm{~K}$, a second began at $343 \mathrm{~K}$ and ended at 347 , and the third began at $350 \mathrm{~K}$ and ended at $355 \mathrm{~K}$. Thus, the hottest CONTAIN curve was $45 \mathrm{~K}$ below that of the hottest experimental data, while the coldest CONTAIN result was in good agreement with the coldest experimental data. Because of the initial and boundary conditions for MELCOR for this problem, the inlet curve represented by CV200 started at 398K and gradually fell to a value of about $380 \mathrm{~K}$ at a time of 3500 seconds. After this time, the temperature curve consistently siayed between $380 \mathrm{~K}$ and $385 \mathrm{~K}$. The diffuser outlet temperatures for Experiment 11.6 were very similar to those of the inlet. Experimental data showed extreme stratification between values of about $315 \mathrm{~K}$ and $390 \mathrm{~K}$. The CONTAIN data fell within $325 \mathrm{~K}$ and 350 $\mathrm{K}$, while the MELCOR temperatures for CV210 stayed between $340 \mathrm{~K}$ and $345 \mathrm{~K}$ for the first 70 minutes, at which time ice was exhausted from the condenser. Then, the temperature gradually increased to about $367 \mathrm{~K}$, a trend which was reflected in the experimental data. The CONTAIN temperatures were only plotted out to 70 minutes for a totally transient experiment that lasted 125 minutes. CONTAIN particle retention was plotted out only to 40 minutes, which leaves one to wonder about particle retention behavior in CONTAIN between 40 and 70 minutes.

Figure 9.1 compares the particle retention results of Experiment 11-6 to those of the MELCOR and CONTAIN predictions. The CONTAIN curve is a digitization of a figure shown in [10]; the actual CONTAIN curve is smooth and continuous. CONTAIN underpredicted particle retention, while MELCOR gave good agreement. Figure 9.2 compares the results of Experiment 16-11 to those of MELCOR and CONTAIN, where the CONTAIN data was again digitized from a figure in [10]. Again, CONTAIN underpredicted the particle retention while MELCOR was in good agreement.

One reason that CONTAIN underpredicted particle retention was that the particle density used.$-1000 \mathrm{~kg} / \mathrm{m}^{3}$.- was probably not as representative of an "average" density as the $2500 \mathrm{~kg} / \mathrm{m}^{3}$ used by MELCOR. Another probable reason was that CONTAIN prediction of temperatures in the ice condenser region was high. Although CONTAIN predicted lower temperatures in the diffuser region, the ice condenser region changed the temperature of the incoming flow drastically, and as seen in some of the MELCOR sensitivity studies, prediction of the correct temperature in the ice condenser control volumes was essential to obtain agreement with experiment for the particle retention. Temperatures in the ice condenser region of CONTAIN were probably too high because the ice melt rate was too low. In other words, not enough heat was transferred from the hot gas to the ice to cause a proper melt rate. CONTAIN predicted that half the ice in Experiment 11-6 melted in 2400 seconds, while both MELCOR and the experimental data showed that $55 \%$ of the ice had been melted by this time. For Experiment 16-11, CONTAIN predicted that total ice melt occurred in 4050 seconds, while MELCOR predicted that total melt occurred in 3400 seconds. The fact that CONTAIN was melting the ice too slowly only implies that this occurred because temperatures in the ice condenser region were too high, but the underprediction of the particle retention data also supports this supposition. 


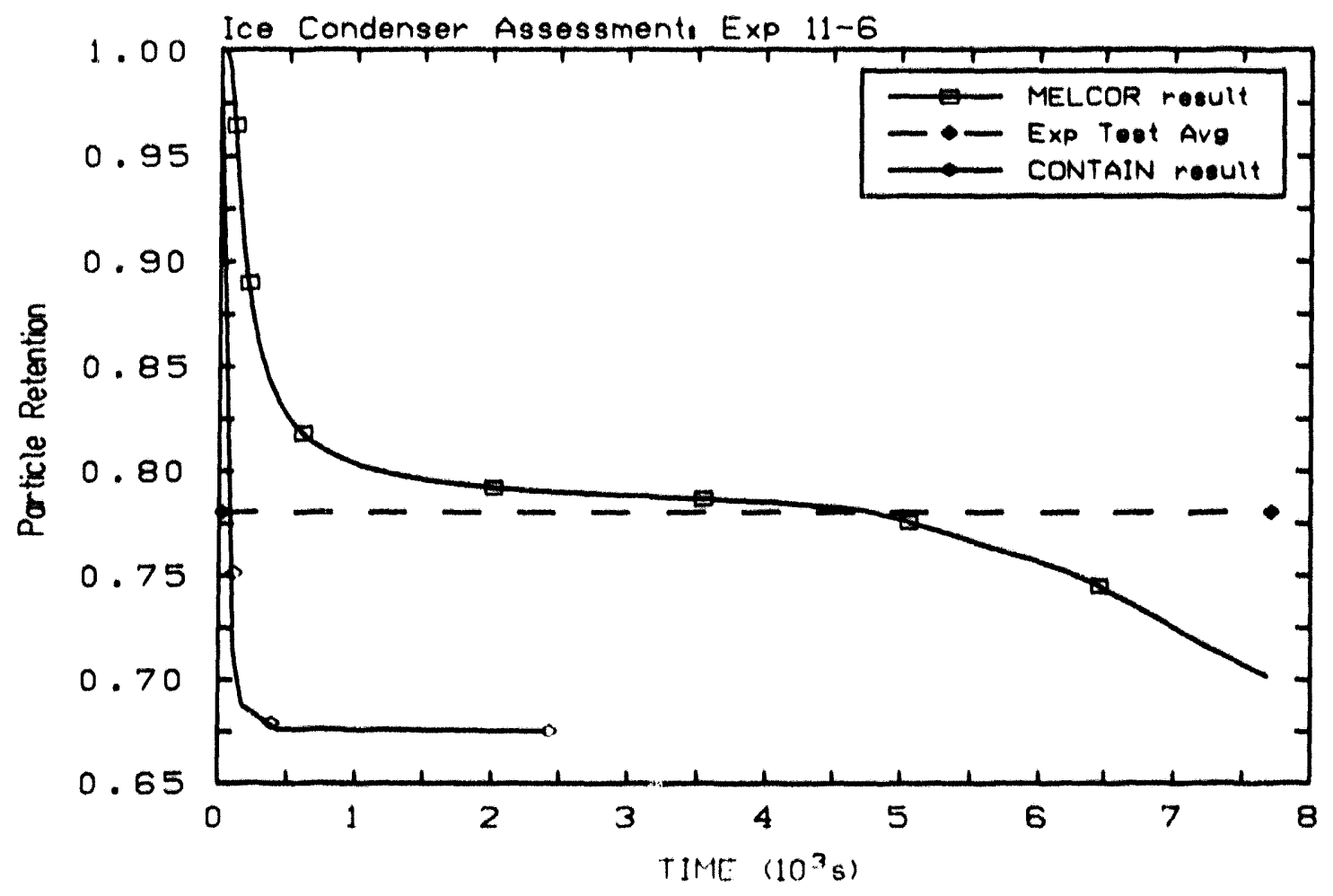

Figure 9.1 Comparison of Experiment 11.6 Particle Retention Data to MELCOR and CONTAIN predictions.

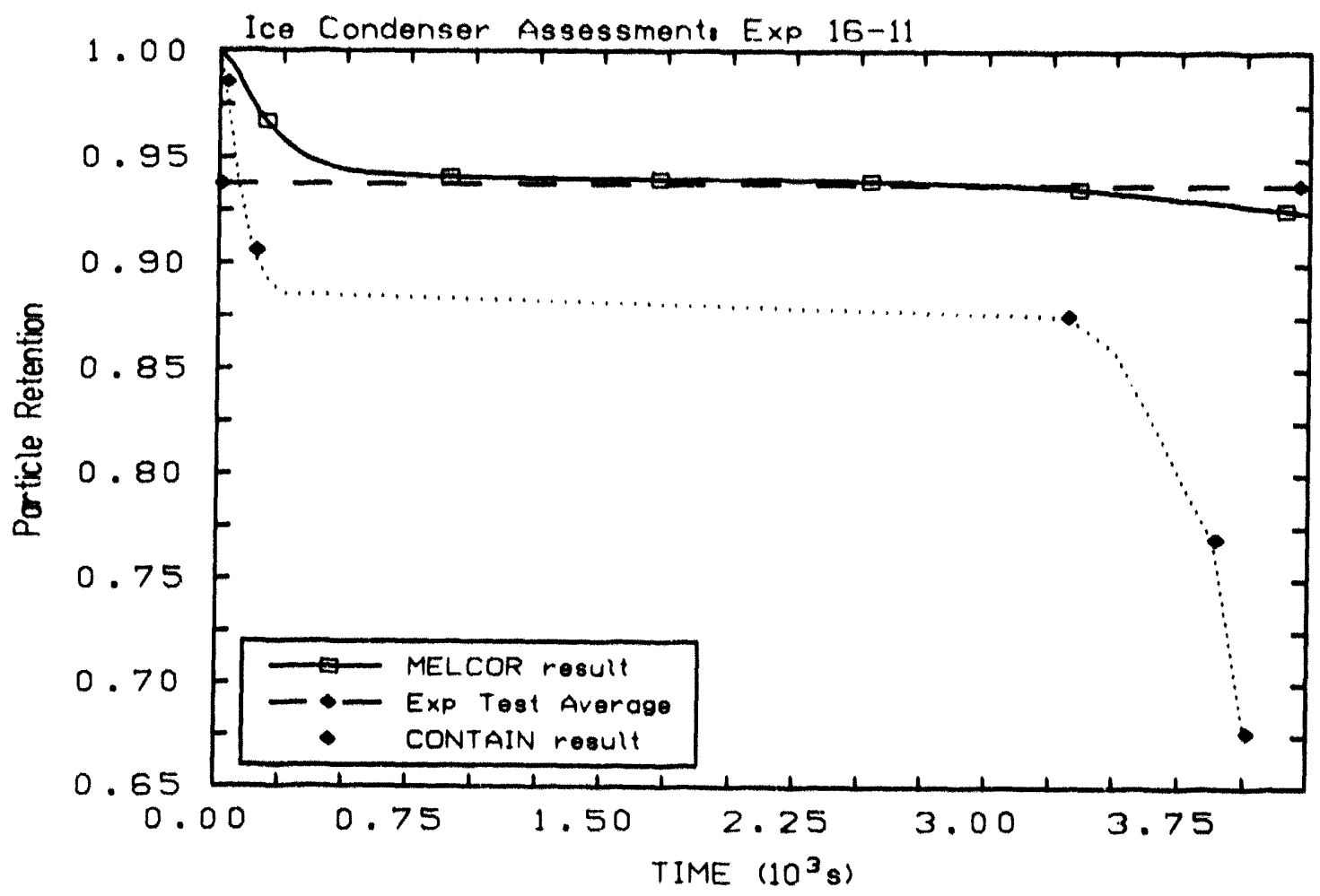

Figure 9.2 Comparison of Experiment 16-11 Particle Retention Data to MELCOR and CONTAIN predictions. 


\section{User Guidelines for Ice Condenser Calculations}

Two difficulties were encountered in the course of this assessment associated with the CVH Package. First, the CVT (Control Volume Thermodynamics) Package, which provides equation of state information to the Control Volume Hydrodynamics Package, has convergence difficulties whenever water is present and the temperature is near freezing $(273.15 \mathrm{~K})$. That is one reason why the value for TEMPL in the ice condenser input is set at $274 \mathrm{~K}$ throughout all the calculations and not the 273.15 value. If MELCOR is en. countering difficulty in $\mathrm{CVH}$ in one of the ice condenser control volumes, then the user should attempt to modify conditions upstream so that the vapor temperature in that control volume is higher. Otten, the problem can be alleviated if the temperature is raised only 5K or less, which should not significantly affect the global results. Second, CVH can also have convergence difficulties associated with condensation when a hot vapor is flowing into is cold control volume. One should check the printed output and determine which contrcl volume is encountering the difficulty, and then adjust boundary and/or initial conditions, whichever is most appropriate, to reduce the condensation in that control volume.

In the low flow experiment, recirculation was a significant physical event that MELCOR will not automatically model. The user must be aware of such physics and determine a method to account for it in the MELCOR model. MELCOR is a flexible code and there are many approaches. In this particular case, we found the $\mathrm{CVH}$ source/sink approach to be satisfactory.

The following discussion applies to the gas source and ice condenser input in the Heat Structure Package, Record HSDGCCCCC1. Proper specification of the low and high temperatures, TEMPL and TEMPU, and the resultant heat of reaction, HTRSRC, is im. portant if an accurate prediction of the rate of ice melt is to obtained. TEMPL is usually (always for this assessment) specified as 274K. TEMPU and HTRSRC are coupled by:

$$
\text { HTRSRC }=2000^{*}(273.15 \cdot \text { TICE })+332619+4218^{*}(\text { TEMPU }-273.15)
$$

where the first term accounts for sensible heat required to raise subcooled ice to the melt temperature, the second term is the latent heat of fusion of water, and the third term accounts for the sensible heating of melted ice water (See [8] for more details.). Units of HTRSRC are J/kg. In Section 8.1, it was demonstrated that the choice of this temperature range can affect ice condenser temperatures. Although, for these two problems, the temperature change did not affect the particle retention and other aerosol results significantly, this may not be the case for other problems. Obviously, the choice of HTRSRC affects the time to melt all of the ice. For certain problems that continu a long after the ice is melted, the timing of this event may be extremely important.

In this study, two flow paths were placed at the inlet and outlet of each lce condenser compartment. As discussed in Section 3, with only one flow path, there was an alternate 
pool build-up and release throughout the calculation that causes pressure oscillations, resulting in flow and temperature fluctuations. After the ice condenser studies had been nearly completed, it was discovered that only one flow path is necessary if the pool/atmosphere momentum exchange (Card FLnnn05 in the FL Package) is made small. Then, the atmosphere moving upwards does not cause the downward flow of liquid water to oscillate. It is also important to point out that, although the experiments certainly showed temperature oscillations, they were caused by density/temperature induced flow instabilities that MELCOR presently cannot model, not because of a temporary liquid flow blockage.

Use an lce condenser heat transfer coefficient multiplier between 1.2 and 3.8. Although CONTAIN applied a value of five, for the reference calculations the MELCOR models never required a value larger than 3.8. In the sensitivity study for this parameter, the value of five always produced results in which the lce would melt much too quickly. Al. though the recommended range is still wide, possible problem variations are too numerous to be more specific.

Use only two nodes to represent the ice condenser heat structures When more than two nodes are used and all the Ice in the outermost cell melts, then the temperature of the outermost node rises in temperature in an unpredictable and discontinuous manner. Using only two nodes, the temperature rises in a smooth, predictable, linear fashion until all of the ice in that heat structure melts. Then, the temperature rises sharply, which is a more physical representation of the phenomenon. 


\section{Code Problems and Limitations Identifled}

Early in the assessment, a round-off problem was discovered in the ice condenser model. In accounting for total ice melt, the method of addition used resulted in more ice being melted than was originally present. Since total ice melt was subtracted from the original value to determine ice remaining, a negative value for this parameter was created and resulted in floating point errors. This was reported to MELCOR code developers in Defect Investigation Report (DIR) 983, and was corrected in MELCOR version 1.8KJ.

Under certain circumstances, the logic for the ice condenser degassing model could be bypassed on the first iteration of MELCOR. This problem was uncovered in both the Characteristic Length and the Timestep Sensitivity Studies. When the logic was bypassed, initialization of parameters was such that all of the ice in an ice condenser would be "melted" on the first iteration. The logic was modified to avold bypassing of the lce condenser model in MELCOR version 1.8KQ (DIR992). Unfortunately, further circum. stances were discovered in which the logic could be bypassed, which was reported in DIR 1002. After a more extensive review of the logic, a more comprehensive correction was added, which became MELCOR version $1.8 \mathrm{KW}$.

Under conditions of extremely small timestep (dt) (such as during the Timestep Dependency Study with a "dt" of one-hundredth normal value), a roundoff error test was violated and again a large quantity of ice would melt in an unrealistically short time. Reprogramming of the roundoff error test corrected the problem in MELCOR version 1.8LE.

Finally, a correction to a Fortran "IF" test in the RN Package was made incorrectly. This became apparent when examining the results of the Particle Size Range and Heat Structure Nodalization Sensitivity Studies. Particle retention and other aerosol results produced results that were not consistent. The "IF" test was corrected under MELCOR version 1.8LF.

Although the following is not a strict limitation of the ice condenser model per $s \theta$, the present implementation of the ice condenser model under the Heat Structure Package restricts the user to using only two nodes to represent the ice condenser heat structure. As pointed out in the Nodalization Sensitivity Study, using more than two nodes results in the creation of an insulating layer between the outer node and inner nodes once the outer heat structure "cell" has melted. The outer node rises in temperature and thus reduces the amount of heat transferred from the ice to control volume regions. Thus, unexpected temperatures and melt times can result. 


\section{Conclusions and Recommendations}

An assessment of the ice condenser model that has been incorporated into MELCOR [8] has been pertormed using the PNL ice condenser aerosol experiments as a basis for evaluation. The MELCOR model created for this assessment was compared to two of the PNL experiments: one was a low flow case with natural recirculation, and another was a high flow case with no recirculation. Agreement of MELCOR with the PNL experiment was very good. MELCOR particle retention predictions agreed with the data qualitatively in that the value began at one and decreased quickly, leveled out during the time that ice was melting, and then finally began decreasing again late in the experiment when the ice supply had been exhausted. Quantitative agreement with the experimental results, based on the few values given for the experimental particle retention, was also excellent. Agreement with temperature data for both experiments was also excellent, with MELCOR results usually falling within the low temperature/high temperature experimental data envelope given at three axial locations. The time at which all of the ice in a region melted was also well-predicted by MELCOR.

The MELCOR results were in better agreement with the experimental measurements of particle retention than the CONTAIN results. Calculated temperature results for the diffuser inlet and outlet are difficult to comment upon because of the differences in nodalization for the two calculations. However, on average, the MELCOR results were similar to those of the CONTAIN results. MELCOR temperatures were perhaps a bit high, while the CONTAIN results were perhaps a bit low compared to the data. Unfortunately, in the true region of interest, the ice condenser, while the MELCOR predictions were in excellent agreement with experiment, there was no CONTAIN temperature data published or available.

In addition to a reference calculation for each experiment, fifteen sensitivity studies were also pertormed for each of the two experiments. During the course of these studies a number of highly useful items were brought to light. First, since the ice condenser model was a new addition to MELCOR, coding errors in the model were not unexpected, and there were several. However, with the methodology used in conducting sensitivity studies a number of problems were uncovered and addressed. Thus, although by no means exhaustive, the studies were conducted in sufficient detall that the ice condenser model within MELCOR can be used, within the guidelines and recommendations given in this report, with a high degree of confidence. Ii is recommended that such an assessment be conducted whenever either a new model is added or an existing model within MELCOR is extensively modified. The largest variety of sensitivity studies that is practical within time and budget constraints should be considered.

Among the sensitivity studies, one examined dependency on timestep. It was found that there was a small timestep dependency, but it was clear that the results were convergent. Another study addressed possible machine dependency. There was, for all practical purposes, no machine dependency observed on the five different platforms on which the 
calculations were pertormed. Thus, the ice condenser model can be used with confldence at least on these platforms. Finally, unless one's model has small control volumes, we recommend not using the heat structure damping that couples with the Control Volume Hydrodynamics Package. It is a numerical antifice that can decrease accuracy.

Thermal/hydraullc sensitivity studies focused on the flow loss coefficients, the type of thermodynamics used, and the possibility of including SPARC physics. Flow loss coefficients should, as with all MELCOR input, be computed with as much care and accuracy as possible. However, it was found for this problem that a variation of as much as a factor of four in all of the flow loss coefficients did not significantly alter the result of either the aerosols or of the temperatures. Use of nonequilibrium thermodynamics is recommendod as is not activating the SPARC physics. Both choices tend to more accurately represent the physics of the problem.

Four sensitivity studies examined parameters associated with the aerosol input with the Radionuclide Package of MELCOR: (1) number of aerosol components, (2) number of aerosol sections, (3) aerosol particle density, and (4) the aerosol particle size range. Separating different aerosols into different components was found to be desirable in the components study. This conclusion was also made in [6]. The apparent gain in accuracy (not to mention a more accurate physical representation) is more than worth the small additional computer time required. In the sections study, for these computations, using five aerosol sections was adequate. Using up to ten sections appeared to improve the results, but incurred a definite, nontrivial additional cost in computational time. Using iwenty section did not change the results significantly and computer time was doubled. Thus, we recommend using five sections if computer time is an issue, and up to ten sections if it is not. In the particle density study, a value of $2500 \mathrm{~kg} / \mathrm{m}^{3}$ was used in the reference calculation, and in [7] a value of about $2200 \mathrm{~kg} / \mathrm{m}^{3}$ was used. This may serve as some guidance for future calculations. Choice of particle density is, of course, highly problem dependent. However, the study did uncover the fact that aerosol results were highly sensitive to the value of this parameter.

Finally, five sensitivity studies examined parameter associated with the input of the ice condensers: (1) the energy capacity of the ice, (2) the ice heat transfer coefficient multiplier, (3) the ice heat structure characteristic length. (4) the number of nodes in the ice condenser heat structure, and (5) radiation heat transter to and from the ice condenser heat structure. The parameters that set the energy capacity of the ice affected the time of complete ice melt much more than temperatures or aerosol results. It is impossible to give guidance on proper values because proper values for these parameters are 100 problem dependent. The study on the ice heat transfer coefficient multiplier discovered that this parameter affected both the ice melt rate and temperatures. Values between 1.2-3.8 were used in the reference calculations. We recommend starting with a value of 1.2 for all ice condenser heat structures and then examining the results. If warranted, then higher values up to 5.0 can be justified [8]. The study on the ice heat structure characteristic length found that this was the parameter that perhaps affected the results the most. Temperatures, ice melt rate, and particle retention were all sensitive to this 
parameter. In the reference calculation, we lound that a length representative of the diameter of a typical ice cube (See Section 3) in the condenser to be the most reasonable and most accurate value. For the heat structure node study, it was lound that using the two nodes as was done in [8] gave the most predictable and, supposedly, accurate results. The present MELCOR ice condenser model does not remove ice in a cell as in a moving boundary model. Rather, when all ice in a cell is melted, it is replaced with an. other heat structure material. This has a deleterious effect on the ice melt rale of further inner cells and on the energy exchange between the ice heat structure and its control volume. Thus, use of more than two nodes 'ur an ice condenser heal structure is not recommended, while use of only two nodes is highly recommended. Finally, the inclusion of radiation did not affect any of the results significantly. However, in [6] it was found that radiation could affect aerosol results. Since, for this problem at least, including radiation did not greally increase the cpu load, the recommendation is to include if.

A positive point concerning MELCOR should be emphasized. First, for the ice condenser problems, there was no machine dependency. Given a code the size of MELCOR, the number of plattorms on which the study was pertormed, and the variety of Fontran com. pilers with which programmers must contend, this was a significant achievement. Second, for all of the aerosol sensitivity studies in Section 6, none of the variations atfected the Control Volume Hydrodynamics (CVH) results. Although this was an expected result, again credit should be given for achieving such a goal. Third, for most numerical algorithms, convergence towards the "exact" solution is dependent on timestep. Usually. a smaller timestep results in higher convergence. For these problems, this was indeed the case with the MELCOR code. Further, the timestep study indicated that the results were converging as the timestep was reduced.

A final recommendation is that at some point in the study, the problem should be nn using a maximum timestep that is significantly smaller than the "standard" value that the user has chosen .. a value an order of magnitude smaller is recommended. Such an input variation tends to uncover aspects of the problem that one otherwise might not have discovered. Sometimes they can be important discoveries, for example, the error dis. covered in the Heat Structures Package during the course of this assessment. The user should be prepared for some investigation if differences in results for different limesteps are encountered. Since MELCOR is a fairly efficient code, running on fairly inexpensive platiorms in reasonable clovk times, this is one quick method of confirming results. 


\section{References}

1. Summers, R.M., et. al., "MELCOR 1.8.0: A Computer Code for Severe Nuclear Reactor Accident Source Term and Risk Assessment Analyses," NUREG/CR-5531, SAND900364, Sandia National Laboratories, Albuquerque, NM, January, 1991.

2. Boucheron, E.A, and Kelly, J.E., "MELCOR Analysis of the TMI-2 Accident, "Transactions of the American Nuclear Society and the European Nuclear Society 1988 International Conference on Nuclear Fission: Fifty Years of Progress in Energy Security and Topical Meeting on TMI-2 Accident: Materials Behavior and Plant Recovery Technology, 57, Washington, DC, SAND88-1259C, October 30-November 4, 1988, pp. 435-436.

3. Madni, I.K., "MELCOR Simulation of Long-Term Station Blackout at Peach Bottom," Pceedings of the 18th Water Reactor Safety Information Meeting, Brookhaven National Laboratory Report No. NUREG/CP-0113, October, 1990.

4. Kmetyk, L.N., "MELCOR 1.8.1 Assessment: FLECHT SEASET Natural Circulation Experiments," SAND91-2218, Sandia National L iboratories, Albuquerque, NM, December, 1991.

5. Kmetyk, L.N., "MELCOR 1.8.1 Assessment: ACRR Source Term Experiments ST-1/ST-2," SAND91-2833, Sandia National Laboratories, Albuquerque, NM, April, 1992.

6. Kmetyk, L.N., "MELCOR 1.8.1 Assessment: LACE Aerosol Experiment LA4," SAND911532, Sandia National Laboratories, Albuquerque, NM, September, 1991.

7. Ligotke, M.W., Eschback, E.J., and Winegardner, W.K., "Ice-Ccndenser Aerosol Tests," NUREG/CR-5768, PNL-7765, Pacific Northwest Laboratory, September, 1991.

8. Smith, R.C., and Summers, R.M., "MELCOR Ice Condenser Modeling," Letter Report to the USNRC dated September 25, 1991.

9. Russell, N.A., and Williams, D.C., "Comparison of CONTAIN Code Simulations to Experimental Ice Condenser Test Data," SAND89-3096C, Sandia National Laboratories, Albuquerque, NM, 1989.

10. Washington, K.E., Russell, N.A., Williams, D.C., and Gido, R.G., "Integrated ThermalHydraulic Analysis with the CONTAIN Code," SAND90-1382C, Sandia National Laboratories, Albuquerque, NM,1990.

11. Fluid Flow Data Book, Genium Publishing Company, September, 1984.

12. "MELCOR 1.8.1 Computer Code Manual, Volume 1: Primer and Package Users' Guides," Sandia National Laboratories, Albuquerque, NM, June, 1991. 


\section{Appendix A - Experiment 16-11 Reference Calculation MELCOR Input Deck}

- ICE CONDENSER ASSESSMENT: MELCOR MODEL OF PNL'S

- ICE CONDENSER EXPERIMENT 16.11

-

- Robert J. Gross

-

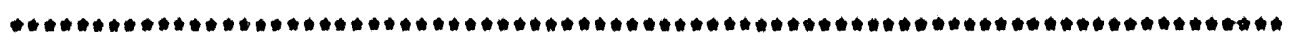

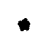

TITLE 'ICECON - EXP 11'

JOBID 'ICECON - EXP 11'

CRTOUT

DIAGF 'icecon_aero.gdia'

OUTPUTF 'icecon_aero.gout'

RESTARTF 'icecon_aero.rst'

TSTART $\quad 0.0$

เ

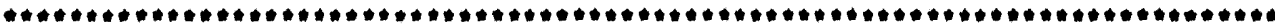

$\bullet$

- MAX NUMBER OF CVH ITERATIONS

SC44010 $440120.0 \quad 3$

-

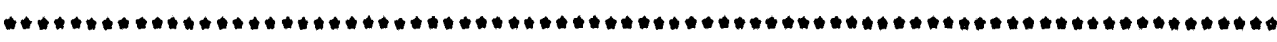

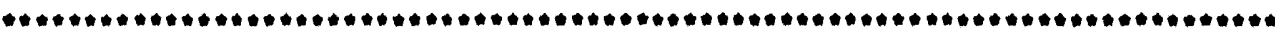

$\star *$

*.* CONTROL VOLUME HYDRODYNAMICS INPUT

$\bullet \bullet$

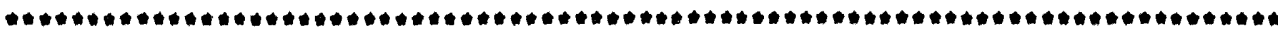

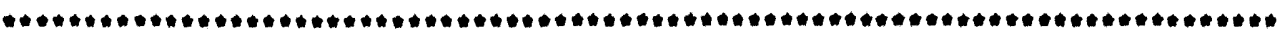

$\bullet$

*.* CV010 IS THE FIRST MIXING CHAMBER - PNL ICE CONDENSER FACILITY -

CV01000 'MIXCH1' 221 'NONEQ., VERT, RCS

$\begin{array}{llll}\text { CV01002 } & 0.0 & 0.0 & \text { VLATMO, VLPOLO }\end{array}$

CV010A1 PVOL 110325.

CVO10A2 TATM 363.

CVO10A3 PH2O 0.0 - NO STEAM INITIALLY 
$\begin{array}{llll}\text { CV010A4 } & \text { MLFR.4 } & 0.8 & * N 2 \\ \text { CV010A5 } & \text { MLFR.5 } & 0.2 & * \text { O2 }\end{array}$

$\begin{array}{lll}\text { CV010B1 } & 5.65549 & 0.0\end{array}$

$\begin{array}{lll}\text { CVO10B2 } & 10.26319 & 0.3366\end{array}$

- alr and steam sources

-

CV010C1 MASS.4 102

CV010C2 TE 208

CV010C3 MASS.5 302

CVO10C4 TE 208

CV010C5 MASS.3 502

CV010C6 AE 602

- N2 FLOW (KG/S) IN TF010

- N2 TEMP HIST IN TFO2O

- O2 FLOW (KG/S) IN TF030

- 02 TEMP HIST IN TF020

- STEAM FLOW (KG/S) IN TF050

- STEAM ENTHALPY (J/S) IN TF060

TF01000 'N2 FLOWRATE' $6 \quad 1.0 \quad 0.0$

- SEC FLOW (KG/S)

$\begin{array}{lll}\text { TF01011 } & 0.0 & 0.0\end{array}$

$\begin{array}{lll}\text { TF01012 } & 0.5 & 0.031715\end{array}$

TF01013 $360.0 \quad 0.031715$

TF01014 $362.0 \quad 0.03045$

TF01015 2100.0 $\quad 0.030$

TF01016 $4200.0 \quad 0.02950$

TF02000 'AlR TEMP' $5 \quad 1.0 \quad 0.0$

- SEC TEMP (K)

TF02011 $0.0 \quad 363.0$

TF02012 $360.0 \quad 363.0$

TF02013 $362.0 \quad 370.0$

TF02014 $2100.0 \quad 378.0$

TF02015 $4200.0 \quad 383.0$

TF03000 'O2 FLOWRATE' $5 \quad 1.0 \quad 0.0$

- SEC FLOW (KG/S)

$\begin{array}{lll}\text { TF03011 } & 0.0 & 0.00793\end{array}$

TF03012 $360.0 \quad 0.00793$

TF03013 $362.0 \quad 0.007614$

TF03014 2100.0 0.0075

TF03015 $4200.0 \quad 0.007374$

TF05000 'STM FLOWRATE' $4 \quad 1.0 \quad 0.0$ 
- SEC FLOW (KG/S)

$\begin{array}{lll}\text { TF05011 } & 0.0 & 0.2\end{array}$

TF05012 $360.0 \quad 0.2$

TF05013 $2100.0 \quad 0.1975$

TF05014 $4200.0 \quad 0.195$

-

TF06000 'STM ENTHALPY' $4 \quad 1.0 \quad 0.0$

- SEC FLOW (J/S)

TF06011 $0.0 \quad 5.351 E+5$

TF06012 $360.0 \quad 5.351 E+5$

TF06013 2100.0 5.304E+5

TF06014 4200.0 5.2577E+5

-

(2).

$\bullet$

* CVO20 IS THE SECOND MIXING CHAMBER - PNL ICE CONDENSER FACILITY -

CV02000 'MIXCH2' 221 'NONEQ., VERT, RCS

CVO2002 $0.0 \quad 0.0 \quad$ VLATMO, VLPOLO

CVO20A1 PVOL 109025.

CVO20A2 TATM 363.

CVO20A3 PH2O 0.0 -NO STEAM INITIALLY

CVO2OA4 MLFR.4 0.8 -N2

CVO2OA5 MLFR.5 $0.2 \quad \cdot 02$

*

CVO20B1 $1.04775 \quad 0.0$

CVO20B2 $\quad 5.65549 \quad 0.3366$

-

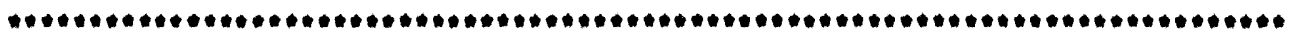

*. CV100 IS THE DIFFUSER INLET

CV10000 'DIFFINLET' 221 'NONEQ., VERT, RCS

CV10002 $0.0 \quad 0.0 \quad$ VLATMO, VLPOLO

CV100A1 PVOL 108825.

CV100A2 TATM 353.

CV1OOA3 PH2O 0.0 - NO STEAM INITIALLY

CV100A4 MLFR.4 0.8 "N2

CV100A5 MLFR.5 0.2 •O2

-

$\begin{array}{lll}C V 100 B 1 & 0.21 & 0.0\end{array}$ 


$\begin{array}{lll}\text { CV100B2 } & 0.2405 & 0.01720 \\ \text { CV100B3 } & 0.271 & 0.04713 \\ \text { CV100B4 } & 0.332 & 0.12360 \\ \text { CV100B5 } & 0.3625 & 0.1655 \\ \text { CV100B6 } & 0.393 & 0.2074 \\ \text { CV100B7 } & 0.4235 & 0.2837 \\ \text { CV100B8 } & 0.4845 & 0.3138 \\ \text { CV100B9 } & 1.04775 & 0.331 \\ \text { C } & & \end{array}$

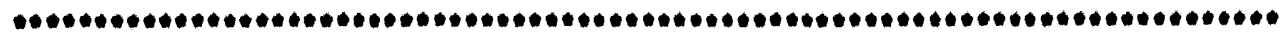

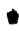

*. CV200 IS THE DIFFUSER

-

CV20000 'DIFFUSER' 211 'NONEQ., HORIZ, RCS

$\begin{array}{llll}\text { CV20002 } & 0.0 & 0.0 & \text { - VLATMO, VLPOLO }\end{array}$

CV200A1 PVOL 105625.

CV200A2 TATM 353.

CV200A3 PH2O 0.0 - NO STEAM INITIALLY

CV200A4 MLFR.4 0.8 'N2

CV200A5 MLFR.5 $0.2 \quad$ O2

-

$\begin{array}{lll}C V 200 B 1 & 0.0 & 0.0\end{array}$

$\begin{array}{lll}\text { CV200B2 } & 0.724 & 0.3498\end{array}$

-

CV200C1 MASS.1 2013

CV200C2 PE 2033

-

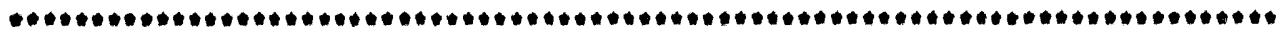

-

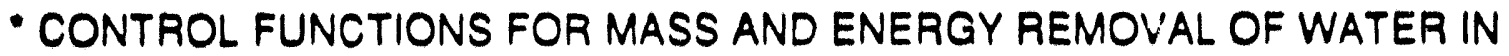

- CONTROL VOLUMES CV200 AND CV210

-

CF20000 TMAX EQUALS $1 \quad 1.0 \quad 0.0$

CF20010 $0.0 \quad 1.1$ TIME

-

CF20100 REMOV-CV200 DIVIDE 2 1.0 0.0

CF20111 $1.0 \quad 0.0$ CFVALU.200

$\begin{array}{llll}\text { CF20112 } & -0.25 & 0.0 & \text { CVH.MASS } 1.200\end{array}$

-

CF20200 REMOV-CV210 DIVIDE 2 1.0 0.0

CF20211 $1.0 \quad 0.0$ CFVALU.200 
$\begin{array}{llll}\text { CF20212 } & -0.25 \quad 0.0 \quad \text { CVH-MASS.1.210 }\end{array}$

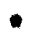

CF20300 REMOV-200E MULTIPLY $2 \quad 1.0 \quad 0.0$

CF20311 $1.0 \quad 0.0$ CFVALU.201

CF20312 $1.0 \quad 0.0$ CVH.H.1.200

-

CF20400 REMOV.210E MULTIPLY $21.0 \quad 0.0$

CF20411 $1.0^{-} \quad 0.0$ CFVALU.202

CF20412 $1.0 \quad 0.0 \quad \mathrm{CVH} \cdot \mathrm{H} .1 .210$

-

CF24000 T2MAX EQUALS $1 \quad 1.0 \quad 0.0$

CF24011 $0.0 \quad 1.1 \quad$ TIME

-

CF24100 H2O.CV32O DIVIDE $2 \quad 1.0 \quad 0.0$

CF24110 $1.0 \quad 0.0$ CFVALU.240

CF24111 $1.0 \quad 0.0$ CVH.MASS.3.310

-

CF24200 H2O.CV32O MULTIPLY $2 \quad 1.0 \quad 0.0$

CF24210 $1.0 \quad 0.0$ CFVALU.241

CF24211 $1.0 \quad 0.0$ CFVALU.264

*

$\begin{array}{lllll}C F 24300 & \text { N2.CV320 DIVIDE } 2 & 1.0 & 0.0\end{array}$

CF24310 $1.0 \quad 0.0$ CFVALU.240

CF24311 $1.0 \quad 0.0$ CVH.MASS.4.310

-

CF24400 N2-CV320 MULTIPLY $2 \quad 1.0 \quad 0.0$

CF24410 $1.0 \quad 0.0$ CFVALU.243

CF24411 $1.0 \quad 0.0$ CFVALU.264

-

$\begin{array}{lllll}C F 24500 & 02-C V 320 & \text { DIVIDE } 2 & 1.0 & 0.0\end{array}$

CF24510 $1.0 \quad 0.0$ CFVALU.240

CF24513 $1.0 \quad 0.0 \quad$ CVH.MASS.5.310

-

CF24600 O2.CV320 MULTIPLY $2 \quad 1.0 \quad 0.0$

CF24610 $1.0 \quad 0.0$ CFVALU.245

CF24611 $1.0 \quad 0.0$ CFVALU.264

-

CF24700 REMOV-3203 MULTIPLY $21.0 \quad 0.0$

CF24710 $1.0 \quad 0.0$ CFVALU.241

$\begin{array}{llll}\text { CF24711 } & 1.0 & 0.0 & \text { CVH.H.3.310 }\end{array}$ 
CF24800 REMOV-3204 MULTIPLY $21.0 \quad 0.0$

CF24810 $1.0 \quad 0.0$ CFVALU.243

CF24811 $1.0 \quad 0.0 \quad$ CVH.H.4.310

-

CF24900 REMOV.3205 MULTIPLY $21.0 \quad 0.0$

CF24910 $1.0 \quad 0.0$ CFVALU.245

CF24911 1.0 , 0.0 CVH.H.5.310

CF25000 REMOV.320E ADD $31.0 \quad 0.0$

CF25010 $1.0 \quad 0.0$ CFVALU.247

CF25011 $1.0 \quad 0.0$ CFVALU.248

CF25012 $1.0 \quad 0.0$ CFVALU.249

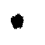

CF25100 REMOV.320E MULTIPLY $21.0 \quad 0.0$

CF25110 $1.0 \quad 0.0$ CFVALU.250

CF25111 $1.0 \quad 0.0$ CFVALU.264

-

CF25200 H2O.CV210 EQUALS $1 \quad 1.0 \quad 0.0$

CF25210 $\quad \cdot 1.0 \quad 0.0$ CFVALU.242

-

CF25300 N2.CV210 EOUALS $1 \quad 1.0 \quad 0.0$

$\begin{array}{llll}\text { CF25310 } & -1.0 \quad 0.0 & \text { CFVALU.244 }\end{array}$

-

CF25400 O2.CV210 EQUALS $1 \quad 1.0 \quad 0.0$

CF25410 - $1.0 \quad 0.0$ CFVALU.246

-

CF25500 ADD.210E EQUALS $111.0 \quad 0.0$

CF25510 $\cdot 1.0 \quad 0.0$ CFVALU.251

-

- Because CF260 is zero tor all time, nothing is removed

- trom CV320 and nothing is added to CV300. This logic

- was retained from the simulation of recirculation in

- Experiment 6

-

CF26000 'PERCENT' EQUALS $11.0 \quad 0.0$

$\begin{array}{lll}\text { CF26010 } & 0.0 & 0.0 \text { TIME }\end{array}$

-

CF26100 'MAXTIME' EQUALS $11.0 \quad 0.0$

CF26110 0.0 100.0 TIME

-

CF26200 'FRAC 1' DIVIDE $2 \quad 1.0 \quad 0.0$ 
CF26210 $1.0 \quad 0.0$ CFVALIJ.261

CF26211 $1.0 \quad 0.0$ TIME

-

CF26300 'FIN FRAC' MIN $2 \quad 1.0 \quad 0.0$

CF26310 $0.0 \quad 1.0$ TIME

CF26311 $1.0 \quad 0.0$ CFVALU.262

-

CF'26400 'TAKEOUT' MULTIPLY $21.0 \quad 0.0$

CF26410 $1.0 \quad 0.0$ CFVALU.260

CF26411 $\quad .1 .0 \quad 0.0$ CFVALU.263

-

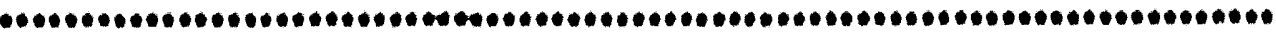

-

*. CV210 IS THE ICE BASKET ENTRY

-

CV21000 'ICE ENTRY' 221 'NONEO., VERT, RCS

$\begin{array}{llll}\text { CV21002 } & 0.0 & 0.0 & \text { V VLATMO, VLPOLO }\end{array}$

CV21003 0.5242

CV210A1 PVOL 104625.

CV210A2 TATM 338.

CV210A3 PH2O 0.0 - NO STEAM INITIALLY

CV210A4 MLFR.4 0.8 'N2

CV210A5 MLFR.5 $0.2 \quad 02$

-

$\begin{array}{lll}\text { CV210B1 } & 0.0 & 0.0\end{array}$

$\begin{array}{lll}\text { CV210B2 } & 1.2557 & 0.8975\end{array}$

-

CV210C1 MASS.1 2023

CV210C2 PE 2043

CV210C3 MASS.3 2523

CV210C4 MASS.4 $253 \quad 3$

CV210C5 MASS.5 2543

CV210C6 AE 2553

-

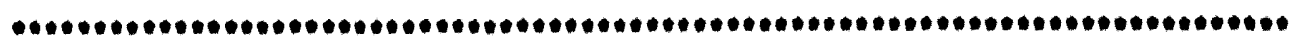

-

-. CV3OO IS THE FIRST ICE CONDENSER SECTION

-

CV30000 'ICECON 1' 221 'NONEQ., VERT, RCS

$\begin{array}{llll}\text { CV } 30002 & 0.0 & 0.0 & \text { "VLATMO, VLPOLO }\end{array}$

CV300A1 PVOL 103525. 
CV3O0A2 TA-M 331.
CV3OOA3 PH2O 0.0
- NO STEAM INITIALLY
CV3O0A4 MLFR.4
0.8
- N2
CV3OOA5 MLFR.5
0.2
- 02
-
$\begin{array}{lll}\text { CV300B1 } & 1.2557 \quad 0.0\end{array}$
$\begin{array}{lll}C V 300 B 2 & 6.1325 & 2.039\end{array}$

-

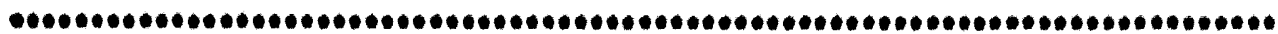

-

CV310 IS THE SECOND ICE CONDENSER SECTION

CV31000 'ICECON 2' 221 'NONEQ., VERT, RCS

$\begin{array}{llll}C V 31002 & 0.0 & 0.0 & \text { 'VLATMO, VLPOLO }\end{array}$

CV310A1 PVOL 102825.

CV310A2 TATM 313.

CV310A3 PH2O 0.0 - NO STEAM INITIALLY

CV310A4 MLFR.4 0.8 'N2

CV310A5 MLFR.5 $0.2 \quad \cdot 02$

-

$\begin{array}{lll}C V 310 B 1 & 6.1325 & 0.0\end{array}$

$\begin{array}{lll}\text { CV310B2 } & 11.0093 \quad 2.039\end{array}$

-

CV310C1 MASS.3 2423

CV310C2 MASS.4 2443

CV310C3 MASS.5 $246 \quad 3$

CV310C4 AE 2513

-

C CV320 IS THE THIRD ICE CONDENSER SECTION

$\cdot$

CV32000 'ICECON 3' 221 'NONEQ, VERT, RCS

$\begin{array}{llll}C V 32002 & 0.0 & 0.0 & \text { OVLATMO, VLPOLO }\end{array}$

CV320A1 PVOL 101425.

CV320A2 TATM 283.

CV320A3 PH2O 0.0 -NO STEAM INITIALLY

CV320A4 MLFR.4 0.8 'N2

CV320A5 MLFR.5 $0.2 \quad \cdot 02$

-

$\begin{array}{lll}C V 320 B 1 & 11.0093 \quad 0.0\end{array}$ 
$\begin{array}{lll}\text { CV320B2 } & 15.9961 \quad 2.039\end{array}$

$\bullet$

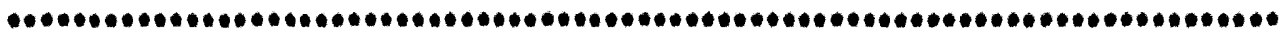

$\bullet$

CVAOO IS THE OUTLET SECTION

$\bullet$

CV40000 'OUTLET' 221 'NONEQ., VERT, RCS

$\begin{array}{llll}\text { CV40002 } & 0.0 & 0.0 & \text { 'VLATMO, VLPOLO }\end{array}$

CV40003 0.5242

CV400A1 PVOL 101325.

CV4OOA2 TATM 283.

CV400A3 PH2O 0.0 - NO STEAM INITIALLY

CV4OOA4 MLFR.4 0.8 'N2

CVAOOAS MLFR.5 $0.2 \quad \cdot 02$

-

CV400B1 $15.8861 \quad 0.0$

CV400B2 $16.9261 \quad 0.7456$

-

[...................................................................................

$\cdot$

.. CV45O IS THE ENVIRONMENT

$\cdot$

CV45000 'ENVIRON' 211 'NONEQ, HORIZ, RCS

$\begin{array}{llll}C V 45002 & 0.0 & 0.0 & \text { VVLATMO, VLPOLO }\end{array}$

CV450A1 PVOL 101125.

CV450A2 TATM 294.

CV450A3 PH2O 0.0 -NO STEAM INITIALLY

CV450A4 MLFR.4 0.8 'N2

CV450A5 MLFR.5 $0.2 \quad \cdot 02$

-

$\begin{array}{lll}C V 450 B 1 & 0.0 & 0.0\end{array}$

CV450B2 $20.0 \quad 1.0 E+6$

-

(.7.

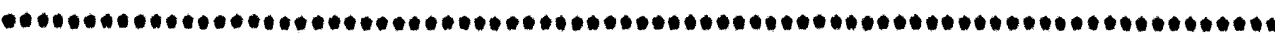

$\bullet$

FLOW PATH INPUT

$\bullet \bullet$

$\bullet \bullet \bullet \bullet \bullet \bullet \bullet \bullet \bullet \bullet \bullet \bullet \bullet \bullet \bullet \bullet \bullet \bullet \bullet \bullet \bullet \bullet \bullet \bullet \bullet \bullet \bullet \bullet \bullet \bullet \bullet \bullet \bullet \bullet \bullet \bullet \bullet \bullet \bullet \bullet \bullet \bullet \bullet \bullet \bullet \bullet \bullet \bullet \bullet \bullet \bullet \bullet \bullet \bullet \bullet \bullet \bullet \bullet \bullet \bullet \bullet \bullet \bullet \bullet \bullet \bullet \bullet \bullet \bullet \bullet \bullet \bullet \bullet \bullet \bullet \bullet \bullet \bullet \bullet$

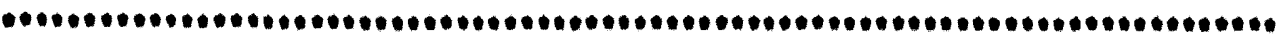

- 
... FL010 IS THE MIXING CHAMBER 1 TO MIXING CHAMBER 2

-

FL01000 'MIX1TO2' $010 \quad 020 \quad 5.65549 \quad 5.65549$

FL01001 $0.073 \quad 4.6077 \quad 1.0 \quad 0.1525 \quad 0.1525$-AREA, LENGTH, OPEN FL01002 0

FL01003 $0.01 \quad 0.01$

- Vert

FLO10S1 $0.073 \quad 4.6077 \quad 0.305$

- LOSS COEFFS

- AREA, LENGTH, HYD. DIA

-

$\bullet \bullet \bullet \bullet \bullet \bullet \bullet \bullet \bullet \bullet \bullet \bullet \bullet \bullet \bullet \bullet \bullet \bullet \bullet \bullet \bullet \bullet \bullet \bullet \bullet \bullet \bullet \bullet \bullet \bullet \bullet \bullet \bullet \bullet \bullet \bullet \bullet \bullet \bullet \bullet \bullet \bullet \bullet \bullet \bullet \bullet \bullet \bullet \bullet \bullet \bullet \bullet \bullet \bullet \bullet \bullet \bullet \bullet \bullet \bullet \bullet \bullet \bullet \bullet \bullet \bullet \bullet \bullet \bullet \bullet \bullet \bullet \bullet \bullet \bullet \bullet \bullet \bullet \bullet$

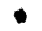

... FL100 IS THE MIXING CHAMBER 2 TO THE DIFFUSER INLET

,

FL10000 'MIX2TOINLET' $020 \quad 100 \quad 1.04775 \quad 1.04775$

FL10001 $0.073 \quad 4.083 \quad 1.0 \quad 0.1525 \quad 0.1525$-AREA, LENGTH, OPEN

FL10002 0

FL10003 $0.60 \quad 0.60$

- VERT

FL100S1

$0.073 \quad 4.083$

0.305

- LOSS COEFFS

- AREA, LENGTH, HYD. DIA

-

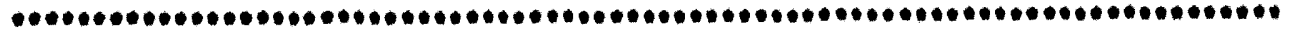

$\cdot$

.. FL200 IS THE DIFFUSER INLET TO THE DIFFUSER

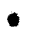

FL20000 'INLETODIFF' $100 \quad 200 \quad 0.362 \quad 0.362$

$\begin{array}{lllllll}\text { FL20001 } & 0.093 & 2.6492 & 1.0 & 0.344 & 0.344 & \text { AREA, LENGTH, OPEN }\end{array}$

FL20002 3

FL20003 $0.01 \quad 0.01$

- HORIZ

FL200S1 $0.093 \quad 2.6492 \quad 2.6492$

- LOSS COEFFS

- AREA, LENGTH, HYD. DIA

-

.

*. FL201 IS THE DIFFUSER TO THE DIFFUSER DRAIN

'FL20100 'DIFF DRAIN' $2002010.0 \quad 0.0$

$\begin{array}{llllllll}\cdot F L 20101 & 0.093 & 0.5 & 1.0 & 0.344 & 0.344 & \text { AREA, LENGTH, OPEN }\end{array}$

-FL20102 2

- POOL FIRST VERT

'FL20103 $0.01 \quad 0.01$

$\begin{array}{llll}\text { "FL201S1 } & 0.093 & 0.5 & 2.6492\end{array}$

- LOSS COEFFS

- AREA, LENGTH, HYD. DIA

$\bullet$

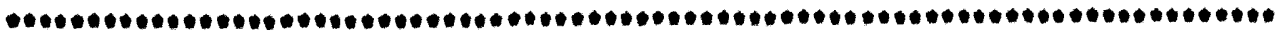

-

$\cdots$ FL210 IS THE DIFFUSER TO BASKET ENTRT 
FL21000 'DIFF TOICECONIN' $200 \quad 210 \quad 0.362 \quad 0.362$

FL21001 $0.524 \quad 1.7264 \quad 1.0 \quad 0.8168 \quad 0.8168$ 'AREA, LENGTH, OPEN

FL21002 3

FL21003 $0.30 \quad 0.30$

FL210S1 $0.524 \quad 1.7264 \quad 0.724$

- HORIZ

- LOSS COEFFS

- AREA, LENGTH, HYD. DIA

-

-

-. Fl300 is Basket entry to ICE CONDENSER 1

$\bullet$

FL30000 'ENTRYTOICECON1' $210 \quad 300 \quad 1.2557 \quad 1.2557$

FL30001 $0.5243 .2948 \quad 1.0 \quad 0.4084 \quad 0.4084$ • AREA, LENGTH, OPEN

FL30002 0

- ATMOS ONLY, VERT

FL30003 $0.50 \quad 0.50$

- LOSS COEFFS

FL300S1 $0.524 \quad 3.2948 \quad 0.724$

- AREA, LENGTH, HYD. DIA

-

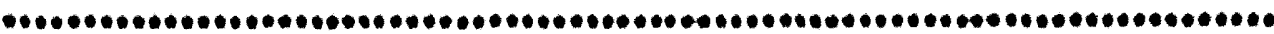

-

*. FL3O1 IS SECOND BASKET ENTRY TO ICE CONDENSER 1

-

FL30100 'ENTRYTOICECON1' $210 \quad 300 \quad 1.2557 \quad 1.2557$

FL30101 $0.05240 .329481 .0 \quad 0.040840 .04084$-AREA, LENGTH, OPEN

FL30102 0

FL30103 $5.00 \quad 5.00$

- POOL ONLY, VERT

FL301S1 $0.0524 \quad 0.32948 \quad 0.0724$

- LOSS COEFFS

-

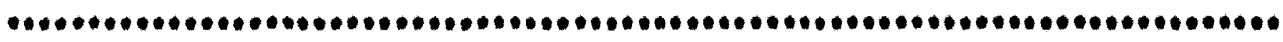

-

*. FL310 IS BASKET 1 TO BASKeT 2

-

FL31000 'BASK1TO2' $300 \quad 310 \quad 6.1325 \quad 6.1325$

FL31001 $0.1672 \quad 4.8768 \quad 1.0 \quad 0.2307 \quad 0.2307$ •AREA, LENGTH, OPEN

FL31002 0

- ATMOS ONLY, VERT

FL31003 $10.0 \quad 10.0$

- LOSS COEFFS

FL310S1 $0.1672 \quad 4.8768 \quad 0.1$

- AREA, LENGTH, HYD. DIA

-

$\bullet \bullet \bullet \bullet \bullet \bullet \bullet \bullet \bullet \bullet \bullet \bullet \bullet \bullet \bullet \bullet \bullet \bullet \bullet \bullet \bullet \bullet \bullet \bullet \bullet \bullet \bullet \bullet \bullet \bullet \bullet \bullet \bullet \bullet \bullet \bullet \bullet \bullet \bullet \bullet \bullet \bullet \bullet \bullet \bullet \bullet \bullet \bullet \bullet \bullet \bullet \bullet \bullet \bullet \bullet \bullet \bullet \bullet \bullet \bullet \bullet \bullet \bullet \bullet \bullet \bullet \bullet \bullet \bullet \bullet \bullet \bullet \bullet \bullet \bullet \bullet \bullet \bullet$

-

*. FL311 IS SECOND BASKET 1 TO BASKET 2

- 
FL31100 'BASK1TO2' $300 \quad 310 \quad 6.1325 \quad 6.1325$

FL31101 $0.016720 .48768 \quad 1.0 \quad 0.02307 \quad 0.02307$ • AREA, LENGTH, OPEN

FL31102 0

FL31103 100. 100.

FL311S1 $0.01672 \quad 0.048768 \quad 0.01$
- POOL ONLY, VERT

- LOSS COEFFS

- AREA, LENGTH, HYD. DIA

-

$\bullet \bullet \bullet \bullet \bullet \bullet \bullet \bullet \bullet \bullet \bullet \bullet \bullet \bullet \bullet \bullet \bullet \bullet \bullet \bullet \bullet \bullet \bullet \bullet \bullet \bullet \bullet \bullet \bullet \bullet \bullet \bullet \bullet \bullet \bullet \bullet \bullet \bullet \bullet \bullet \bullet \bullet \bullet \bullet \bullet \bullet \bullet \bullet \bullet \bullet \bullet \bullet \bullet \bullet \bullet \bullet \bullet \bullet \bullet \bullet \bullet \bullet \bullet \bullet \bullet \bullet \bullet \bullet \bullet \bullet \bullet \bullet \bullet \bullet \bullet \bullet \bullet \bullet \bullet$

$\bullet$

*. FL320 IS BASKeT 2 TO BASKeT 3

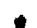

FL32000 'BASK2TO3' $310 \quad 320 \quad 11.0093 \quad 11.0093$

$\begin{array}{lllllll}\text { FL32001 } & 0.1672 & 4.8768 & 1.0 & 0.2307 & 0.2307 & \text { *AREA, LENGTH, OPEN }\end{array}$

FL32002 0

FL32003 $10.0 \quad 10.0$

- ATMOS ONLY, VERT

FL320S1 $0.1672 \quad 4.8768 \quad 0.1$

- LOSS COEFFS

- AREA, LENGTH, HYD. DIA

-

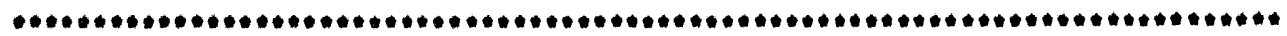

$\cdot$

-. FL321 IS SECOND BASKET 2 TO BASKET 3

-

FL32100 'BASK2TO3' $310 \quad 320 \quad 11.0093 \quad 11.0093$

FL32101 $0.016720 .48768 \quad 1.0 \quad 0.02307 \quad 0.02307$ *AREA, LENGTH, OPEN

FL32102 0

FL32103 100. 100.

- POOL ONLY, VERT

$\begin{array}{llll}\text { FL321S1 } & 0.01672 & 0.48768 & 0.01\end{array}$

- LOSS COEFFS

- AREA, LENGTH, HYD. DIA

-

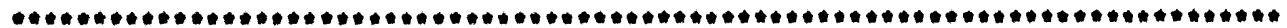

-

*. FL 400 IS BASKET 3 TO THE OUTLET SECTION

-

FL40000 'BASK3TOOUT' $320 \quad 400 \quad 15.8861 \quad 15.8861$

FL40001 $0.1672 \quad 3.2064 \quad 1.0 \quad 0.2307 \quad 0.2307$ 'AREA, LENGTH, OPEN

FL40002 0

FL40003 $6.0 \quad 6.0$

FL400S1 $0.1672 \quad 3.2064 \quad 0.1$

- VERT

- LOSS COEFFS

- AREA, LENGTH, HYD. DIA

-

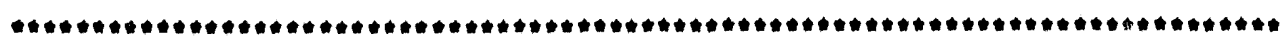

-

*. Fl450 is THE OUTLET TO THE ENVIRONMENT

-

FL45000 'OUTTOENV' $400 \quad 45 \backsim 16.5529 \quad 16.5529$ 


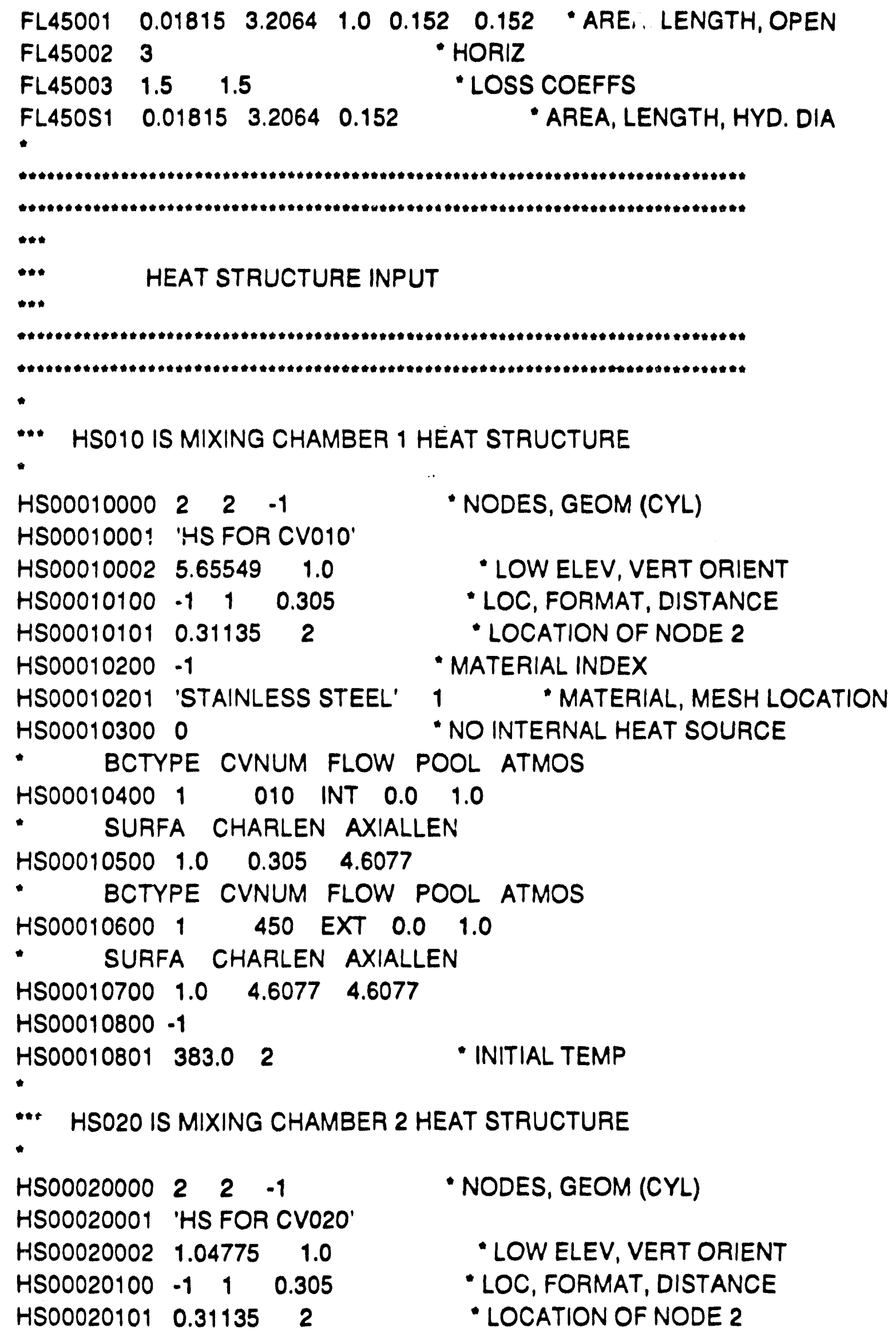

$\begin{array}{llll}H S 00020000 & 2 & 2 & -1\end{array}$ HS00020001 'HS FOR CV020' HSO0020002 $1.04775 \quad 1.0$ $\begin{array}{llll}H S 00020100 & -1 & 1 & 0.305\end{array}$ HSO0020101 $0.31135 \quad 2$

- NODES, GEOM (CYL)

- LOW ELEV, VERT ORIENT

- LOC, FORMAT, DISTANCE

- LOCATION OF NODE 2 


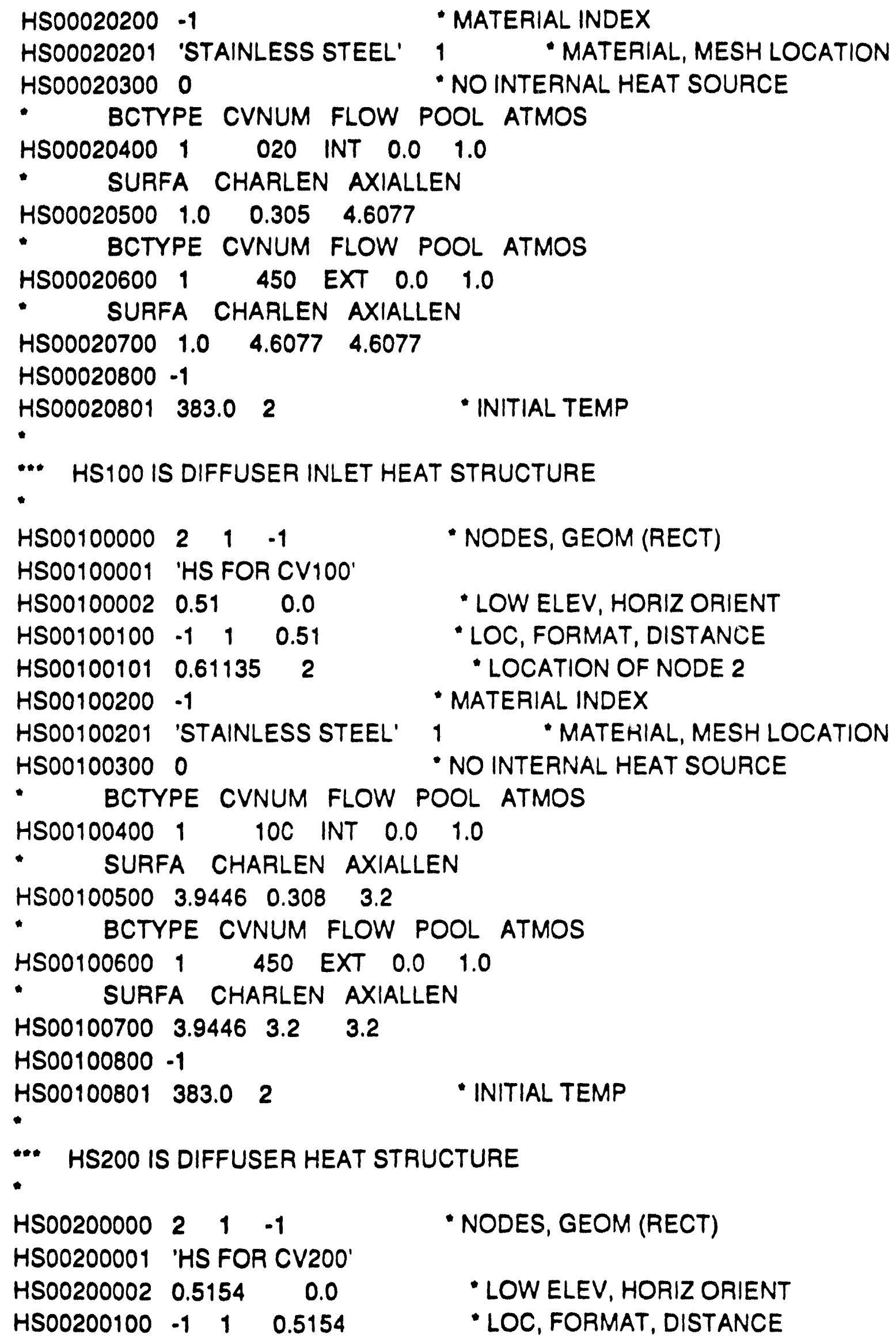

$\begin{array}{llll}H S 00200000 & 2 & 1 & -1\end{array}$ HSO0200001 'HS FOR CV200' $\begin{array}{lll}\text { HSO0200002 } & 0.5154 & 0.0\end{array}$ $\begin{array}{llll}H S 00200100 & -1 & 1 & 0.5154\end{array}$

- NODES, GEOM (RECT)

- LOW ELEV, HORIZ ORIENT

- LOC, FORMAT, DISTANCE 
HSO0200101 $0.52175 \quad 2$

HSO0200200 - -1

HSO0200201 'STAINLESS STEEL'

HSO0200300 O
- LOCATION OF NODE 2

- material INDEX

1 - MATERIAL, ". ESH LOCATION

- No INTERNAL hEAT SOURCE

- BCTYPE CVNUM FLOW POOL ATMOS

HSO0200400 $1 \quad 450$ EXT $0.0 \quad 1.0$

- SURfa charlen axiallen

$\begin{array}{llll}H S 00200500 & .2 .53 & 1.74 & 1.74\end{array}$

- BCTYPE CVNUM FLOW POOL ATMOS

$\begin{array}{llllll}H S 00200600 & 1 & 200 & \text { INT } & 0.0 & 1.0\end{array}$

- SURFa charlen axIALLEN

$\begin{array}{llll}H S 00200700 & 2.53 & 0.5154 & 1.74\end{array}$

HSO0200800 - 1

HSO0200801 $373.0 \quad 2$

- inITIAL TEMP

-

*.* HS210 IS THE VERTICAL PORTIO: OF ICE BASKET ENTRY HEAT STRUCTURE

HSO0210000 $2 \quad 1 \quad-1$

- NODES, GEOM (RECT)

HSO0210001 'VERT HS-CV210'

$\begin{array}{lll}H S 00210002 & 0.0 & 1.0\end{array}$

$\begin{array}{llll}H S 00210100 & -1 & 1 & 0.724\end{array}$

HSO0210101 $0.73035 \quad 2$

HSO0210200 - 1

HSO0210201 'STAINLESS STEEL'

HSO0210300 O

- BCTYPE CVNUM FLOW POOL ATMOS

- LOW ELEV, VERT ORIENT

- LOC, FORMAT, DISTANCE

- LOCATION OF NODE 2

- MATERIAL INDEX

1 - MATERIAL, MESH LOCATION

HSO0210400 1210 INT $0.0 \quad 1.0$

- SURFa charlen axiallen

$\begin{array}{llll}H S O 0210500 & 1.048 & 0.724 & 0.362\end{array}$

- bCTYPe cVNuM flow pOOL atMOs

$\begin{array}{llllll}H S 00210600 & 1 & 450 & \text { EXT } & 0.0 & 1.0\end{array}$

- surfa charlen axiallen

$\begin{array}{llll}\text { HSOO210700 } & 1.048 & 0.724 & 0.362\end{array}$

HSO0210800 - 1

HSO0210801 $363.0 \quad 2$

- INITIAL TEMP

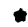

** HS215 IS THE HORIZONTAL PORTION OF ICE BASKET ENTRY HEAT STRUCTURE

-

$\begin{array}{llll}H S 00215000 & 2 & 1 & -1\end{array}$

HSO0215001 'HORIZHS.CV210'

$\begin{array}{lll}H S 00215002 & 0.724 & 0.0\end{array}$
- NODES, GEOM (RECT)

- LOW ELEV, HORIZ ORIENT 153 
$\begin{array}{llll}H S 00215100 & -1 & 1 & 0.724\end{array}$

HSOO215101 $0.73035 \quad 2$

HSO0215200 - 1

HSO0215201 'STAINLESS STEEL'

HSO0215300 O
- LOC, FORMAT, DISTANCE

- LOCATION OF NODE 2

- MATERIAL INDEX

1

- mateRIAL, MESH LOCATION

- NO INTERNAL HEAT SOURCE

- BCTYPE CVNUM FLOW POOL ATMOS

HSO0215400 1

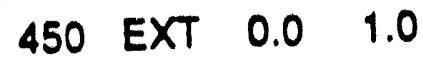

SURFA CHARLEN AXIALLEN

$\begin{array}{llll}H S O 0215500 & 2.3655 & 0.8168 & 0.8168\end{array}$

- BCTYPE CVNUM FLOW POOL ATMOS

$\begin{array}{llllll}H S 00215600 & 1 & 210 & \text { INT } & 0.0 & 1.0\end{array}$

- SURFa charlen axiallen

$\begin{array}{llll}H S 00215700 & 2.3655 & 0.8168 & 0.8168\end{array}$

HSO0215800 - 1

HSO0215801 $348.0 \quad 2$

- inItial TEMP

*

*.* HS3OO IS ICE CONDENSER 1

HSO0300000 $2 \quad 2 \quad .1$

HSO0300001 'ICE CONDENS 1'

HSO0300002 $1.2557 \quad 1.0$

HSO0300100 $-1 \quad 1 \quad 0.0$

HSOO300101 $0.23125 \quad 2$

HSO0300200 -1

HSO0300201 'BASKET' 1

HSO0300300 O

HSO0300400 O
- NODES, GEOM (CYL)

- LOW ELEV, VERT ORIENT

- LOC, FORMAT, DISTANCE

- LOCATION OF NODE 2

- MATERIAL INDEX

- MATERIAL, MESH LOCATION

- NO INTERNAL HEAT SOURCE

- ADIABATIC INSIDE BOUND

- BCTYPE CVNUM FLOW POOL ATMOS

HSO0300600 1

$300 \quad$ ICE $\quad 0.5 \quad 0.5$

- SURFa charlen axIALLEN

$\begin{array}{llll}H S 00300700 & 533.0 & 0.032 & 4.8768\end{array}$

HSO0300800 - 1

HSO0300801 $274.0 \quad 2$

- INITIAL TEMP

- SPECIAL ICE CONDENSER CARDS ARE NEXT

HSDG003000 $00300 \quad 1$ 'POOL'

HSDG003001 $1002.0 \quad 374799$. 274. 284. 1.20 .250 .5

... HS301 IS THE hORIZONTAL METAL BASKET OF ICE CONDENSER 1

*

HSO0301000 $2 \quad 1 \quad-1$

- NODES, GEOM (RECT)

HS00301001 'BASKET 1H' 


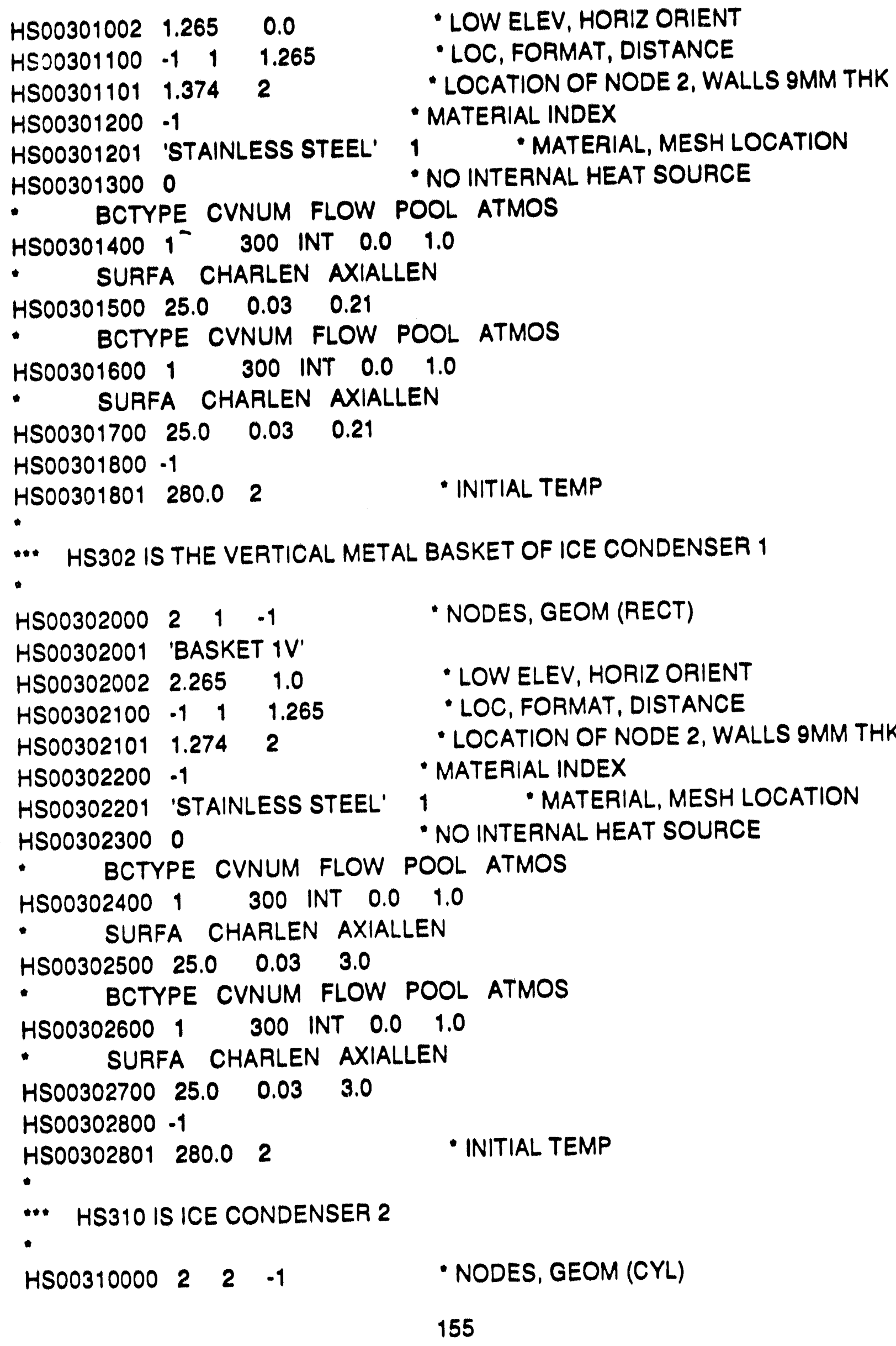


HSO0310001 'ICE CONDENS 2'

\begin{tabular}{|c|c|c|}
\hline HSO0310002 & $6.1325 \quad 1.6$ & • LOW ELEV, VERT ORIENT \\
\hline HSO0310100 & -11 & • LOC, FORMAT, DISTANCE \\
\hline HS00310101 & $0.23125 \quad 2$ & - LOCATION OF NODE 2 \\
\hline HSO0310200 & -1 & - MATERIAL INDEX \\
\hline HSO0310201 & 'BASKET' & - MATERIAL, MESH LOCATION \\
\hline $\begin{array}{l}\text { HSO0310300 } \\
\text { HSO0310400 }\end{array}$ & & $\begin{array}{l}\text { - NO INTERNAL HEAT SOURCE } \\
\text { - ADIABATIC INSIDE BOUND }\end{array}$ \\
\hline
\end{tabular}

- BCTYPE CVNUM FLOW POOL ATMOS

$\begin{array}{llllll}H S 00310600 & 1 & 310 & \text { ICE } & 0.5 & 0.5\end{array}$

- surfa charlen axiallen

$\begin{array}{llll}H S 00310700 & 533.0 & 0.032 & 4.8768\end{array}$

HSO0310800 - 1

HSO0310801 274.02 - INITIAL TEMP

- SPECIAL ICE CONDENSER CARDS ARE NEXT

HSDG003100 003101 'POOL'

HSDG003101 $1002.0 \quad 374799.274 .284 .1 .20 .250 .5$

-

*. HS311 IS THE HORIZONTAL METAL BASKET OF ICE CONDENSER 2

$\bullet$

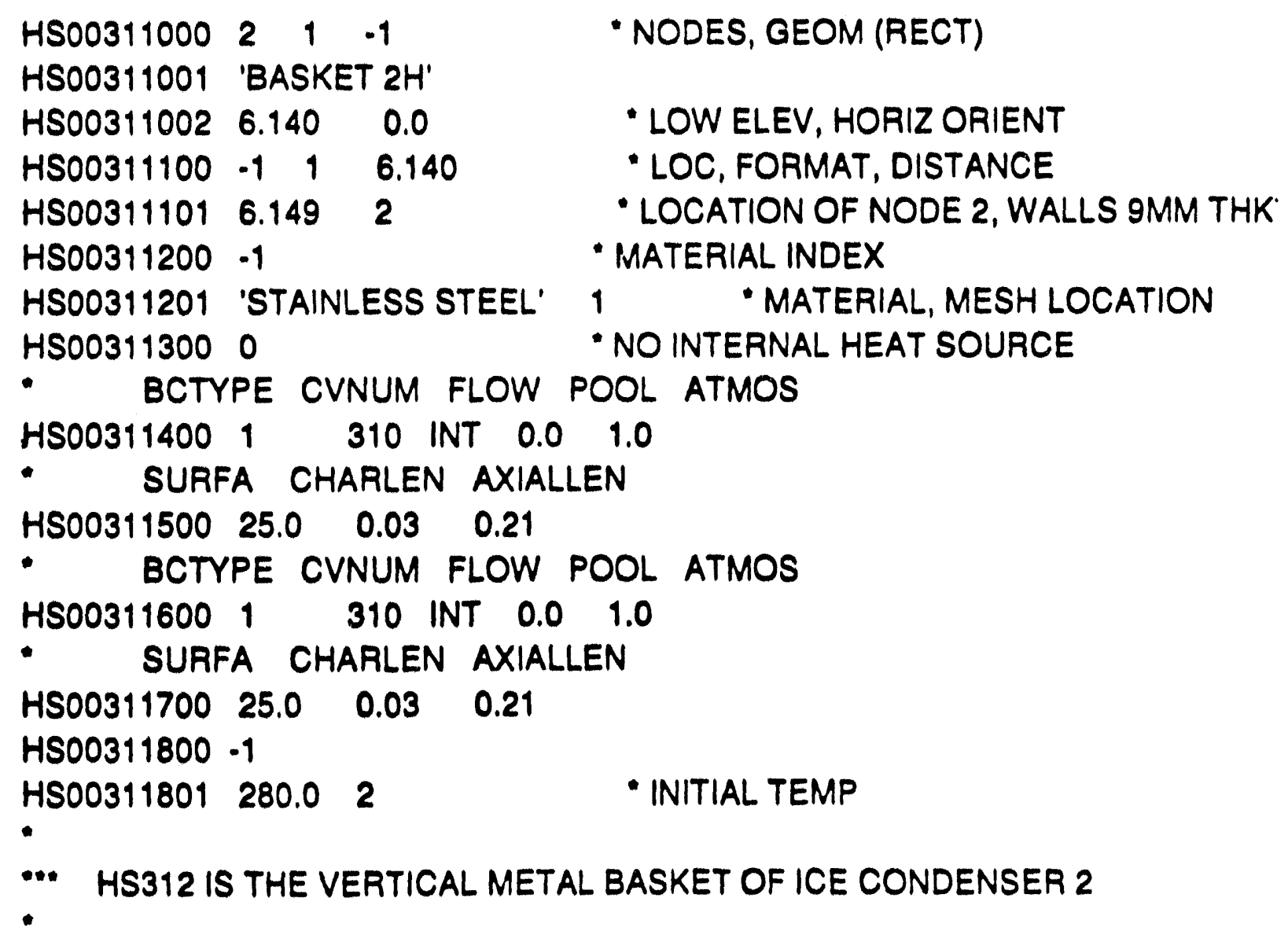




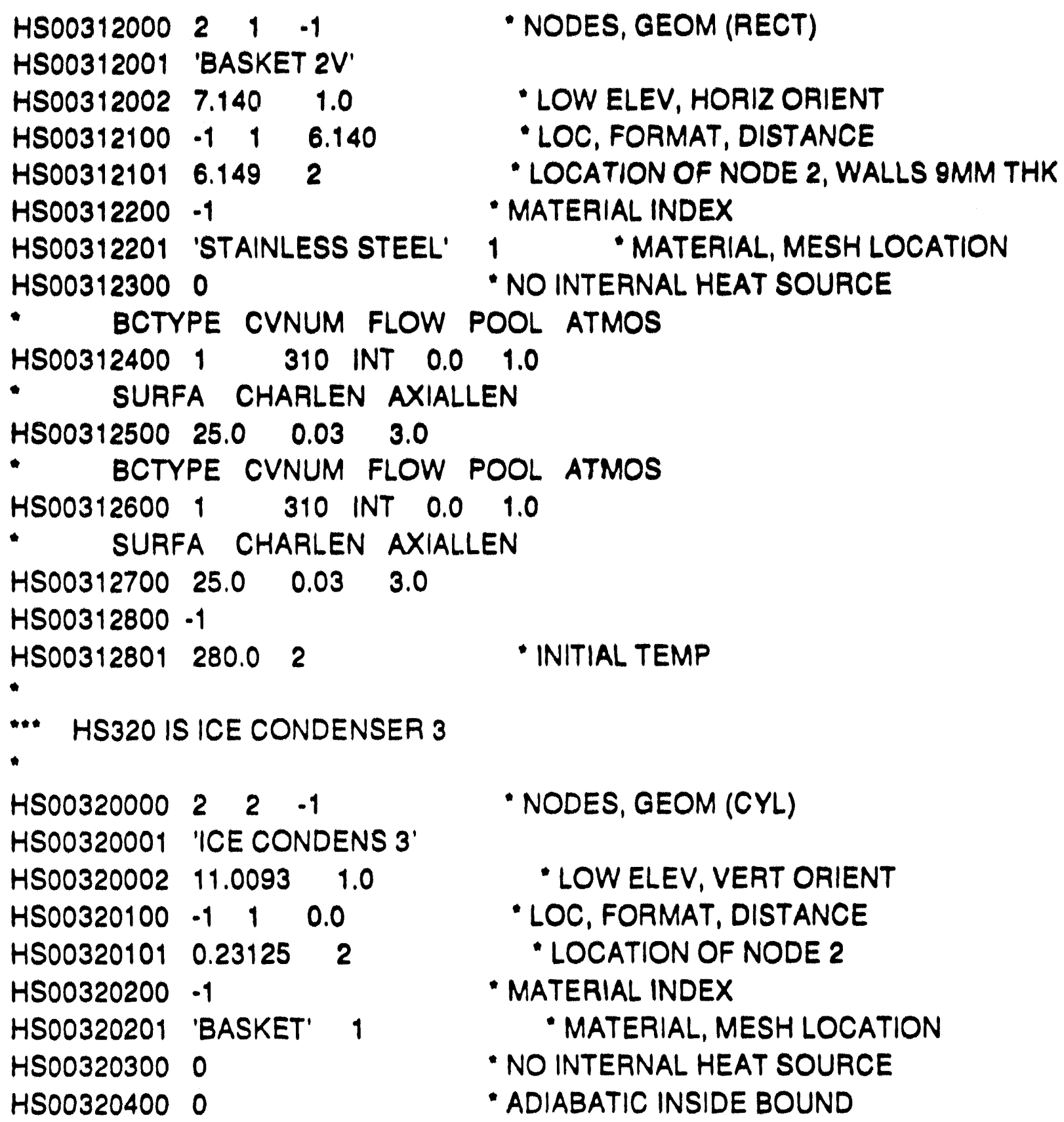




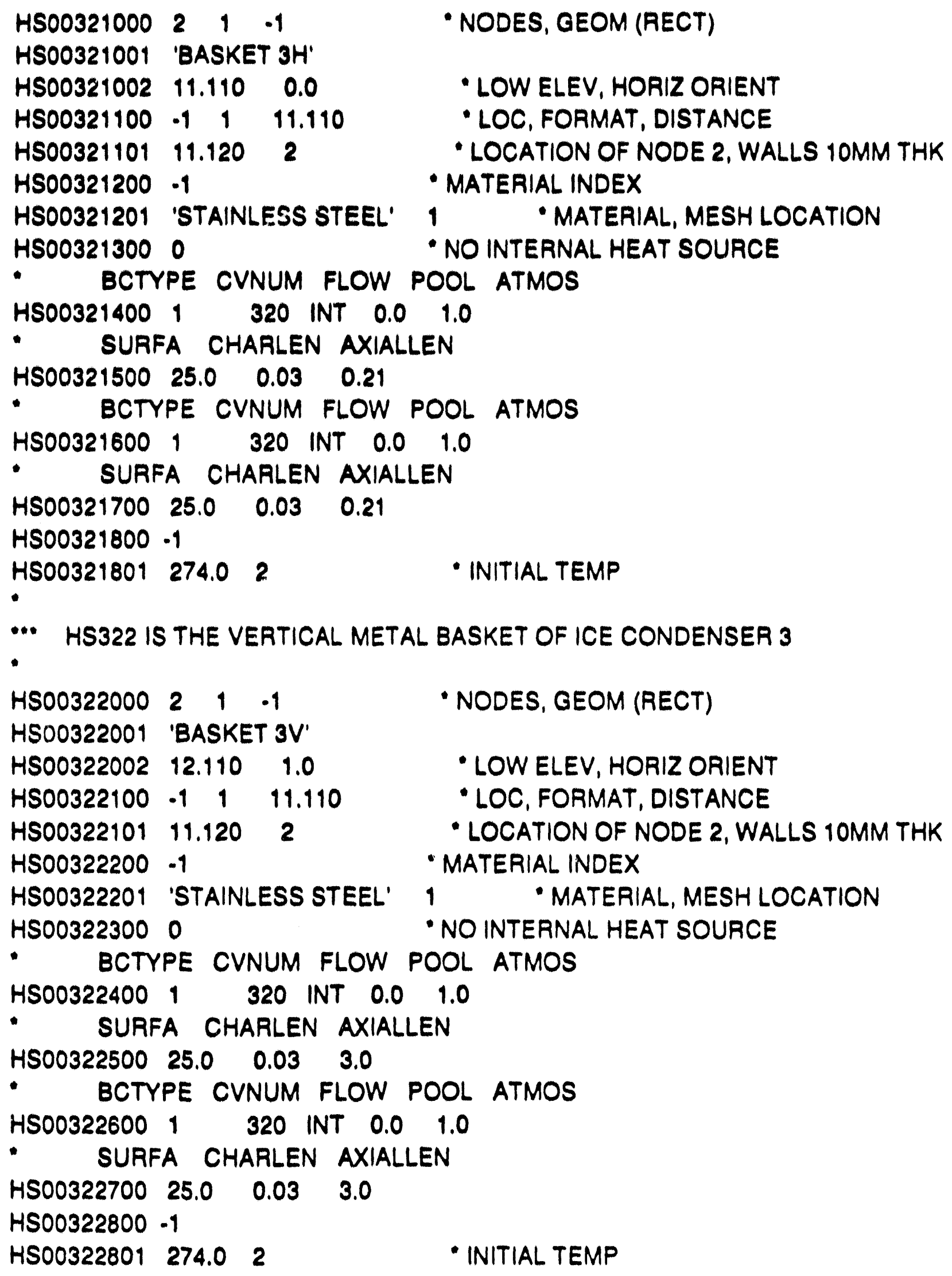

$\begin{array}{llll}H S 00321000 & 2 & 1 & -1\end{array}$

HSO0321001 'BASKET 3H'

HSO0321002 $11.110 \quad 0.0$

HSO0321100

HSO0321101 $11.120 \quad 2$

HSO0321200 -1

HSO0321201 'STAINLESS STEEL' I

HSOO321300 O

- NODES, GEOM (RECT)

- LOW ELEV, HORIZ ORIENT

- LOC, FORMAT, DISTANCE

- LOCATION OF NODE 2, WALLS 1OMM THK

- MATERIAL INDEX

1 MATERIAL, MESH LOCATION

- NO INTERNAL HEAT SOURCE

- BCTYPE CVNUM FLOW POOL ATMOS

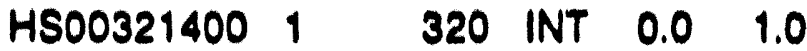

- SURFa charlen axiallen

$\begin{array}{llll}H S 00321500 & 25.0 & 0.03 & 0.21\end{array}$

- BCTYPE CVNUM FLOW POOL ATMOS

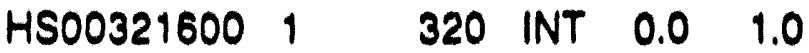

- SURFA CHARLEN AXIALLEN

$\begin{array}{llll}H S O 0321700 & 25.0 & 0.03 & 0.21\end{array}$

HSO0321800 - 1

HSO0321801 274.02 - INITIAL TEMP

*.* HS322 IS THE VERTICAL METAL BASKET OF ICE CONDENSER 3

$\begin{array}{llll}H S 00322000 & 2 & 1 & -1\end{array}$

- NODES, GEOM (RECT)

HSO0322001 'BASKET 3V'

HSO0322002 $12.110 \quad 1.0$

- LOW ELEV, HORIZ ORIENT

HSO0322100

- LOC, FORMAT, DISTANCE

HSOO322101 $11.120 \quad 2$

- LOCATION OF NODE 2, WALLS 1OMM THK

HSO0322200 - 1

- MATERIAL INDEX

HSO0322201 'STAINLESS STEEL'

HSO0322300 O

- MATERIAL, MESH LOCATION

- NO INTERNAL HEAT SOURCE

BCTYPE CVNUM FLOW POOL ATMOS

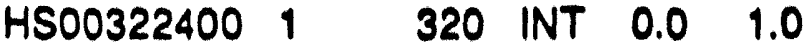

- surfa charlen axiallen

$\begin{array}{llll}H S 00322500 & 25.0 & 0.03 & 3.0\end{array}$

- BCTYPE CVNUM FLOW POOL ATMOS

$\begin{array}{llllll}H S 00322600 & 1 & 320 & \text { INT } & 0.0 & 1.0\end{array}$

- SURFA CHARLEN AXIALLEN

$\begin{array}{llll}H S 00322700 & 25.0 & 0.03 & 3.0\end{array}$

HSO0322800 - 1

HSO0322801 274.02 ・INITIAL TEMP 


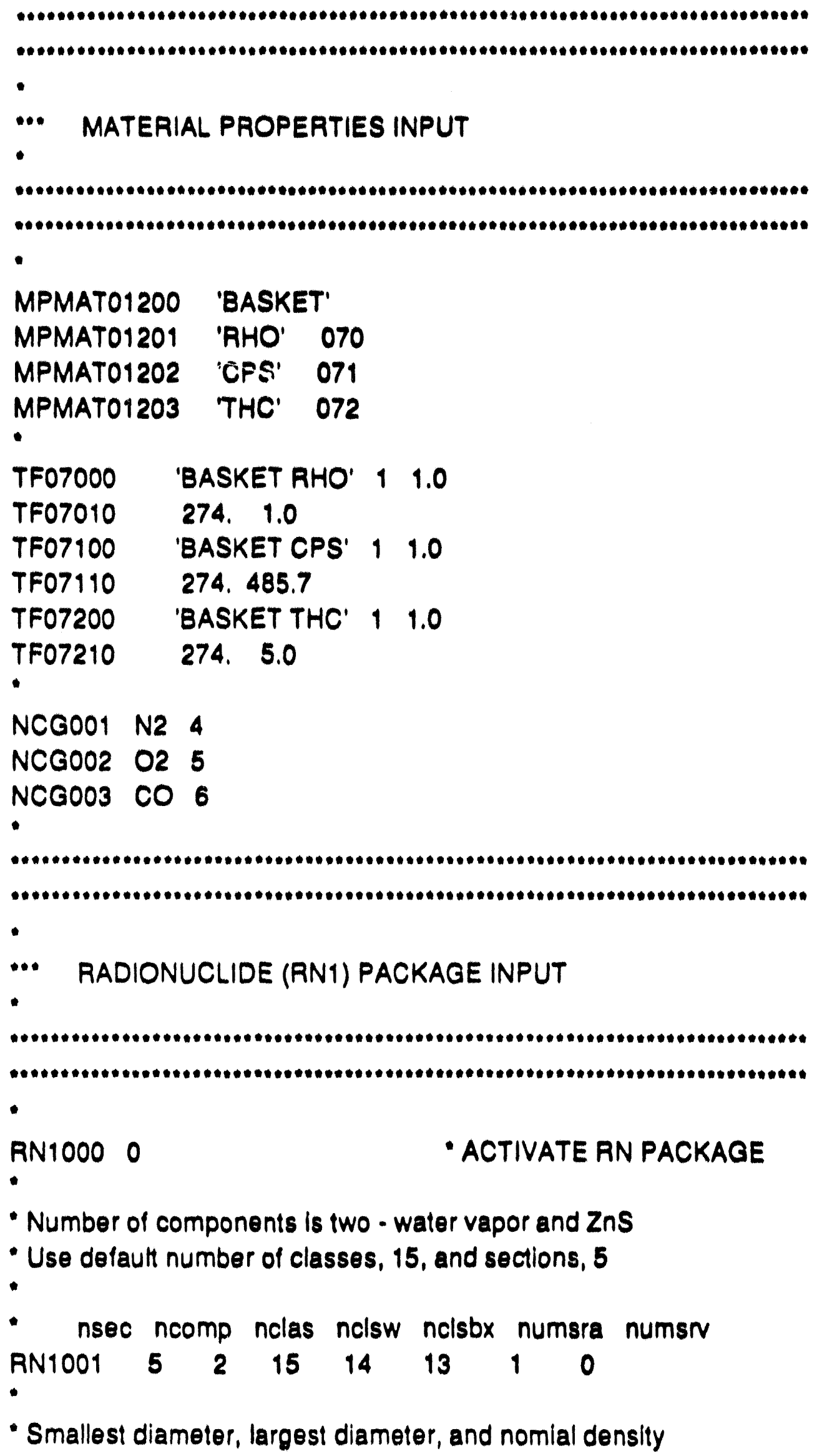

- Number of components is two - water vapor and Zns

- Use default number of classes, 15, and sections, 5

-

- nsec ncomp nclas nclsw ncisbx numsra numsr

$\begin{array}{llllllll}R N 1001 & 5 & 2 & 15 & 14 & 13 & 1 & 0\end{array}$

- Smallest diameter, largest diameter, and nomial density 
RN1100 0.1E-6 100.0E-6 2500.

RNACOEF 1

RNPTO00 $9.0 E+4 \quad 2.0 E+5$ 273. 500.
- code calcs aerosol coeffs

- PIT MINS AND MAXS

$\bullet$

- aerosol sources

- ZNS IS THE ONLY AEROSOL

-

- CV Source Phase Class Rad frac MassRate Tabfunc Dist

$\begin{array}{llllllll}\text { RNASOOD } & 10 & 2 & 11 & 0.0 & 1.0 & 065 & 2\end{array}$

RNASO01 3.5E-6 2.0

$\bullet$

CFO6500 'AERO SOURCE' TAB.FUN $1 \quad 1.0 \quad 0.0$

CF06503 065

CF06510 $1.0 \quad 0.0$ TIME

TF06500 'AERO SOURCE' $3 \quad 1.0 \quad 0.0$

TF06510 $\quad 0.0 \quad 0.030$

TF06511 $2400.0 \quad 0.030$

TF06512 $4200.0 \quad 0.030$

-

$\begin{array}{llllllllll}\text { RNMSO00 } & 1.0 & 1.0 & 1.257 & 1.0 & 0.001 & 0.05 & 1.0 & 1.0 E \cdot 5 & \text { - DEFAULT VALUES }\end{array}$ -

- Class/COMPONENT MaP

- WATER IS COMPONENT 1 (THE ONE IN CLASS 14)

- ZNS IS COMPONENT 2 (THE TWO IN CLASS 11)

RNCCOOO 111111111121111

$\bullet$

- Aerosol Deposition and Settling

-

RNDSO00 302 RHS INACTIVE

RNDSO01 312 RHS INACTIVE

RNDSO02 322 RHS INACTIVE

-

RNSETO00 $320310 \quad 11.0093 \quad 0.524176$ - area is 0.724 squared

RNSETO01 $310300 \quad 6.1325 \quad 0.524176$

RNSETOO2 $300 \quad 210 \quad 1.2557 \quad 0.524176$

RNSETO03 $010 \quad 020 \quad 5.655490 .073$

RNSETO04 $020 \quad 100 \quad 1.04775 \quad 0.073$

RNSETO05 $100 \quad 200 \quad 0.724 \quad 0.073$

RNSETO06 $400 \quad 320 \quad 15.8861 \quad 0.524176$ 
- Control Functions for the Aerosol input

-

CF21500 'ZNS MASS 010' EQUALS $111.0 \quad 0.0$

CF21510 1.0 0.0 RN1-AMGT-11.1.010

CF21600 'ZNS MASS 020' EQUALS $1 \quad 1.0 \quad 0.0$

CF21610 1.0 Q.0 RN1-AMGT-11.1.020

CF21700 'ZNS MASS 100' EQUALS $1 \quad 1.0 \quad 0.0$

CF21710 1.0 0.0 RN1-AMGT-11.1.100

CF21800 'ZNS MASS 200' EQUALS $1 \quad 1.0 \quad 0.0$

CF21810 1.0 0.0 RN1-AMGT.11.1.200

CF21900 'ZNS MASS 210' EQUALS $111.0 \quad 0.0$

CF21910 $1.0 \quad 0.0$ RN1-AMGT-11-1.210

CF22000 'ZNS MASS 300' EQUALS $1 \quad 1.0 \quad 0.0$

CF22010 $1.0 \quad 0.0$ RN1-AMGT.11.1.300

CF22100 'ZNS MASS 310' EQUALS $1 \quad 1.0 \quad 0.0$

CF22110 $1.0 \quad 0.0$ RN1-AMGT-11.1.310

CF22200 'ZNS MASS 320' EQUALS $1 \quad 1.0 \quad 0.0$

CF22210 $1.0 \quad 0.0$ RN1.AMGT.11.1.320

CF22300 'ZNS MASS 400' EQUALS $1 \quad 1.0 \quad 0.0$

CF22310 1.0 0.0 RN1.AMGT.11.1.400

CF22400 'ZNS MASS 450' EQUALS $1 \quad 1.0 \quad 0.0$

$\begin{array}{llll}\text { CF22410 } & 1.0 & 0.0 & \text { RN1.AMGT.11.1.450 }\end{array}$

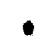

CF22500 ' $H 120$ MASS 010' EQUALS $1 \quad 1.0 \quad 0.0$

CF22510 $1.0 \quad 0.0$ RN1.AMGT-14.1.010

CF22600 'H2O MASS 020' EQUALS $1 \quad 1.0 \quad 0.0$

CF22610 $1.0 \quad 0.0$ RN1-AMGT-14.1.020

CF22700 'H2O MASS 100' EQUALS $1 \quad 1.0 \quad 0.0$

CF22710 $1.0 \quad 0.0$ RN1.AMGT-14.1.100

CF22800 'H2O MASS 200' EQUALS 11.00 .0

CF22810 $1.0 \quad 0.0$ RN1-AMGT-14.1.200

CF22900 'H2O MASS 210' EQUALS $11.0 \quad 0.0$

CF22910 $1.0 \quad 0.0$ RN1-AMGT-14-1.210

CF23000 'H2O MASS 300' EQUALS $11.0 \quad 0.0$

CF23010 1.0 0.0 RN1-AMGT-14.1.300

CF23100 'H2O MASS 310' EQUALS $1 \quad 1.0 \quad 0.0$

CF23110 $1.0 \quad 0.0$ RN1.AMGT-14-1.310

CF23200 'H2O MASS 320' EQUALS $1 \quad 1.0 \quad 0.0$

CF23210 1.0 0.0 RN1.AMGT.14.1.320

CF23300 'H2O MASS 400' EQUALS $11.0 \quad 0.0$ 
CF23310 1.0 0.0 RN1.AMGT-14.1.400

CF23400 'H2O MASS 450' EQUALS $1 \quad 1.0 \quad 0.0$

CF23410 1.0 0.0 RN1-AMQT-14.1.450

-

CF30000 'AERO MASSIN' MULTIPLY $2 \quad 1.0 \quad 0.0$

CF30010 $0.0 \quad 0.030$ TIME

CF30011 1.0 1.0E.7 TIME

-

CF30100 'DFY' DIVIDE $21.0 \quad 0.0$

CF30110 1.0 0.0 CFVALU.300

CF30111 $1.0 \quad 0.0$ CFVALU.224

-

CF30200 'PART RENT' ADD $21.0 \quad 0.0$

CF30210 $\cdot 1.0 \quad 0.0 \quad$ CFVALU.301

CF30211 $0.0 \quad 1.0$ TIME

-

- Necessary Decay Heat Input

-

DCHDECPOW 'TF.066'

DCHCLSNOAM YES

DCHDEFCLSO 1233456789101112131415

-

TF06600 'DCHDECAY' $2 \quad 1.0 \quad 0.0$

$\begin{array}{lll}\text { TF06610 } & 0.0 & 0.0\end{array}$

TF06611 $100000.0 \quad 0.0$

-

- Elemental Molocular Woight

- Compound Molecular Weight

-

SC00000 $712065.37 \quad 1 \quad 11$

SC00001 712087.434211

-

"eor" melcor

,

- ICE CONDENSSR ASSESSMENT: MELCOR MODEL OF PNL'S ICE

CONDENSER EXPERIMENT 16.11

-

- Robert J. Gross

- 
TITLE 'ICECON - EXP 11'

JOBID 'ICECON - EXP 11'

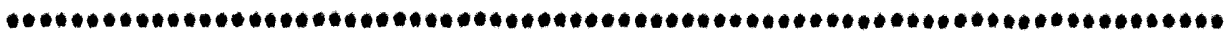

RESTARTF 'icocon_coro.rst'

RESTART $\quad \cdot 1$

OUTPUTF 'icecon_aero.out'

MESSAGEF 'Icecon_avio.mes'

DIAGF 'icocon_aero.dia'

PLOTF 'icecon_auro.ptf'

DTSUMMARY

$\bullet$

RNEDTFLG 0110

-

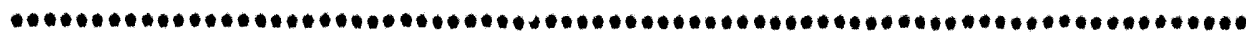

- melcor ICE CONDENSER INPUT

-

DTTIME 0.2

CPULEFT 10.

CPULIM 20000.

-

- TIME DTMAX DTMIN DTEDIT DTPLOT DTRST DCREST

$\begin{array}{llllllll}\text { TIME1 } & 0 . & 1.1 & 0.00000001 & 200 . & 10.0 & 99999 . & 1200 .\end{array}$

TIME2 2000. $1.1 \quad 0.00000001 \quad 200.10 .0 \quad 99999.1200$.

TIME3 2900. $1.1 \quad 0.00000001200 \quad 10.0 \quad 99999.1200$.

TEND 4200. 
External Distribution:

U.S. Nuclear Regulatory Commission (16)

Attn: S. Acharya, NLS-372

Y. S. Chen, NLN-344

M. A. Cunningham, NLS-372

F. Eltawila, NLN-344

R. B. Foulds, NLN-344

C. G. Tinkler, NLN-344

L. E. Lancaster, NLS-372

R. O. Meyer, NLS-007

J. A. Mitchell, NLS-314

C. P. Ryder, NLS-372

L. Soffer, NLS-324

B. Sheron, NLS-007

J. A. Murphy, NLS-007

L. M. Shotkin, NLN-353

N. Lauben, NLN-353

R. Landry, NLN-344

Washington, DC 20555

S. Y. Chen

Argonne National Laboratory

9700 South Cass Avenue

Argonne, IL 60439

Battelle Columbus Laboratories (3)

Attn: P. Cybulskis

M. Carmel

R. S. Denning

505 King Avenue

Columbus, $\mathrm{OH} 43201$

Brookhaven National Laboratory (2)

Attn: I. K. Madni

T. Pratt

Building 130

32 Lewis

Upton, NY 11973 
Idaho National Engineering Laboratory (5)

Attn: A. Brown

R. J. Dallman

D. W. Golden

S. E. Reed

G. W. Johnsen

EG\&G Idaho

P. O. Box 1625

Idaho Falls, ID 83404

D. Jones

El International

P. O. Box 50736

Idaho Falls, ID 83405

Electric Power Research Institute (3)

Attn: E. Fuller

R. N. Oehlberg

B. R. Sehgal

P. O. Box 10412

Palo Alto, CA 94303

Los Alamos National Laboratory (2)

Attn: B. E. Boyack, K-551

D. R. Liles, K-553

P. O. Box 1663

Los Alamos, NM 87545

Oak Ridge National Laboratory (11)

Attn: S. R. Greene, MS-8057

R. H. Morris, MS-8057

S. E. Fisher, MS-8057

R. Sanders, MS-8057

T. L. Heatherly, MS-8057

S. A. Hodge, MS-8057

C. R. Hyman, MS-8057

B. W. Pation, MS-8057

D. B. Simfison, MS.8057

R. P. Taleyarkhan, MS-8057

M. L. Tobias, MS -8088

P. O. Box 2009

Oak Ridge, TN 37831-8057 
Andrzej Drozo

Nuclear Regulatory Commission

OWFN, MS 8E1

11555 Rockville Pike

Rockville, MD 20852

W. P. Barthold

Banthold \& Associates

132 Seven Oaks Drive

Knoxville, TN 37922

Science Applications Intl. Corp. (4)

Attn: E. Dombrowski

M. T. Leonard

K. C. Wagner

K. A. Williams

2109 Air Park Road, SE

Albuquerque, NM 87106

Savannah River Laboratory (2)

Attn: J. K. Norkus

L. A. Wooten

Westinghouse Savannah River Co.

Bldg. 773-41A

Aiken, SC 29808-0001

Westinghouse Hanford Company (2)

Attn: D. Ogden

O. Wang

P. O. Box 1970

Richland, WA 99352

General Electric Company (4)

Knolls Atomic Power Laboratory

Attn: D. F. McMullan

G. H. Epstein

E. Mennard Joe Alfeo

Building F3, Room 8

P. O. Box 1072

Schenectady, NY 12301-1072 
Bettis Atomic Power Laboratory (4)

Attn: Mark Riley

Mark Lucot

Vincent Baiamonte

Jim Lucas

P. O. Box 79

West Miftlin, PA 15122

Mohsen Khatib-Rahbar

Energy Research Inc.

P. O. Box 2034

Rockville, MD 20852

V. K. Dhir

2445 22nd Street

Santa Monica, CA 90403

R. Viskanta

Purdue University

Heat Transfer Laboratory

School of Mechanical Engineering

West Lafayette, IN 47907

Dr. Jim Gieseke

Battelle Memorial Institute

505 King Avenue

Columbus, Ohio 43201

M. A. Kenton

Gabor, Kenton \& Associates

770 Pasquinelli Drive

Sulte 426

Westmont, IL 60559

University of Callfornia (2)

Attn: W. H. Amarasooriya

$T$. Theofanous

ERC.CRSS

Santa Barbara, CA 93106 


\section{F. E. Haskin}

University of New Mexico

Department of Chemical and Nuclear Engineering

Albuquerque, NM 87131

\section{J. C. Le日}

University of Michigan

Department of Nuclear Engineering

Cooley Building, North Campus

College of Engineering

Ann Arbor, MI 48109-2104

University of Wisconsin (2)

Department of Nuclear Engineering

Attn: M. L. Corradini

G. A. Moses

Engineering Research Bullding

1500 Johnson Drive

Madison, WI 53706

Ramu K. Sundaram

Manager, LOCA Analysis Group

Nuclear Engineering

Yankee Atomic Electric Company

580 Main Street

Bolton, MA 01740

\section{CEGA}

Attn: John Bolin

Roseanne Harrington

P. O. Box 85608

San Diego, CA 92186-9784

M. Plys

Fauske \& Associates

16W070 West 83rd Street

Burr Ridge, IL 60521 
Nick Trikouros

GPU Nuclear Corporation

One Upper Pond Road

Parsippany, NJ 07054

B. Raychaudhuri

Nebraska Public Power District

PRA \& Engineering Review Group

P. O. Box 499

Columbus, NE 68601

Frank Elia

Stone \& Webster Engineering Corp.

245 Summer Street

Boston, MA 02210

Samir S. Girgis

Atomic Energy of Canada Limited

CANDU Operations

Sheridan Park Research Community

Mississagua, Ontario

CANADA L5K1B2

Paul J. Fohrer tack

Chalk River Nuclear Laboratories

Fuel Engineering Branch, RSR Division

Chalk River, Ontario

CANADA KOJIJO

Andrej Mitro

Institute of Radioecology and Applied Nuclear Techniques

Garbiarska 2

P. O. Box A.41

$04061 \mathrm{Kos} i c 0$

CZECHOSLOVAKIA

Shih-Kuel Cheng

Atomic Energy Councll, Nuclear Safety

67, Lane 144, Keolung Road Sec. 4

Taipel, Talwan

REPUBLIC OF CHINA 
Lainsu Kao, Associate Scientist

Atomic Energy Council

Institute of Nuclear Energy Research

P. O. Box 303

Lung-Tan, 32500

Talwan

REPUBLIC OF CHINA

Technical Research Centre of Finland (3)

Nuclear Engineering Laboratory

Attn: Lasse Mattila

Ilona Lindholm

Esko Pekkarinen

P. O. Box 208 (Teknilkantio 4)

SF.002151 Espoo

FINLAND

Jorma V. Sandberg

Finnish Center Radiation \& Nucl. Safety

Dept. of Nuclear Safety

P. O. Box 268

SF.00101 Helsinki

FINLAND

Akihide Hidaka

Safety Research Department

Reactor Accident Studies and Modelling Branch

DRS/SEMAR

Cadarache Nuclear Center

13108 Saint-Paul-Lez-Durance Cedex

FRANCE

Dr. Lothar Wolf

Battelle Institute EV

AM Romerhof 35

D.6000

FrankturtMain 80

GERMANY 
Gesellschaft für Reaktorsicherheit (2)

Attn: Uirich Erven

Walter Erdmann

Schwertnergasse 1

D.5000 Koln 1

GERMANY

Kernforschungzentrum, Karlsruhe (2)

Attn: P. Hofmann

Werner Scholtyssek

P. O. Box 3640

D.7500 Karlsnuhe 1

GERMANY

György Gyenes

Central Research Institute for Physics

Institute for Atomic Energy Research

H.1525 Budapest, P. O. Box 49

HUNGARY

Joint Research Center

Commission of the European Communities

Attn: Alan Jones

lain Shepherd

Safety Technology Institute

21020 Ispra (Va)

ITALY

Glovanni Saponaro

\section{ENEA}

National Committee for R\&D of Nuclear Energy

Via Vitaliano Brancati, 48

00144 Rome

ITALY

Kunihisa Soda

Japan Atomic Energy Research Institute

Tokai-mura, Naka-gun, Ibaraki-ken

319-11, JAPAN 
Dr. Susumi Sugurl, Director General

Japan Institute of Nuclear Safety

Fujlta Kankou Toranoman Bldg. $7 F$

3-17-1, Toranoman

Minato-Ku, Tokyo, 105

JAPAN

Korea Atomic Energy Research Inst. (3)

Attn: Kun-Joong Yoo

Song-Won Cho

Dong-Ha KIm

P. O. Box 7, Daeduk Danjl

Daejon

SOUTH KOREA 305.353

Netherlands Energy Research Foundation (2)

Attn: Karel J. Brinkmann

E. J. Velema

P. O. Box 1

1755 ZG Petten

THE NETHERLANDS

Dr. Valery F. Strizhov

Russian Academy of Science

Institute of Nuclear Safety

Moscow, G. Gulsky, 52

113191, RUSSIA

Universidad Politecnica de Madrid (2)

Attn: Augustin Alonzo Santos

Francisco Martin

E.T.S. Ingenieros Industriales

Jose Butierrez Abascal, 2

28006 Madrid

SPAIN 
Juan Bagues

Consejo de Seguridad Nuclear

Justo Dorado, 11

28040, Madrid

SPAIN

Oddbjörn Sandervág

Statens Kärnkraftinspektion

Swedish Nuclear Power Inspectorate

Box 2710610252 Stockholm

SWEDEN

L. Hammar, Director

Division of Research

Swedish Nuclear Power Inspectorate

Statens Kärnkrattinspektion

Sehlstedtsgatan 11

Box 27106

S.102.50 Stockholm

SWEDEN

Swiss Federal Nuclear Safety Inspectorate (4)

Attn: S. Chakraborty

Sang Lung Chan

$U$. Schmocker

H. P. Isaak

$\mathrm{CH} \cdot 5232$ Villigen-HSK

SWITZERLAND

United Kingdom Atomic Energy Agency (3)

Winfrith Technology Center

Attn: T. Haste

S. R. Kinnersley

S. W. Sweet

Winfrith, Dorchester, Dorset

UNITED KINGDOM, DTS BDH 
United Kingdom Atomic Energy Authority (2)

Safety \& Reliability Directorate

Attn: M. I. Robertson

C. Wheatley

Wigshaw Lane, Culcheth, Warrington

Cheshire, WA3 4NE

UNITED KINGDOM 
Internal Distribution:

6400 N. R. Ontiz

6412 A. L. Camp

6412 S. E. Dingman

6413 F. T. Harper

6414 J. E. Kolly

6415 K. D. Bergeron

6418 S. L. Thompson (10)

6418 E. A. Boucherson

6418 R. K. Colo

6418 A. A. Elsbernd

6418 R. J. Gross (10)

6418 L. N. Kmetyk

6418 G. M. Martinez

6418 R. C. Smith

6418 D. S. Sivart

6418 R. M. Summers

6418 T. J. Tautges

6429 K. E. Washington

7141 Technical Library (5)

7151 Technical Publications

7613-2 Document Processing for DOEJOSTI (10)

8523-2 Central Technical Files 

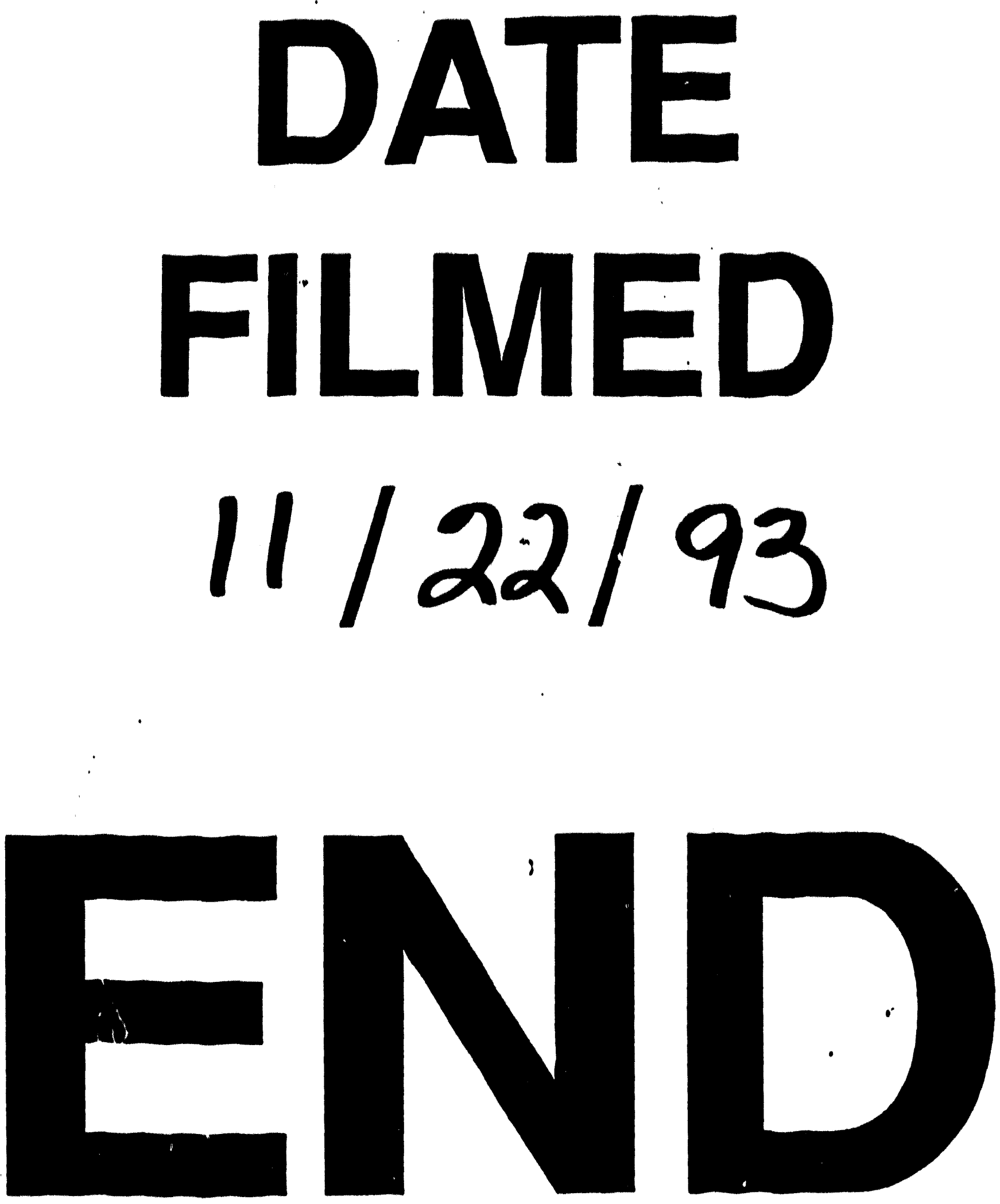


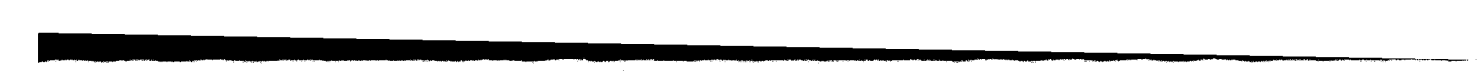

